EXPERIMENTAL INVESTIGATION OF SINGLE PHASE LIQUID FLOW AND HEAT TRANSFER IN MULTIPORT MINICHANNELS

A THESIS SUBMITTED TO

THE GRADUATE SCHOOL OF NATURAL AND APPLIED SCIENCES OF

MIDDLE EAST TECHNICAL UNIVERSITY

BY

MESRU ALTINÖZ

IN PARTIAL FULFILLMENT OF THE REQUIREMENTS

FOR

THE DEGREE OF MASTER OF SCIENCE

IN

MECHANICAL ENGINEERING

NOVEMBER 2013 

Approval of the thesis:

\section{EXPERIMENTAL INVESTIGATION OF SINGLE PHASE LIQUID FLOW AND HEAT TRANSFER IN MINICHANNELS}

Submitted by MESRU ALTINÖZ in partial fulfillment of the requirements for the degree of Master of Science in Mechanical Engineering Department, Middle East Technical University by,

Prof. Dr. Canan Özgen

Dean, Graduate School of Natural and Applied Sciences

Prof. Dr. Suha Oral

Head of Department, Mechanical Engineering

Assoc. Prof. Dr. Almıla Güvenç Yazıcıoğlu

Supervisor, Mechanical Engineering Dept., METU

Assoc. Prof. Dr. Derek K. Baker

Co-Supervisor, Mechanical Engineering Dept., METU NCC

\section{Examining Committee Members:}

Assist. Prof. Merve Erdal

Mechanical Engineering Dept., METU

Assoc. Prof. Almıla Güvenç Yazıcıoğlu

Mechanical Engineering Dept., METU

Assoc. Prof. Dr. Derek K. Baker

Mechanical Engineering Dept., METU NCC

Assist. Prof. Cüneyt Sert

Mechanical Engineering Dept., METU

Dr. M. Zeki Yılmazoğlu

Mechanical Engineering Dept., GAZI UNIVERSITY

Date: $\quad 29-11-2013$ 
I hereby declare that all information in this document has been obtained and presented in accordance with academic rules and ethical conduct. I also declare that, as required by these rules and conduct, I have fully cited and referenced all material and results that are not original to this work.

Name, Last name $\quad$ : Mesru Altınöz

Signature 


\begin{abstract}
EXPERIMENTAL INVESTIGATION OF SINGLE PHASE LIQUID FLOW AND HEAT TRANSFER IN MULTIPORT MINICHANNELS
\end{abstract}

\author{
Altınöz, Mesru \\ M.Sc., Department of Mechanical Engineering \\ Supervisor : Assoc. Prof. Dr. Almıla G. Yazıcıoğlu \\ Co-supervisor : Assoc. Prof. Dr. Derek K. Baker
}

November 2013, 155 pages

This thesis aims to experimentally investigate pressure drop and heat transfer characteristics of single phase water flow in rectangular minichannels. The small channels are an area of interest in heat transfer field since 1970's owing to their enhanced heat transfer characteristics. However, the heat transfer and pressure drop characteristics of these channels are not fully established as there is a wide number of studies in literature showing inconsistent results with each other. In order to investigate this matter further, an experimental set-up is designed and constructed. Laminar region is considered during the experiments because the flow inside minichannels is generally laminar due to pressure drop considerations. Additionally, constant heat flux condition is selected to stimulate cooling with internal flow in minichannels. In the scope of this study, three minichannels with different hydraulic and different port numbers diameters were examined. The results are presented in terms of Poiseulle numbers and average Nusselt numbers. Generally, average Nusselt number results and Poiseuille number results showed a good agreement with constant Po theory and constant $\overline{N u}$ theory excluding developing effects and experimental errors. On the other hand, developing effects are found to be increasing as hydraulic diameter decreases. Similarly, constant $\overline{N u}$ value showed a decrease with increasing 
hydraulic diameter. The small scale heat transfer correlations and conventional heat transfer correlations are compared with experimental resuts. The conventional correlations followed the trend of results precisely but predictions of correlations overestimated most of the results. When a correction factor is applied, several correlations predicted almost all results within $11 \%$. Small scale correlations showed agreement with a few results but mostly overestimated the $\overline{N u}$ results. No early transition were observed for Reynolds number smaller than 1800. No signs of Poiseuille number or average Nusselt number dependency on Reynolds number were observed considering developing effects and uncertainty values.

Keywords: Minichannels, Heat transfer, Pressure drop, Laminar, Single phase, Convection 


\title{
$\ddot{O} \mathbf{z}$
}

\section{MULTIPORT MINIKKANALLARDA TEK FAZLI SIVI AKIŞININ VE ISI TRANSFERINIIN DENEYSEL İNCELENMESI}

\author{
Altınöz, Mesru \\ Yüksek Lisans, Makina Mühendisliği Bölümü \\ Tez Yönetici : Doç. Dr. Almıla G. Yazıcıŏglu \\ Ortak Tez Yöneticisi : Doç. Dr. Derek K. Baker
}

Kasim 2013, 155 sayfa

$\mathrm{Bu}$ tezde dikdörtgen kanallarda tek fazlı su akışının basınç kaybı ve 1sı transferi özelliklerinin deneysel olarak incelenmesi hedeflenmiştir. Isı transferini artırması özelliği sebebiyle 1970'lerden itibaren küçük kanallar 1s1 transferi alanında ilgi sahası olmuştur. Buna rağmen, bu boyuttaki kanalların 1sı transferi ve basınç kaybı özellikleri ile ilgili literatürde birbiriyle çelişen bir çok araştırmanın olmasından da anlaşılacağı gibi tam anlamıyla belirlenememiştir. Bu konuyu daha derinlemesine incelemek için bir deney düzeneği tasarlanmış ve kurulmuştur. Deneyin tasarımı ve deney düzeneği ile ilgili diğer detaylar tezde açıklanmıştır. Minikanallardaki akış genellikle basınç kaybı sebebiyle laminer olduğu için, deneyler sırasında laminar bölge ele alınmıştır. Bununla beraber, minikanallarda içsel akışla soğutma durumun benzetimi için sabit 1sı akısı sınır şartı seçilmiştir. Bu çalışmanın kapsamında, hidrolik çapları birbirinde farklı üç minikanal incelenmiştir. Sonuçlar Poiseuille sayısı ve ortalama Nusselt sayısı olarak sunulmuştur. Genel olarak, ortalama Nusselt sayısı ve Poiseuille sayısı sonuçları gelişim etkisi ve deneysel hataları hesaba katmazsak sabit Po ve sabit $\overline{N u}$ theorisi ile iyi bir eşleşme göstermiştir. Öte yandan, gelişim etkilerinin azalan hidrolik çap ile beraber arttığı ortaya çıkmıştır. Benzer 
olarak, sabit $\overline{N u}$ değerleri artan hidrolik çap ile beraber bir azalış göstermiştir. Küçük kanallarda 1s1 transferi korelasyonlarının ve klasik 1s1 transferi korelasyonlarının tahminleri deneysel sonuçlar ile karşılaştırılmıştır. Klasik korelasyonların tahminleri sonuçların eğilimini yüksek bir uyum ile takip etmiştir ancak korelasyonlar sonuçların çoğunun gerçek değerinden fazlası olarak tahmin etmiştir. Bir düzeltme faktörü uygulandığı zaman, korelasyonlar sonuçları \%11 hata payı ile tahmin edebilmiştir. Küçük kanallarda 1sı transferi korelasyonları bir iki sonuç ile uyum göstermiştir. Ancak çoğu $\overline{N u}$ sonucunu olduğundan fazla olarak tahmin etmiştir. Reynolds sayısının 1800'den küçük olduğu durumlarda türbülanslı akışa erken geçişe ait herhangi bir işaret görülmemiştir. Gelişim etkisi ve hata payı hesaba katıldığı zaman, Poiseuille sayısının ya da ortalama Nusselt sayısının Reynolds sayısına bağlı değişimini gösteren herhangi bir bulgu görülmemiştir.

Anahtar Kelimeler: Minikanallar, Isı transferi, Basınç kaybı, Laminer, Tek faz, Konveksiyon 


\section{ACKNOWLEDGEMENTS}

I am very grateful to my advisor Dr. Almıla Güvenç Yazıcıŏglu for her deep knowledge in academia, guidance and precious advices. I truly appreciate her great amount of help, everlasting support and constructive criticism.

I would also like to thank my co-advisor Dr. Derek Baker. I admire greatly his way of thinking, positive altitude and most of all his professionalism. I have learned a lot under his supervision and I have considered myself truly lucky to have his support and encouragement.

I would like to express my special thanks to my dearest mother, father and sister who have been my role models for my whole life with their perseverance. Like my all successes in life, this thesis would not be possible without their support.

I also want to thank my dear friend Mr. Serkan B. Körpe for being a trusted companion throughout the master program.

I would like to thank my friends Mr. Can Uçkun, Mr. Serhat Bilyaz, Mr. Onur Özkan and Mr. Çağlar Yılmaz, Mr. Hakan Şahin for insightful discussions and coffee breaks but more importantly for all the fun in last three years.

I would like to acknowledge the great amount of technical support from Mr. Mustafa Yalçınoğlu, the best technician I have met in our department. 


\section{TABLE OF CONTENTS}

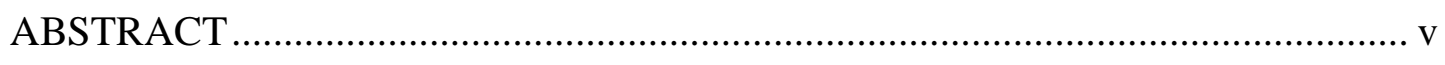

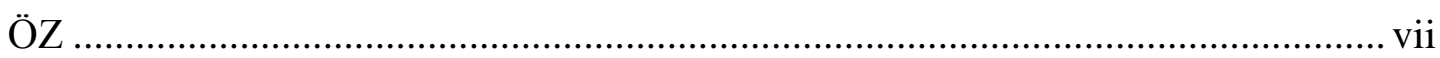

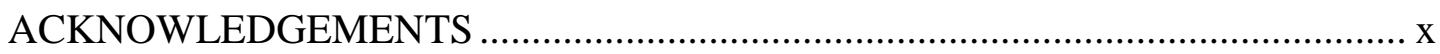

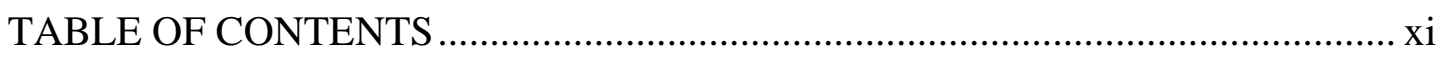

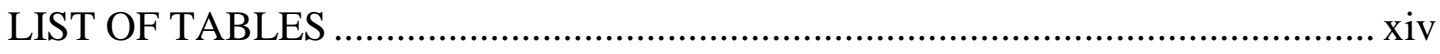

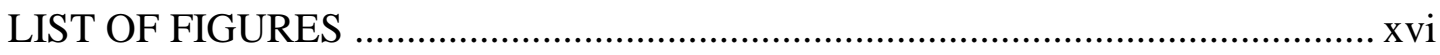

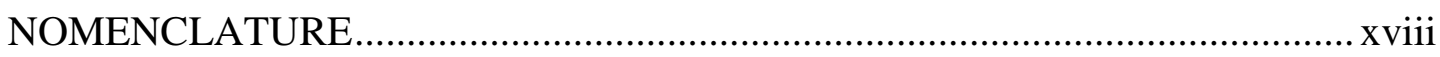

CHAPTERS

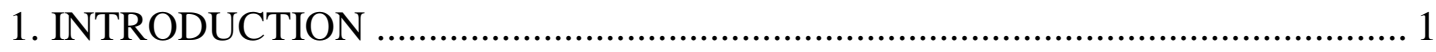

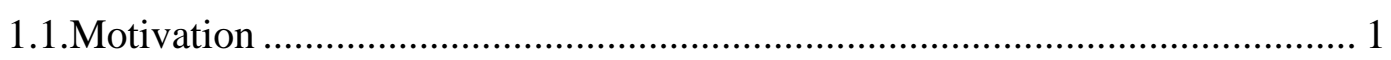

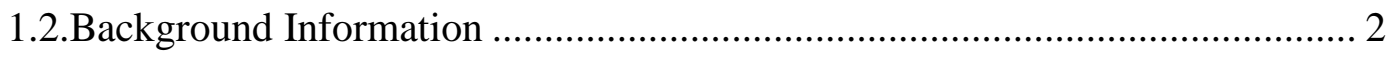

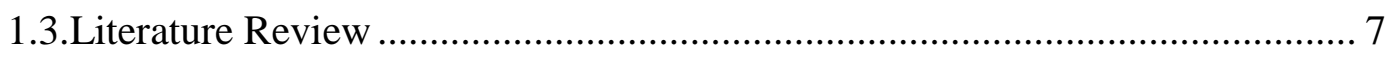

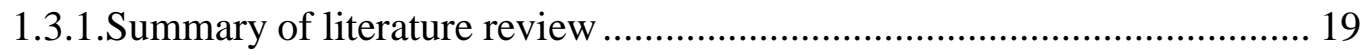

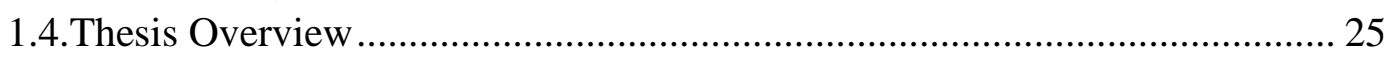

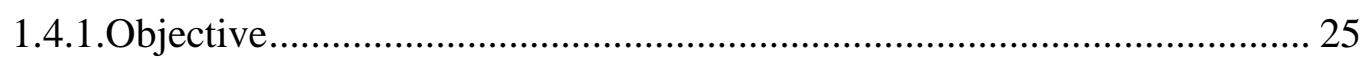

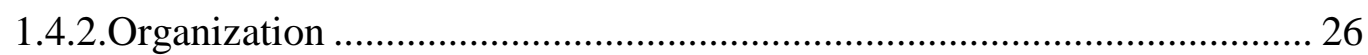

2. FUNDAMENTALS OF SINGLE PHASE LIQUID FLOW AND HEAT

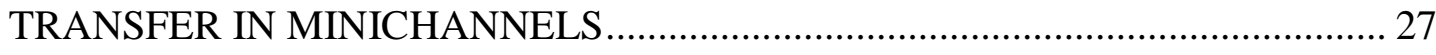

2.1.Validation of Continuum Theory in Small Scale Channels ........................... 27

2.2.Transition from Laminar to Turbulent .......................................................... 28

2.3.Single Phase Fluid Flow in Channels in the Laminar Flow Regime.............. 29

2.4.Heat Transfer in Channels in the Laminar Flow Regime............................... 34

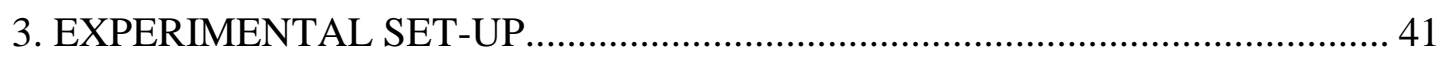

3.1.Minichannels Used in the Experiments .................................................... 41

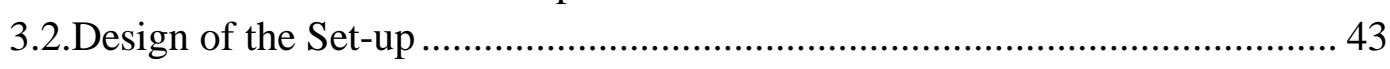

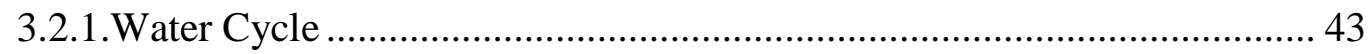

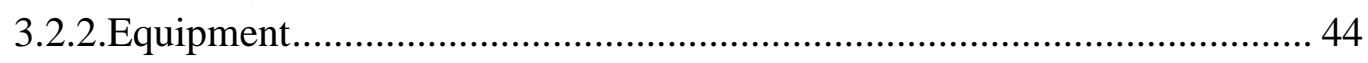

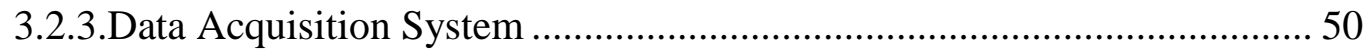

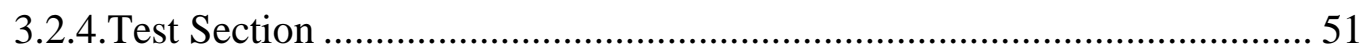

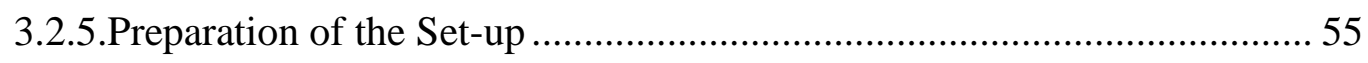

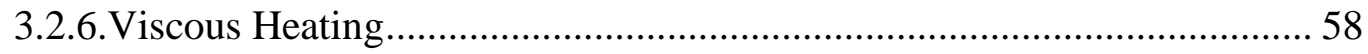

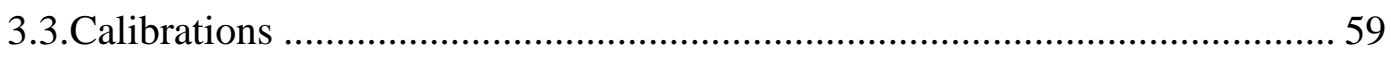




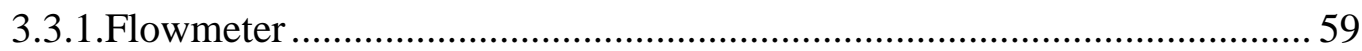

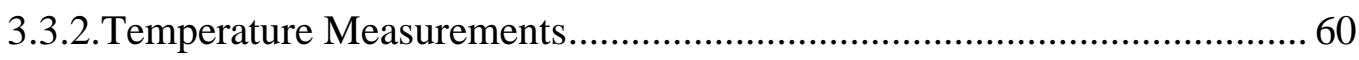

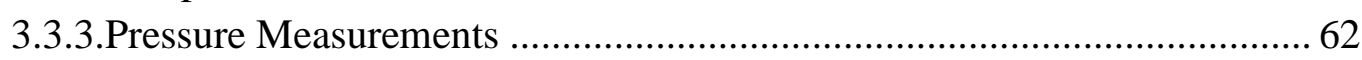

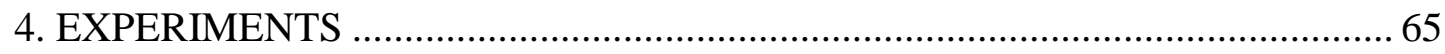

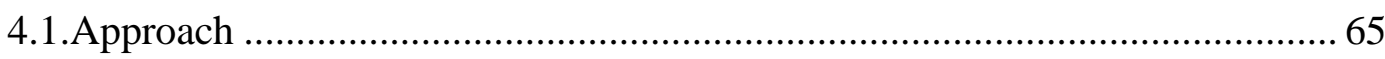

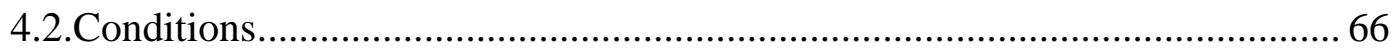

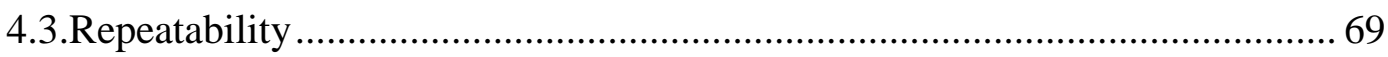

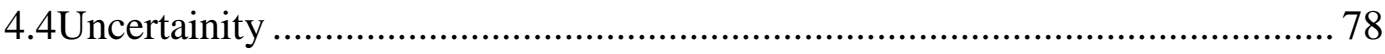

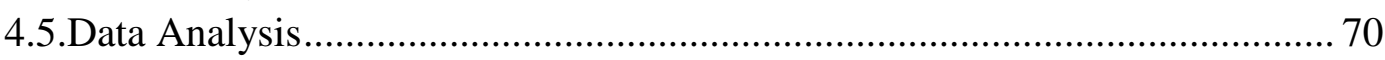

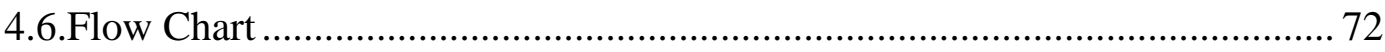

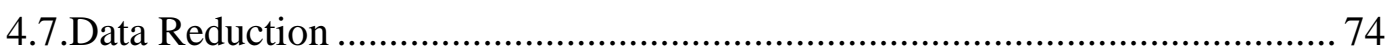

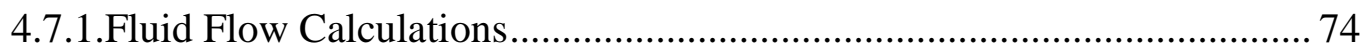

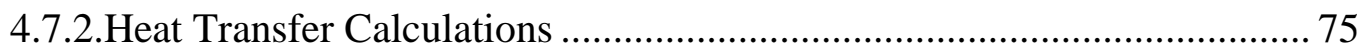

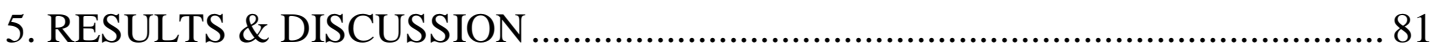

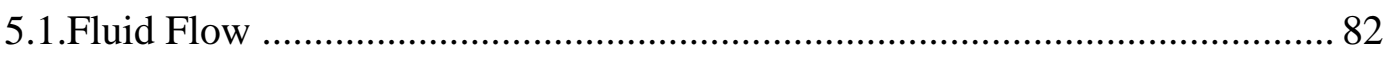

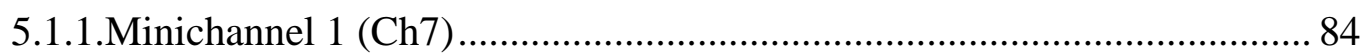

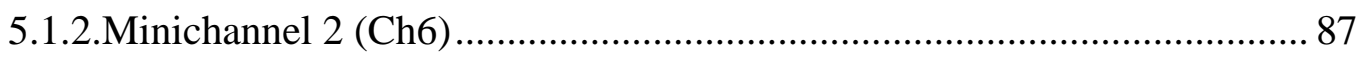

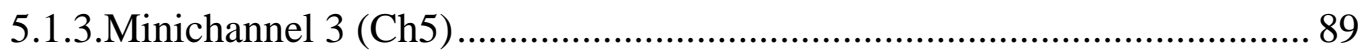

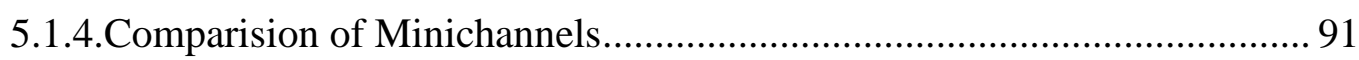

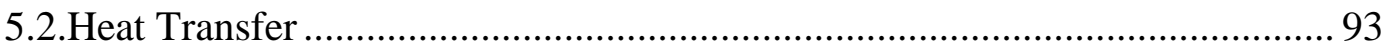

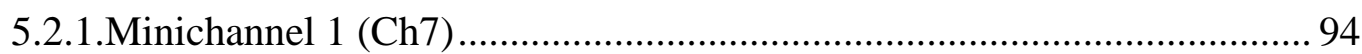

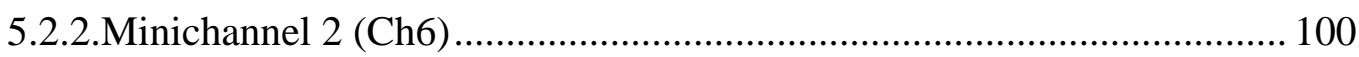

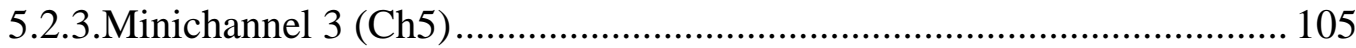

5.2.4.Comparision of Minichannels............................................................. 110

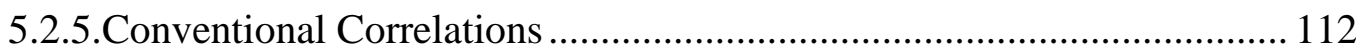

5.2.6.Small Scale Correlations...................................................................... 115

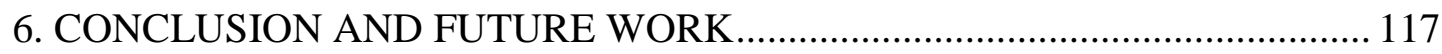

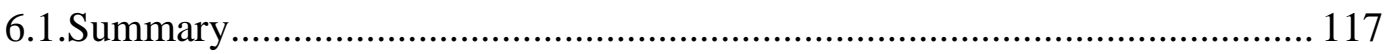

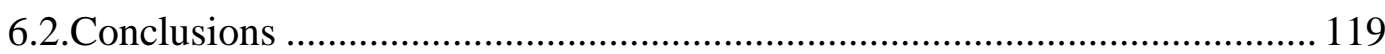

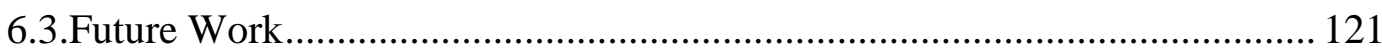

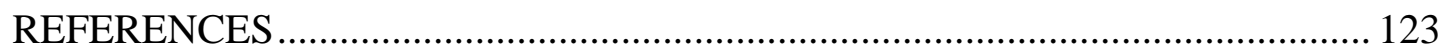

\section{APPENDICES}

A. INTERPOLATION EQUATIONS FOR POISEUILLE NUMBER AND
NUSSELT NUMBER ….............................................................................. 129
B. DETAILS OF THE COMPONENTS IN THE EXPERIMENTAL SET-UP $\ldots 131$
C. THE TECHNICAL DRAWINGS OF THE MANIFOLD ............................... 139 
D. THE CALIBRATION TABLES AND GRAPHS FOR MEASUREMENT

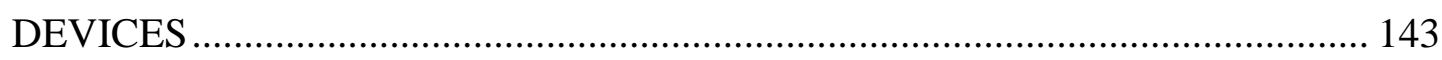

E. THE RAW EXPERIMENTAL RESULTS …………………………………..... 149

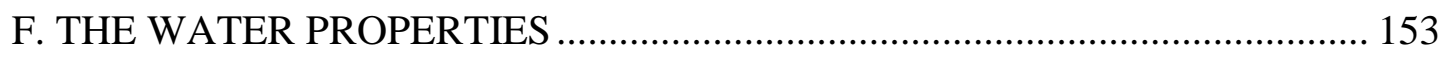




\section{LIST OF TABLES}

\section{TABLES}

Table 1.1 Channel classification according to hydraulic diameters in [6] and [7].......5

Table 1.2. Experimental results for Poiseuille number .......................................... 20

Table 1.3. Experimental results of transition from laminar to turbulent region......... 22

Table 1.4 Experimental results on Nusselt number................................................. 23

Table 2.1 Friction factor for fully developed laminar flow in ducts [3] ..................... 30

Table 2.2 Laminar flow friction factor for developing flow in rectangular channels

[3] 32

Table 2.3 Nusselt number values for different cross sections for H1, H2 and T

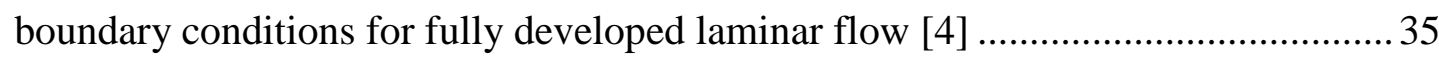

Table 2.4 Fully developed laminar flow Nusselt number values for three-side heated

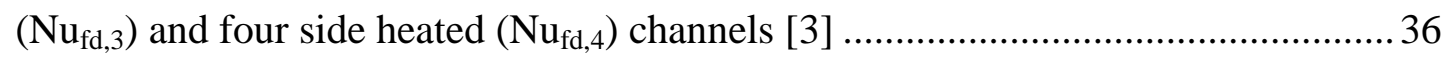

Table 2.5 Nusselt numbers for thermally developing flow [3], [37]......................... 37

Table 2.6 Conventional correlations for prediction of heat transfer in laminar flow for

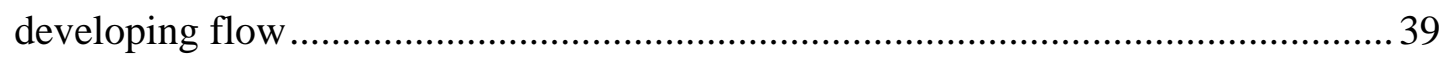

Table 2.7 Convective heat transfer correlations for small scale channels ................. 40

Table 3.1 Geometry properties of the minichannels ................................................. 42

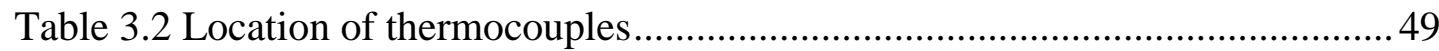

Table 3.3 Thermal conductivities of materials in layer group .................................54

Table 3.4 Maximum Morini [57] criterion results for each minichannel for viscous

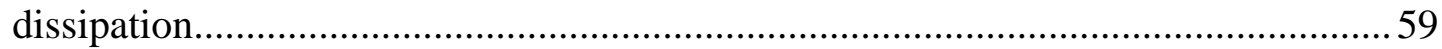

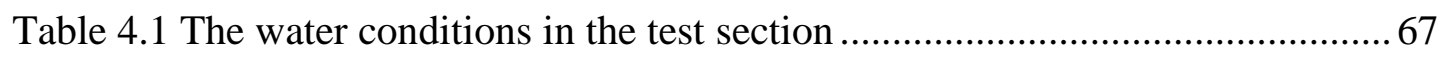

Table 4.2 The amount of heat transferred in the cooling fluid..................................6 68

Table 4.3 Normalized repeatability data for Ch6 according to inlet temperature...... 70

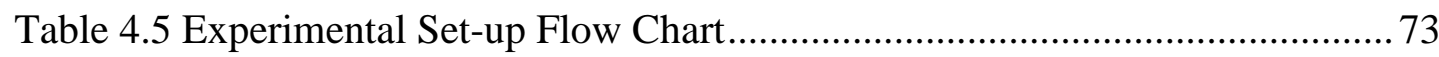

Table 4.5 Relative uncertainties in calculated parameters ....................................... 79

Table 5.1 Dimensionless axial distance for developing flow in minichannels .......... 83

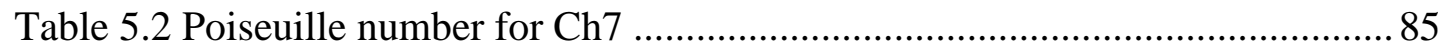

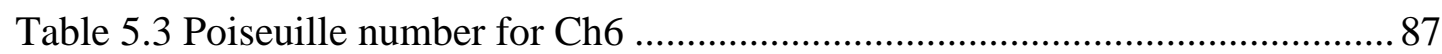

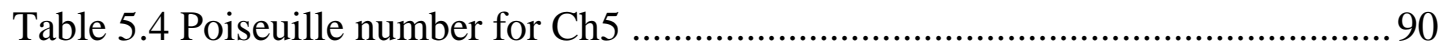

Table 5.5 Experimental and calculated $N u$ using conventional correlations(Ch7)...96

Table 5.6 Experimental and calculated $N u$ using small scale correlations (Ch7) .....98

Table 5.7 Experimental and calculated $N u$ using conventional correlations (Ch6). 101

Table 5.8 Experimental and calculated $N u$ using small scale correlations (Ch6) ... 103

Table 5.9 Experimental and calculated $N u$ using conventional correlations (Ch5). 106 
Table 5.10 Experimental and calculated $N u$ using small scale correlations (Ch5) . 108 Table 5.11 Agreement and accuracy of predicted $\mathrm{Nu}$ with experimental

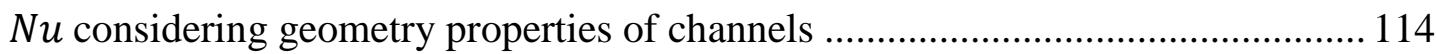

Table 5.12 Correction factors for conventional correlations for Ch6 and Ch7 ....... 115 


\section{LIST OF FIGURES}

\section{FIGURES}

Figure 1.1 Various examples of channel flow in natural and mechanical systems [3] 2 Figure 1.2 Heat transfer coefficient variation with respect to hydraulic diameter for laminar flow under constant heat flux for fully developed conditions [3] .................. 4 Figure 1.3 Pressure gradient variation with respect to hydraulic diameter for laminar flow under constant heat flux for fully developed conditions [3] ............................. 4 Figure 1.4. Poiseuille numbers in literature compared with theoretical values for different small scale channels (after [3] and [35]) ................................................ 21 Figure 2.1 Hagenbach's factor and $f R e(P o)$ for different aspect ratios of rectangular

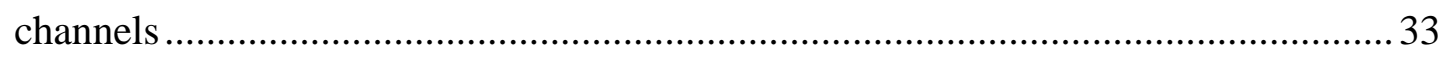

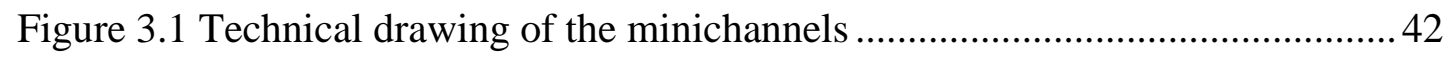

Figure 3.2 The water cycle in the experiments .................................................... 44

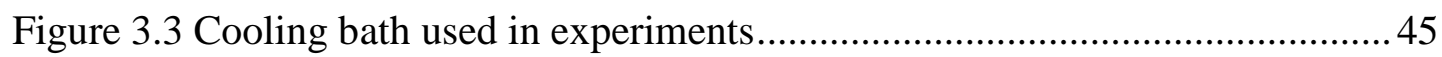

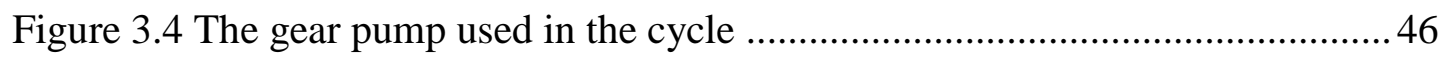

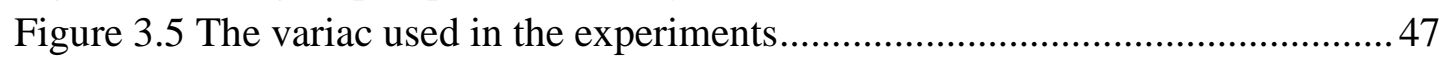

Figure 3.6 The power analyzer used in the cycle ................................................... 48

Figure 3.7 Data logger and DC power supply used in the experiments.....................50

Figure 3.8 Heating wires wrapped around the mica sheet .......................................52

Figure 3.9 Heating layer model (not to scale) ........................................................53

Figure 3.10 Schematic view of the test section before the insulation (not to scale) .. 55

Figure 3.11 Test section without layer group and insulation ..................................56

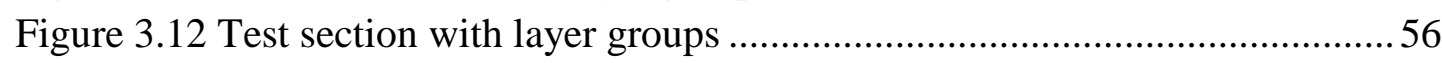

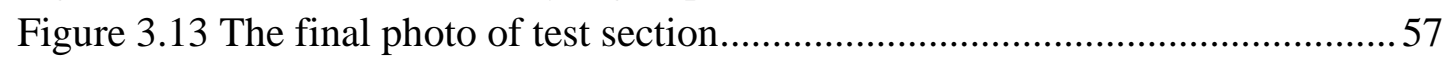

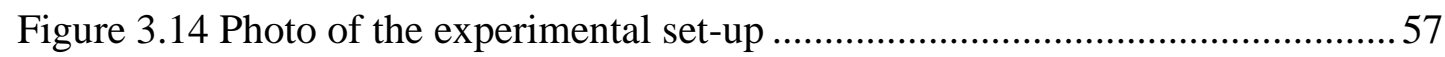

Figure 3.15 Open cycle for gravimetric calibration of the flowmeter [59] ................6 60

Figure 3.16 Schematic of the pressure transducer calibration assembly....................63

Figure 3.17 Photo of the piping section in the pressure transducer calibration

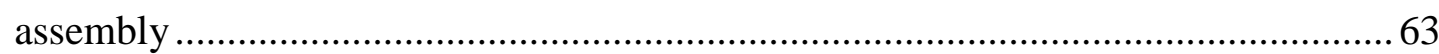

Figure 4.1 Forced convection heat transfer to electrical power ratio vs Reynolds number.

Figure 4.2 Sudden contraction and expansion loss coefficients for rectangular ducts

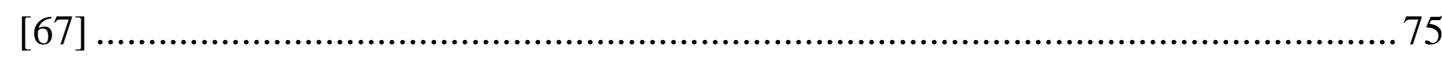

Figure 5.1 Poiseuille number versus Reynolds number for Ch7 ............................. 86

Figure 5.2 Poiseuille number versus Reynolds number for Ch6.............................8 89

Figure 5.3 Poiseuille number versus Reynolds number for Ch5 .............................. 91 
Figure 5.4 Experimental $P o$ to theoretical $P o$ ratio for all minichannels

Figure 5.5 Experimental average Nusselt number and calculated Nusselt number through conventional correlations versus Reynolds number ( $\mathrm{Ch} 7)$

Figure 5.6 Experimental average Nusselt number and calculated Nusselt number using small scale correlations versus Reynolds number (Ch7) .99

Figure 5.7 Local Nusselt number versus $x *(\mathrm{Ch} 7)$. 100

Figure 5.8 Experimental average Nusselt number and calculated Nusselt number through conventional correlations versus Reynolds number (Ch6) 102

Figure 5.9 Experimental average Nusselt number and calculated Nusselt number through small scale correlations versus Reynolds number (Ch6) ............................ 104

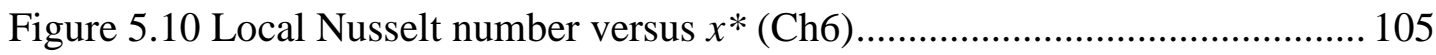
Figure 5.11 Experimental average Nusselt number and calculated Nusselt number through conventional correlations versus Reynolds number (Ch5) 107

Figure 5.12 Experimental average Nusselt number and calculated Nusselt number through small scale correlations versus Reynolds number (Ch5) ........................... 109

Figure 5.13 Local Nusselt number versus $x^{*}(\mathrm{Ch} 5)$............................................. 110 Figure 5.14 The ratio of experimental $N u$ to theoretical $N u$ for thermally developing flow (TD) and fully developed flow (FD) versus $R e$ for all minichannels 111

Figure 5.15 Average heat transfer coefficient versus $R e$ for all minichannels ........ 112

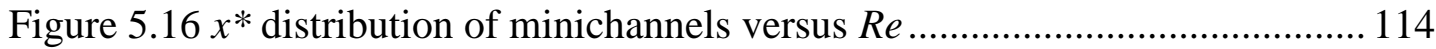




\section{NOMENCLATURE}

\section{SYMBOLS}

\begin{tabular}{|c|c|}
\hline$A$ & area, $\mathrm{m}^{2}$ \\
\hline$C$ & Constant \\
\hline$C_{p}$ & specific heat, $\mathrm{kJ} \mathrm{kg}^{-1} \mathrm{~K}^{-1}$ \\
\hline$D$ & diamater, $\mathrm{m}$ \\
\hline$E c$ & Eckert number, $E c=V^{2} C_{p}^{-2} \Delta T^{1}$ \\
\hline$e_{w}$ & wall thickness, m \\
\hline$f$ & fanning friction factor \\
\hline$G z$ & Graetz number, $G z=D_{h} \operatorname{Re} \operatorname{Pr} L^{-1}$ \\
\hline$h$ & convective heat transfer coefficient, $\mathrm{W} \mathrm{m} \mathrm{m}^{-2} \mathrm{~K}^{-1}$ \\
\hline $\bar{h}$ & average convective heat transfer coefficient, $\mathrm{W} \mathrm{m}{ }^{-2} \mathrm{~K}^{-}$ \\
\hline$H$ & channel height, $\mathrm{m}$ \\
\hline$K$ & loss coefficient \\
\hline$k$ & thermal conductivity, $\mathrm{W} \mathrm{m}{ }^{-1} \mathrm{~K}^{-1}$ \\
\hline$K(\infty)$ & Hagenbach's factor \\
\hline$K(x)$ & incremental pressure drop number \\
\hline$K n$ & Knudsen number, $K n=\lambda L^{-1}$ \\
\hline$L$ & length, $\mathrm{m}$ \\
\hline$L_{c}$ & characteristic length, $\mathrm{m}$ \\
\hline$M$ & axial conduction number, $M=k e_{w} L^{-1} \rho^{-1} C_{p}^{-1} H^{-1} u_{m}^{-1}$ \\
\hline$\dot{m}$ & mass flow rate, $\mathrm{kg} \mathrm{s}^{-1}$ \\
\hline $\mathrm{Nu}$ & local Nusselt number, $N u=h D_{h} k^{-1}$ \\
\hline
\end{tabular}




\begin{tabular}{|c|c|}
\hline$\overline{N u}$ & average Nusselt number, $\overline{N u}=\bar{h} D_{h} k^{-1}$ \\
\hline$p$ & pressure, $\mathrm{kPa}$ \\
\hline$P$ & perimeter, $\mathrm{m}$ \\
\hline$P e$ & Peclet number, $P e=\operatorname{Re} P r$ \\
\hline Po & Poiseuille number, $P o=f R e$ \\
\hline $\operatorname{Pr}$ & Prandtl number, $P r=C_{p} \mu k^{-1}$ \\
\hline$q^{\prime \prime}$ & heat flux, $\mathrm{W} \mathrm{m}^{-2}$ \\
\hline$R^{\prime \prime}$ & thermal resistance per unit area, $\mathrm{W}^{-1} \mathrm{~m}^{2} \mathrm{~K}$ \\
\hline $\operatorname{Re}$ & Reynolds number, $\operatorname{Re}=\rho u_{m} D \mu^{-1}$ \\
\hline$T$ & temperature, ${ }^{\circ} \mathrm{C}$ \\
\hline$Q$ & flow rate, $\mathrm{L} / \mathrm{h}$ \\
\hline$\dot{Q}$ & heat transfer, W \\
\hline$u_{m}$ & mean flow velocity, $\mathrm{m} \mathrm{s}^{-1}$ \\
\hline$V$ & voltage difference, $\mathrm{V}$ \\
\hline$W$ & width, m \\
\hline$W_{c}$ & distance between center of channels, $\mathrm{m}$ \\
\hline$x$ & axial distance, $\mathrm{m}$ \\
\hline$x^{*}$ & dimensionless thermal axial distance \\
\hline$x^{+}$ & dimensionless axial distance \\
\hline
\end{tabular}

\section{Greek letters}

$\alpha \quad$ aspect ratio

$\Delta \quad$ difference

$\varepsilon \quad$ uncertainty

$\lambda$ molecular mean path, $\mathrm{m}$ 
dynamic viscosity, $\mathrm{N} \mathrm{s} \mathrm{m}^{-2}$

$v$

kinematic viscosity, $\mathrm{Pa} \mathrm{s}$

$\rho$

density, $\mathrm{kg} \mathrm{m}^{-3}$

$\Phi$

power, W

$\sigma$

area ratio

\section{Subscripts}

$\begin{array}{ll}\text { app } & \text { apparent } \\ \text { av } & \text { average } \\ \text { cr } & \text { contraction } \\ \text { e } & \text { cross section } \\ \text { elec } & \text { expansion } \\ \text { fl } & \text { fluid } \\ \text { h } & \text { hydraulic } \\ \text { hd } & \text { hydrodynamically developed } \\ \text { ht } & \text { heat transfer } \\ \text { lm } & \text { logaritmic mean } \\ \text { m } & \text { mean } \\ \text { td } & \text { thermally developed } \\ \text { t } & \text { turbulent } \\ \text { w } & \text { wall }\end{array}$




\section{Superscripts}

$\begin{array}{ll}+ & \text { hydrodynamical } \\ * & \text { thermal }\end{array}$

Abbrevation

CHF Constant Heat Flux

CWT Constant Wall Temperature

LMTD Logaritmic Mean Temperature Difference

RTD Resistance Temperature Detector

SD Simulatenously Developing

TC Thermocouple

TD Thermally Developing 


\section{CHAPTER 1}

\section{INTRODUCTION}

\subsection{Motivation}

Enhancing heat transfer is critical in many current technologies and in the daily life of human beings. Society benefits from heat transfers in technologies such as radiators, air conditioners and refrigerators, industrial burners, furnaces and condensers. Many electronic devices and mechanical equipment require cooling enhanced by using fans, heat sinks or pumps to control or decrease their operating temperature. In these types of equipment, generally, a type of fluid driven by external means such as a pump, fan or compressor is used, and electrical or mechanical energy is consumed during such applications. Thus, they form one of the critical shares of energy consumption, especially electricity consumption. For example, more than $60 \%$ of residential energy use is due to heat transfer involving applications such as heating, cooling and refrigeration [1].

Nowadays, researchers from a variety of different disciplines work to decrease global warming and the harmful effects of carbon based fuels on the environment. Carbon based fuels such as natural gas, oil and coal are the main cause of global warming and represent $82 \%$ of the primary energy used for energy generation [2]. Two options to decrease the consumption of harmful fuel sources are to decrease energy consumption and increase the usage of renewable energy. The usage of renewable energy resources for electricity generation is relatively new compared to the usage of fossil fuels such as oil, gas and coal, and currently renewable energies having difficulties competing with fossil fuels in the market, even though price of energy generation through renewable sources is projected to decrease in following years [2]. On the other hand, decreasing fuel consumption by improving the performance of components and devices is also a promising method to decrease harmful 
environmental effects. Additionally, it will still be economically beneficial even when energy generation through renewable sources becomes cheaper.

Therefore, investigation and improvement of heat transfer characteristics may both decrease the electrical or mechanical energy consumed to operate a device such as an air conditioner and decrease fossil fuel usage to generate electrical and mechanical power such as in a boiler. In addition, decreasing the harmful effects of excessive energy consumption on the environment will provide positive value. As a result, research on effective heat transfer for different kinds of applications clearly promises development and practical benefits for society's needs.

\subsection{Background Information}

Many manmade and natural systems require cooling or heating. Due to advances in computer science and machinery, mankind is challenged with higher heat flux demands, especially in cooling systems. The main types of cooling systems are evaporative cooling, natural convection, and forced convection. One of the most common cooling methods is forced convection heat transfer due to fluid flow inside a channel or a heat sink. Figure 1.1 presents several examples of fluid flow in a closed conduit and demonstrates that flow in natural channels mainly involve heat and mass transfer whereas manmade conduits are mainly designed to transfer heat effectively.

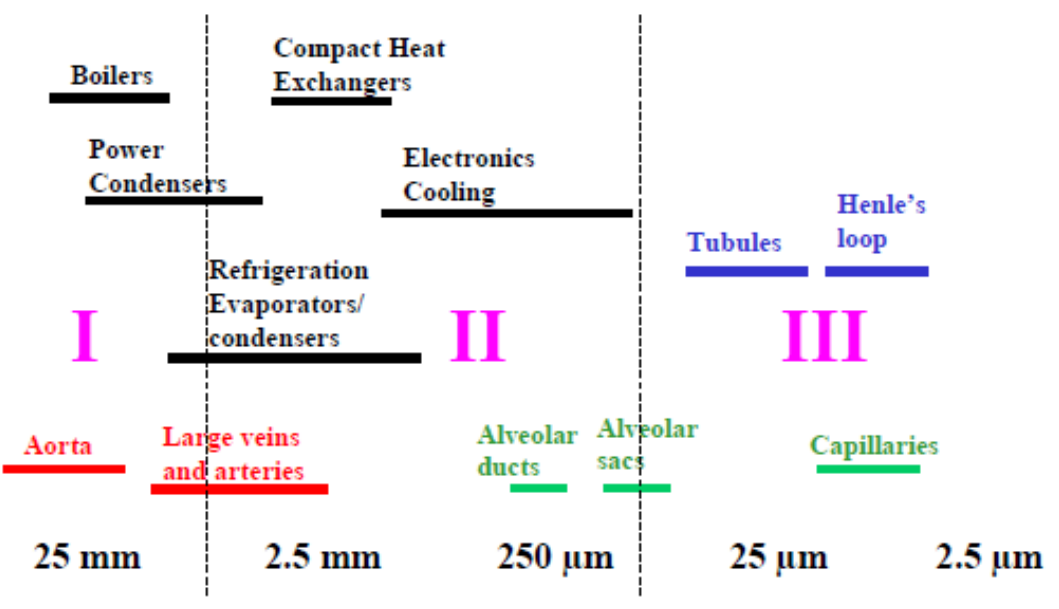

Figure 1.1 Various examples of channel flow in natural and mechanical systems [3] 
The hydraulic diameters of manmade channels' cover a wide range from a few micrometers to meters, and the hydraulic diameter of a channel is selected considering many factors such as cost, pressure drop, heat transfer, compactness, cleaning and reliability. However, enhancing heat transfer and reducing pressure drop are typically the most critical factors in scientific research. Moreover, only after a concrete determination of the heat transfer and pressure drop behavior of channels can other factors be investigated and then considered to find the optimum selection for industrial applications.

The channel's hydraulic and heat transfer characteristics are explicitly dependent on the hydraulic diameter of the channel. Eqn.'s (1.1) and (1.2) [3] present the average convective heat transfer coefficient and pressure drop per unit length due to friction in laminar fully developed channel flow.

$$
\bar{h}=\frac{\overline{N u} k}{D_{h}}
$$

where $D_{h}$ is hydraulic diameter, $\bar{h}$ is the average convective heat transfer coefficient, $k$ is thermal conductivity and $\overline{N u}$ is average Nusselt number.

$$
\frac{\Delta p}{L}=\frac{2(f R e) \mu u_{m}}{D_{h}^{2}}=\frac{2 P o \mu u_{m}}{D_{h}^{2}}
$$

In eqn. (1.2.) the variables are defined as follows: $\Delta p$ (pressure drop), $L$ (channel length), $f$ (friction factor), $\mu$ (dynamic viscosity), $u_{m}$ (average flow velocity), $P o$ (Poiseuille number).

The Eqn. (1.1) shows that heat transfer coefficient is only a function of hydraulic diameter because $\overline{N u}$ is constant for laminar flow. On the other hand, eqn. (1.2) shows that pressure drop per unit length is a function of Reynolds number and hydraulic diameter. Since Nusselt number $(\overline{N u})$ and Poiseuille number $(P o)$ are independent of Reynolds number in the laminar region for channel flow, smaller diameters result in higher heat transfer coefficients and higher pressure losses per unit length as demonstrated in Figure 1.2 and Figure 1.3. A more detailed explanation can be found about the basics of heat transfer in the following Chapter. 


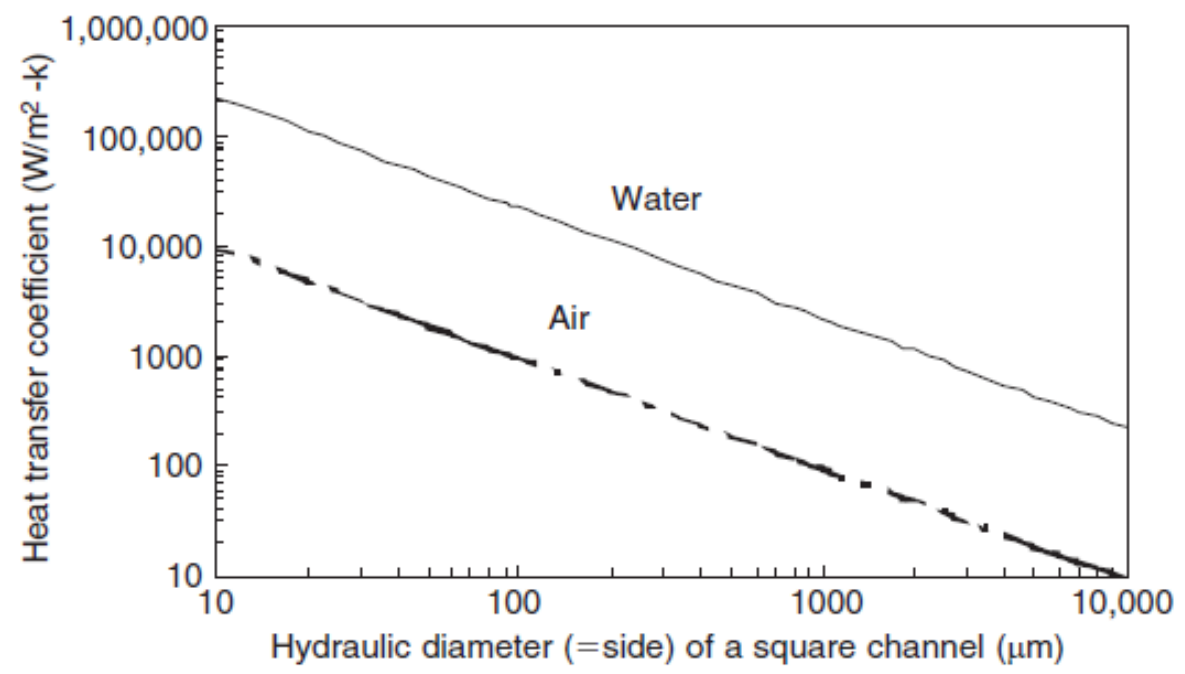

Figure 1.2 Heat transfer coefficient variation with respect to hydraulic diameter for laminar flow under constant heat flux for fully developed conditions [3]

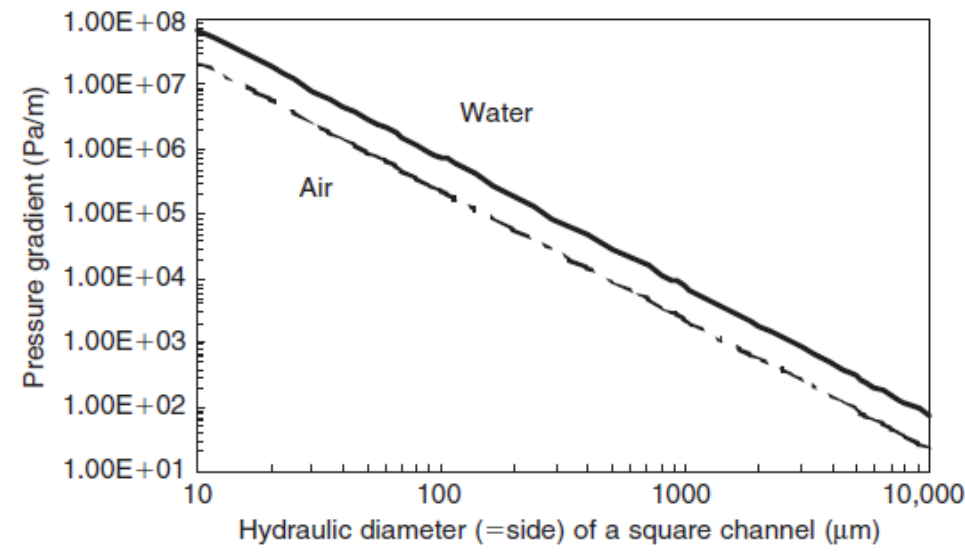

Figure 1.3 Pressure gradient variation with respect to hydraulic diameter for laminar flow under constant heat flux for fully developed conditions [3]

In the turbulent region, heat transfer for constant Reynolds numbers is also enhanced with decreasing hydraulic diameter similar to the laminar region. However, the pressure drop also increases with decreasing hydraulic diameter. In other words, smaller conduits can be very appropriate for high heat flux applications, but higher pumping power will be required.

Knowledge about the heat transfer characteristics for conventional channels is mature and published by several leading researchers such as Kakac and Shah [4] and Shah and London [5]. These researchers investigated pressure drop in conventional 
channels which have circular and non-circular geometries such as rectangular and triangular, through experimental researches and produced empirical correlations. However, their research included only large diameter channels with a single port, and not small scale channels and multiport channels.

Although smaller channels promised better heat transfer characteristics according to heat transfer theory as presented in Figure 1.2, small scale heat transfer through channels were not investigated until 1970's and 1980's due to limitations such as manufacturing and measurement problems. After advances in manufacturing and measurement technologies, small systems like compact heat exchangers became available. Similarly, electronic devices and mechanical devices started to become smaller while performing the same duty. Therefore, their heat generation per volume increases as their size decreases and thus cooling fluxes demands are increasing rapidly every year. Due to these increasing cooling fluxes, small scale heat transfer has become an important topic in the heat transfer field in recent decades.

In order to classify channels as small scale channels or conventional channels, two channel classifications according to their hydraulic diameters are presented by Kandlikar [6] and Mahandele [7] and these are presented together in Table 1.1. In this thesis, Kandlikar's classification is used since it is the most widely accepted one in the literature. Also, this classification is used to distinguish channel types in Figure 1.1 .

Table 1.1 Channel classification according to hydraulic diameters in [6] and [7]

\begin{tabular}{lc|lr}
\hline Kandlikar [6] & Mahandele [7] & \\
\hline Conventional channels & $D_{h}>3 \mathrm{~mm}$ & Conventional passages & $D_{h}>6 \mathrm{~mm}$ \\
Minichannels & $3 \mathrm{~mm} \geq D_{h}>200 \mu \mathrm{m}$ & Compact passages & $6 \mathrm{~mm} \geq D_{h}>1 \mathrm{~mm}$ \\
Microchannels & $200 \mu \mathrm{m} \geq D_{h}>10 \mu \mathrm{m}$ & $1 \mathrm{~mm} \geq D_{h}>100 \mu \mathrm{m}$ \\
Transitional Channels & $200 \mu \mathrm{m} \geq D_{h}>0.1 \mu \mathrm{m}$ & Microchannels & $100 \mu \mathrm{m} \geq D_{h}>0.1 \mu \mathrm{m}$ \\
\hline
\end{tabular}


In the early 1980 's, the limits to electronic cooling power was believed by some scientists to be $20 \mathrm{~W} / \mathrm{cm}^{2}$ [8] as indicated in [9]. Tuckerman and Pease's study [9] in 1981 is considered to be a pioneering study by many people researching heat transfer on a small scale as it proved that significantly higher heat fluxes are possible. Tuckerman and Pease investigated heat sinks to cool high speed planar integrated circuits. In their study, a $1 \mathrm{~cm} \times 1 \mathrm{~cm}$ area was cooled by 3 different heat sink configurations with liquid water flow. One of the heat sinks had rectangular channels of $50 \mu \mathrm{m}$ width, $307 \mu \mathrm{m}$ height and $50 \mu \mathrm{m}$ wall thickness. This heat sink was able to dissipate $790 \mathrm{~W} / \mathrm{cm}^{2}$ and the researchers claimed that $1000 \mathrm{~W} / \mathrm{cm}^{2}$ heat dissipation is possible. The study made an impact on the heat transfer field and motivated other researches to investigate small scale heat transfer. On the other hand, it was uncertain whether conventional channel theory also covers small scale heat transfer. Tuckerman and Pease's results agreed with constant Poiseuille number theory and some researchers' studies agreed with conventional theory. However, other researchers' studies [10-12,14,20,22,27,31] showed discrepancies and deviations from conventional channel theory for several factors such as critical Reynolds number, Poiseuille number and Nusselt number. A number of different correlations for small scale channels which do not agree with each other are provided and explained in details in the Literature Review section of this thesis. Therefore, more research is needed to validate or correlate conventional theory for small scale heat transfer or find new correlations. Hence, in the present work the main areas of investigation can be summarized as [3]:

- Experimental validation of transport equations;

- Verification or correlation of empirical constants of conventional channel theory;

- Verification of laminar to turbulent transition range in small scale channels.

Additionally, it is important to note that in small scale channels flow is generally in the laminar region due to the small diameters as suggested by eqn. (2.4). 


\subsection{Literature Review}

Tuckerman and Pease's study [9] made heat transfer in small scale channels an active research field and a large number of studies were conducted afterwards. Yet, there are still gaps in the literature and further research is needed. Scientists are primarily investigating different types of channels and flow to find friction factor and heat transfer characteristics. The main variables investigated in the literature can be summarized as:

- Type of flow (single phase, two phase flow);

- Types of fluid (gas, liquid, mixture);

- Type of channel geometry (circular, rectangular, triangular, etc.);

- Number of ports (singular, two, three, etc.);

- Boundary conditions (constant heat flux, constant wall temperature).

- Flow Regime (laminar flow, turbulent flow)

There are a large number of articles and conference proceedings on small scale channels. In this section, only the most important ones among these studies for the objective and the scope of this study are shown for the sake of clarity and brevity. Interested readers may use keywords to search the literature for further information.

One of the earliest studies was performed by Pfahler et al. [10] in 1990 to investigate the effects of smaller dimensions on fluid flow behavior. Three different rectangular channels were machined on silicon substrates. The heights of the channels were 135 $\mu \mathrm{m}, 100 \mu \mathrm{m}$, and $100 \mu \mathrm{m}$ and the width of the channels were $53 \mu \mathrm{m}, 1.7 \mu \mathrm{m}$ and 0.8 $\mu \mathrm{m}$, respectively. A pressurized gas cylinder is used to pressurize the fluid (npropanol) in the open cycle. All fluid flow is laminar. For the largest channel with Reynolds number ranging from 50 to 300, conventional correlations showed relatively good agreement with constant Poiseuille number theory considering the effects of entrance region where. On the other hand, the Poiseuille number for fluid 
flow in the smallest channel was much higher than conventional theory predicts and followed a decreasing trend with increasing Reynolds number. For the last channel, the Poiseuille number was approximately constant, however conventional theory underestimated the results. However, it is important to note that the Reynolds number for smaller channels were very small and only between 0.0001 and 0.0060 .

In 1994, frictional flow characteristics of liquid water flow in rectangular microchannels were investigated by Peng and Peterson [11]. Seven different channels were manufactured on a stainless steel substrate producing 3-walls of a channel and a fiberglass plastic cover is used as the fourth wall. The hydraulic diameter of the channels varied between 0.133 and $0.367 \mathrm{~mm}$ and the aspect ratios varied between $1 / 3$ and 1 . The Reynolds number varied between 50 and 4000 to cover the laminar, transition and turbulent regions. The results did not agree with conventional theory and it was observed that conventional correlations underpredicted for some channels but overpredicted for others. They also observed an increasing Poiseuille number in the laminar region which contradicted with constant Poiseuille number theory for conventional theory. Correlations for friction factor for both the fully developed turbulent region and the laminar region are suggested. Another interesting observation in their study was the determination of the critical Reynolds numbers where transition to turbulent flow occurs. They reported that critical Reynolds numbers are strongly dependent on hydraulic diameter, and critical Reynolds numbers increase when hydraulic diameter increases. Moreover, transition to turbulence starts at Reynolds numbers between 200 and 700, which is quite low when compared to the critical Reynolds number $\left(R e_{c r}=2300\right)$ for fluid flow in conventional channels. Additionally, they expressed that the hydraulic diameter strongly influences the friction factor, and an aspect ratio of 0.5 provides the lowest friction factor. They suggested the following correlation for laminar flow which contradicts with constant Poiseuille theory.

$$
\mathrm{C}=f R e^{1.98}
$$


Wang and Peng [12] performed an experimental study to investigate heat transfer and transition from laminar to turbulent flow. The refrigeration fluids were methanol and deionized water in liquid form and the flow range was between 70 and 4000 Reynolds numbers. The width of the test section was $18 \mathrm{~mm}$ and six different 0.7 $\mathrm{mm}$ deep rectangular channels having a width ranging between $0.2-0.8 \mathrm{~mm}$ were machined in the test section. The test section was heated with joule heating only from the top and the fluid was driven by a pump in an open loop. They found that heat transfer in fully developed turbulent region can be predicted using the Dittus-Boelter correlation [13] when its constant was modified with approximately one-quarter of the original constant of the correlation. On the other hand, they reported that transitions occur at $R e=1000-1500$ which also contradicted with the conventional channel theory indicating that transition occurs around $R e=2300$. They claimed that liquid temperature, viscosity and channel size were dominating factors affecting the critical Reynolds number.

Peng and Peterson [14] constructed another experimental set-up to further investigate fluid flow and heat transfer in rectangular channels. Similarly, they manufactured several channels in $18 \mathrm{~mm}$ wide steel plates. The channels' hydraulic diameters were between $0.133 \mathrm{~mm}$ and $0.343 \mathrm{~mm}$, and the height to width ratio $(H / W)$ of the channels differed from 0.5 to 3.0. The channel was directly heated with a low voltage high current DC power supply and 3 sides of the channels were heated. An insulator placed on the top of the steel plate served as the fourth wall and sealant. They also defined a new parameter, which is the hydraulic diameter to distance between channel centers $\left(D_{h} / W_{c}\right)$, to research its effects on heat transfer. Friction factor results and critical Reynolds results showed good agreement with their previous correlations [11]. However, it was pointed out that they strongly depend on the height to width ratio $(H / W)$ and $D_{h}$ of the channel. The results showed that heat transfer behavior also depends on $D_{h} / W_{c}$ and $H / W$ in addition to $R e$ and Prandl Number $(P r)$ dependence. Thus, two correlations including $D_{h} / W_{c}$ and $H / W$ for laminar and turbulent flows were suggested. Moreover, they commented that an 
aspect ratio equal to 0.5 maximizes heat transfer in the fully developed turbulent region. They also suggested a correlation as indicated in Table 2.7.

Spiga and Morini [15] analytically found Nusselt numbers under thermally and hydrodynamically fully developed conditions for fully developed flow under H2 boundary condition(constant axial heat flux and constant peripheral heat flux). Eight different H2 conditions (1 short wall heated, 3 walls heated and one short wall adiabatic, all walls heated, etc.) were investigated in rectangular channels with different aspect ratios. They found that there is very good agreement with conventional theories such as Shah and London [5]. Additionally, they suggested a $5^{\text {th }}$ order polynomial for $\mathrm{Nu}$ for different aspect ratios. Similarly, Morini [16] determined temperature distribution analytically for fully developed flow under H1 boundary (constant axial heat flux and constant peripheral temperature). Like in his previous work, eight different conditions were investigated for rectangular channels. After comparison with the open literature like Shah and London [5] and [17], he found a good agreement and suggested a $5^{\text {th }}$ order polynomial function of aspect ratio to calculate $\mathrm{Nu}$ numbers.

Adams et al. [18] worked on turbulent single phase water flow in two circular channels having $0.76 \mathrm{~mm}$ and $1.09 \mathrm{~mm}$ diameters. The channels were heated through joule heating up to $300 \mathrm{~W} / \mathrm{cm}^{2}$ with band heaters controlled with a variac. Radial distances between the channels and heaters were around $30 \mathrm{~mm}$ to approximate a constant temperature boundary condition by increasing the axial conduction. The flow velocity ranged between 0 and $18.9 \mathrm{~m} / \mathrm{s}$ to investigate Reynolds numbers in the range 3200 - 23000. The Prandtl number varied between 3.7 and 6.43. Temperature data along the channel were obtained from six thermocouples and a finite difference software. After friction factor and heat transfer coefficient computations, Nusselt numbers for both channels were compared with one well accepted forced turbulent flow correlation (Grinilenski correlation [13]), and it was observed that the Grinilenski correlation underpredicted the experimental data. By presenting their own and other experimental data in the literature, Adams et al. [18] showed that heat transfer enhancement on small scale channels is inversely proportional with 
hydraulic diameter. A modification to the Grinilenski correlation, which predicts heat transfer in their experimental data ranging within $18.6 \%$ error, is suggested and presented in Table 2.7.

In order to find effects of simultaneously developing flow effects on heat transfer in rectangular tubes in heat exchangers in the automotive industry, Garimella et al. [19] conducted an experimental study. They built a single-tube single-shell cross-flow heat exchanger in which cold water flowed in the shell-side whereas hot glycol solutions flowed in the rectangular tubes. The annulus side heat transfer resistance was minimized to clearly observe the change of heat transfer coefficient in the tube side. Three different rectangular tube geometries having hydraulic diameters 2.21 $\mathrm{mm}, 3.02 \mathrm{~mm}, 3.74 \mathrm{~mm}$ and aspect ratios $(\alpha)$ 0.050, 0.108 and 0.029 were investigated for different lengths to investigate entrance region effects. Additionally, different concentrations of glycol solution are used as the working fluid to observe bulk-to-wall property variations. Log Mean Temperature Difference (LMTD) methodology was performed to find tube side heat transfer coefficients with an uncertainty within $2.9 \%$ and $4.9 \%$. The researchers observed that as the length of the channel decreases, $\mathrm{Nu}$ values are higher for constant $R e$ values for all channels. On the other hand, it was discovered that aspect ratio effects on heat transfer performance were negligible for low $\alpha$ values. Another interesting result of the study is transition to turbulent $\left(R e_{c r}\right)$. Researchers observed a gradual transition between $R e$ $=800$ and $R e=2000$ rather than a sharp transition. They suggested a lengthy correlation which is a function of $\operatorname{Re}, L, \operatorname{Pr}, D_{h}, \alpha$ and $\mu_{b} / \mu_{w}$. The correlation covers experimental data for $1.74 \mathrm{~mm}<D_{h}<3.02 \mathrm{~mm}, 6.5<\operatorname{Pr}<16.2$ and small aspect ratios. A comparison indicated that the correlation's predictions are in good agreement with developing flow correlations in the literature.

Owhaib and Palm [20] experimentally studied heat transfer in three minitubes with equal $325 \mathrm{~mm}$ axial lengths and $0.8 \mathrm{~mm}, 1.2 \mathrm{~mm}$ and $1.7 \mathrm{~mm}$ diameters, respectively. Liquid R-134a flow inside the tubes was investigated under constant heat flux boundary condition as the Reynolds number varied between 1000 and 17000. The researchers found that the heat transfer coefficients for all tubes were 
quite close in the laminar region whereas the smallest tube has the higher heat transfer coefficient in the transition and turbulent regions. The Nusselt numbers were somewhat close for all tubes in the laminar and turbulent region but significant scatter was observed in the transition region. After comparison with conventional theories [13] and small scale correlations such as [14] and [18], they concluded that conventional theories predicted data reasonably well for turbulent and laminar regions. However, none of the considered small scale correlations succeeded to predict the results.

Lelea et al. [21] investigated heat transfer both numerically and experimentally for liquid flow in microtubes. Three stainless steel microtubes having diameters 0.125 $\mathrm{m}, 0.300 \mathrm{~mm}$ and $0.500 \mathrm{~mm}$ are investigated in laminar region Re ranging up to 800 using distilled water as working fluid. Joule heating through a power supply under vacuum was used for constant heat flux boundary condition. Global Poiseuille number and Nusselt numbers were found in laminar region. Moreover, several thermocouples were placed on the wall of the tube to investigate local $\mathrm{Nu}$ numbers. After correcting pressure drop by extraction entrance region, contraction and expansion losses, they observed that $\mathrm{Nu}$ and Po numbers showed an excellent agreement with conventional theory. Additionally, numerical results followed closely experimental data and conventional theory. Maximum sensitivity was $4.0 \%$ for channel having $0.3 \mathrm{~mm}$ diameter and less for the larger channels. After this article, number of studies on microtubes decreased.

Agostini et al. [22] conducted experiments to investigate friction factor and heat transfer coefficient for single phase R-134a liquid flow. They used 2 multiport extruded minichannels with hydraulic diameters of $0.77 \mathrm{~mm}$ and $1.17 \mathrm{~mm}$. The test section was heated with direct joule heating of the minichannel through a low voltage high current power supply. The mass flux of the flow was varied to yield Reynolds numbers between 500 and 6000 to cover both laminar and turbulent regimes. The smallest channel was placed horizontally while the largest channel was placed vertically. They observed that friction factors for laminar and turbulent regions were predicted well for the small channel and underpredicted for the large channel by 
conventional correlations such as Shah \& London [5] for laminar flow and the Blasius correlation for turbulent flow. However, they commented that minor losses caused increases in friction factor and established a pressure loss coefficient for the large channel. Moreover, transition to turbulent flow was observed at $1800<R e<$ 2000 for both channels. In the turbulent region, the Grielinsky correlation [13] estimated heat transfer coefficients quite well. In the laminar region, Shah and London correlation [5] predicted reasonably well for the large channel although the heat transfer coefficient of the small channel followed an increasing trend and contradicted with the correlation. However, it was expressed that the thermal entrance length and longitudinal conduction might also be the cause for non-constant Nusselt number for the small channel in the laminar region. They also compared their results with correlations for small scale channels established by Peng and Peterson [14], Adams et. al [18], and Garimella et al [19]. It was found that the correlation suggested by Garimella et al. [19] best predicted their results.

Judy et al. [23] analyzed frictional pressure drop in single phase liquid flow through microchannels in the laminar region. Three different working fluids (distilled water, methanol and isopropanol) flowed inside fused silicon circular tubes, fused silicon square channels and stainless steel circular tubes to investigate and contrast the effects of different geometries, working fluids and surface materials. The hydraulic diameters of the tubes ranged between $15 \mu \mathrm{m}$ and $150 \mu \mathrm{m}$. After excluding entrance, exit and hydraulic developing effects, it was found that the frictional drop follows constant $P o$ theory and shows excellent agreement considering all data are within the uncertainty bounds for all tube materials, working fluids and geometries. A maximum deviation for all data sets was found to be $3 \%$. Additionally, no early transitions were observed in their study in any data set.

Gao et al. [24] investigated scaling effects to inspect heat transfer, friction factors and transition to turbulence. They built an experiment set-up to cover rectangular small-scale smooth channels $(0.1 \mu \mathrm{m}$ roughness $)$ with constant $25 \mathrm{~mm}$ width and 7 different heights (e) $0.1,0.2,0.3,0.4,0.50 .7$ and $1 \mathrm{~mm}$ using demineralized water as a working fluid. The experimental uncertainty in $\mathrm{Nu}$ were less than $4.5 \%$ whereas the 
uncertainty in $R e$ was less than $1 \%$. After correlating entrance head loss, they found that their friction factor data shows good agreement with constant $P o$ number theory. On the other hand, they observed that for channels having heights smaller than 0.4 $\mathrm{mm}$, Nusselt numbers were lower than conventional theory predictions. Also a constant heat coefficient was observed for increasing Nusselt number for low height values. On the other hand, differences between experimental and predicted heat transfer coefficients at high $R e$ become significant for higher height values. Using Nusselt number calculations, it is seen that onset to turbulence occurs between $\operatorname{Re}$ 2200 and 3500 while onset to turbulence using friction factor calculations was at $\operatorname{Re}$ between 2500 and 4000. Additionally, local Nusselt numbers are found to be increasing for constant non-dimensional distance $\left(L^{*}\right)$ for different thermocouples. Especially, local Nusselt numbers found using thermocouples closer to the exit of channels are higher due to the transition to turbulence.

Caney et al. [25] investigated heat transfer in a 1x1 mm square cross-sectional mini channel machined on a $15 \mathrm{~mm}$ thick $80 \mathrm{~mm}$ wide $500 \mathrm{~mm}$ long aluminium plate in a vertical flow configuration. Emphasis was placed on longitudinal conduction heat transfer and temperature measurement and the thermocouples were located at the fluid-wall interface, not on a wall surface. The Reynolds number ranged from 310 to 7780 to cover both laminar and turbulent regions. Considering friction factor, Caney et al.'s data showed good agreement with the conventional correlations of Shah \& London [5] and Blasius [13]. In order to compare longitudinal conduction with axial convection, they use a parameter M which is introduced by Maranzana et al. [26] and given as follows:

$$
M=\frac{k \frac{e_{w}}{L}}{\rho C_{p} H u_{m}}
$$

where $M$ is axial conduction number, $e_{w}$ is wall thickness, $\rho$ is density, $C_{p}$ is the specific heat of the fluid, and $H$ is channel height. 
Maranzana et al. [26] showed in their analytical study that longitudinal conduction becomes significant if the $M$ parameter is larger than 0.01 . On the other hand, the temperature difference along the channel was not showing the expected linear distribution and it was found that the $M$ parameter was equal to 0.57 . Thus, they commented that there was a significant longitudinal heat conduction that alters the temperature distribution. They performed a numerical study to compare with experimental results. The numerical study also supported their temperature trend and longitudinal conduction hypothesis and they found that temperature profiles taken 50 $\mu \mathrm{m}$ from the wall shows the best fit with experimental data. They also commented that $N u$ did not converge to a asymptote value due to the heat flux distribution and thermal entrance length. Lastly, it was pointed out that no unexplained physical phenomenon was observed in their study after careful observation and correlations.

Lee et al. [27] investigated the effect of heat transfer and fluid flow in rectangular microchannels both numerically and experimentally. Five different rectangular channel configurations with hydraulic diameters ranging from $318 \mu \mathrm{m}$ to $903 \mu \mathrm{m}$ were investigated. These channels were machined on $25.4 \mathrm{~mm} \times 25.4 \mathrm{~mm} \times 70 \mathrm{~mm}$ copper blocks (length of channels were equal to $25.4 \mathrm{~mm}$ ) as a heat sink. The working fluid was selected as deionized water and 300-3500 Reynolds number range were covered. Cartridge heaters up to $800 \mathrm{~W}$ power capacity were placed on the bottom section of the copper block. Using the commercial software Fluent, a 3D conjugate CFD analysis modeling both the fluid and copper substrate to simulate both convection and conduction was performed. Additionally, simplified versions of the numerical study were performed with $\mathrm{H} 1, \mathrm{H} 2$ and $\mathrm{T}$ boundary conditions. In order to implement the $\mathrm{H} 1$ boundary condition a thin, highly conductive wall was employed while other boundary conditions were directly implemented on the fluid boundaries. The researchers also questioned small scale heat transfer equations and calculated hydrodynamic entrance and thermal entrance lengths of experimental studies used to find these correlations. They pointed out that in most of these studies, flow was hydrodynamically developing, thus in the simultaneously developing region, and argued that the discrepancy between conventional correlations are due to 
inappropriately selected correlations. The fluid flow in Lee et al.'s study [27] were not fully developed and either fell in the thermally developing region or simultaneously developing region. The Nusselt numbers in their study showed an increasing trend in both laminar and turbulent regions. They observed a transition to turbulence at $R e$ between 1500 and 2000 where there was an increase in the $\mathrm{Nu}$ number's slope. None of the conventional channel predictions such as Shah and Londan [5] and Sieder and Tate [13] could predict the data in the laminar region because these correlations do not take entrance region effects and aspect ratios into consideration. Similarly, none of turbulent correlations were able to predict their data. On the other hand, the $3 \mathrm{D}$ conjugate analysis predicted the experimental data fairly well. Among the simplified numerical analysis, H1 (also termed as thin wall by investigators) showed an excellent match with 3D conjugate numerical results whereas other boundary conditions underestimated the $\mathrm{Nu}$ results (H1 12.4\% smaller and $\mathrm{T} 7.1 \%$ smaller than $3 \mathrm{D}$ conjugate data). It was suggested that the thin wall approach was most appropriate to use when full conjugate analysis is not possible due to computer limitation, etc. Additionally, Lee et al. underlined that Navier Stokes equations are still valid for their size range and was a good way to evaluate heat transfer performance of small scale channels while the use of conventional correlations were not appropriate due to significant differences with microchannel boundary and inlet conditions.

There are not many studies on multiport minichannel tubes. One of the experimental studies was performed by Stignor et al. [28] to investigate the heat transfer performance of these type of tubes for the laminar flow regime. An experimental setup was constructed which contains 3 loops (heating, cooling and testing loops). In the test section, heat transfer in a coaxial heat exchanger with the working fluid flowing in the tubes and cooling water flowing inside the annulus was tested to simulate boundary condition close to constant temperature. The four different working fluids flowing inside the tubes were liquid secondary refrigerants (propylene glycol, Temper-20 and Hycoll 20) and water. Three different tubes were investigated. The First tube has 8 ports with a hydraulic diameter of $4.73 \mathrm{~mm}$. The 
Second tube had 9 ports with fins and its $D_{h}$ was $3.19 \mathrm{~mm}$. The hydraulic diameter of the $3^{\text {rd }}$ tube containing 25 ports was $2.06 \mathrm{~mm}$. The flow was heated after a hydrodynamic development length. In other words, the flow inside the tubes was thermally developing. The authors compared their results with several correlations in the literature including the Garimella model [19], Grinelinski model [29] and Muzychka model [30] which takes the root of the cross-sectional area as the characteristic length. In order to clearly visualize the effect of thermally development, characteristic length $\left(L^{*}\right)$ effects on $\mathrm{Nu}$ are presented in graphs with predictions of correlations. For the first tube, the Grinelinski model [29] predicted the experimental results best whereas the Garimella model [19] showed good agreement for higher $L^{*}$ but overestimated for low $L^{*}$ values. On the other hand, the Muzychka model [30] in which the root of the cross-sectional area is taken as the characteristic length predicted lower $L^{*}$ values, but underpredicted higher $L^{*}$ values. For the second tube, results followed the same trend with the Grinelinski model [29] but there was a constant difference between predictions. The authors found that after neglecting the fins while calculating $\mathrm{D}_{\mathrm{h}}$ (i.e. taking the channel as pure plain square), there was an excellent agreement with the Grinelinski model [29] predictions. Additionally, the Muzychka model [30] showed very good agreement. Therefore, it was suggested that for channels with fins, fins should be taken into calculation for the cross section but neglected for hydraulic diameter. All models overpredicted heat transfer in the $3^{\text {rd }}$ tube but the Grinelinski model [29] again best predicted the data with uncertainties less than 20\%. The authors commented the cause of overpredictions might be longitudinal conduction along the channel or gross flow maldistribution among ports. However, the authors did not take into consideration how different port numbers may effect heat transfer performance and made no comments about it.

Park and Punch [31] investigated heat transfer and friction factor for single phase liquid flow in ten different microchannel arrays. Deionized water was used as the working fluid. The microchannel arrays with hydraulic diameters ranging from 106 $\mu \mathrm{m}$ to $307 \mu \mathrm{m}$ were tested in the laminar flow regime as Re numbers varied from 69 
to 800 . The number of channels in different arrays was between 16 and 100 . Microchannels were heated only for an area of $10 \mathrm{~mm}$ x $10 \mathrm{~mm}$ from the bottom surface with resistance heaters. After excluding inlet and exit losses, they found excellent agreement with conventional friction factor theory [32]. On the other hand, conventional heat transfer correlations [32] and [5] failed to predict the actual results. Therefore, they proposed another correlation that also includes Brickman number $(\mathrm{Br})$, thus including viscous dissipation effects. However, they also noted that viscous dissipation were negligible due to low Prandtl number and flow speed. It was pointed out that the effects of viscous dissipation is negligible for typical flow conditions and becomes critical when there is slip flow.

Fernando et al. [33] studied the single-phase heat transfer performance of a crossflow shell and tube compact heat exchanger built with extruded aluminum multiport rectangular minichannels similar to the channels used in the present thesis. Thirty rectangular minitubes containing six ports with $1 \mathrm{~mm}$ height and $2.65 \mathrm{~mm}$ width $\left(D_{h}\right.$ $=1.42 \mathrm{~mm}$ ) were used to construct the heat exchanger. Hot water flowed through the tube side whereas cold water flowed through the shell side $\left(D_{h}=3.62 \mathrm{~mm}\right)$. The Reynolds number range for tube side and shell side was 170-6000 and 1000-5000, respectively. The length of tubes was $661 \mathrm{~mm}$ with $651 \mathrm{~mm}$ being heated. The researchers suggested a correlation which gives the best prediction of their data for the turbulent region in the tube side and also made a comparison with the open literature for both tube side and shell side. For the tube side, the researchers found great agreement with the Grinelinski correlation [34] used for conventional channel for Reynolds number ranging 2300-6000 (turbulent region). However, none of correlations for small scale channels such as the Peng and Peterson correlation [14] gave a good estimation in the turbulent region. For laminar region, a slight linear gradual increase of Nusselt number was observed up to Reynolds number of 1200. At Reynolds equals to 1200 , there was a sharp incline in slope on the gradual increase of Nusselt number up to Reynolds number of 2300. The researchers thought that this might be due to an increase in the thermal entrance length as the Reynolds number increases while length is held constant even though this might be a sign for 
onset to turbulent flow or transition flow at $R e=1200$. Neither conventional nor small scale correlations were able to predict $N u$ between 1200 and $2300 R e$ numbers. On the other hand, the Peng and Peterson correlation [14] gave a reasonably good prediction when $R e$ was less than 1200. Considering heat transfer in the shell side, conventional and small scale correlations failed to predict shell-side heat transfer coefficients due to change in velocity between baffles and flow condition that were not hydraulically fully developed. Thus, the researchers also suggested correlations for laminar and turbulent regions in the shell side which predicted their data within $5 \%$ uncertainty.

H1 boundary condition is defined as [4] heat flux, with circumferential constant wall temperature and axially constant wall heat flux. H2 boundary condition [4] is defined as axially and circumferentially uniform wall heat flux. H1 boundary condition is assumed to be the boundary condition in mostly with applications such as electrical resistance heating and counterflow heat exchangers heating with high conductive wall materials. On the other hand, $\mathrm{H} 2$ is close to $\mathrm{H} 1$ with low conductive wall materials. For circular channel, $\mathrm{H} 1$ and $\mathrm{H} 2$ boundary conditions are identical.

\subsubsection{Summary of literature review}

A summary of Poiseuille number results in literature review is presented in Table 1.2. A large number of studies in the literature review agreed with conventional theory (in which Po equals to a constant and is independent of Re in the laminar flow regime). On the other hand, there are some researchers that found lower and higher Poiseuille numbers than conventional theory predicts. Moreover, some researchers found a Reynolds number dependence in the laminar region which contradicts conventional constant Poiseuille number theory. Furthermore, it should be noted that all circular channels (tubes) agreed with conventional theory. The laminar regimes of the studies which covered also transitional and turbulent regime in Table 1.2 is presented as critical Reynolds numbers in Table 1.3. 
Table 1.2. Experimental results for Poiseuille number

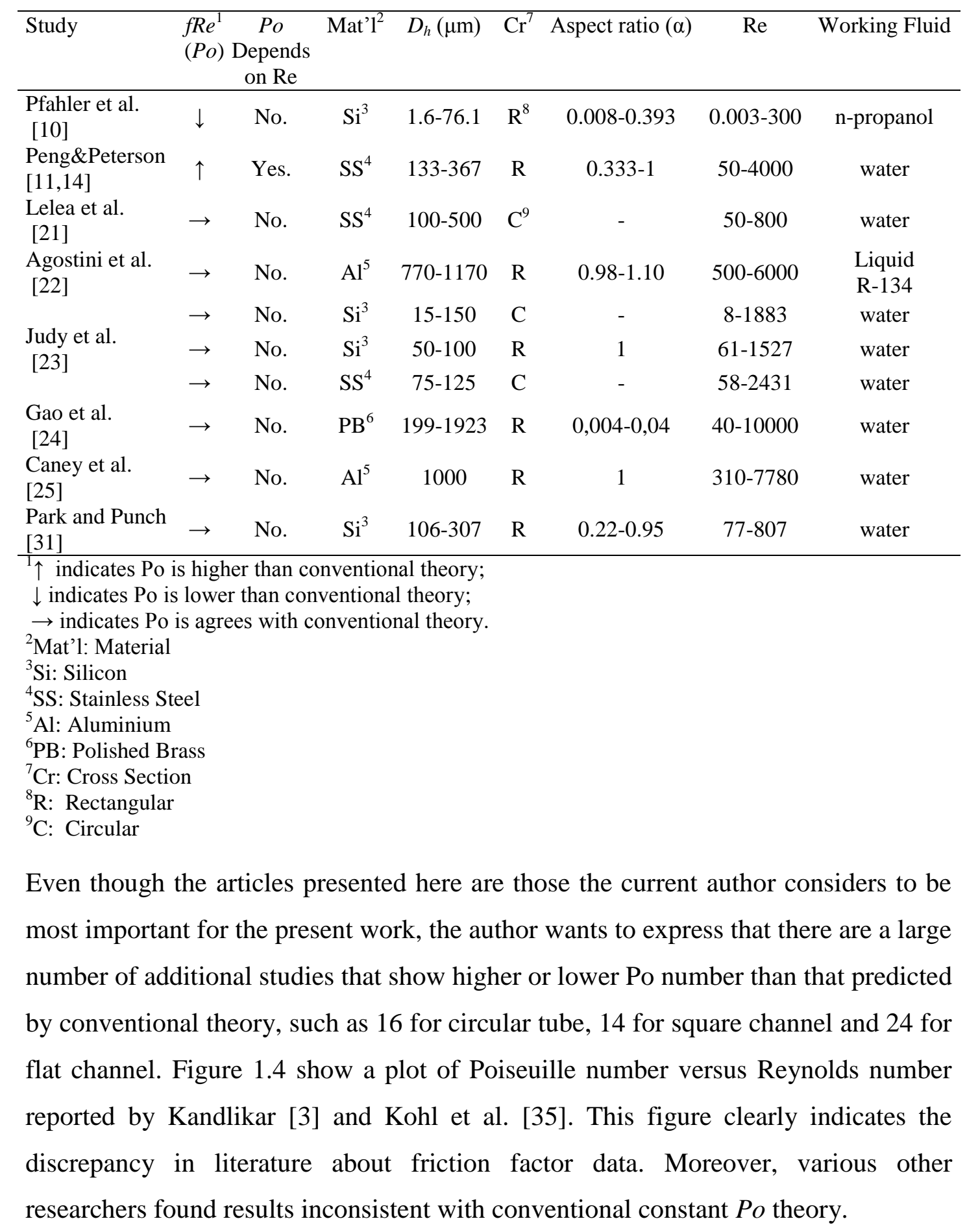



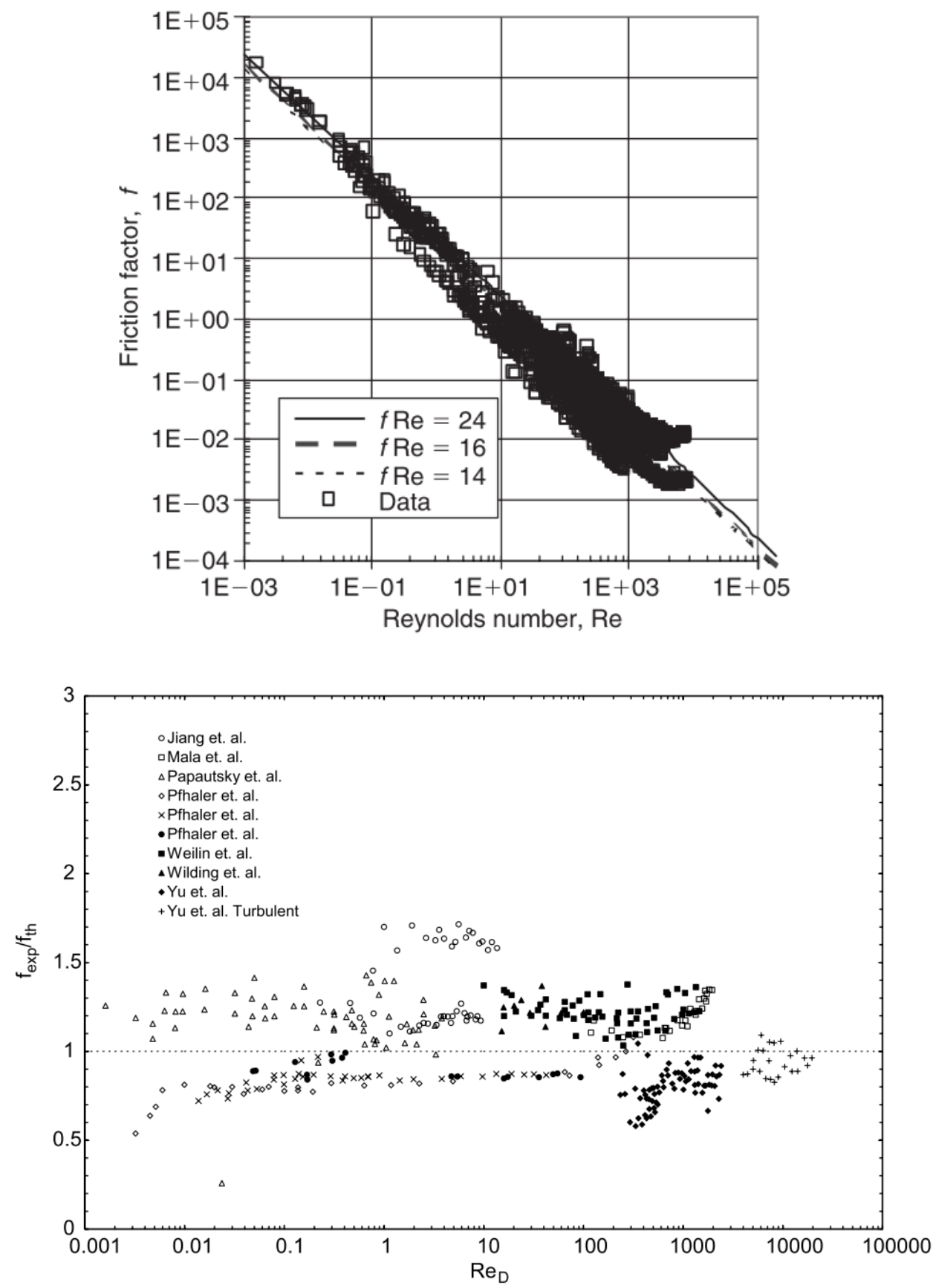

Figure 1.4. Poiseuille numbers in literature compared with theoretical values for different small scale channels (after [3] and [35]) 
Table 1.3 gives a summary of critical Reynolds numbers when the flow enters the transition region. Laminar to turbulent transition occurs at a $R e$ of 2200 for rectangular ducts [3]. As indicated in Table 1.3., the transition occurred earlier according to some of the experimental data in reviewed literature. The relative roughness of tubes was not measured in most of these studies. Therefore, the reason for this discrepancy might be differences in roughness. On the other hand, roughness of materials such as aluminum and brass are very low and on the order of a few micrometers. Furthermore, roughness is not a factor that affects friction factor and Poiseulle number.

Table 1.3. Experimental results of transition from laminar to turbulent region

\begin{tabular}{|c|c|c|c|c|c|c|c|}
\hline Study & $\mathrm{Re}_{\mathrm{cr}}$ & $\begin{array}{c}\text { Cross } \\
\text { section }\end{array}$ & $\mathrm{e}^{\mathrm{d}} \mathrm{D}_{\mathrm{h}}{ }^{\mathrm{T}}$ & $\begin{array}{c}\mathrm{Dh} \\
(\mu \mathrm{m})\end{array}$ & Mat'l' $^{2}$ & Aspect ratio $(\alpha)$ & $\begin{array}{l}\text { I.F. }^{3} \\
\text { N.F. }\end{array}$ \\
\hline Peng\&Peterson $[11,14]$ & $200-700$ & Rect. & Not meas. & $133-367$ & $\mathrm{SS} 4^{4}$ & $0.33-1.00$ & I.F. \\
\hline Wang and Peng [12] & $\begin{array}{l}400- \\
1000\end{array}$ & Rect. & Not meas. & $381-1295$ & $\mathrm{SS}^{4}$ & $0.05-0.24$ & N.F. \\
\hline Garimella et al. [19] & $\begin{array}{l}1200- \\
2000\end{array}$ & Rect. & Not meas. & $1737-3018$ & $\mathrm{Al}^{5}$ & $0.029-0.108$ & N.F. \\
\hline Owhaib \& Palm [20] & $\begin{array}{c}2300- \\
3000\end{array}$ & Circ. & Not meas. & $800-1700$ & $\mathrm{SS}^{4}$ & - & N.F. \\
\hline Agostini et al. [24] & $\begin{array}{l}1800- \\
2000\end{array}$ & Rect. & Not meas. & $770-1170$ & $\mathrm{Al}^{5}$ & & N.F. \\
\hline Gao et al. [24] & $\begin{array}{l}2200- \\
3500\end{array}$ & Rect. & $<0.1 \mu \mathrm{m}$ & $199-1923$ & $\mathrm{~PB}^{6}$ & $0.004-0.04$ & N.F. \\
\hline Caney et al. [25] & $\begin{array}{l}2100- \\
3000\end{array}$ & Rect. & Not meas. & 1000 & $\mathrm{Al}^{5}$ & 1 & N.F. \\
\hline Lee et al. [27] & $\begin{array}{l}1500- \\
2000\end{array}$ & Rect. & Not meas. & $318-903$ & $\mathrm{Co}^{7}$ & 0.2 & N.F. \\
\hline Fernando et al. [33] & $\begin{array}{c}1200- \\
1500\end{array}$ & Rect. & Not meas. & 1420 & $\mathrm{Al}^{5}$ & 0.377 & N.F. \\
\hline $\begin{array}{l}{ }^{1} \mathrm{e} / \mathrm{D}_{\mathrm{h}} \text { indicates relative } \mathrm{r} \\
{ }^{2} \mathrm{Mat} \text { ': Material } \\
{ }^{3} \text { I.F. indicates isotherma }\end{array}$ & $\begin{array}{l}\text { oughness } \\
1 \text { flow }\end{array}$ & & & & & & \\
\hline $\begin{array}{l}\text { N.F. indicates non isoth } \\
{ }^{4} \mathrm{SS} \text { : Stainless Steel } \\
{ }^{5} \mathrm{Al} \text { : Aluminium } \\
{ }^{6} \mathrm{~PB} \text { : Polished Brass } \\
{ }^{7} \mathrm{Co} \text { : Cooper }\end{array}$ & ermal flow & & & & & & \\
\hline
\end{tabular}


A comparison of Nusselt number with conventional theory (in which $\mathrm{Nu}$ is constant and independent of $\mathrm{Re}$ in the laminar flow regime) is summarized in Table 1.4. There is a large scatter in Nusselt number results and no general trend is observed in terms of hydraulic diameter, cross section and aspect ratio.

Table 1.4 Experimental results on Nusselt number

\begin{tabular}{lccccc}
\hline Study & $\mathrm{Nu}$ & Port Number & Cross section & Dh $(\mu \mathrm{m})$ & $\alpha$ \\
\hline Wang and Peng [12] & $\downarrow$ & $4-6$ & Rect. & $381-1295$ & $0.05-0.24$ \\
Peng\&Peterson [13] & $\downarrow$ & $2-8$ & Rect. & $133-367$ & $0.333-1$ \\
Adams et al. [18] & $\uparrow$ & 1 & Circ. & 760,1090 & - \\
Garimella et al. [19] & $\uparrow$ & 1 & Rect. & $1737-3018$ & $0.029-0.108$ \\
Owhaib \& Palm [20] & $\uparrow$ & 1 & Circ. & $800-1700$ & - \\
Lelea et al. [21] & $\rightarrow$ & 1 & Circ. & $100-500$ & - \\
Agostini et al. [22] & $\uparrow$ & $18-32$ & Rect. & $770-1170$ & $0.98-1.10$ \\
Gao et al. [24] & $\uparrow$ & 1 & Rect. & $199-1923$ & $0,004-0,04$ \\
Caney et al. [25] & $\rightarrow$ & 1 & Rect. & 1000 & 1 \\
Lee et al. [27] & $\downarrow$ & 10 & Rect. & $318-903$ & 0,2 \\
Stignor et al. [28] & $\rightarrow$ & $8-25$ & Rect. & $2060-4730$ & $0.11-0.44$ \\
Park and Punch [31] & $\uparrow$ & $16-100$ & Rect. & $106-307$ & $0.22-0.95$ \\
Fernando et al. [33] & $\uparrow$ & 6 & Rect. & 1420 & 0.377 \\
\hline$\uparrow$ & indicates Nu is higher than conventional theory & & & \\
$\downarrow \quad$ indicates Nu is lower than conventional theory & & & \\
$\rightarrow$ indicates Nu is agrees with conventional theory & & & \\
$\uparrow \quad$ indicates Nu is agrees with conventional theory for some data but does not agree for all data.
\end{tabular}

Based on this literature review, the following conclusions are drawn:

1. The literature review showed that the Poiseuille number is not constant in the laminar region in some experiments. It was argued that the reason might be due to not taking inlet contraction, exit expansion and the developing region into consideration. However, there are still studies that do not agree with conventional theory even after considering minor head losses. Some researchers argued that Poiseuille number is dependent on Reynolds number in the laminar region and proposed correlations. Other researchers disagreed and pointed out that Poiseuille number is constant and there is no unexpected behavior when presenting their experimental results. 
2. An understanding of transition to turbulent region is another aspect that is not mature in the small-scale heat transfer area. Surface roughness is an important parameter for early transition since relative roughness becomes larger as the hydraulic diameter of channel decreases. Experimental results differ significantly especially for rectangular channels.

3. Many correlations for small scale channels were suggested by researchers. While these correlations were able to predict some experimental results, they failed to predict others. Similarly, conventional correlations were not able to predict all experimental data as presented in Table 1.4. Therefore, it is still a question mark which correlations are more suitable for specific channels and which ones of them give more accurate predictions.

4. Predictions from conventional correlations are generally better in the turbulent region as opposed to the laminar region. The reason might be that the hydraulic and thermally developing length is much lower in the turbulent regime in comparison to the laminar region and thus the conditions of flow are closer to conventional correlations.

5. The largest variation in heat transfer results occurs in the laminar region. This might be due to longitudinal conduction and developing effects. As indicated previously, the length of small scale channels are limited due to pressure drop considerations. Therefore, the flow is generally laminar and sometimes not thermally fully developed. 


\subsection{Thesis Overview}

\subsubsection{Objective}

After a careful literature review, gaps in the literature are found in Poiseuille numbers and Nusselt numbers in the laminar region for single phase flow. Additionally, there are a limited number of studies investigating variations in heat transfer with respect to port number, even though the effect of different port numbers which is the number of parallel passages in the channel on heat transfer is not clearly established. Therefore, this study aims to experimentally test heat transfer and fluid flow in three different mini channels having five to eight ports.. The objective of the study can be given as follows:

- Verification of the validity of constant Poiseuille number theory in the laminar region;

- Investigation of any possible variations in Poiseuille number and its dependency on Reynolds number;

- Verification of the validity of constant Nusselt number theory in the laminar region;

- Evaluation of availability and applicability of conventional heat transfer correlations;

- Evaluation of availability and applicability of small scale heat transfer correlations;

- Evaluation of effects of different port number on heat transfer; 


\subsubsection{Organization}

The motivation and the objective of the thesis and current state-of-the-art on mini channels were presented and discussed with a literature review and overview of general knowledge in Chapter 1.

The fundamentals of heat transfer and fluid flow in minichannels are presented with small scale and conventional correlations in Chapter 2.

The details of experimental set-up, flow cycle and equipment are presented in Chapter 3.

The experimental approach and conditions with procedure and calculations used for data reduction are given in Chapter 4.

The results of experimental data are provided and discussed in Chapter 5.

The outcome of thesis is discussed and the study is concluded with a brief summary with suggestions for future work in Chapter 6. 


\section{CHAPTER 2}

\section{FUNDAMENTALS OF SINGLE PHASE LIQUID FLOW AND HEAT TRANSFER IN MINICHANNELS}

Conventional heat transfer and fluid dynamics in closed conduits is a broad area and it contains many subfields such as non-Newtonian flow, slip flow, two-phase flow, electro kinetic flow and supersonic flow. Investigation of all these subfields is outside the scope of this thesis. Hence, only related physical phenomena will be discussed in this Chapter. Interested readers are referred to [36] for a wider treatment.

\subsection{Validation of Continuum Theory in Small Scale Channels}

Fluid molecules have very small diameters compared to their intermolecular distance and these molecules continually move in different directions and undergo collisions. Therefore, the terms such as fluid density or velocity do not hold practical meaning at molecular. On the other hand, at a macroscopic level a fluid follows a constant motion and demonstrates constant properties such as pressure and density. Using bulk properties is more practical in most engineering studies and is defined as continuum theory. The smallest element which shows continuum properties is called a fluid particle [36]. Internal flow in conventional channels and pipes (i.e. large diameters or at the macro scale) are generally continuum flow. However, the dimensions of small scale channels are quite small compared to conventional channels and it should verified whether the flows in small scale channels are continuum, especially for gas flow. To determine the validity of continuum model in a channel flow, the dimensionless Knudsen number is defined as

$$
K n=\frac{\lambda}{L_{c}}
$$


where $\lambda$ is molecular mean free path and $L_{\mathrm{c}}$ is a characteristic length scale for the channel, usually the hydraulic diameter.

$K n$ ranges for different flow types are [3]:

$K n \leq 0.001 \quad$ continuum flow

$0.001<K n \leq 0.1 \quad$ slip flow regime

$10 \leq K n \quad$ free molecular flow

Navier-Stokes equations are valid for larger channels, when Knudsen number is smaller than 0.001 .

\subsection{Transition from Laminar to Turbulent}

The Reynolds number $(R e)$ is probably the most known dimensionless number in fluid mechanics and represents the ratio of inertial forces to viscous forces. When inertial forces dominate flow tends to fluctuate and mix whereas when viscous forces dominate flow tends to be smooth. In other words, low $R e$ means viscous forces dominate the flow and the flow is smooth and steady (laminar region). As $R e$ increases, flow transitions from being smooth and steady to being fluctuating and unsteady with significant mixing (turbulent region). The $R e$ where transition from laminar to turbulent flow occurs is defined as the critical Reynolds number $\left(R e_{c r}\right)$. Moreover, it is important to note that this value depends on the surface roughness and inlet velocity profile. For external flow over a flat plate, $R e_{c r}$ is generally assumed as $5 \times 10^{5}$ [13]. For internal tubular flow, it is widely accepted [13] that $R e_{c r}$ is approximately 2300 . For internal flow, Reynolds number is defined by,

$$
R e=\frac{\rho u_{m} D}{\mu}=\frac{u_{m} D}{v}
$$

where $D$ is the diameter of a circular channel, $u_{m}$ is the mean velocity of the fluid, $\rho$ is the density and $v$ is the kinematic viscosity. 
When the cross section of the channel is noncircular, the Re is defined using a hydraulic diameter $\left(D_{h}\right)$.

$$
D_{h}=\frac{4 A_{c r}}{P_{w}}
$$

Where $A_{c r}$ is the cross sectional area and $P_{w}$ is the wetted perimeter.

\subsection{Single Phase Fluid Flow in Channels in the Laminar Flow Regime}

For a Newtonian fluid, such as water or oil, the Fanning friction factor, $f$, is a nondimensional number used to estimate total pressure drop in a channel or over a plate. For fully developed channel flow, pressure drop can be found through the following equation $[3,35]$.

$$
\Delta p=\frac{2 f \rho u_{m}^{2} L}{D}
$$

Here, $L$ is the channel length. The diameter is replaced with $D_{h}$ if the cross section of the channel in noncircular.

For hydrodynamically fully developed laminar flow in a circular channel, a velocity profile can be found assuming Hagen-Poiseuille flow [36]. Using this velocity profile and wall shear stresses, a friction factor can be can be derived as being equal to a constant divided by Reynolds number as given in Eqn. (2.5). This constant is named after J. L. Poiseuille and is called the Poiseuille number (Po).

$$
f R e=P o
$$

For fully developed laminar flow in a circular pipes, the constant Poiseuille number is 16 as indicated in [3]. Poiseuille number is also used for non-circular cross section channels to find the friction factor in fully developed laminar flow. Shah and London [5] provide Po $(f \operatorname{Re})$ for various cross sectional geometries for closed ducts as presented by Kandlikar [3] in Table 2.1. 
Table 2.1 Friction factor for fully developed laminar flow in ducts [3]

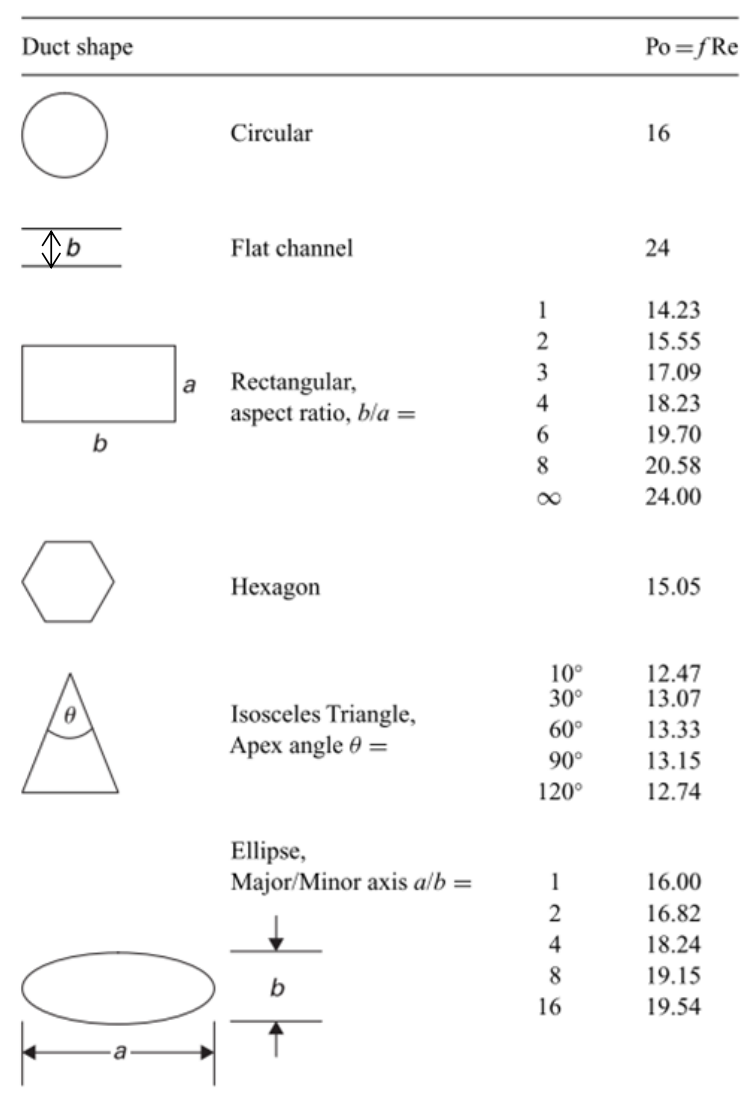

The $P o$ values for rectangular cross section ducts are given by:

$$
\begin{gathered}
f R e=P o=24\left[1-1.3553 \alpha+1.9467 \alpha^{2}-1.702 \alpha^{3}+0.9564 \alpha^{4}\right. \\
\left.-0.2537 \alpha^{5}\right]
\end{gathered}
$$

where aspect ratio $(\alpha)$ is equal to height $(H)$ divided by the width $(W)$ of the rectangular channel. Another important parameter for fluid flow is the dimensionless axial distance $x^{+}$which is defined as [4]

$$
x^{+}=\frac{x / D_{h}}{R e}
$$

where $x$ is the axial distance along the channel. 
Dimensionless axial length is a parameter generally used to examine whether the flow is hydrodynamically fully developed or developing. The hydrodynamic entrance length of laminar fluid flow in circular channels is generally estimated using the following well known equation [4]:

$$
L_{h d}=0.05 \operatorname{Re} D_{h}
$$

In other words, the flow is assumed to be hydrodynamically fully developed if $L>$ $L_{h d}$. Wall shear stress is larger in the developing region of flow, thus it creates a higher resistance to flow. Therefore, the friction factor and pressure drop are higher in the developing region. To account for the higher pressure losses in developing region, an apparent friction factor, $f_{a p p}$, is defined. The apparent friction factor replaces the fully developed friction factor in Eqn. (2.4). For long channels, the developing region effects become negligible and the friction factor and apparent friction factor are equal to the fully developed friction factor. This phenomenon can be observed more clearly in Table 2.2: as $\mathrm{x}^{+}$increases, $f_{a p p} \operatorname{Re}$ converges asymptotically to a constant value. This shows that laminar flow becomes fully developed when $\mathrm{x}^{+}$is larger than $1.0\left(\mathrm{x}>\mathrm{L}_{\mathrm{hy}}\right)$. 
Table 2.2 Laminar flow friction factor for developing flow in rectangular channels [3]

\begin{tabular}{|c|c|c|c|c|}
\hline \multirow[b]{2}{*}{$x^{+}=\left(x / D_{\mathrm{h}}\right) / \operatorname{Re}$} & \multicolumn{4}{|l|}{$f_{\text {app }} \mathrm{Re}$} \\
\hline & $\alpha_{\mathrm{c}}^{1}=1.0$ & $\alpha_{\mathrm{c}}=0.5$ & $\alpha_{\mathrm{c}}=0.2$ & $\begin{array}{l}\alpha_{\mathrm{c}} \leq 0.1 \\
\alpha_{\mathrm{c}} \geq 10\end{array}$ \\
\hline 0 & 142.0 & 142.0 & 142.0 & 287.0 \\
\hline 0.001 & 111.0 & 111.0 & 111.0 & 112.0 \\
\hline 0.003 & 66.0 & 66.0 & 66.1 & 67.5 \\
\hline 0.005 & 51.8 & 51.8 & 52.5 & 53.0 \\
\hline 0.007 & 44.6 & 44.6 & 45.3 & 46.2 \\
\hline 0.009 & 39.9 & 40.0 & 40.6 & 42.1 \\
\hline 0.01 & 38.0 & 38.2 & 38.9 & 40.4 \\
\hline 0.015 & 32.1 & 32.5 & 33.3 & 35.6 \\
\hline 0.02 & 28.6 & 29.1 & 30.2 & 32.4 \\
\hline 0.03 & 24.6 & 25.3 & 26.7 & 29.7 \\
\hline 0.04 & 22.4 & 23.2 & 24.9 & 28.2 \\
\hline 0.05 & 21.0 & 21.8 & 23.7 & 27.4 \\
\hline 0.06 & 20.0 & 20.8 & 22.9 & 26.8 \\
\hline 0.07 & 19.3 & 20.1 & 22.4 & 26.4 \\
\hline 0.08 & 18.7 & 19.6 & 22.0 & 26.1 \\
\hline 0.09 & 18.2 & 19.1 & 21.7 & 25.8 \\
\hline 0.10 & 17.8 & 18.8 & 21.4 & 25.6 \\
\hline 0.20 & 15.8 & 17.0 & 20.1 & 24.7 \\
\hline$>1.0$ & 14.2 & 15.5 & 19.1 & 24.0 \\
\hline
\end{tabular}

The apparent friction factor contains fully developed friction factor and an additional parameter to account for developing region effects. This additional parameter is defined [5] as the incremental pressure drop number, $K(x)$ :

$$
K(x)=\left(f_{\text {app }}-f\right) \frac{4 x}{D_{h}}
$$

where $x$ is the position starting from the inlet of the channel. 
When $x$ is larger than hydrodynamic developing length, incremental pressure drop number $K(x)$ is not dependent on length and becomes the constant $K(\infty)$, also known as Hagenbach's factor. Kandlikar [3] suggested an equation for Hagenbach's factor based on aspect ratio:

$$
\begin{aligned}
K(\infty)=0.6796 & +1.2197 \alpha+3.3809 \alpha^{2}-9.5921 \alpha^{3}+8.9089 \alpha^{4} \\
- & 2.9959 \alpha^{5}
\end{aligned}
$$

The variation of $P o$ and Hagenbach's factor with respect to aspect ratio is presented in Figure 2.1.

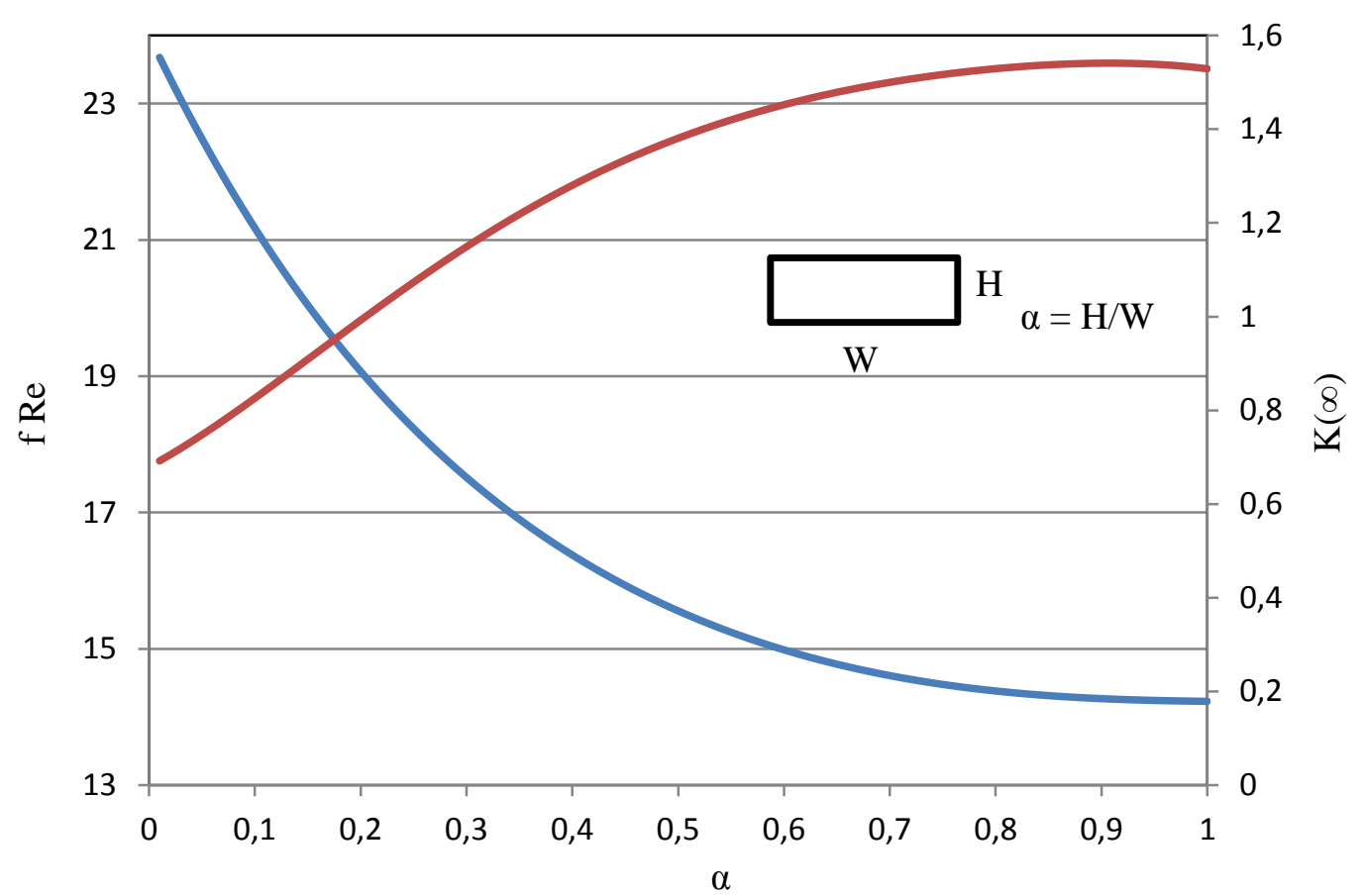

Figure 2.1 Hagenbach's factor and $f \operatorname{Re}(\mathrm{Po})$ for different aspect ratios of rectangular channels

The relation between apparent friction factor, fully developed friction factor and Poiseiulle number can be derived by combining Eqn. (2.7) and (2.9):

$$
f_{\text {app }} R e=f R e+K(\mathrm{x}) \operatorname{Re} \frac{D_{h}}{4 x}
$$


Combining Eqns. (2.7) and (2.11), it can be shown that apparent friction factor is a function of dimensionless axial distance in the developing region as presented in Eqn. (2.12)

$$
f_{\text {app }} \operatorname{Re}=f \operatorname{Re}+K(\mathrm{x}) / x^{+}
$$

As a result of the discussion presented above, Table 2.2 is used to find friction factor for hydrodynamically developing and developed flows. Additionally, a curve fit equation to approximate apparent friction factor in Table 2.2 was suggested by Kandlikar [3] and is provided in Appendix A.

\subsection{Heat Transfer in Channels in the Laminar Flow Regime}

Nusselt number is a well-known dimensionless number and it can be defined as the ratio of convective heat transfer to pure molecular conductive heat transfer at the boundary. The local Nusselt number is defined as

$$
N u=\frac{h}{k / D_{h}}
$$

The Nusselt number is widely used to predict average convective heat transfer coefficient $\bar{h}$ in a channel flow and Nusselt number is predicted to be a constant in a fully developed laminar flow by conventional theory. This constant depends on the cross section of the channel and the heat transfer boundary condition. Table 2.3 shows Nusselt number for different cross sections under different boundary conditions. 
Table 2.3 Nusselt number values for different cross sections for $\mathrm{H} 1, \mathrm{H} 2$ and $\mathrm{T}$ boundary conditions for fully developed laminar flow [4]

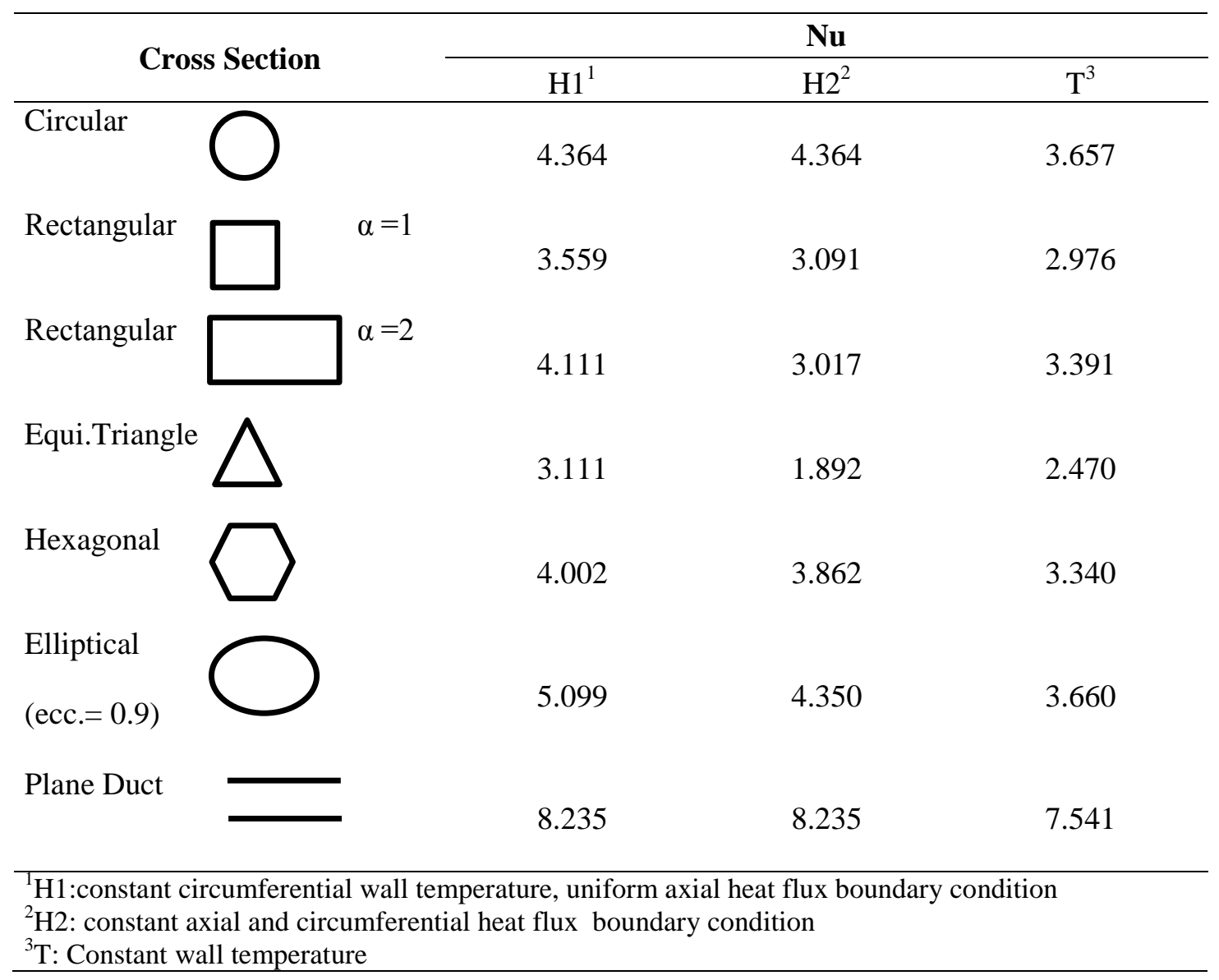

The constant Nusselt number for a rectangular channel varies with respect to aspect ratio in fully developed laminar flow. The aspect ratio $(\alpha)$ is height divided by width as shown in Figure 2.1. Notice that the definition of aspect ratios may be different in references. The Nusselt number equations for different heat transfer boundary conditions are given as follows:

$$
\begin{aligned}
& \text { H1: } \quad N u_{H 1}=8.235\left(1-2.0421 \alpha+3.0853 \alpha^{2}-2.4765 \alpha^{3}+1.0578 \alpha^{4}\right. \\
& -0.1861 \alpha^{5} \\
& N u_{H 2}=8.235\left(1-10.6044 \alpha+61.1755 \alpha^{2}-155.1803 \alpha^{3}\right. \\
& +176.9203 \alpha^{4}-72.9236 \alpha^{5} \\
& \mathrm{~T}: \quad N u_{T}=7.541\left(1-2.610 \alpha+4.970 \alpha^{2}-5.119 \alpha^{3}+2.702 \alpha^{4}-0.548 \alpha^{5}\right.
\end{aligned}
$$


Microchannels are sometimes utilized in heat sinks, especially for electronics. In such cases, only three sides of the channels are heated. Additionally, the boundary conditions do not generally match experimental studies and generally lie somewhere between the three boundary conditions $\mathrm{H} 1, \mathrm{H} 2$, and $\mathrm{T}$ defined in Chapter 1 and in the footnote of Table 2.3. Fully developed Nusselt number values for three-side heated and four-side heated channels are tabulated in Table 2.4.

Table 2.4 Fully developed laminar flow Nusselt number values for three-side heated $\left(\mathrm{Nu}_{\mathrm{fd}, 3}\right)$ and four side heated $\left(\mathrm{Nu}_{\mathrm{fd}, 4}\right)$ channels [3]

\begin{tabular}{lll}
\hline$\alpha=\mathrm{H} / \mathrm{W}$ & $\mathrm{Nu}_{\mathrm{fd}, 3}$ & $\mathrm{Nu}_{\mathrm{fd}, 4}$ \\
\hline 0 & 8.235 & 8.235 \\
0.10 & 6.939 & 6.700 \\
0.20 & 6.072 & 5.704 \\
0.30 & 5.393 & 4.969 \\
0.40 & 4.885 & 4.457 \\
0.50 & 4.505 & 4.111 \\
0.70 & 3.991 & 3.740 \\
1.00 & 3.556 & 3.599 \\
1.43 & 3.195 & 3.740 \\
2.00 & 3.146 & 4.111 \\
2.50 & 3.169 & 4.457 \\
3.33 & 3.306 & 4.969 \\
5.00 & 3.636 & 5.704 \\
10.00 & 4.252 & 6.700 \\
$>10.00$ & 5.385 & 8.235 \\
\hline
\end{tabular}

In $\alpha, H$ is the unheated side for 3 side heated channels. An interpolation equation is provided in Appendix A for $\mathrm{Nu}$ for intermediate values of aspect ratio.

For conventional size channels, fluid flow is generally thermally developed. On the other hand, fluid flow in smaller channels may be thermally developing due to smaller hydraulic diameters and shorter lengths. Therefore, thermal development of the fluid should be carefully considered in small scale channels.

The thermal entry length of a channel is defined as follows:

$$
L_{t d}=C \operatorname{Re} \operatorname{Pr} D_{h}=C \operatorname{Pe} D_{h}
$$


where $P e$ is the Peclet number, $P r$ is the Prandtl number, and $C$ is a constant for channels.

The thermal development of flow is generally investigated in terms of a dimensionless parameter defined as dimensionless thermal axial distance:

$$
x^{*}=\frac{x}{D_{h} \operatorname{Re} P r}
$$

The flow becomes thermally developed when $x^{*}$ is higher than thermal entry constant, $C$. The thermal entry constant $C$ is generally assumed as constant and equal to 0.05 for circular channels [13]. On the other hand, $C$ for rectangular channels was approximated as 0.1 by Shah and London [5] and 1 by Kandlikar [3]. Nusselt number in the thermal entry region is presented in Table 2.5 for thermally developing flow. It can be seen that the difference between Nusselt numbers when $x^{*}$ equals to 0.1 and 1 is very small in Table 2.5 , which is consistent with the fully developed flow approximation of Shah and London after $x^{*}$ equals to 0.1 .

Table 2.5 Nusselt numbers for thermally developing flow [3], [37]

\begin{tabular}{|c|c|c|c|c|c|c|}
\hline \multirow[b]{2}{*}{$x^{*}$} & \multirow[b]{2}{*}{$\alpha_{\mathrm{c}} \leq 0.1^{*}$} & \multicolumn{4}{|l|}{$\mathrm{Nu}_{x .4}$} & \multirow[b]{2}{*}{$\alpha_{\mathrm{c}} \geq 10^{* *}$} \\
\hline & & $\alpha_{\mathrm{c}}=0.25$ & $\alpha_{\mathrm{c}}=0.333$ & $\alpha_{\mathrm{c}}=0.5$ & $\alpha_{\mathrm{c}}=1.0$ & \\
\hline 0.0001 & 31.4 & 26.7 & 27.0 & 23.7 & 25.2 & 31.6 \\
\hline 0.0025 & 11.9 & 10.4 & 9.9 & 9.2 & 8.9 & 11.2 \\
\hline 0.005 & 10 & 8.44 & 8.02 & 7.46 & 7.1 & 9.0 \\
\hline 0.00556 & 9.8 & 8.18 & 7.76 & 7.23 & 6.86 & 8.8 \\
\hline 0.00625 & 9.5 & 7.92 & 7.5 & 6.96 & 6.6 & 8.5 \\
\hline 0.00714 & 9.3 & 7.63 & 7.22 & 6.68 & 6.32 & 8.2 \\
\hline 0.00833 & 9.1 & 7.32 & 6.92 & 6.37 & 6.02 & 7.9 \\
\hline 0.01 & 8.8 & 7 & 6.57 & 6.05 & 5.69 & 7.49 \\
\hline 0.0125 & 8.6 & 6.63 & 6.21 & 5.7 & 5.33 & 7.2 \\
\hline 0.0167 & 8.5 & 6.26 & 5.82 & 5.28 & 4.91 & 6.7 \\
\hline 0.025 & 8.4 & 5.87 & 5.39 & 4.84 & 4.45 & 6.2 \\
\hline 0.033 & 8.3 & 5.77 & 5.17 & 4.61 & 4.18 & 5.9 \\
\hline 0.05 & 8.25 & 5.62 & 5.00 & 4.38 & 3.91 & 5.55 \\
\hline 0.1 & 8.24 & 5.45 & 4.85 & 4.22 & 3.71 & 5.4 \\
\hline 1 & 8.23 & 5.35 & 4.77 & 4.11 & 3.6 & 5.38 \\
\hline
\end{tabular}

$x^{*}=x /\left(\operatorname{Re} \operatorname{Pr} D_{\mathrm{h}}\right) ;{ }^{*}-$ parallel plates, both sides heated; ${ }^{* *}-$ parallel plates, one side heated. 
As mentioned previously, the length of the small scale channels are generally short due to pressure drop consideration. Therefore, the flow does not become fully developed for some applications and thermal entry and hydrodynamic entry effects become significant. In order to evaluate the thermal entry effect theoretically, Table 2.5 and the interpolation equation presented in Appendix A are used. In addition, some of the conventional channel correlations that are used to evaluate Nusselt number are presented in Table 2.6. Despite the circular geometry of channels and different boundary conditions used in developing the correlations in Table 2.6, some researchers such as [27], [28], [33] compared these correlations with their work and reported that these correlations also gave good predictions for some experimental data ([28], [33]) for thermally developping flow. Additionally, Nusselt number approximation for developing flow in a square channel [3] are also provided in Table 2.6 for the completeness.

In the literature review section 1.2, correlations were suggested by several researchers for laminar flow in small scale channels based on the argument that correlations for flow in conventional channels are not sufficient to predict small scale heat transfer. These correlations are compiled and listed in Table 2.7.

In the Chapter 2, basics of fluid flow and heat transfer were discussed for small scale channels with suggested correlations from various researchers. In the Chapter 3, the construction of the experimental set up will be discussed in details. 
Table 2.6 Conventional correlations for prediction of heat transfer in laminar flow for developing flow

\begin{tabular}{|c|c|c|c|c|c|}
\hline Reference & Correlation & & $\begin{array}{l}\text { Cross } \\
\text { Sect. }\end{array}$ & $\begin{array}{l}\text { Flow } \\
\text { Regime }\end{array}$ & $\begin{array}{c}\text { Range } \\
\text { of } \\
\text { Validity }\end{array}$ \\
\hline $\begin{array}{l}\text { Kandlikar } \\
{[3]}\end{array}$ & $\begin{aligned} N u=6.7702-3.1702 A+0.4187(\ln A)^{2} \\
+ \\
+2.155 \ln A \\
+2.76 \times 10^{-6} A^{-1.5}\end{aligned}$ & (2.19) & $\begin{array}{l}\text { Rect. } \\
(\alpha=1)\end{array}$ & $\begin{array}{l}\text { TD, } \\
\text { CHF }\end{array}$ & $\operatorname{Re}<2200$ \\
\hline $\begin{array}{l}\text { Stephan\& } \\
\text { Preußer } \\
\text { [38] }\end{array}$ & $N u=3.657+\frac{0.0677(\operatorname{Re} \operatorname{Pr} D / L)^{1.33}}{1+0.1 \operatorname{Pr}(\operatorname{Re} \mathrm{D} / \mathrm{L})^{0.30}}$ & $(2.20)$ & Circ. & $\begin{array}{l}\mathrm{SD} \\
\mathrm{CHF}\end{array}$ & $0.7<\operatorname{Pr}<7$ \\
\hline $\begin{array}{l}\text { Stephan\& } \\
\text { Preußer } \\
\end{array}$ & $N u=4.364+\frac{0.086(\operatorname{Re} \operatorname{Pr} D / L)^{1.33}}{1+0.1 \operatorname{Pr}(\operatorname{Re} D / L)^{0.83}}$ & (2.21) & Circ. & $\begin{array}{l}\text { SD, } \\
\text { CWT }\end{array}$ & $0.7<\operatorname{Pr}<7$ \\
\hline $\begin{array}{l}\text { Shah\& } \\
\text { London } \\
{[5]}\end{array}$ & $N u=4.364+0.0722(\operatorname{Re} \operatorname{Pr} D / L)$ & $(2.22)$ & Circ. & $\begin{array}{l}\text { TD, } \\
\text { CWT }\end{array}$ & - \\
\hline \multirow[t]{3}{*}{$\begin{array}{l}\text { Gnielinski } \\
{[29]}\end{array}$} & $N u=\left\{3.66^{3}+0.7^{3}\right.$ & & & & \\
\hline & $\begin{array}{l}+\left[1.615(\operatorname{Re} \operatorname{Pr} D / L)^{1.33}\right. \\
\left.-0.7^{3}\right]\end{array}$ & (2.23) & Circ. & $\begin{array}{l}\text { TD, } \\
\text { CWT }\end{array}$ & - \\
\hline & $\left.+\left(\frac{2(\operatorname{Re} \operatorname{Pr} D / L)^{3}}{1+22 \operatorname{Pr}}\right)^{0.5}\right\}^{1 / 3}$ & & & & \\
\hline
\end{tabular}

$A=(\operatorname{Re} \operatorname{Pr} D / L)^{-1}$

TD: Thermally Developing

SD: Simultaneously Developing

CHF: Constant Heat Flux

CWT: Constant Wall Temperature 
Table 2.7 Convective heat transfer correlations for small scale channels

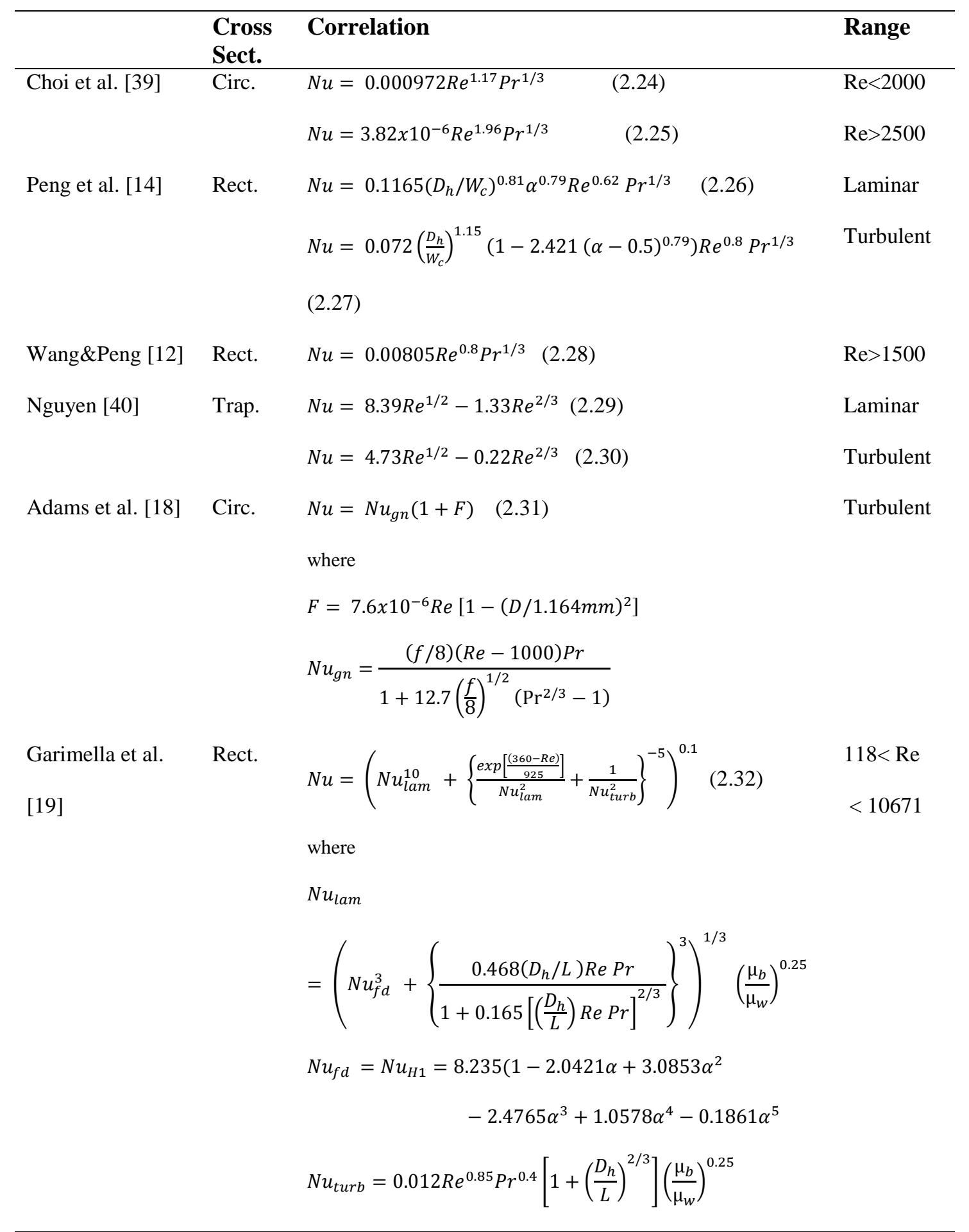

$W_{c}$ : Distance between centers of the channels 


\section{CHAPTER 3}

\section{EXPERIMENTAL SET-UP}

To investigate heat transfer and fluid flow characteristics of water flow in minichannels, an experimental test set-up is constructed. In this chapter, the details of the set-up will be explained. Most of the equipment in the experiments were provided from previous experimental works by two former MSc. Students [41], [42]. The details of all equipment used in the experiments are provided in Appendix B.

\subsection{Minichannels Used in the Experiments}

In order to evaluate heat transfer and fluid flow characteristics of flow in minichannels, three donated minichannels were experimentally investigated. $\mathrm{Ch} 7$ and Ch6 were donated by Hydro and Ch5 were donated by Arçelik. They were produced by extrusion process and have the relative surface roughness of about $01 \%$. The cross sectional views of these three channels are presented in Figure 3.1. All channels are made of aluminum. One objective of the study is to investigate the effects of port number on heat transfer and fluid flow. Therefore, the channels have different port numbers. The port numbers of the channels were used in naming the channels. As shown in Figure 3.1, the first channel has five ports whereas the second and third channels have six and seven ports, respectively. Therefore, the minichannels were named $\mathrm{Ch} 5, \mathrm{Ch} 6$ and $\mathrm{Ch} 7$ according to their port numbers for brevity. The geometric details of the minichannels are given in Table 3.1. The technical drawings of the manifolds for the connection of the minichannels to the root of the set-up are provided in Appendix C. 
Table 3.1 Geometry properties of the minichannels

\begin{tabular}{lcccc} 
Parameter & Units & Ch5 & Ch6 & Ch7 \\
\hline Port number & - & 5 & 6 & 7 \\
Width & $\mathrm{mm}$ & 18.3 & 18 & 12 \\
Height & $\mathrm{mm}$ & 2.5 & 2 & 1.8 \\
Hydraulic diameter & $\mathrm{mm}$ & 2.27 & 1.66 & 1.30 \\
Aspect Ratio & - & 0.52 & 0.41 & 0.89 \\
Inner Wall thickness & $\mathrm{mm}$ & 0.2 & 0.25 & 0.25 \\
Outer Wall thickness & $\mathrm{mm}$ & 0.4 & 0.4 & 0.3 \\
Channel height & $\mathrm{mm}$ & 1.7 & 1.2 & 1.2 \\
Channel width & $\mathrm{mm}$ & 3.3 & 2.9 & 1.35 \\
Channel length & $\mathrm{mm}$ & 990 & 670 & 580 \\
Cross sectional area & $\mathrm{mm}$ & 27.8 & 18.8 & 11.6 \\
Wetted perimeter & $\mathrm{mm}^{2}$ & 48.9 & 45.26 & 35.6 \\
Inner heat transfer area & $\mathrm{mm}^{2}$ & 48451 & 28067 & 19207 \\
\hline
\end{tabular}
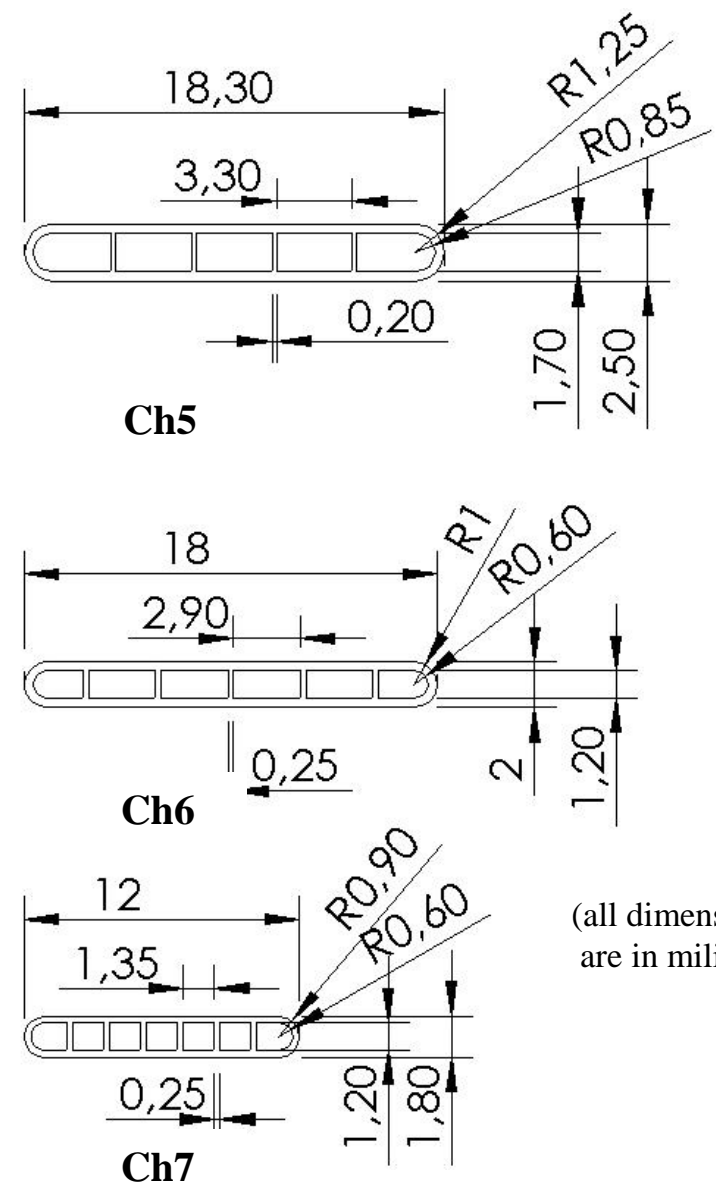

(all dimensions are in milimeters)

Figure 3.1 Technical drawing of the minichannels 


\subsection{Design of the Set-up}

The set-up was designed for single phase liquid water flow experiments for cooling purposes under a constant heat flux boundary condition. The liquid flows continuously in a loop rather than passing through the test-section once and therefore undergoes a cycle, and this was found to be sufficient to investigate fluid flow and heat transfer in minichannels. In this section, the water cycle in the experiments, equipment used for construction of the set-up, data acquisition system and test section are explained.

\subsubsection{Water Cycle}

The water cycle contains a cooling bath, gear pump, flow meter, test section with heaters, and a data acquisition system. The schematic view of the water cycle is presented in Figure 3.2. A closed cycle was preferred due to its longer working time under steady state conditions.

Experiments are run as follows. The water temperature at the exit of the bath is adjusted to a desired temperature. Afterwards, the flow rate of the fluid is controlled to the desired value by two valves in the set-up. The fluid is pressurized in the pump and passes through the flowmeter. Then the pressure and temperature of the fluid are measured at the inlet of test section. Temperature and pressure measurements are repeated at the exit of the test section. The average temperature values are considered to determine the properties of the fluid such as thermal conductivity and dynamic viscosity. The data acquisition system stores the measured values. The details of the test section and heating equipment are explained in Section 3.1.4. 


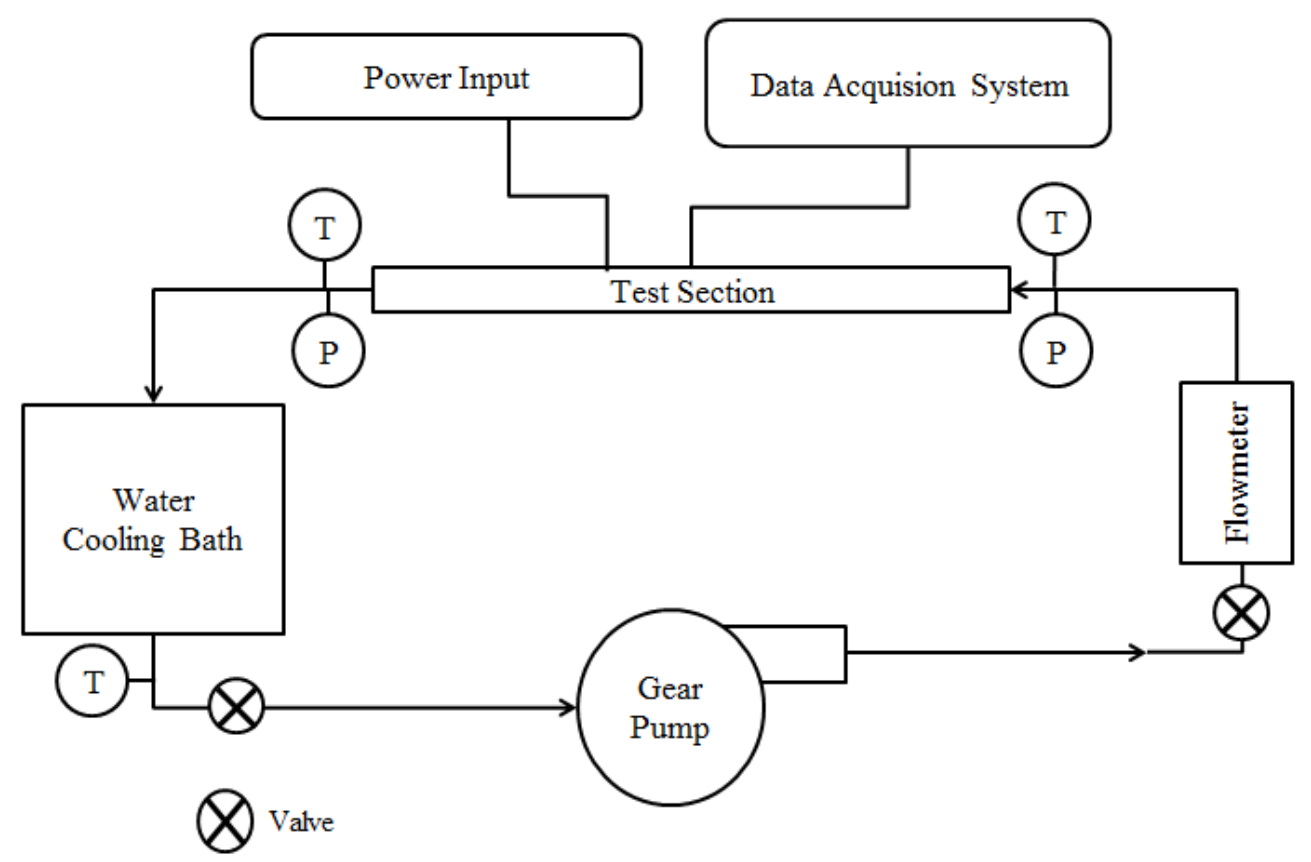

T: Temperature measurements using RTDs

P: Pressure measurements using pressure transducers

Figure 3.2 The water cycle in the experiments

\subsubsection{Equipment}

The equipment used in the closed cycle are cooling bath, pump, flowmeter, thermocouples, RTDs, pressure transducers, power analyzer, variable-ac transformer, data acquisition system, and dc power supply. The details of all equipment used in the construction of the test set-up are provided in Appendix B.

A cooling bath [43] is used to reduce the temperature of fluid after the test section. No external water reservoir is used in the system since the bath has an internal water tank with seven liters capacity. The exit temperature of fluid from the bath was controlled by selecting the desired exit temperature. Additionally, the bath exit temperature was also checked by the data acquisition system through a thermocouple connected at the exit pipe of the bath for verification. Generally, the bath exit temperature of the fluid is selected equal to the ambient temperature to reduce 
thermal losses from the tubing. The maximum heat removal capacity of the bath is $800 \mathrm{~W}$, however it was observed that the exit temperature of the water starts to deviate slowly from the desired bath exit temperature over time for heat removal rates higher than $500 \mathrm{~W}$. Thus, $500 \mathrm{~W}$ is considered as the upper limit when providing power to the heater. In addition to the gear pump, the cooling bath has an internal pump thus also provides pumping power. The cooling bath is shown in Figure 3.3. In order to make sure that the fluid is not over pressurized after the bath and no high pressure damage occurs in the gear pump, a valve is placed after the bath.

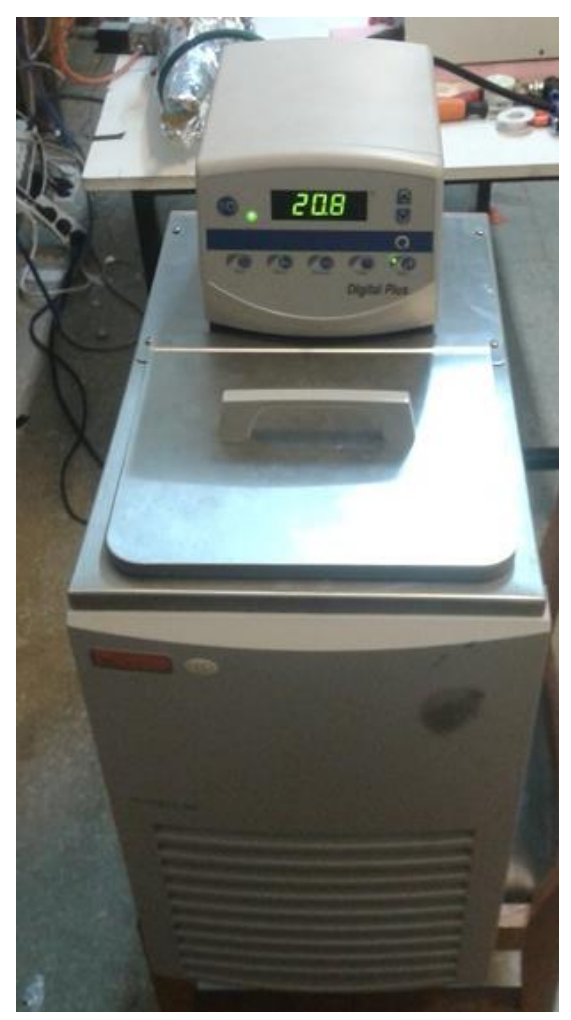

Figure 3.3 Cooling bath used in experiments

The water is primarily pressurized by a gear pump [44] . The gear pump is a positive displacement pump that provides constant volumetric flow rate of fluid at steady state and this flow rate is not affected by changes in upstream pressure. Due to this characteristic, gear pumps are widely used in small channel steady flow experiments [45]. In these experiments, the gear pump is used to drive the fluid at a constant flow 
rate with negligible oscillations. The desired flow rate by the pump can be adjusted manually. The maximum flow rate capacity of the pump is $68.4 \mathrm{l} / \mathrm{h}$ when it provides no pressure increase to the fluid. Therefore, the maximum flow rate of the flow is limited by the pump's capacity. The gear pump is shown in Figure 3.4.

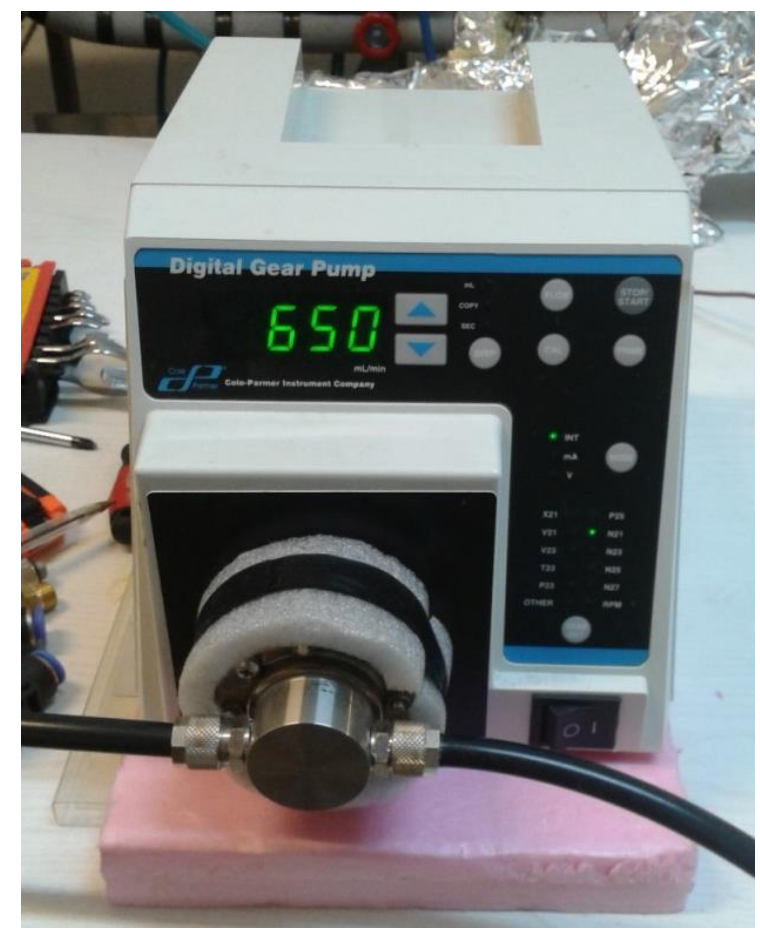

Figure 3.4 The gear pump used in the cycle

Flow rate is measured by a flowmeter [46] placed after the gear pump. The flowmeter is a rotameter type with regulator. The regulator in the rotameter acts similar to a valve, thus a valve is visualized before the flowmeter in Figure 3.2. The flowmeter is selected considering the maximum flow rate of the gear pump. The flowmeter range is from $10 \mathrm{l} / \mathrm{h}$ to $60 \mathrm{l} / \mathrm{h}$. The stated accuracy of the flow meter is $2.5 \%$ of full scale.

The power to the heater is provided from the electrical grid in the laboratory. Although a DC power supply would have been better for constant power to the heater, the power oscillations for all experiments were less than $1 \%$ and almost negligible. The electrical grid is $50 \mathrm{~Hz}$ alternating current (AC) with 220 root mean square voltage in the laboratory. 
In order to adjust the power input to the heater, a variable transformer-ac (variac) [47] is implemented in the experimental set-up. Using a variable power transformer, the voltage input to the heater was controlled between 0 and $220 \mathrm{~V}$. Since the resistance of the heater is constant, power input to the heater was adjusted by varying the output voltage. The maximum possible real power output from the variac is 2.1 kVA. The variac is shown in Figure 3.5.

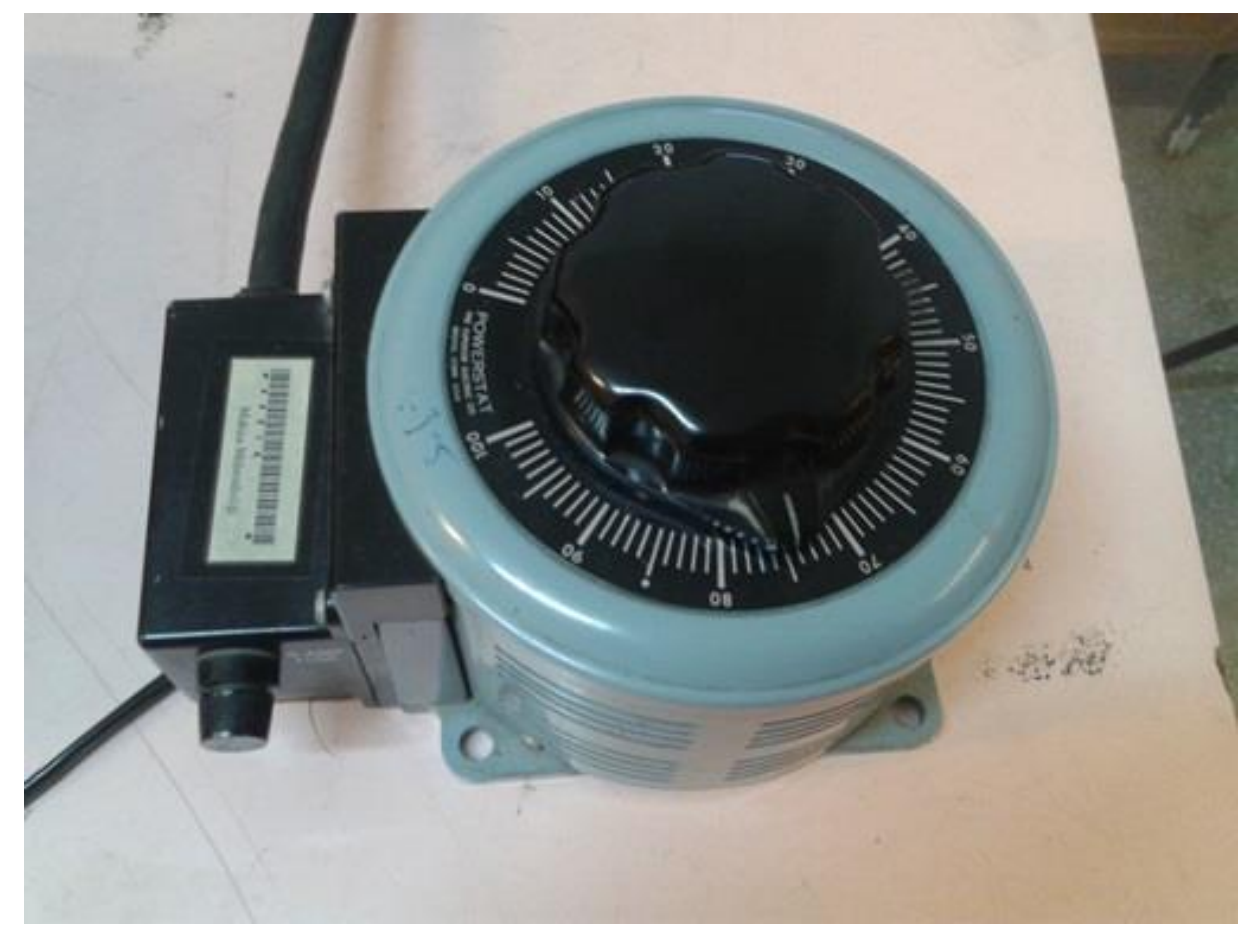

Figure 3.5 The variac used in the experiments

A power analyzer is connected to wires from the variac to the heater. Two wire couples were connected from the power analyzer to wires between the variac and the heater. One wire couple was connected in series to measure the current while the other wire couple was connected in series to measure the voltage in the wire to the heater. The accuracy of the power analyzer is $1.5 \%$ of the measured values. Due to voltage fluctuations in the laboratory, the measured values from power analyzer were noted and averaged in steady state conditions as explained in Section 4.6. The power analyzer while in operation is shown in Figure 3.6. 


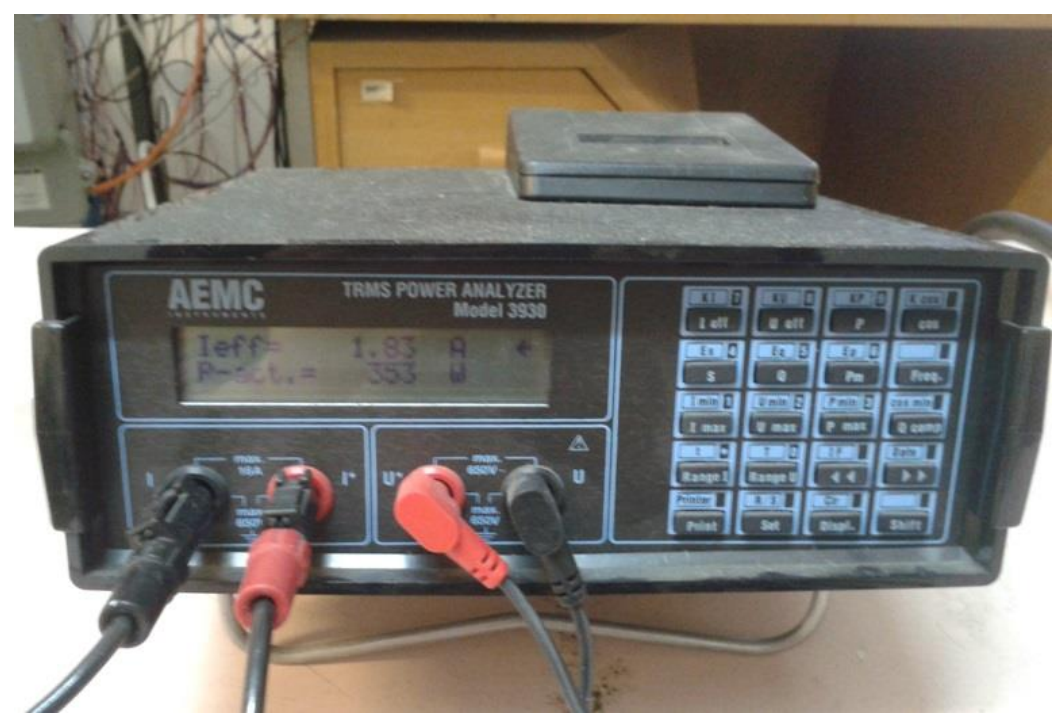

Figure 3.6 The power analyzer used in the cycle

Resistance temperature detectors (RTD) [48] and thermocouples (TC) [49] are used for measuring the temperature in the set-up. The wall temperature of the channels is needed to find local and average heat transfer coefficients. The sensitivity and accuracy of RTDs is better than those for thermocouples. However, it was not possible to implement RTDs to measure the wall temperatures of the channel for the selected experimental configuration. Therefore, thermocouples were connected to the wall surface of the channel. The thermocouples were distributed along the channel wall with roughly equal spacing. RTDs were implemented in the manifolds before the channel inlet and after the channel exit to determine the temperature of the fluid. Using the measurements from RTDs which are inside the unheated manifolds, the temperature of the fluid inside the channel is approximated assuming a constant gradient due to the constant heat flux boundary condition. The locations of the thermocouples for each channel are provided in Table 3.2. Additionally, schematic view and photo of RTD and thermocouple connection can be viewed in Figure 3.10 and Figure 3.11. 
Table 3.2 Location of thermocouples

\begin{tabular}{cccc} 
& $\begin{array}{c}\text { Ch5 } \\
(\mathbf{m m})\end{array}$ & $\begin{array}{c}\text { Ch6 } \\
(\mathbf{m m})\end{array}$ & $\begin{array}{c}\text { Ch7 } \\
(\mathbf{m m})\end{array}$ \\
\hline TC1 & 55 & 70 & 75 \\
TC2 & 180 & 150 & 115 \\
TC3 & 305 & 230 & 230 \\
TC4 & 430 & 310 & 320 \\
TC5 & 555 & 380 & 390 \\
TC6 & 680 & 460 & 530 \\
TC7 & 805 & 550 & - \\
TC8 & 940 & 620 & - \\
L & 990 & 674 & 582 \\
\hline
\end{tabular}

For the pressure measurements, two compact pressure transducers [50] which measure absolute pressure values and a differential pressure transducer [51] are used. They are implemented in the manifolds before the channel inlet and after the channel exit to determine the pressure of the fluid. The voltage needed by the pressure transducers were provided by the DC power supply [52].

The signal in volts from the thermocouples and RTD and the signal in amperes from the pressure transducer are fed to the data acquisition system where the signals were converted into necessary units.

For piping between the equipment, a pneumatic flexible polyurethane hose was found to be suitable due to the low pressure drop inside the tubes. The inner and outer diameters of the hose are $6.5 \mathrm{~mm}$ and $10 \mathrm{~mm}$, respectively. The inner diameter of the pipe is chosen to have as low a pressure drop as possible within the pipes. The connections, valves and junctions were chosen according to the pneumatic piping. The pneumatic hose can withstand temperatures between $40{ }^{\circ} \mathrm{C}$ and $70{ }^{\circ} \mathrm{C}$ and a pressure up to 3.7 bar. 


\subsubsection{Data Acquisition System}

Temperature and pressure measurements were collected through a data acquisition system whereas flow rate and power input were manually adjusted and read. The data logger used in the experiments has 3 cards with each card having inputs for 20 voltage and 2 current readings. The current inputs from the pressure transducers and voltage inputs from the RTDs and thermocouples were converted into signals in the datalogger and the corresponding data were collected by the datalogger. The data sampling rate was input by the user. Visual readings on the datalogger screen are also possible. A software program on the HP VEE software development environment was designed for collecting and storing data between intervals and was designed by Arçelik [41], [42]. This software program was also used in the current thesis. The program lets the user to specify the interval of data collection and present data in a csv format which makes it possible to take average values over time and perform data reduction. Moreover, the user may check steady state conditions using temperature and pressure graphs generated instantly by the program. The data logger and DC power supply that power the data logger are presented in Figure 3.7.

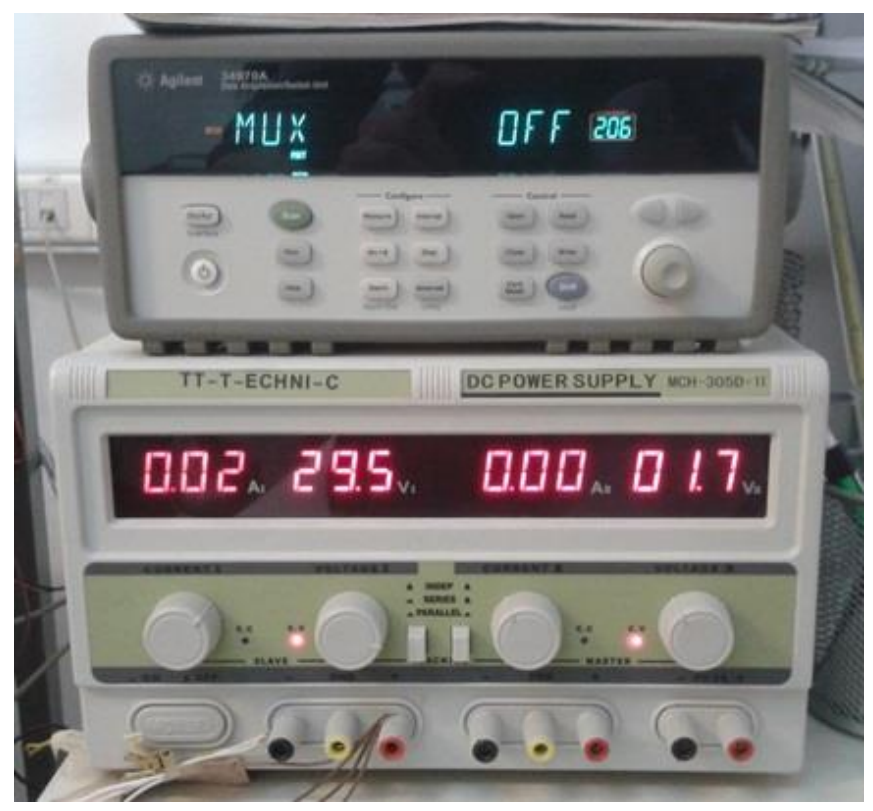

Figure 3.7 Data logger and DC power supply used in the experiments. 


\subsubsection{Test Section}

The test section contains the minichannels, thermocouples, RTD's, pressure transducers, variac, power analyzer, heating layer group and compression layer group. To connect the piping to the channels, manifolds were manufactured from aluminum. RTD and pressure connection holes were also drilled and threaded in the manifolds. Welding was one option but it was not performed due to possible damage that may occur to the aluminum channels during the welding process. The upper and lower covers of the manifolds are connected with screws and bounded with an adhesive bonding method to prevent any leakage from the connection between these covers and the minichannel. The technical drawing of the manifold of $\mathrm{Ch} 7$ is given in Appendix C.

In order to provide constant heat flux conditions, resistive heating is applied. A DC power supply is best for this constant power application. However, the DC power supplies available in the lab are not sufficient to provide a significant temperature difference between the fluid inlet and exit. Therefore, electrical power to the heating resistances was supplied from the electrical grid in the laboratory which is an AC power source. Due to voltage variations during the experiments, the power input to the heaters varied slightly, and thus an average power value is used.

Initially, the wall itself was taken into consideration as resistance for heating. However, the resistance values of channel walls were quite low since the resistivity of aluminum is very low. For instance, the electrical resistance of Ch6 was measured as $3.6 \times 10^{-1} \Omega$. In order to supply $500 \mathrm{~W}$ electrical power, $37 \mathrm{~A}$ current is needed at a 13.4 V voltage difference using a DC power supply.

The second option considered was resistive coating on the channels. In heating using a resistive coating, a material such as a combination of Titanium-chromium and aluminum oxide is implemented on the surface using methods such as spray coating, brush coating, needle coating or screen printing. Due to the limited budget of this experimental study, other options were taken into consideration. 
Considering economic constraints, resistive heating wires were used as the heating unit. The required resistance of the heaters was calculated by considering the cooling capacity of the bath and maximum flow rate of the pump.

In the initial design, the heating wire was wrapped around the channels to provide a constant heat flux. For electrical insulation between the channels and heating wire, thin muscovite type mica insulation sheets [53] were inserted between them. The thickness of the mica sheet is $0.5 \mathrm{~mm}$. Thermocouples were placed along the wall between the mica sheet and the wall to measure wall temperature distribution. However, the temperature readings from thermocouples were unusually high in this configuration, which indicated an error in the readings. Since the thermocouples were calibrated as explained in Section 3.3, the author considered that the error was probably due to the configuration. The two main sources of error of this large magnitude are commented as contact resistances between the mica sheet and the channel wall, and the position of the heating wires relative to the thermocouples. Since the thermocouples have a finite width, there is a gap between the mica sheet and channel wall. Additionally, there is a need for a finite gap between the wire wraps around the mica sheet to prevent a short circuit in the resistance wires. A resistance wire wrapped around a mica sheet is shown in Figure 3.8.

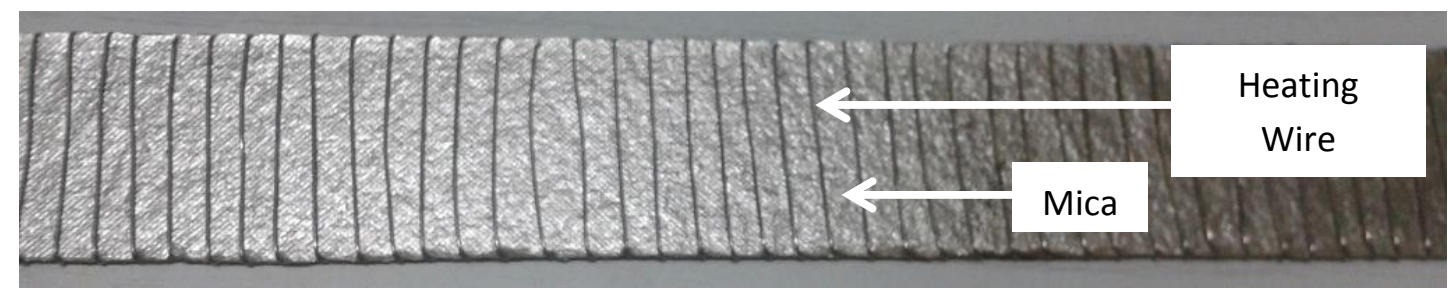

Figure 3.8 Heating wires wrapped around the mica sheet

Therefore, thermocouples closer to the heating wires were strongly affected by the heating source and measured higher values than expected. Moreover, the gaps between the wire wraps resulted in a rather wavy heat flux condition and disturbed 
the intended uniform heat flux condition. Therefore, a rectangular copper layer was inserted between the heating source and channel to more evenly the distribute heat flux and the correct thermocouple readings. The thickness of the copper layer is 1 mm and and the length and width are equal to the length and width of the channels. Another mica sheet is inserted between the copper layer and heating source to achieve electrical isolation. The thickness of the mica sheet is $0.5 \mathrm{~mm}$. The schematic view of this heating layer model is given in Figure 3.9.

\begin{tabular}{|c|}
\hline Glass Wool Insulation \\
\hline Iron Bar Layer \\
\hline Glass Fiber Layer \\
\hline Mica Laver \\
\hline Heater Layer \\
\hline Mica Laver \\
\hline Copper Layer \\
\hline Mica Laver \\
\hline Channel Wall \\
\hline
\end{tabular}

Figure 3.9 Heating layer model (not to scale) 
During the initial experiments, a nonphysical temperature fluctuation along the channel wall was observed. The reason behind this situation was identified to be contact resistances between layers. To reduce contact resistances, first a nonflammable silk cord was wrapped around the layers. However, it was not sufficient to provide enough pressure to overcome the contact resistances. In order to provide enough pressure to sufficiently reduce contact resistances, clamps were considered. Since a rigid body is needed to provide pressure along the layers, an iron metal layer is inserted between the clamps and heating sources. Additionally, a glass fiber layer was inserted to increase thermal resistance between the iron metal layer and heating layer. The thermal conductivity, thickness and thermal resistance per unit area of the materials in the layer group are given in Table 3.3.

Table 3.3 Thermal conductivities of materials in layer group

\begin{tabular}{cccc} 
Material & Thickness $(\mathbf{m m})$ & $\mathbf{k}(\mathbf{W} / \mathbf{m ~ K})$ & $\mathbf{R} "\left(\mathbf{m}^{2} \mathbf{K} / \mathbf{W}\right)$ \\
\hline Aluminum (Ch.wall) & $0.3-0.4$ & 237 & $1.27 \mathrm{E}-3-1.69 \mathrm{E}-3$ \\
Mica & 0.5 & 0.3 & $1.67 \mathrm{E} 00$ \\
Copper & 1.0 & 401 & $2.49 \mathrm{E}-03$ \\
Glass fiber & 3.0 & 0.036 & $8.33 \mathrm{E} 01$ \\
Iron & 5.0 & 80.2 & $6.23 \mathrm{E}-02$ \\
Glass Wool & 30 & 0.031 & $9.68 \mathrm{E} 02$ \\
\hline
\end{tabular}

If a simple 1D wall conductance model is assumed for the layer group, the thermal resistance per unit area from the heater to the iron layer outer surface is $83.4 \mathrm{~m}^{2} \mathrm{~K} / \mathrm{W}$ and the thermal resistance from the heater to channel inner surface wall per unit area is $3.34 \mathrm{~m}^{2} \mathrm{~K} / \mathrm{W}$. The thermal resistance per unit area to the outer surface of the steel layer is 25 times greater than thermal resistance per unit area to the channel wall. As a result, it was assumed that the heat flux is not highly disturbed by clamps considering the simple 1D conductance model. However, the author wants to express that implementing a constant heat flux boundary condition was the most challenging part of the thesis using the available equipment and funding. The constant heat flux boundary condition can be improved and simplified. The suggestions about these improvements are given in section 6.3. 
After implementing the clamps, the channel and the layer group were insulated again to prevent heat loss to surroundings. Specifically, 3-cm thick glass wool [54] was wrapped around the test section. The thermal resistance per unit area of the layers from the heating source to the surrounding including the $3-\mathrm{cm}$ thick glass wool insulation is $1050 \mathrm{~m}^{2} \mathrm{~K} / \mathrm{W}$. These insulation values are considered as sufficient.

\subsubsection{Preparation of the Set-up}

In order to prepare the experimental set-up, all components except the test section are connected to each other with piping. Afterwards, the tubes and manifolds are connected with adhesive bonding [55] which can withstand temperatures up to 300 ${ }^{\circ} \mathrm{C}$. RTDs and pressure transducers are connected to the manifold for measuring the properties of the fluid. The sketch of the experimental set-up showing the approximate location of the RTDs, thermocouples and pressure transducers are given in Figure 3.10.

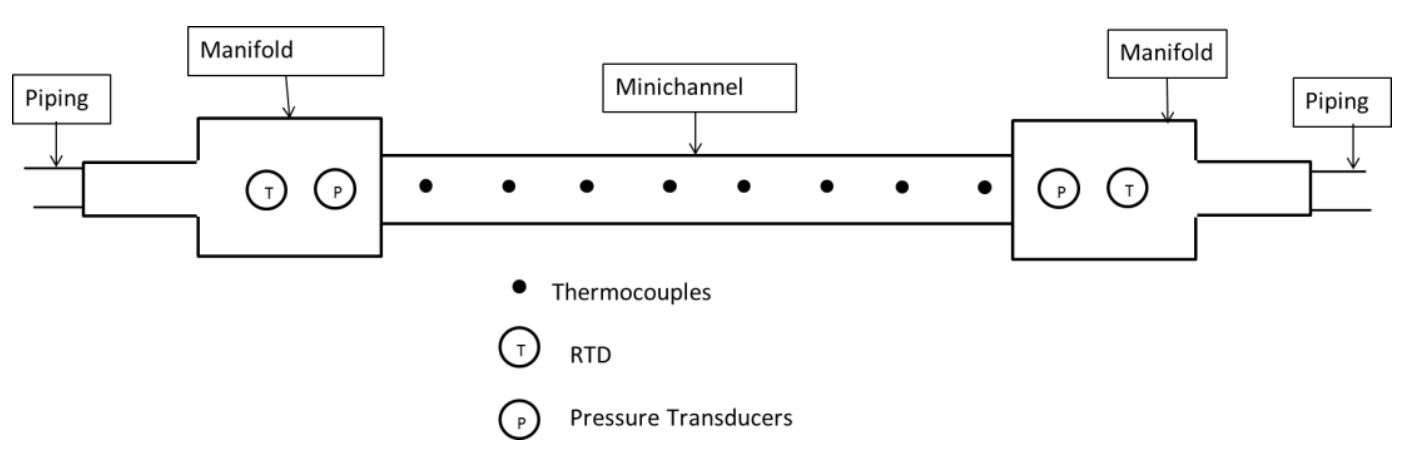

Figure 3.10 Schematic view of the test section before the insulation (not to scale)

The test section without the layer group and insulation is shown in Figure 3.11. Additionally, thermocouples attached to the minichannel and plug panels of the thermocouples are also shown in Figure 3.11. 


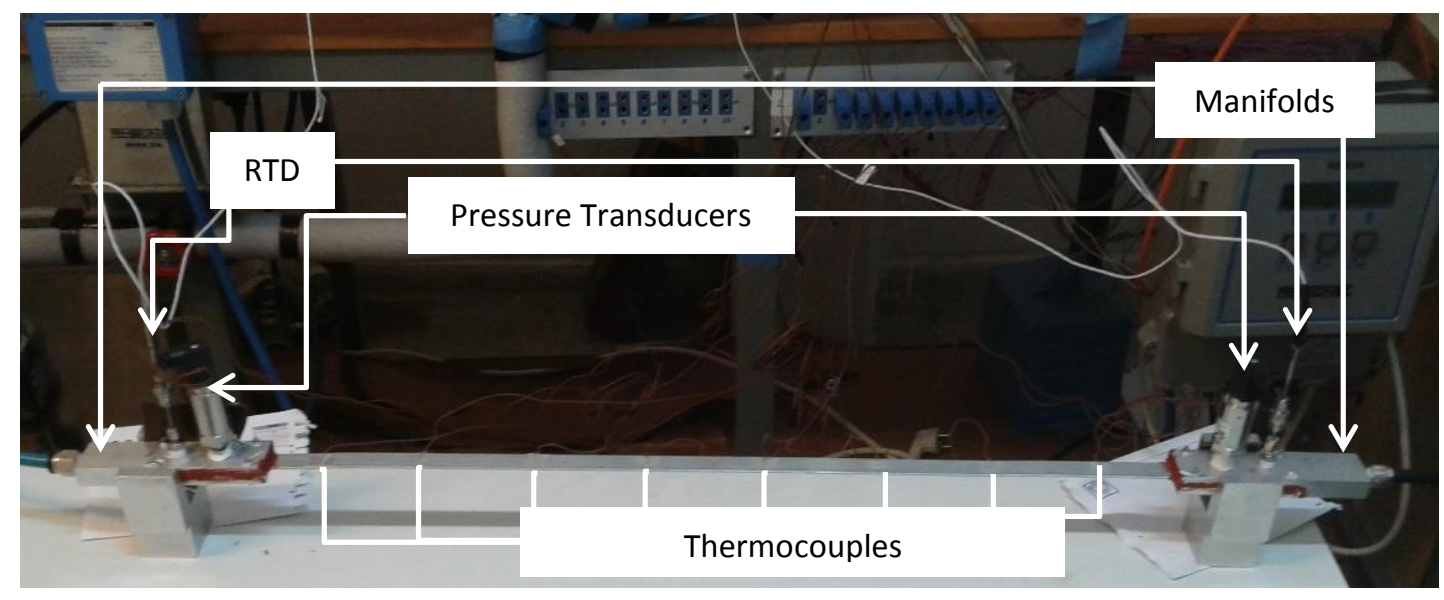

Figure 3.11 Test section without layer group and insulation

After running the experiments to make sure no leakage occurs in the experimental set-up, layer groups are added to the top and bottom of the minichannel. Layer groups are prepared as two separate groups as the heating layer group and the compression group which contains the glass fiber layer and iron layer. A picture of the test section after placing the layers and compressing the layers with clamps is provided in Figure 3.12.

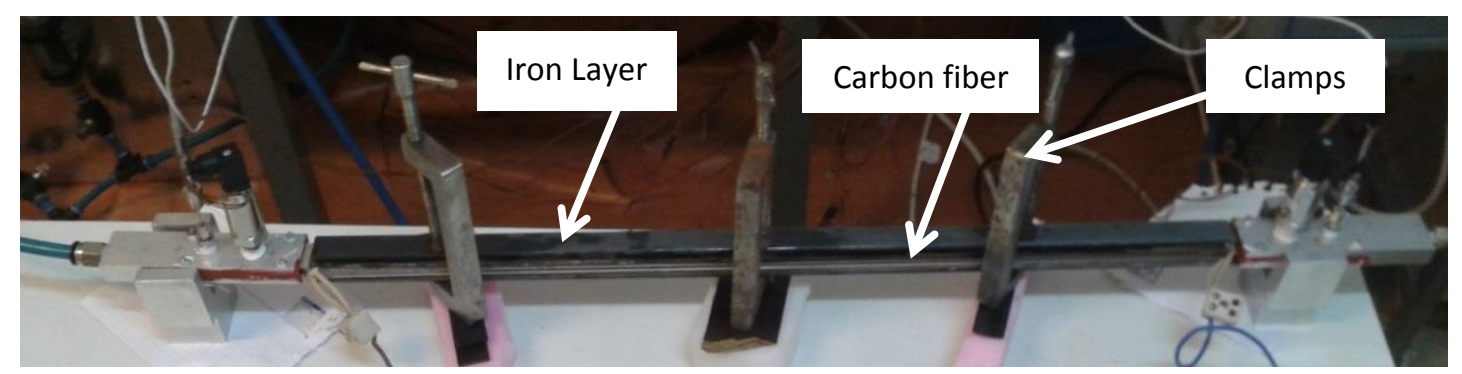

Figure 3.12 Test section with layer groups

Before applying insulation, the set-up was run to check whether any problems are present with the heating section and power input. Afterwards, the glass wool insulation was applied to the test section. On top of the glass wool insulation, an aluminum tape is applied to hold the insulation due to its heat reflective property. The test section after the glass wool insulation was applied is demonstrated in Figure 3.13. After preparing the test section, the construction of the test set-up is finalized. The picture of the final test set-up is shown in Figure 3.14. 


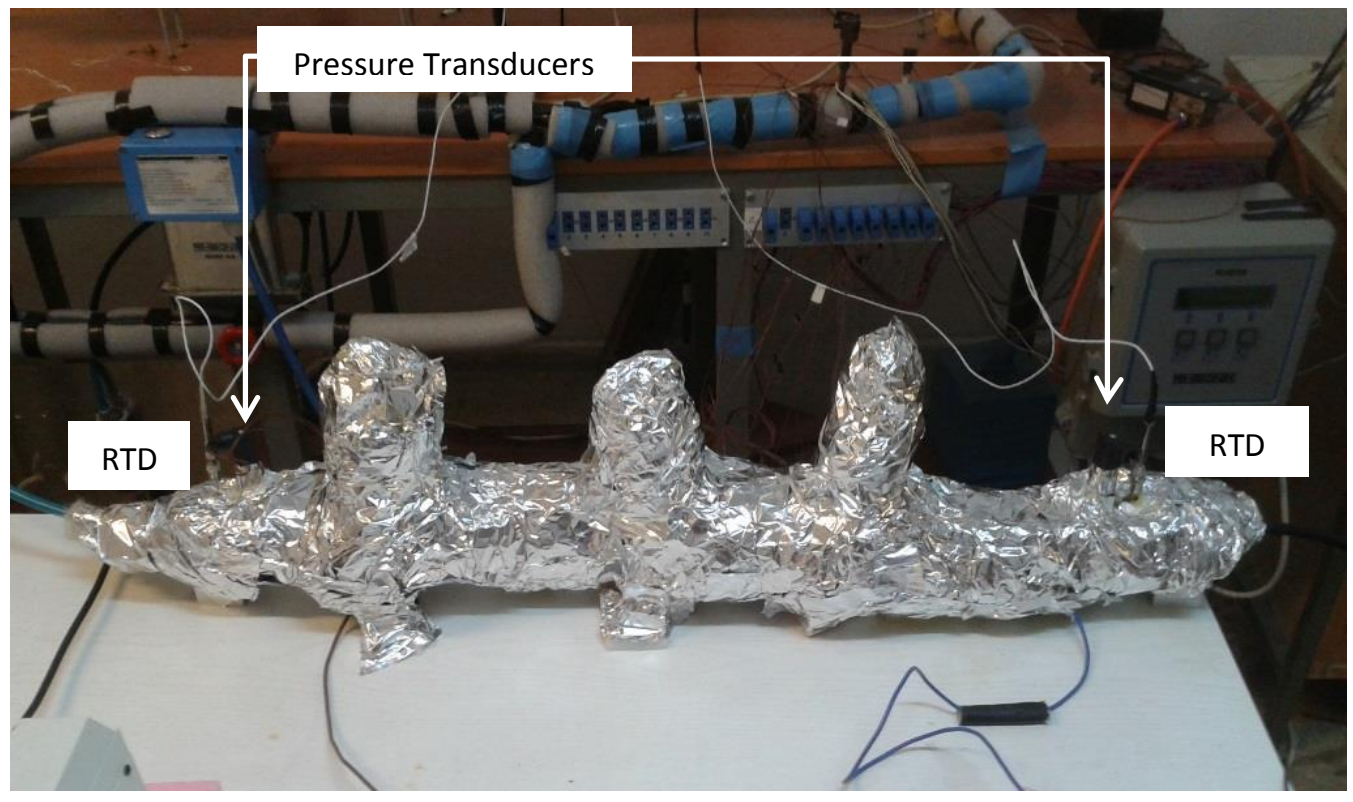

Figure 3.13 The final photo of test section

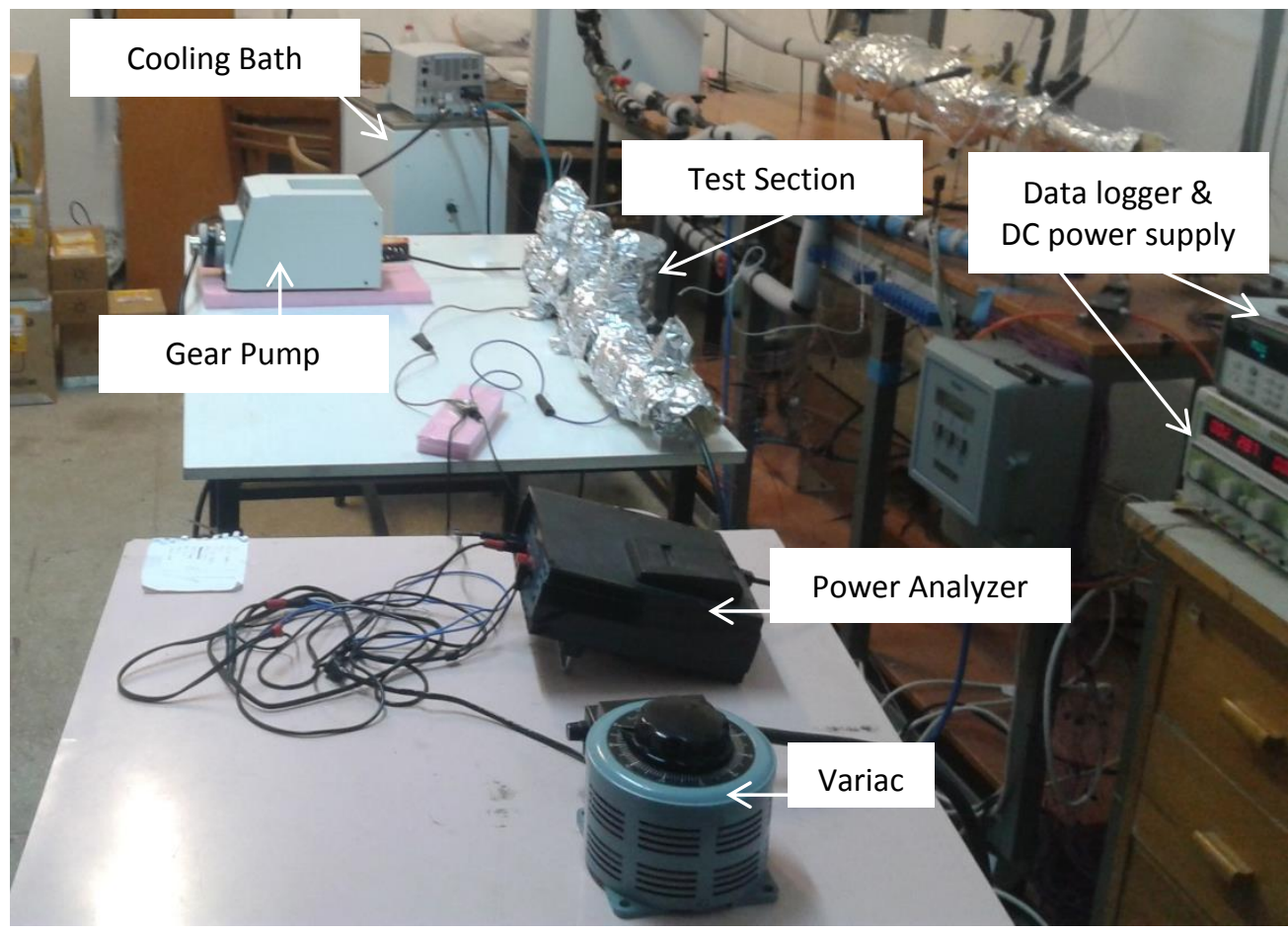

Figure 3.14 Photo of the experimental set-up 


\subsubsection{Viscous Heating}

Before providing a heat flux to the test section, the water is circulated under adiabatic flow conditions sustained by no heating. An important aspect of small scale channels is viscous dissipation inside the channels. As the hydraulic diameter of the channel decreases, there might be a significant temperature difference for small channels due to viscous heating. Koo and Kleinstreuer [56] analytically investigated viscous dissipation in small scale channels considering experimental data from other studies such as [23]. They emphasized that viscous dissipation might affect flow conditions and measurements in experiments. They identified channel aspect ratio, Reynolds number, Prandtl number and Eckert number as the main variables for predicting viscous dissipation for common fluids such as water, methanol and iso-propane. Moreover, they commented that viscous dissipation should specifically be taken into consideration for water flow in channels having hydraulic diameters smaller than 50 $\mu \mathrm{m}$.

In the current experimental study, no significant variations between inlet and exit temperatures of the fluid were observed for all flow conditions inside all three minichannels during adiabatic flow with no heating source. The maximum temperature difference was less than $0.1 \mathrm{~K}$, which is negligible considering the sensitivity of the RTDs. In order to be certain that no experimental error exists, a condition defined by Morini [57] is considered. Morini [57] defined that viscous dissipation cannot be neglected if the following condition is satisfied:

$$
4 \frac{E c}{R e} x^{*} f R e \geq 1
$$

where $E c$ is Eckert number which is provided in eqn. (3.2):

$$
E c=\frac{u_{m}{ }^{2}}{C_{p}\left(T_{f l, o u t}-T_{f l, \text { in }}\right)}
$$

This criterion is defined as Morini Criterion for brevity by the author. The maximum results of the Morini Criterion for flow in each minichannel are shown in Table 3.4 
The maximum value observed for the criterion is less than $10^{-4}$. Therefore, viscous dissipation along the channel is neglected.

Table 3.4 Maximum Morini [57] criterion results for each minichannel for viscous dissipation

\begin{tabular}{|c|c|}
\hline Channel & $\begin{array}{c}\text { Maximum } \\
\text { Morini } \\
\text { Criterion }\end{array}$ \\
\hline Ch5 & $1.65 \mathrm{E}-05$ \\
\hline Ch6 & $2.86 \mathrm{E}-05$ \\
\hline Ch7 & $6.39 \mathrm{E}-05$ \\
\hline
\end{tabular}

\subsection{Calibrations}

The calibration of the equipment is important to check the values in terms of errors. Holman [58] defined three possible sources for calibrating equipment: a primary standard, a secondary standard with higher efficiency than the equipment, and a known source. In this thesis, secondary standard such as a high-accuracy thermometer to calibrate thermocouples and RTDs and known sources such as weight of water in a tank are applied for calibration and verification.

\subsubsection{Flowmeter}

The calibration of the flowmeter was performed before the purchase by the supplying company. In order to be on the safe side, this calibration is verified with gravimetric calibration [59]. The open cycle used in flowmeter calibrations is shown in Figure 3.15. The regulator is shown again as a control valve. The flow rate of the water through the flowmeter is controlled with the regulator and a stop valve is added for quick stop. The fluid is weighed after a time interval. Approximately 4 liters of water is chosen as the fixed volume for all flow rates according to the procedure [59]. Hence, the time intervals for low flow rates are higher. Moreover, a correction factor [59] is suggested for air buoyancy effects for measuring weight in a weighing scale. On the other hand, the correction factor is calculated as less than 1.001 and thus neglected owing to its small magnitude. The results of the calibration of the 
flowmeter are provided in Appendix D. The results are generally within 2\% percent with the controlled flowmeter value except for the lowest flow rates. The deviations from the controlled flow rate are probably due to experimental errors such as weighing scale sensitivity and manual reading error while varying the flow rate through the valve. For an adjusted flow rate of $10 \mathrm{l} / \mathrm{h}$ by valves and flowmeter scale, actual flow rate is found to be $6 \%$ lower. The reason for this is believed to be evaporation from the tank due to higher time interval and lower sensitivity of the flowmeter at low flow rates. Sensitivity of the flowmeter is $4 \%$ of the flow rate of 10 $\mathrm{L} / \mathrm{h}$ and $2.5 \%$ of the flow rate of $60 \mathrm{~L} / \mathrm{h}$.

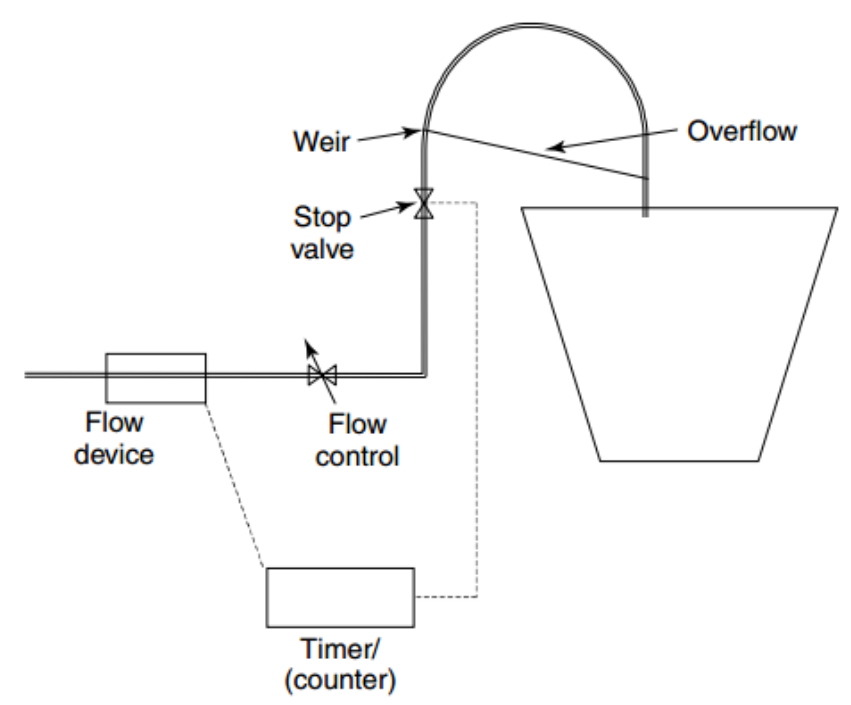

Figure 3.15 Open cycle for gravimetric calibration of the flowmeter [59]

\subsubsection{Temperature Measurements}

The calibration of the cooling bath was performed before purchase [42] by the producers. However, the accuracy of the bath is tested again relative to a known source before the experiments. The thermometer [60] with the best accuracy $\left(0.3^{\circ} \mathrm{C}\right)$ and highest resolution $\left(0.1^{\circ} \mathrm{C}\right)$ from available thermometers was used as a known source for verification of the bath temperature. The bath temperature showed an excellent match with the thermometer's readings. The temperature was taken over a two minute interval to observe if any oscillations were present. However, it was found out that the temperature of the fluid inside the bath does not vary with time. 
The calibration of the RTDs and thermocouples were performed in Tekin's study [42] by Arçelik. In this study, the curve fit equations for RTDs and thermocouples were determined. All these curve fit equations were found to be linear. These equations are entered to a data acquisition program, which is also used in this experiment. A sample calibration curve from this study is provided in Appendix D.

The calibrations of the RTDs and thermocouples were checked using a method similar to that for the fluid temperature in the cooling bath. For the thermocouple calibration, a bath is needed as a known source according to the NIST standard [61]. Since the accuracy of the cooling bath is checked, the cooling bath filled with deionized water is used as a reference bath to check RTD and thermocouple measurement values. Additionally, the same thermometer is also used during the measurements. First, the thermocouples are placed inside the bath with the thermometer. After thermocouples measurements, RTDs' measurements are performed. A temperature measurement is taken for 2 minutes and after that the bath temperature is increased by $0.4^{\circ} \mathrm{C}$ intervals. The temperature range between $10^{\circ} \mathrm{C}$ and $45{ }^{\circ} \mathrm{C}$ is thought to be sufficient according to our experimental conditions. The resolution of the temperature readings are given as $0.01^{\circ} \mathrm{C}$ due to curve fitting equations from the mentioned previous calibrations. However, only $0.1^{\circ} \mathrm{C}$ resolution is taken into consideration due to the thermometer and thermocouple sensitivities. The thermocouples showed a perfect match with the reference temperature values. On the other hand, fixed measurement errors for both RTDs are found to be present. The inlet RTD measured values are $0.1{ }^{\circ} \mathrm{C}$ and $0.2{ }^{\circ} \mathrm{C}$ higher than the reference temperature for several data. The exit RTD measured value reads $0.1{ }^{\circ} \mathrm{C}$ higher than the reference temperature for several data. Therefore, fixed errors are corrected by making corrections after the data are gathered according to these calibration values. The temperature measurements are inside the calibrated temperature range. The calibration data for temperature readings are presented in Appendix D. 


\subsubsection{Pressure Measurements}

Similar to temperature measurements, pressure measurements were also calibrated in the previous study by Arçelik. The curve fit equations from the previous calibration study were entered to the data acquisition program. The previous calibration data of compact pressure transducers are given in Appendix D. Additionally, curve fit equations of the compact pressure transducers are given as follows:

$$
\begin{gathered}
p[\mathrm{psi}]=12682 \mathrm{~A}[\mathrm{~mA}]-50.147 \\
p[\mathrm{psi}]=12705 \mathrm{~A}[\mathrm{~mA}]-50.52
\end{gathered}
$$

In order to be more confident about the pressure measurements, a calibration set-up is prepared according to [62]. Both compact pressure transducers are connected in the same manner to the same pipe where the static pressure is constant. There was no available known source for a reference pressure measurement. Therefore, two pressure gauges with $0.5 \mathrm{kPa}$ uncertainty that are calibrated by producer were purchased [63] as they were thought to be the most economical option. The compact pressure transducers measure absolute pressures. Therefore, the pressure readings of the barometer in the laboratory are also added to the readings of the pressure gauges. The author comments that any possible small error due to this calculation is insignificant, because a small variation in absolute pressure does not have a significant effect on the properties of water. Hence, this procedure is thought to be sufficient. The most important part of the measurement is believed to be the precision between two compact pressure transducers.

The schematic of the set-up is shown in Figure 3.16. The pressure source is pressurized air. The pressure inside the piping is increased by opening the inlet valve and varied by adjusting the relief valve. Additionally, a cut-off valve is placed just before pressure transducers. The photograph of the pipe section of the assembly is presented in Figure 3.17. The pressure in the piping is varied from $92 \mathrm{kPa}$ to 120 $\mathrm{kPa}$. A fixed error of $0.3 \mathrm{kPa}$ is found between the pressure transducers. This error is corrected after gathering the data. 


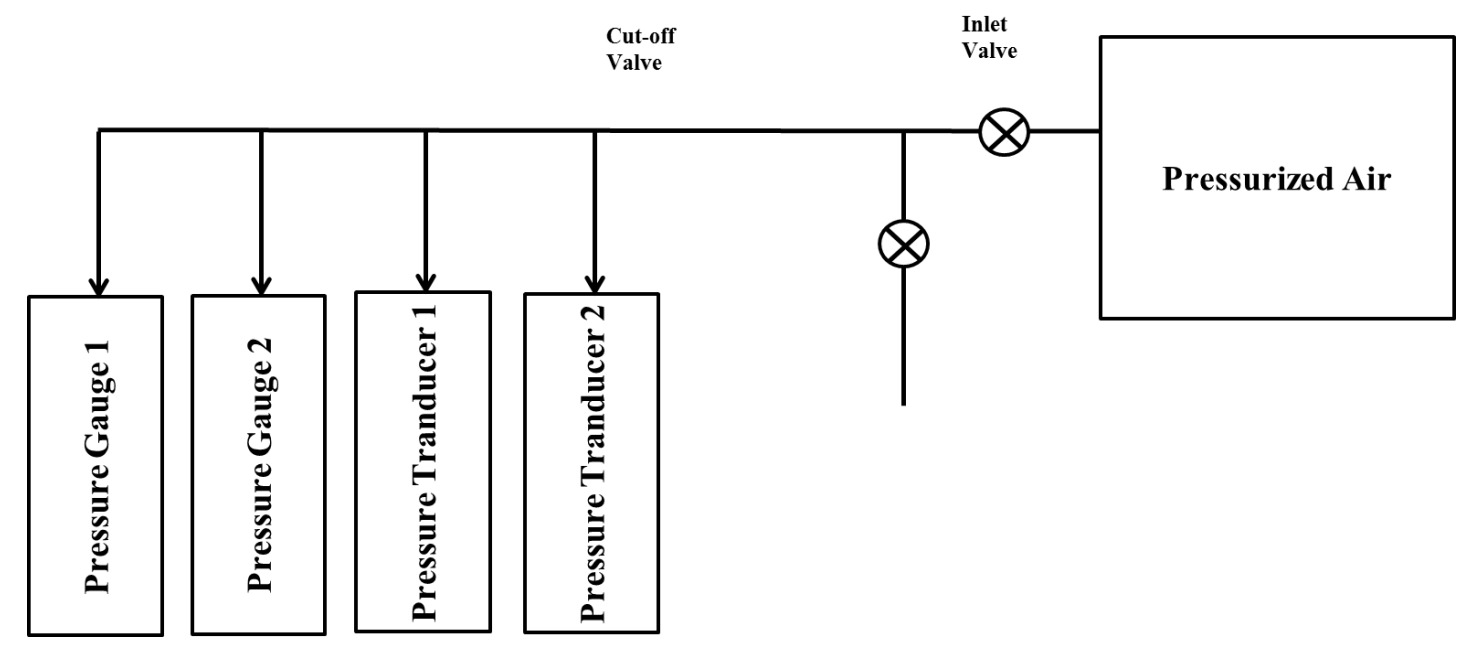

Figure 3.16 Schematic of the pressure transducer calibration assembly

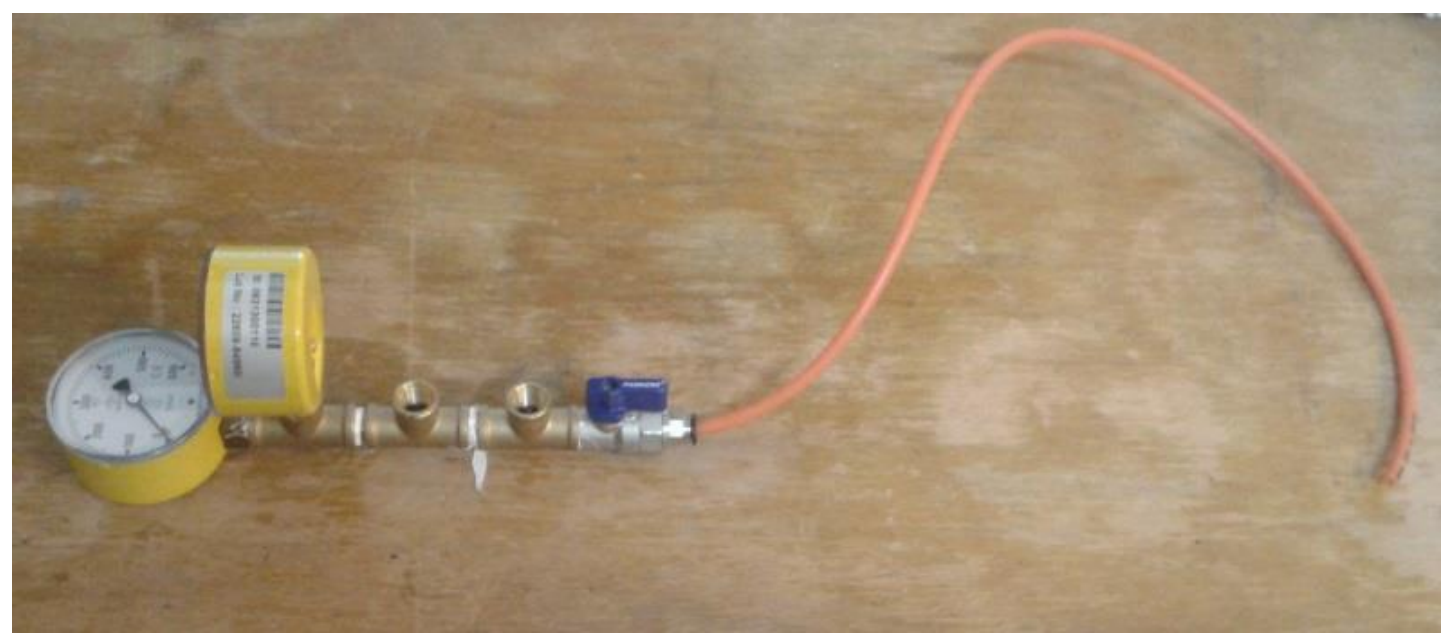

Figure 3.17 Photo of the piping section in the pressure transducer calibration assembly

For Ch5, a differential pressure transducer is used instead of the compact pressure transducers. The previous calibration of the pressure transducers is given in Appendix D. The curve fit entered to the data acquisition program is given as follows:

$$
\Delta p[\text { bar }]=1.0485 \mathrm{~V}[\mathrm{~V}]-0.4153
$$

The differential pressure transducer was installed to the system and calibrated [41] after the compact pressure transducers. Additionally, available equipment within the 
laboratory was not sufficient to perform a calibration for the differential pressure transducer. Thus, the calibration of the differential pressure transducer is considered as recent and no calibration is applied to the differential pressure transducer. 


\section{CHAPTER 4}

\section{EXPERIMENTS}

The experimental approach, physical parameters and conditions in experiments, the procedures followed during the operation, analysis of the outcome data and calculations used for data reduction are explained in the following sections in this chapter in details.

\subsection{Approach}

Cooling using two phase flow is generally complex and problematic for practical cooling purposes for most applications. On the other hand, cooling by single phase flow is widely used in cooling systems. Despite the obvious problems when an electronic device is wetted, the enhanced heat transfer characteristic of liquid over gas makes single phase liquid flow cooling a promising alternative. The experimental works in literature have both constant temperature and constant heat flux boundary condition. Mostly, air and water are used for practical cooling systems. However, many cooling systems, especially electronic cooling systems, reject heat at a constant rate in stable operations. Moreover, single phase liquid cooling are promising for network server cooling [64]. In this thesis, deionized water was used as the cooling liquid because of this reason. Therefore, constant heat flux boundary condition was found to be appropriate for boundary condition.

Determining pressure drop along the channel for varying Reynolds number was one of the main goals of the study. Hence, varying Reynolds number was obtained by adjusting flow rate and fluid temperature at the exit of cooling bath. Flow rate was controlled by changing the rotations per minute of the rotor of the gear pump and adjusting the valves. By controlling temperature and pressure at the inlet of the test section, the Reynolds number was approximately controlled. The pressure drop is 
directly measured by pressure transducers and corrected through calculations. Additional correlations for minor losses are also added.

Several thermocouples were implemented on the upper wall of the channel. Using these thermocouples, the temperature distribution along the channel wall was measured. The closest thermocouples to the inlet and exit of the test section were the ones used in average heat transfer calculations. The inlet and exit temperatures of the cooling liquid were also important. The usage of RTDs was not possible for temperature measurement on the channel wall. However, two RTDs having higher sensitivity than thermocouples were used at the inlet and exit of the test section. Monitoring the wall temperatures along the channel at several points, and inlet pressure, exit pressure and temperature of the fluid is followed by heat transfer calculations which are the second goal of the study. It is important to note that there is a small distance difference between the RTD and thermocouple measurement at the inlet and exit. A linear interpolation for temperature of the liquid at the locations of thermocouples on the wall was performed with a linear interpolation between RTD temperature readings due to the linear mean temperature increase behavior of the fluid under constant heat flux condition [13]. After this method, heat transfer coefficients were calculated.

\subsection{Conditions}

Single phase liquid flow experiments were conducted for various conditions. In this section a summary of the experimental conditions is presented. Moreover, all of the raw data from the experiments are given in Appendix E.

The water conditions in test cycle are given in Table 4.1. The properties of water were found using an add-in for excel [65]. This add-in is generated using the industrial standard IAPWS-IF97. The validity of the program was checked by comparison with the book of Incropera et al. [13]. The difference was found to be very small. The density, constant specific heat, dynamic viscosity and thermal conductivity values of water generated through the program are provided in Appendix F. The properties of water were evaluated at average fluid temperatures. 
The measured values for conditions are volumetric flow rate, inlet and exit pressures and inlet and exit temperatures. These conditions are presented in Table 4.1 with other calculated values such as Reynolds number and flow velocity. Reynolds number, thermal conductivity and Prandtl number are also evaluated at average fluid temperatures.

In order to investigate both the laminar regime and early transition flow regime, the desired Reynolds number range for the experiments was up to a Reynolds number of 2500. However, the cooling capacity of the bath and flow rate range of the gear pump limited Reynolds number range for some of the channels. Additionally, the lowest flow rate is $10 \mathrm{l} / \mathrm{h}$, which is the minimum reading level for the flowmeter. Similarly, the highest flow rate is selected as $60 \mathrm{l} / \mathrm{h}$ which is the maximum reading level for the flowmeter and close to the maximum flow rate capacity of the gear pump. The highest mean velocity among all channels is calculated as $1.44 \mathrm{~m} / \mathrm{s}$ for Ch7. On the other hand, the lowest mean velocity is found to be $0.12 \mathrm{~m} / \mathrm{s}$ for Ch5 which has the highest hydraulic diameter. The pressure drop for Ch6 and $\mathrm{Ch} 7$ are measured using compact pressure transducers due to the maximum limit of the differential pressure transducer. As expected, the maximum pressure drop occurred in $\mathrm{Ch} 7$, the one with the smallest hydraulic diameter. On the other hand, the differential pressure transducer is used to measure pressure for Ch5.

Table 4.1 The water conditions in the test section

\begin{tabular}{cccccccc}
\hline & & \multicolumn{2}{c}{ Ch5 } & \multicolumn{2}{c}{ Ch6 } & \multicolumn{2}{c}{ Ch7 } \\
Parameter & Unit & Min. & Max. & Min. & Max. & Min. & Max. \\
\hline$Q$ & $\mathrm{~L} / \mathrm{h}$ & 12 & 60 & 12 & 60 & 10 & 60 \\
$u_{m}$ & $\mathrm{~m} / \mathrm{s}$ & 0.12 & 0.60 & 0.89 & 1.18 & 0.24 & 1.44 \\
$p_{\text {in }}$ & $\mathrm{kPa}$ & 79.9 & 82.1 & 67.9 & 74.3 & 86.4 & 68.8 \\
$p_{\text {out }}$ & $\mathrm{kPa}$ & 78.6 & 78.9 & 65.7 & 66.9 & 67.2 & 65.4 \\
$\Delta p$ & $\mathrm{kPa}$ & 1.1 & 3.5 & 1.8 & 8.6 & 2.6 & 20.1 \\
$T_{\text {in }}(R T D)$ & ${ }^{\circ} \mathrm{C}$ & 21.5 & 22.9 & 21.6 & 24.1 & 20.7 & 27.0 \\
$T_{\text {out }}(R T D)$ & ${ }^{\circ} \mathrm{C}$ & 28.6 & 31.7 & 29.0 & 32.6 & 28.8 & 36.3 \\
$\Delta T=T_{\text {in }}-T_{\text {out }}$ & ${ }^{\circ} \mathrm{C}$ & 5.9 & 13.6 & 6.17 & 10.5 & 7.1 & 8.7 \\
$\operatorname{Re}$ & - & 227 & 1378 & 346 & 1732 & 360 & 2209 \\
$P r$ & - & 5.87 & 6.10 & 5.78 & 6.06 & 5.29 & 6.00 \\
\hline
\end{tabular}


The most important controlled properties of the flow were inlet temperature and flow rate. The dynamic viscosity, which is a variable in $R e$ calculation, is very dependent on temperature. Therefore, flow rates and exit temperature of the water from the bath were adjusted to cover the largest Reynolds number range in laminar regime possible. The adjustments were done by valves and reducing the rotation speed of gear pump.

A temperature difference of $10^{\circ} \mathrm{C}$ between inlet and exit fluid temperature is desired throughout the experiments. Due to limitations in heater and cooling bath power, for some data the temperature difference is less than $10^{\circ} \mathrm{C}$. The lowest temperature increase is $5.9^{\circ} \mathrm{C}$ in $\mathrm{Ch} 5$ as presented in Table 4.1 .

During the experimentation process, heat loss to the surrounding was also taken into account. Table 4.2 displays the amount of heat that is transferred into the cooling fluid and the electrical power supplied to the electrical heaters, with $\Phi_{\text {elec }}$ being the electrical power supplied to the heaters.

Table 4.2 shows that maximum percentage of the electrical power transferred into the cooling water is $96 \%$ with an uncertainty of calculation being between $5.2 \%$ and $7.8 \%$. The uncertainty is calculated using the procedure presented in Section 4.4. On the other hand, the percentage of transfer decreases to $70 \%$ in $\mathrm{Ch} 7$. However, the transfer percentage is generally between $85 \%$ and $95 \%$ and lower values occurred in low flow rates.

Table 4.2 The amount of heat transferred in the cooling fluid

\begin{tabular}{lccccccc}
\hline & & \multicolumn{2}{c}{ Ch5 } & \multicolumn{2}{c}{ Ch6 } & \multicolumn{2}{c}{ Ch7 } \\
\multicolumn{1}{c}{ Parameter } & Unit & Min. & Max. & Min. & Max. & Min. & Max. \\
\hline$\Phi_{\text {elec }}$ & W & 140 & 526 & 180 & 500 & 181 & 475 \\
$\dot{Q}_{f l}=\dot{m}_{f l} C_{p} \Delta T_{f l}$ & W & 114 & 445 & 435 & 143 & 129 & 423 \\
$\dot{Q}_{f l}$ & $\%$ & 81 & 92 & 80 & 96 & 70 & 96 \\
\hline$\Phi_{\text {elec }}$ & & & & & & & \\
\hline
\end{tabular}


Figure 4.1 displays relatively good agreement in heat transfer balance from heaters to cooling fluid especially for middle Reynolds number range. It is possible to comment that the largest difference at low flow rates may occur due to several reasons. A possible explanation might be that the flow is poorly mixed at the exit and inlet manifold and the temperature readings deviate from actual bulk temperature of the fluid. Another reason might be increasing heat loss from external sides due to increasing natural convection.

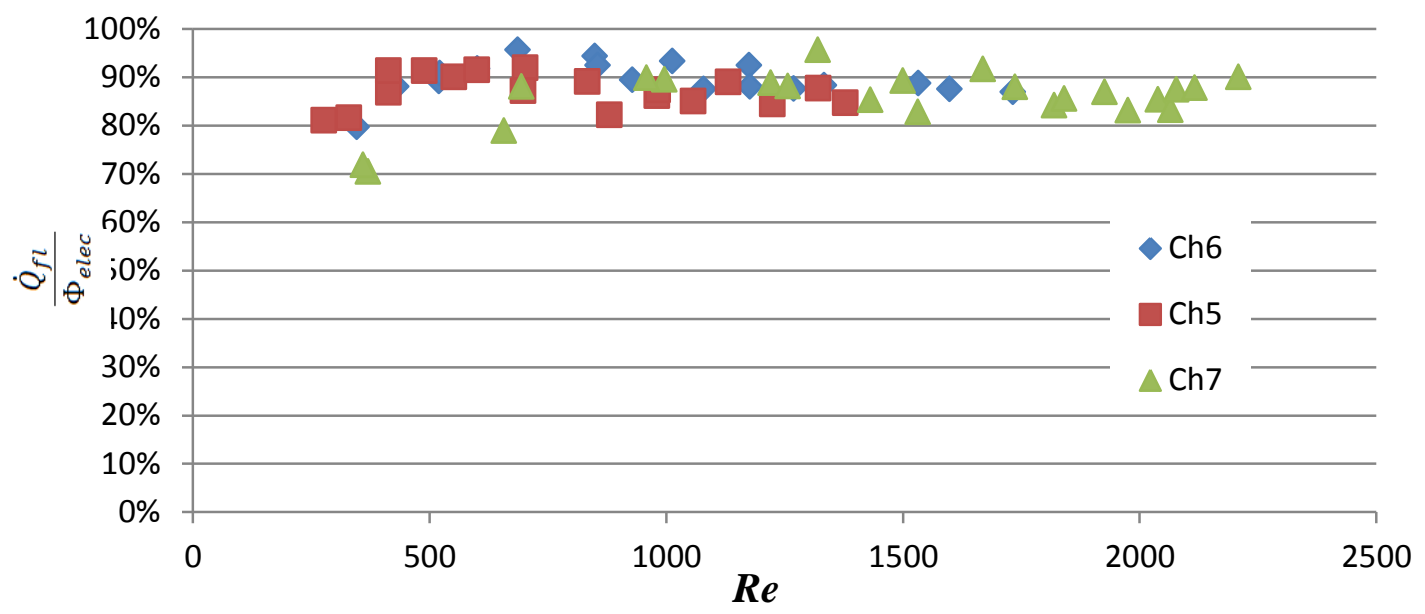

Figure 4.1 Forced convection heat transfer to electrical power ratio vs Reynolds number

\subsection{Repeatability}

Repeatability is important in experiments to verify the degree of agreement of data and consistency of the test set up. In the current experiments, the repeatability is also considered.

The first tested channel is Ch7. For repeatability analysis, six of the conditions in Ch7 experiments were repeated during the re-run of the set-up. For the other channels, only three conditions were repeated due to time consideration. The temperature measurements were normalized to have the same inlet temperature, which is selected as $20^{\circ} \mathrm{C}$ for easier comparison. The sensitivity of thermocouples and RTDs are $0.5{ }^{\circ} \mathrm{C}$ and $0.55^{\circ} \mathrm{C}$ plus $0.06 \%$ of the reading, respectively. The Ch6 repeatability analysis for normalized temperature readings, pressure drop along the 
channel and Reynolds number are displayed in Table 4.3. The difference in thermocouple readings were less than $0.6^{\circ} \mathrm{C}$ for all data. The maximum exit fluid temperature difference is $0.6^{\circ} \mathrm{C}$ whereas pressure drop difference is less than $0.5 \mathrm{kPa}$. The repeatability of Poiseuille number and Nusselt number are presented in Chapter 5. The repeatability of the other two channels is slightly poorer than Ch6 but sufficiently good to lend some confidence to the results. Their repeatability is not presented here. However, the raw experimental data in Appendix E can be used to evaluate the repeatability.

Table 4.3 Normalized repeatability data for Ch6 according to inlet temperature

\begin{tabular}{ccccccccccccc}
\hline $\begin{array}{c}\mathbf{Q} \\
\mathbf{L} / \mathrm{h}\end{array}$ & $\mathbf{R e}$ & $\begin{array}{c}\Delta \mathbf{p} \\
-\end{array}$ & $\begin{array}{c}\mathbf{T}_{\text {in }} \\
\mathrm{kPa}\end{array}$ & $\begin{array}{c}\mathbf{T}_{\mathbf{1}} \mathrm{C} \\
{ }^{\circ} \mathrm{C}\end{array}$ & $\begin{array}{c}\mathbf{T}_{\mathbf{2}} \\
{ }^{\circ} \mathrm{C}\end{array}$ & $\begin{array}{c}\mathbf{T}_{\mathbf{3}} \\
{ }^{\circ} \mathrm{C}\end{array}$ & $\begin{array}{c}\mathbf{T}_{\mathbf{4}} \\
{ }^{\circ} \mathrm{C}\end{array}$ & $\begin{array}{c}\mathbf{T}_{\mathbf{5}} \\
{ }^{\circ} \mathrm{C}\end{array}$ & $\begin{array}{c}\mathbf{T}_{\mathbf{6}} \\
{ }^{\circ} \mathrm{C}\end{array}$ & $\begin{array}{c}\mathbf{T}_{\mathbf{7}} \\
{ }^{\circ} \mathrm{C}\end{array}$ & $\begin{array}{c}\mathbf{T}_{\mathbf{8}} \\
{ }^{\circ} \mathrm{C}\end{array}$ & $\begin{array}{c}\mathbf{T}_{\text {out }} \\
{ }^{\circ} \mathrm{C}\end{array}$ \\
\hline 18 & 519 & 2.1 & 20 & 24.9 & 26.3 & 27.5 & 29.2 & 31.2 & 32.4 & 33.7 & 35.2 & 30.3 \\
\hline Diff. & 2 & 0.1 & & 0.2 & 0.2 & 0.2 & 0.2 & 0.4 & 0.3 & 0.3 & 0.3 & 0.2 \\
\hline Diff. (\%) & 0.4 & 4.8 & & 1.9 & 1.9 & 1.9 & 1.9 & 3.8 & 2.9 & 2.9 & 2.9 & 1.9 \\
\hline 30 & 849 & 3.8 & 20 & 25.9 & 27.1 & 29.1 & 30.3 & 32.1 & 33.3 & 34.5 & 35.9 & 29.3 \\
30 & 855 & 3.4 & 20 & 26.0 & 27.3 & 28.6 & 30.1 & 32.1 & 33.3 & 34.6 & 36.0 & 29.2 \\
\hline Diff. & 6 & 0.4 & & -0.1 & -0.2 & 0.5 & 0.2 & 0.0 & 0.0 & -0.1 & -0.1 & 0.2 \\
\hline Diff. (\%) & 0.7 & 11.8 & & 1.1 & 2.2 & 5.4 & 2.2 & 0.0 & 0.0 & 1.1 & 1.1 & 2.2 \\
\hline 42 & 1175 & 5.1 & 20 & 27.3 & 27.9 & 29.4 & 30.8 & 33.2 & 34.2 & 34.8 & 36.2 & 28.1 \\
42 & 1177 & 5.2 & 20 & 26.7 & 27.7 & 29.0 & 30.6 & 33.0 & 33.7 & 34.9 & 36.2 & 27.7 \\
\hline Diff. & 2 & 0.1 & & 0.6 & 0.2 & 0.5 & 0.2 & 0.2 & 0.5 & -0.1 & 0.1 & 0.4 \\
\hline Diff. (\%) & 0.1 & 2.0 & & 7.8 & 2.6 & 6.5 & 2.6 & 2.6 & 6.5 & 1.3 & 1.3 & 5.2 \\
\hline
\end{tabular}

The percentage differences are found by dividing the differences with minimal values for $\mathrm{Re}$ and $\Delta \mathrm{p}$. For temperature measurements, differences are divided by $\left(\mathbf{T}_{\mathbf{i n}}-\mathbf{T}_{\text {out }}\right)$.

\subsection{Data Analysis}

Single phase water flow in the minichannels was experimentally investigated as outlined by the flow chart presented in Table 4.5. The data obtained is analyzed with different methodologies according to readings and measurements from equipment. These equipment can be divided into two groups: manual readings and computer readings in defined intervals. 
Flow range, water bath temperature measurement and power input measurements in the water cycle are read manually. Since these measurements were not recorded into a computer, they are manually noted in short intervals to check for steady state conditions. After steady state conditions were reached, data were collected for 15 minutes under steady state conditions. The flowmeter readings were checked and recorded every thirty second after reaching steady state. Visually observed oscillations in flow rate were very small. Despite the small oscillations in flow range, the recorded values in steady state operation were averaged over time and accepted as the final flow rate reading. The water bath temperature is the exit temperature of water and to have a steady state operation this value should not differ throughout the experimentation. Therefore, the water exit temperature was checked every thirty seconds on a digital temperature screen in steady state operation. Additionally, the exit temperature of water from the bath was recorded with a thermocouple and two readings were compared to check for any inconsistency. As explained in the previous chapter, the variac is used to control and adjust the power input to the heaters. The voltage is adjusted by the variac and the power output is read by a power analyzer. In steady state operation, power input readings in thirty second intervals were recorded for fifteen minutes. Similar to flow meter readings, an average value of power input over the steady state operation time period is accepted as the final power input to the heater.

The temperature and pressure measurements are recorded to a computer using the data acquisition unit. Thermocouples were used for wall temperature measurements whereas RTDs were used for measuring the inlet and exit temperatures of water flowing through the channel. Pressure drop along the channel was measured by pressure transducers. The time intervals between measured data were 15 seconds during the whole experiment. The measured data were directly visualized by the data acquisition program HP VEE through real time graphs. Through these graphs, steady state conditions were checked. Additionally, steady state conditions were also confirmed by data mining using the excel output file using graphs. When the steady state conditions were reached, pressure and temperature values were taken for 
another 15 minutes. Similar to manual readings, the data recorded in the computer were averaged and the average results were accepted as final temperature and pressure values.

For single phase liquid flow, fluid resistance and heat transfer characteristics for varying flow rates were investigated. After collecting the data for the specified flow rate, the heater was turned off for at least 30 minutes to cool the whole test section to release thermal energy stored in the channel walls and insulation. After gathering sufficient data for the channel, the experiment was stopped. The gathered data were reduced through calculations in the following section.

\subsection{Flow Chart}

The operations of equipment were performed by following a flow chart. The procedures in the flow chart are explained in Table 4.5 in detail. Flow order chart in the thesis of Tekin [42] was taken as a template in the preparation of the chart . 
Table 4.4 Experimental Set-up Flow Chart

\begin{tabular}{|c|c|c|}
\hline & 1 & Turn on the computer, DC power supply, and the data logger. \\
\hline \multicolumn{2}{|l|}{2} & Start data acquisition program on the computer for temperature recordings. \\
\hline \multicolumn{2}{|l|}{3} & Be sure that all valves in the system are open. \\
\hline \multicolumn{2}{|l|}{4} & Turn on the water bath and gear pump. \\
\hline \multicolumn{2}{|l|}{5} & Adjust the bath temperature to the desired water exit temperature. \\
\hline \multicolumn{2}{|l|}{6} & Check water temperatures with RTD and Thermocouples. \\
\hline \multirow[t]{3}{*}{7} & & Has inlet water temperature reached to the adjusted inlet temperature? \\
\hline & YES & Continue with step 8 \\
\hline & NO & Go back to 6 \\
\hline \multicolumn{2}{|l|}{8} & Turn on the heater. \\
\hline \multicolumn{2}{|l|}{9} & Adjust power of heater to a small power input. \\
\hline \multicolumn{2}{|c|}{10} & Adjust the flow rate with valve. \\
\hline \multicolumn{2}{|c|}{11} & Adjust power of heater according to flow rate. \\
\hline \multicolumn{2}{|c|}{12} & Wait until steady-state conditions are reached. \\
\hline \multirow[t]{3}{*}{13} & & Has the inlet and exit water temperature reached steady state? \\
\hline & YES & Continue with step 14. \\
\hline & NO & Go back to step 12 . \\
\hline \multirow[t]{3}{*}{14} & & Has the wall temperature along the channels reached steady state? \\
\hline & YES & Continue with step 15. \\
\hline & NO & Go back to step 12 . \\
\hline \multirow[t]{3}{*}{15} & & Are there any oscillations in pressure difference? \\
\hline & YES & Continue with step 16. \\
\hline & NO & Go back to step 12 . \\
\hline \multirow[t]{3}{*}{16} & & Are there any oscillations in flow rate, water bath temperature, power input?** \\
\hline & YES & Continue with step 17 \\
\hline & NO & Go back to step 12 . \\
\hline \multirow[t]{3}{*}{17} & & Is the experiment finished for the specified flow rate? \\
\hline & YES & Continue with step 18. \\
\hline & NO & Go back to step 12. \\
\hline \multicolumn{2}{|c|}{18} & Note down the time interval and record the flow rate in the water cycle. \\
\hline \multirow[t]{5}{*}{19} & & Are the experiments finished for all desired flow rates? \\
\hline & YES & $\begin{array}{l}\text { Shut down the system } \\
\text { - Turn off the heater } \\
\text { - Tait for } 20 \text { minutes to cool water in the system } \\
\text { - Turn off the pump and water bath. } \\
\text { - Terminate the data acquisition program on the computer. } \\
\text { - Turn off the computer, DC power supply, and the data logger. }\end{array}$ \\
\hline & NO & Turn off the heater for 30 minutes to cool water in the system..Go back to step 8 . \\
\hline & * & 50 constant consecutive readings in the range of device accuracy. \\
\hline & $* *$ & Check from flowmeter and water bath screen. \\
\hline
\end{tabular}




\subsection{Data Reduction}

Some of the equations presented in Chapter 2 on the basics of fluid flow and heat transfer are general equations. The remaining equations used for experimental calculation of data are presented for evaluation of pressure drop and heat transfer in minichannels. Like Chapter 2, calculations are divided as fluid flow calculations and heat transfer calculations.

\subsubsection{Fluid Flow Calculations}

Fluid flow calculations are used to obtain the friction factor. The friction factor equation is given in Eqn. (2.4). However, this equation only contains friction factor for fully developed flow along the channel. In the experimental study, there are some minor losses. Before the evaluation of friction factor coefficient, the minor losses should be excluded. These minor losses are hydraulic developing effect, contraction loss in the inlet and expansion loss at the exit. The calculation of friction factor is performed through Eqn. (4.1)

$$
f_{a p p}=\left(\frac{2\left(p_{\text {in }}-p_{\text {out }}\right)}{\rho u_{m}^{2}}-K_{c}-K_{e}\right) \frac{D_{h}}{4 L}
$$

Here $K_{c}$ and $K_{e}$ are loss coefficients due to inlet contraction and exit expansion.

The mean velocity $u_{m}$ is calculated using the Eqn. (4.2)

$$
u_{m}=\frac{Q}{A_{c r}}
$$

The values of sudden contraction and expansion loss coefficients for rectangular ducts are presented in Figure 4.2. The $K_{c}$ and $K_{e}$ values for the three minichannels considered are 0.05 and 0.72 for Ch5, 0.20 and 0.75 for Ch6 and -0.33 and 0.48 for $\mathrm{Ch} 7$, respectively. The area ratio $(\sigma)$ in Figure 4.2 is the change of area between inlet and exit area at contraction and expansion connections. The hydraulic developing effect is included in the apparent friction factor $\left(f_{a p p}\right)$ and the calculated friction factor from data in the experiments $\left(f_{\text {exp }}\right)$ is the apparent friction factor. 
The Pouiseuille number is found by Eqn. (4.3).

$$
P o_{\text {exp }}=f_{\text {exp }} R e
$$

Lastly, the experimental $f_{a p p}$ and $P o$ results from calculations are compared to conventional values from Table 2.2.

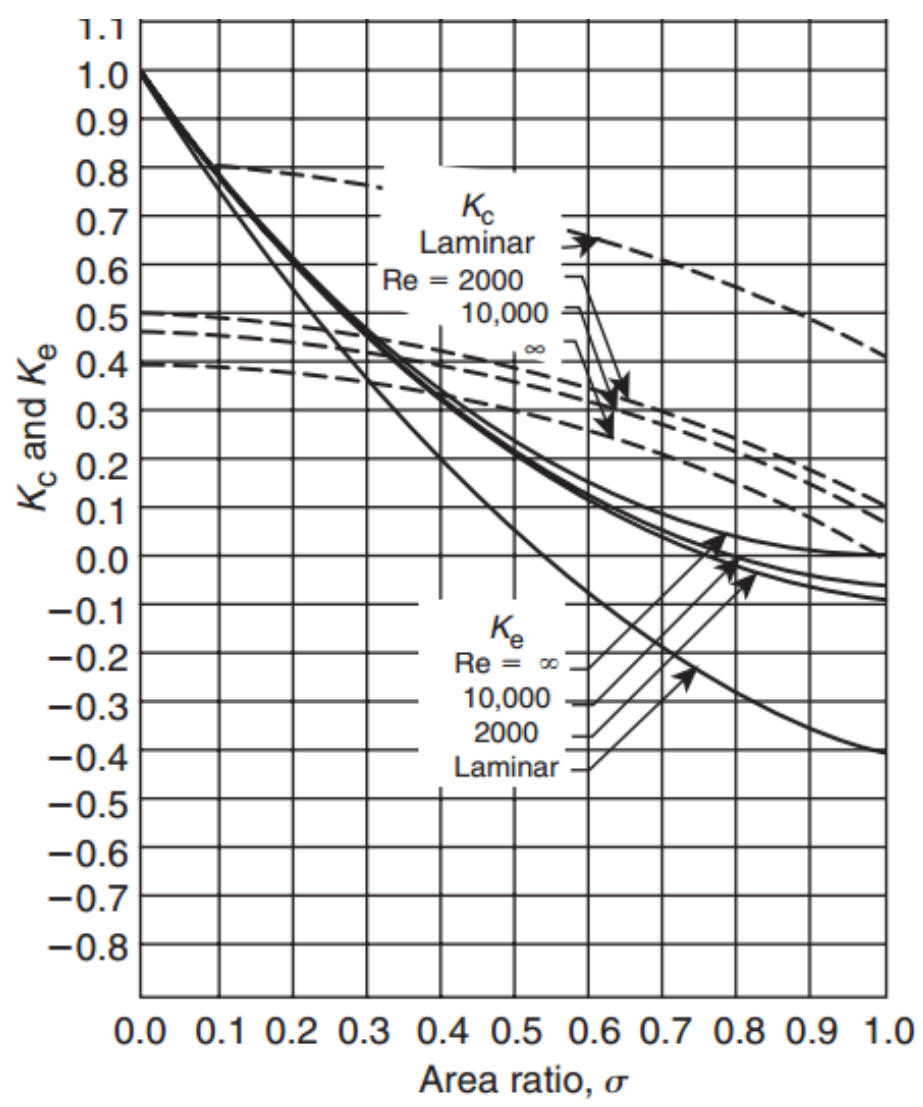

Figure 4.2 Sudden contraction and expansion loss coefficients for rectangular ducts [67]

\subsubsection{Heat Transfer Calculations}

Fundamental equations for heat transfer calculation are given in Section 2.4. In this section, additional equations used in the calculations for data reduction in order to find heat transfer coefficient and Nusselt number in the laminar region are presented. The power of the heater was adjusted manually to have a sufficient temperature 
increase in the cooling fluid. However, some of the heat is lost to the surroundings. In order to calculate the heat removed by the cooling fluid, Eqn. (4.4) is applied.

$$
\dot{Q}_{f l}=\dot{m}_{f l} C_{p}\left(T_{f l, o u t}-T_{f l, \text { in }}\right)
$$

where $C_{p}$ is constant specific heat at average fluid temperature and $T_{f l, i n}$ and $T_{f l, o u t}$ are the fluid temperatures at the inlet and exit of channel, respectively, and $\dot{m}_{f l}$ is the mass flow rate of fluid. As mentioned previously, $C_{p}$ values are obtained from excel add-in and temperature readings are from RTD measurements. Additionally, mass flow rate is obtained from multiplying measured flow rate and density calculated using the excel add-in for water properties.

The points where temperature readings using RTDs and thermocouples are taken are slightly different. Thus, the fluid temperature is approximated at the location of thermocouples using fluid temperature readings from RTDs at the inlet and the exit. The temperature of the fluid along the channel using this methodology is evaluated with Eqn. (4.5).

$$
T_{f l}(x)=\frac{\dot{Q}_{f l}}{\dot{m}_{f l} C_{p}} \frac{x}{L}+T_{f l, i n}
$$

where $T_{f l}(x)$ is local fluid temperature at a distance of $x$ from the inlet.

In order to calculate heat transfer coefficient, the temperature difference between wall and cooling fluid is needed. Therefore, the closest thermocouples to the sides of the channel for wall temperature and inlet and exit RTD reading for fluid temperature were used to calculate temperature difference after correcting for fluid temperatures using Eqn (4.5). The logarithmic mean temperature method is used for temperature difference as given in Eqn. (4.6),

$$
\Delta T_{l m}=\frac{\left(T_{w, \text { in }}-T_{f l, \text { in }}\right)-\left(T_{w, \text { out }}-T_{f l, \text { out }}\right)}{\ln \left(\frac{T_{w, \text { in }}-T_{f l, \text { in }}}{T_{w, \text { out }}-T_{f l, \text { out }}}\right)}
$$


where $T_{w, i n}$ and $T_{w, o u t}$ are the wall temperatures at the inlet of the channel and exit of the channel. It is important to note that these temperature readings are directly measured on the wall as also explained in section 3.2.4.

The average heat transfer coefficient of convection is calculated using Eqn. (4.7)

$$
\bar{h}=\frac{\dot{Q}_{f l}}{A_{h t} \Delta T_{l m}}
$$

where $A_{h t}$ is heat transfer area of the channel. The heat transfer area of the channels is found by multiplying heated perimeter of the channel which is equal to the wetted perimeter and heated length. Heat transfer area is shown in Eqn. (4.8)

$$
A_{h t}=P_{h t} L
$$

where $P_{h t}$ is the heated perimeter. The values in Eqn. (4.8) are provided in Table 3.1. After calculation of average heat transfer coefficient, experimental average Nusselt number was calculated as demonstrated in Eqn. (4.9).

$$
\overline{N u}=\frac{\bar{h} D_{h}}{k}
$$

The heat flux on the channel wall surface was assumed to be uniform and was found through Eqn. (4.10).

$$
q^{\prime \prime}=\frac{\dot{Q}_{f l}}{A_{h t}}
$$

The local Nusselt numbers were calculated as demonstrated in Eqn. (4.11),

$$
N u=\frac{h D_{h}}{k}
$$

where local heat transfer coefficient $(h)$ is found as shown in Eqn. (4.12).

$$
h=\frac{q^{\prime \prime}}{T_{w}-T_{f l}}
$$


Lastly, the experimental $\overline{N u}$ and $N u$ results from calculations were compared to conventional values from Table 2.5, Table 2.6 and Table 2.7 The results will be presented in the next Chapter.

\subsection{Uncertainity}

The uncertainties of the variables in the experiments were calculated using the methodology suggested by Moffat [66]. In his work, Moffat defined uncertainty of a calculated value according to Eqn. (4.13).

$$
\varepsilon_{Y}=\left[\left(\frac{\partial Y}{\partial x_{1}} \varepsilon_{1}\right)^{2}+\left(\frac{\partial Y}{\partial x_{2}} \varepsilon_{2}\right)^{2}+\left(\frac{\partial Y}{\partial x_{3}} \varepsilon_{3}\right)^{2}+\cdots+\left(\frac{\partial Y}{\partial x_{n}} \varepsilon_{n}\right)^{2}\right]^{0.5}
$$

Here $\varepsilon_{1}$ is the uncertainty of independent variable $x_{1}$ and $Y$ is the calculated parameter. Table 4.4 shows the relative uncertainties found in the experiments. For some parameters, a range is provided rather than a fixed relative uncertainty, because the parameter was changed during the experiments even though the uncertainty of the parameter is constant. The relative uncertainty of mass flow rate and Reynolds numbers are not constant because the accuracy of the flowmeter decreases as flow rate decreases. Thus, the highest relative uncertainty in Reynolds number occurred for the lowest flow rate which is $5.82 \%$ for $\mathrm{Ch} 7$. The relative uncertainties in Poiseuille number show a decreasing trend from $\mathrm{Ch} 5$ to $\mathrm{Ch} 7$. The reason for this is the pressure drop in minichannels decreases as hydraulic diameter of the channels increases. Since Ch5 has the largest hydraulic diameter, it has the lowest pressure drop, thus highest relative uncertainty range. Similarly, highest uncertainties occurred at lowest flow rates due to lower pressure drops at these flow rates. Furthermore, the relative uncertainty of heat transfer coefficient and Nusselt numbers were dominated by logarithmic mean temperature term. These levels of uncertainties are thought to be sufficiently good to draw broad conclusions but the conclusions can be strengthened by reducing these uncertainties. Suggestions for uncertainty improvement are added as a future work in Chapter 6. 
Table 4.5 Relative uncertainties in calculated parameters

\begin{tabular}{cccc}
\hline \multirow{2}{*}{ Paramete } & Ch5 & Ch6 & Ch7 \\
\cline { 2 - 4 } $\mathbf{r}$ & $\begin{array}{c}\text { Relative } \\
\text { uncertainty } \\
(\%)\end{array}$ & $\begin{array}{c}\text { Relative } \\
\text { uncertainty }(\%)\end{array}$ & $\begin{array}{c}\text { Relative } \\
\text { uncertainty (\%) }\end{array}$ \\
\hline $\boldsymbol{D}_{\boldsymbol{h}}$ & 4.08 & 5.48 & 6.25 \\
$\boldsymbol{A}_{\boldsymbol{c r}}$ & 3.73 & 5.19 & 5.81 \\
$\boldsymbol{A}_{\boldsymbol{h} \boldsymbol{t}}$ & 2.46 & 2.66 & 3.38 \\
$\boldsymbol{\Delta} \boldsymbol{T}_{\boldsymbol{l} \boldsymbol{m}}$ & $3.31-9.62$ & $6.47-13.74$ & $3.94-8.56$ \\
$\dot{\boldsymbol{m}}$ & $2.51-4.01$ & $2.58-4.01$ & $2.58-4.01$ \\
$\boldsymbol{R} \boldsymbol{e}$ & $4.11-5.23$ & $4.58-5.49$ & $4.93-5.82$ \\
$\boldsymbol{P r}$ & 1.81 & 1.81 & 1.81 \\
$\overline{\boldsymbol{h}}$ & $6.48-13.2$ & $9.36-16.80$ & $7.21-12.03$ \\
$\overline{\boldsymbol{N u}}$ & $6.96-14.4$ & $9.96-17.52$ & $8.16-13.20$ \\
$\boldsymbol{P o}$ & $13.12-31.25$ & $12.38-23.07$ & $8.75-18.38$ \\
\hline
\end{tabular}

The uncertainty in Po number is calculated using Eqn. (4.14) which is derived using Eqn. (4.13). The other uncertainties are evaluated similarly.

$$
\begin{gathered}
\varepsilon_{P o}=P o\left[2\left(\frac{\varepsilon_{\rho}}{\rho}\right)^{2}+\left(\frac{\varepsilon_{\mu}}{\mu}\right)^{2}+\left(\frac{\varepsilon_{\Delta p}}{\Delta p}\right)^{2}+\left(\frac{\varepsilon_{L}}{L}\right)^{2}+3\left(\frac{\varepsilon_{Q}}{Q}\right)^{2}+5\left(\frac{\varepsilon_{H}}{H}\right)^{2}\right. \\
\left.+5\left(\frac{\varepsilon_{W}}{W}\right)^{2}+2\left(\frac{\varepsilon_{H}}{H+W}\right)^{2}+2\left(\frac{\varepsilon_{W}}{H+W}\right)^{2}\right]^{0.5}
\end{gathered}
$$




\section{CHAPTER 5}

\section{RESULTS \& DISCUSSION}

In this chapter, heat transfer and fluid flow results for three minichannels are presented and discussed within the context of conventional theory and small scale correlations. Eighteen experiments for Ch5 and Ch6 were conducted while 23 experiments were conducted for $\mathrm{Ch} 7$. The repeatability experiments are also included in the presented results for comparison.

The chapter is divided into two main parts which are heat transfer and fluid flow. Each experimental data is reduced through data reduction for each minichannel using calculations presented in Chapter 2 and Chapter 4. First, each minichannel is discussed separately. Afterwards, fluid flow and heat transfer characteristics of all minichannels are compared and discussed.

Before the discussion of the results, the major assumptions in this study are given as follows:

- Heat flux boundary condition on the walls is assumed to be uniform. This assumption is considered to be accurate as discussed in details in section 3.2.

- The water temperature along the channel changes linearly with axial distance. According to fundamental knowledge of heat transfer as stated in [4], the temperature variation should be linear.

- The wall temperatures on the top surface of the minichannels were measured by thermocouples. These measurements are assumed to be same with inner channel temperature due to high conductivity of walls of minichannels as discussed in details in section 3.2. 
- It is assumed that no clogging occurred inside the minichannels during the experiments. Because, the cooling fluid in this study is deionized water which contains no minerals and impurities.

\subsection{Fluid Flow}

In this section, pressure drop calculations are evaluated using experimental data and conventional correlations. Pressure drops along the channel were measured with differential pressure transducers for $\mathrm{Ch} 5$ and compact pressure transducers for Ch6 and Ch7. Poiseuille number and Reynolds number are the flow variables investigated for the minichannels. Rather than presenting results as pressure drops along the minichannels, results are presented in terms of Poiseuille number versus Reynolds number. Another possible way of presenting results is demonstration of fanning friction factor variation with respect to Reynolds number. On the other hand, this demonstration will be identical to the Poiseuille number versus Reynolds number demonstration if Poiseuille number is divided by Reynolds number. Both methods are found in literature although their outcome is identical in terms of fluid flow. Agreement with conventional Hagen-Poiseuille flow theory and transition to turbulent regime is the main focus of the study. Additionally, developing region effects on Poiseuille number was another point of investigation. According to HagenPoiseuille theory, Poiseuille number is constant for fully developed laminar flow. On the other hand, the flow inside the minichannels is not fully developed for almost all of the experimental data. Table 5.1 gives axial dimensionless distance at the exit of the channel. The fluid flow inside the minichannels is not hydrodynamically fully developed as $x^{+}$calculated using Eqn. (2.7) should be larger than one for hydrodynamically fully developed flow as indicated in Chapter 2. Only for seven data $x^{+}$are larger than one. Despite the fact that the change of Poiseuille number between $x^{+}$of 0.2 and 1.0 is small as shown in Table 2.2, theoretical Poiseuille

numbers are considered for hydrodynamically developing flow using Table 2.2. Similarly, Po for developing flow is plotted on graphs instead of for fully developed flow. 
Table 5.1 Dimensionless axial distance for developing flow in minichannels

\begin{tabular}{|c|c|c|c|c|c|c|}
\hline \multirow{2}{*}{ Data } & \multicolumn{2}{|c|}{ Ch5 } & \multicolumn{2}{|c|}{ Ch6 } & \multicolumn{2}{|c|}{ Ch7 } \\
\hline & $\boldsymbol{R e}$ & $x_{\text {exit }}^{+}$ & $\boldsymbol{R e}$ & $x_{\text {exit }}^{+}$ & $R e$ & $x_{\text {exit }}^{+}$ \\
\hline 1 & 277 & 1,60 & 346 & 1,16 & 360 & 1,24 \\
\hline 2 & 330 & 1,34 & 429 & 0,94 & 370 & 1,21 \\
\hline 3 & 413 & 1,07 & 519 & 0,78 & 657 & 0,68 \\
\hline 4 & 413 & 1,07 & 521 & 0,77 & 694 & 0,65 \\
\hline 5 & 489 & 0,91 & 601 & 0,67 & 958 & 0,47 \\
\hline 6 & 551 & 0,80 & 687 & 0,59 & 996 & 0,45 \\
\hline 7 & 600 & 0,74 & 849 & 0,47 & 1221 & 0,37 \\
\hline 8 & 702 & 0,63 & 855 & 0,47 & 1257 & 0,36 \\
\hline 9 & 698 & 0,63 & 928 & 0,43 & 1320 & 0,34 \\
\hline 10 & 833 & 0,53 & 1013 & 0,40 & 1431 & 0,31 \\
\hline 11 & 880 & 0,50 & 1079 & 0,37 & 1500 & 0,30 \\
\hline 12 & 980 & 0,45 & 1175 & 0,34 & 1532 & 0,29 \\
\hline 13 & 982 & 0,45 & 1177 & 0,34 & 1669 & 0,27 \\
\hline 14 & 1057 & 0,42 & 1269 & 0,32 & 1737 & 0,26 \\
\hline 15 & 1131 & 0,39 & 1334 & 0,30 & 1819 & 0,25 \\
\hline 16 & 1224 & 0,36 & 1532 & 0,26 & 1840 & 0,24 \\
\hline 17 & 1321 & 0,34 & 1599 & 0,25 & 1926 & 0,23 \\
\hline 18 & 1378 & 0,32 & 1732 & 0,23 & 1976 & 0,23 \\
\hline 19 & & & & & 2039 & 0,22 \\
\hline 20 & & & & & 2065 & 0,22 \\
\hline 21 & & & & & 2078 & 0,22 \\
\hline 22 & & & & & 2116 & 0,21 \\
\hline 23 & & & & & 2209 & 0,20 \\
\hline
\end{tabular}


The results are presented through both graphs for visualization of the trends and tables to discuss numerical results. Additionally, the Blasius equation is used to determine any possible transition to turbulent regime. The Blasius equation is given in the fundamental heat transfer textbooks such as $[4,5,13]$ for friction factor calculation in turbulent regime. It is for smooth circular pipes but also widely used for rectangular channels in the literature as in [11,22,24,25].The multiplication of turbulent friction factor in the Blasius equation [13] with Reynolds number are illustrated in graphs and given in Eqn. (5.1).

$$
\operatorname{Re} f_{\text {turb }}=\operatorname{Re}\left(0.0791 R e^{-0.25}\right)
$$

\subsubsection{Minichannel $1(\mathrm{Ch} 7)$}

The experimental Poiseuille number and theoretical Poiseuille number for $\mathrm{Ch} 7$ are given in Table 5.2 as numerical values. Additionally, the experimental Poiseuille numbers in Tables in section 5.1 are found using Eqn. (4.3) for all minichannels. The decrease of $P o$ at early $R e$ range might be due to poor mixing of water at the exit manifold which may cause a slight pressure alteration at low flow rates, particularly. Considering the higher uncertainties at low flow rates, it is not reasonable to suggest that an unexpected phenomenon occurs due to the decrease of Poiseuille number. Generally, the ratio of experimental values to theoretical values is within approximately $20 \%$ of deviation boundaries of theoretical results up to a Reynolds number of 1532. After this value, the ratio of experimental value to theoretical value increases significantly. This indicates that the flow entered transition regime. 
Table 5.2 Poiseuille number for $\mathrm{Ch} 7$

\begin{tabular}{|c|c|c|c|c|}
\hline Data & $\boldsymbol{R e}$ & $\begin{array}{c}P o_{\text {exp }} \\
\left(f_{\text {exp }} R e\right)\end{array}$ & $\begin{array}{c}P_{\text {theo }} \\
\left(f_{\text {app }} R e\right)\end{array}$ & $P o_{\text {exp }} / P o_{\text {theo }}$ \\
\hline 1 & 360 & 18.35 & 15.40 & 1.19 \\
\hline 2 & 370 & 17.34 & 15.40 & 1.13 \\
\hline 3 & 657 & 14.93 & 15.50 & 0.96 \\
\hline 4 & 694 & 12.93 & 15.52 & 0.83 \\
\hline 5 & 958 & 12.22 & 15.73 & 0.78 \\
\hline 6 & 996 & 13.07 & 15.77 & 0.83 \\
\hline 7 & 1221 & 13.95 & 15.98 & 0.87 \\
\hline 8 & 1257 & 13.35 & 16.00 & 0.83 \\
\hline 9 & 1320 & 15.36 & 16.06 & 0.96 \\
\hline 10 & 1431 & 16.61 & 16.18 & 1.03 \\
\hline 11 & 1500 & 15.35 & 16.23 & 0.95 \\
\hline 12 & 1532 & 17.11 & 16.27 & 1.05 \\
\hline 13 & 1669 & 17.40 & 16.37 & 1.06 \\
\hline 14 & 1737 & 18.28 & 16.44 & 1.11 \\
\hline 15 & 1819 & 17.39 & 16.52 & 1.05 \\
\hline 16 & 1840 & 17.08 & 16.56 & 1.03 \\
\hline 17 & 1926 & 18.53 & 16.61 & 1.12 \\
\hline 18 & 1976 & 24.03 & 16.67 & 1.44 \\
\hline 19 & 2039 & 22.61 & 16.71 & 1.35 \\
\hline 20 & 2065 & 21.24 & 16.72 & 1.27 \\
\hline 21 & 2078 & 22.55 & 16.75 & 1.35 \\
\hline 22 & 2116 & 21.54 & 16.79 & 1.28 \\
\hline 23 & 2209 & 22.62 & 16.85 & 1.34 \\
\hline \multicolumn{4}{|c|}{ Min. Diff. (\%) } & 3.1 \\
\hline \multicolumn{4}{|c|}{ Max. Diff. (\%) } & 44 \\
\hline
\end{tabular}

The trend followed by Poiseuille number versus Reynolds number for $\mathrm{Ch} 7$ is illustrated in Figure 5.1. The laminar Po with developing flow curve in Figure 5.1 has been developed using Eqn. (A.1) in Appendix A. As mentioned, there is a decrease in Poiseuille number at low Reynolds numbers which might be an experimental error. On the other hand, there is an increasing $P o$ trend after approximately $R e$ of 1200 . The slope of the trend is almost equal to the slope of the Blasius equation which is given in Eqn. (5.1). Due to the uncertainties, it is difficult 
to find the critical Reynolds number exactly. However, there is a drastic increase in Poiseuille number around Reynolds number of 2000. Therefore, it is reasonable to say that the flow enters the transition regime at a Reynolds number between 1800 and 2000. Additionally, the increase in $P o$ after $R e$ equals to 1000 is probably due to hydrodynamically developing effect which showed higher gradient than predicted by conventional theory with developing flow.

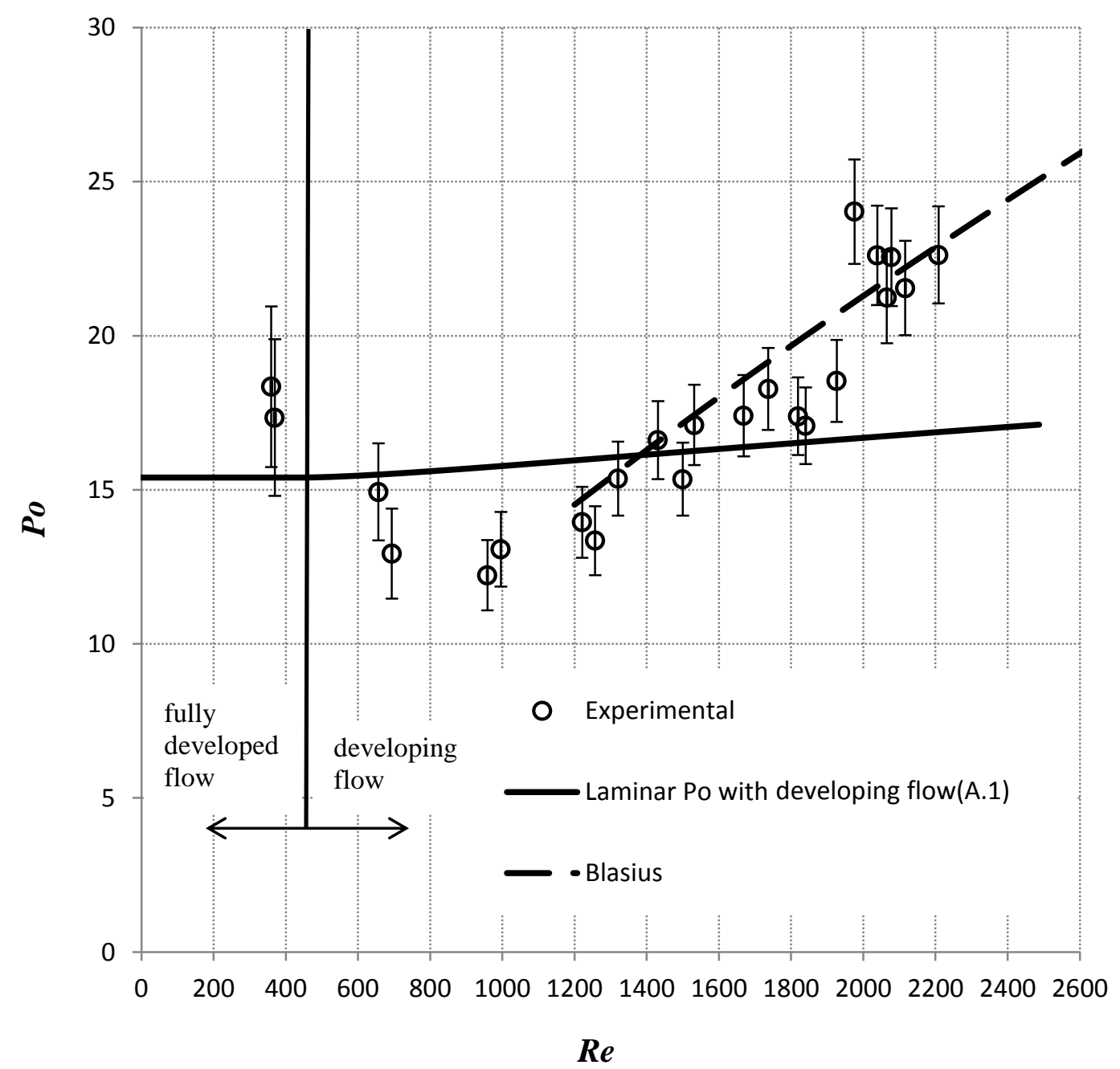

Figure 5.1 Poiseuille number versus Reynolds number for $\mathrm{Ch} 7$ 


\subsubsection{Minichannel 2 (Ch6)}

The experimental Poiseuille number and theoretical laminar Poiseuille number for Ch6 is given in Table 5.3 with numerical values. Similar to $\mathrm{Ch} 7$, there is a decrease in Poiseuille number in the range of small Reynolds numbers. The cause of this situation may be the same reasons which are poor mixing at the exit manifold and high uncertainty. The experimental results are within $10 \%$ of the theoretical values for $500<R e<1300$. An interesting point might be the difference between data 7 and data 8 which are repeated conditions. The results are within uncertainty limits but this indicates that pressure drop values are somewhat varying around theoretical values. On the contrary, data 3-4 and data 12-13 are also repeated condition pairs and show very good repeatability.

Table 5.3 Poiseuille number for Ch6

\begin{tabular}{c|c|c|c|c}
\hline Data & $\boldsymbol{R} \boldsymbol{e}$ & $\begin{array}{c}\boldsymbol{P} \boldsymbol{o}_{\text {exp }} \\
\left(\boldsymbol{f}_{\text {exp }} \boldsymbol{R} \boldsymbol{e}\right)\end{array}$ & $\begin{array}{c}\boldsymbol{P o}_{\text {theo }} \\
\left(\boldsymbol{f}_{\text {app }} \boldsymbol{R e}\right)\end{array}$ & $\boldsymbol{P o}_{\text {exp }} / \boldsymbol{P o}_{\text {theo }}$ \\
\hline 1 & 346 & 22.15 & 16.58 & 1.34 \\
\hline 2 & 429 & 20.24 & 16.59 & 1.22 \\
\hline 3 & 519 & 16.98 & 16.63 & 1.02 \\
\hline 4 & 521 & 17.86 & 16.63 & 1.07 \\
\hline 5 & 601 & 16.83 & 16.68 & 1.01 \\
\hline 6 & 687 & 15.92 & 16.74 & 0.95 \\
\hline 7 & 849 & 18.11 & 16.88 & 1.07 \\
\hline 8 & 855 & 15.92 & 16.88 & 0.94 \\
\hline 9 & 928 & 16.97 & 16.94 & 1.00 \\
\hline 10 & 1013 & 18.21 & 17.02 & 1.07 \\
\hline 11 & 1079 & 17.65 & 17.08 & 1.03 \\
\hline 12 & 1175 & 16.84 & 17.17 & 0.98 \\
\hline 13 & 1177 & 17.50 & 17.17 & 1.02 \\
\hline 14 & 1269 & 18.50 & 17.25 & 1.07 \\
\hline 15 & 1334 & 18.81 & 17.31 & 1.09 \\
\hline 16 & 1532 & 19.64 & 17.49 & 1.12 \\
\hline 17 & 1599 & 19.81 & 17.56 & 1.13 \\
\hline 18 & 1732 & 21.09 & 17.68 & 1.19 \\
\hline Min. Diff. (\%) & & & & 2.3 \\
Max. Diff. (\%) & & & & 34 \\
\hline
\end{tabular}


The trend followed by Poiseuille number versus Reynolds number for Ch 6 is illustrated in Figure 5.2. The laminar Po with developing flow curve in Figure 5.2 has been developed using Eqn. (A.1) in Appendix A. A drop explained previously is obvious for the first three data. For middle Reynolds number ranges, the Poiseuille number follows a roughly constant trend considering hydrodynamically developing effects on pressure. Ch6 has a smaller hydraulic diameter than Ch7. Therefore, the increase in Poiseuille number due to hydrodynamically developing effects is less than in Ch6 as observed in Figure 5.2. A possible early transition is investigated with the Blasius equation. Even though the Blasius equation shows strong agreement with last three data, this result may also be considered as an experimental reading error due to uncertainty or stronger hydrodynamically developing effects occur than predicted for conventional channels. Therefore, the minichannel agrees with constant Poiseuille theory if developing effect is taken into account and the trend is somewhat constant even though there is scatter and there is some deviation from theory. 


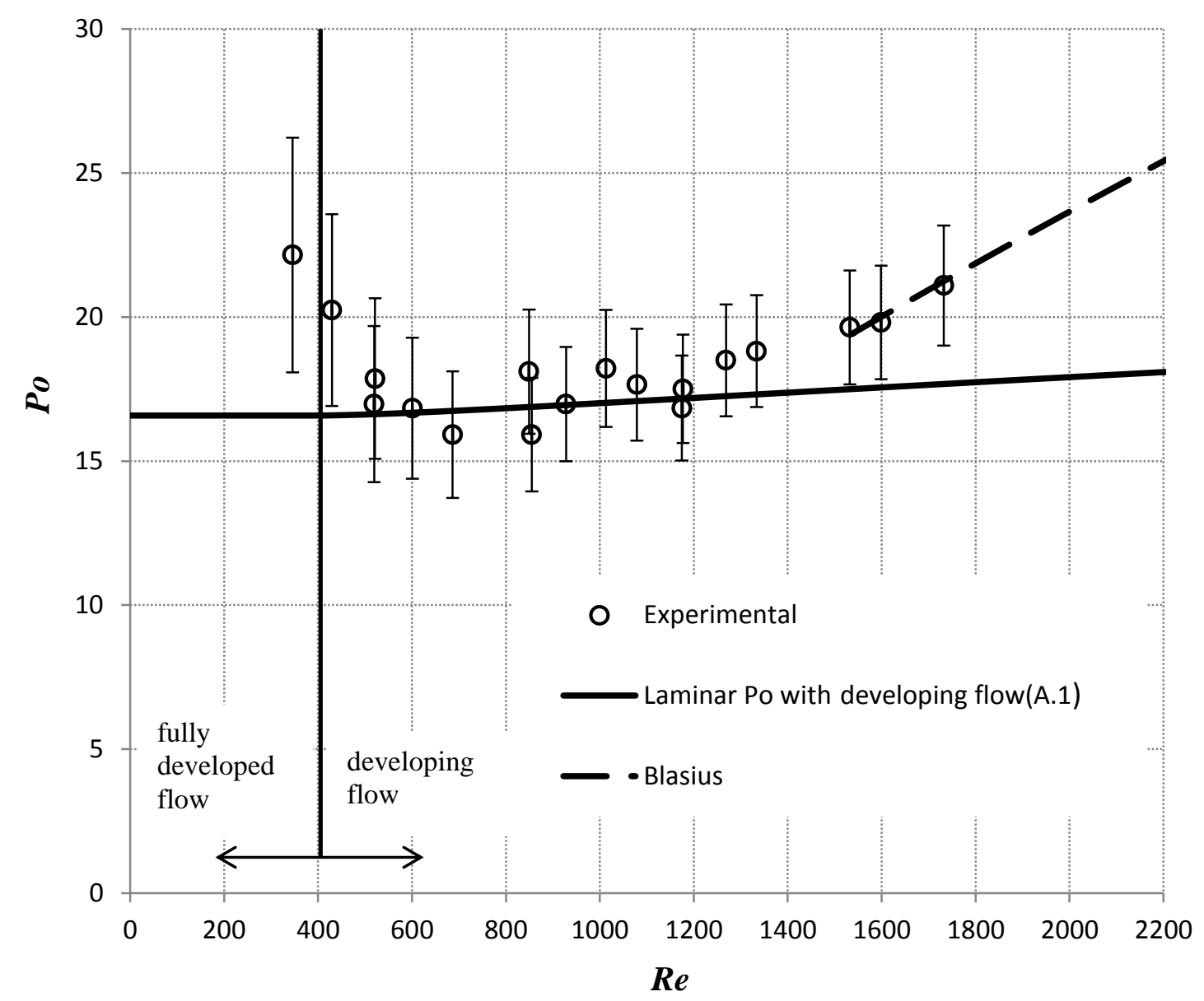

Figure 5.2 Poiseuille number versus Reynolds number for Ch6

\subsubsection{Minichannel 3 (Ch5)}

Experimental Poiseuille numbers and comparison with theory for $\mathrm{Ch} 5$ is presented in Table 5.4 with numerical values. Like the previous channels, the Poiseuille numbers for the first and second data are unreasonably high although they show great repeatability. Considering that $\mathrm{Ch} 5$ has the highest hydraulic diameter and smallest pressure drop, its uncertainty values are quite large particularly at low flow rates. Therefore, this large Poiseuille number for the first and second conditions might be explained with similar reasons with the previous channels. On the other hand, other than these three data all values are within $20 \%$ error limits of conventional theory. 
Table 5.4 Poiseuille number for Ch5

\begin{tabular}{c|ccc|c}
\hline Data & $\boldsymbol{R e}$ & $\begin{array}{c}\text { Po } \boldsymbol{e}_{\text {exp }} \\
\left(\boldsymbol{f}_{\text {exp }} \boldsymbol{R e}\right)\end{array}$ & $\begin{array}{c}\boldsymbol{P o}_{\text {theo }} \\
\left(\boldsymbol{f}_{\text {app }} \boldsymbol{R e}\right)\end{array}$ & $\boldsymbol{P o}_{\text {exp }} / \boldsymbol{P o}_{\text {theo }}$ \\
\hline 1 & 277 & 24.83 & 15.45 & 1.61 \\
\hline 2 & 330 & 24.89 & 15.45 & 1.61 \\
\hline 3 & 413 & 16.25 & 15.45 & 1.05 \\
\hline 4 & 413 & 20.12 & 15.45 & 1.30 \\
\hline 5 & 489 & 18.13 & 15.46 & 1.17 \\
\hline 6 & 551 & 14.13 & 15.48 & 0.91 \\
\hline 7 & 600 & 16.73 & 15.51 & 1.08 \\
\hline 8 & 702 & 13.54 & 15.58 & 0.87 \\
\hline 9 & 698 & 14.99 & 15.58 & 0.96 \\
\hline 10 & 833 & 12.77 & 15.69 & 0.81 \\
\hline 11 & 880 & 15.28 & 15.73 & 0.97 \\
\hline 12 & 980 & 12.98 & 15.81 & 0.82 \\
\hline 13 & 982 & 14.52 & 15.81 & 0.92 \\
\hline 14 & 1057 & 15.06 & 15.88 & 0.95 \\
\hline 15 & 1131 & 13.83 & 15.95 & 0.87 \\
\hline 16 & 1224 & 13.88 & 16.04 & 0.87 \\
\hline 17 & 1321 & 15.66 & 16.13 & 0.97 \\
\hline 18 & 1378 & 13.87 & 16.18 & 0.86 \\
\hline Min. Diff. (\%) & & & & 2.8 \\
\hline Max. Diff. (\%) & & & & 61 \\
\hline & & & & \\
\hline
\end{tabular}

The trend followed by Poiseuille number versus Reynolds number for Ch5 is illustrated in Figure 5.3. The laminar Po with developing flow curve in Figure 5.3 has been developed using Eqn. (A.1) in Appendix A. There is a decreasing trend observed up to a Reynolds number of 700. For Reynolds number larger than 700, the theory slightly over estimates experimental values. The deviation from theory is approximately $10 \%$. However, the constant trend is obvious for $R e>700$. No signs of early transition to turbulent regime are observed for Ch5. Additionally, it is important to note that an increase in Po due to hydrodynamically developing effects is not evident. The reason behind this is the axial dimensionless number $\left(x^{+}\right)$is generally large for most of the data given in Table 5.1 owing to a larger hydraulic diameter. 


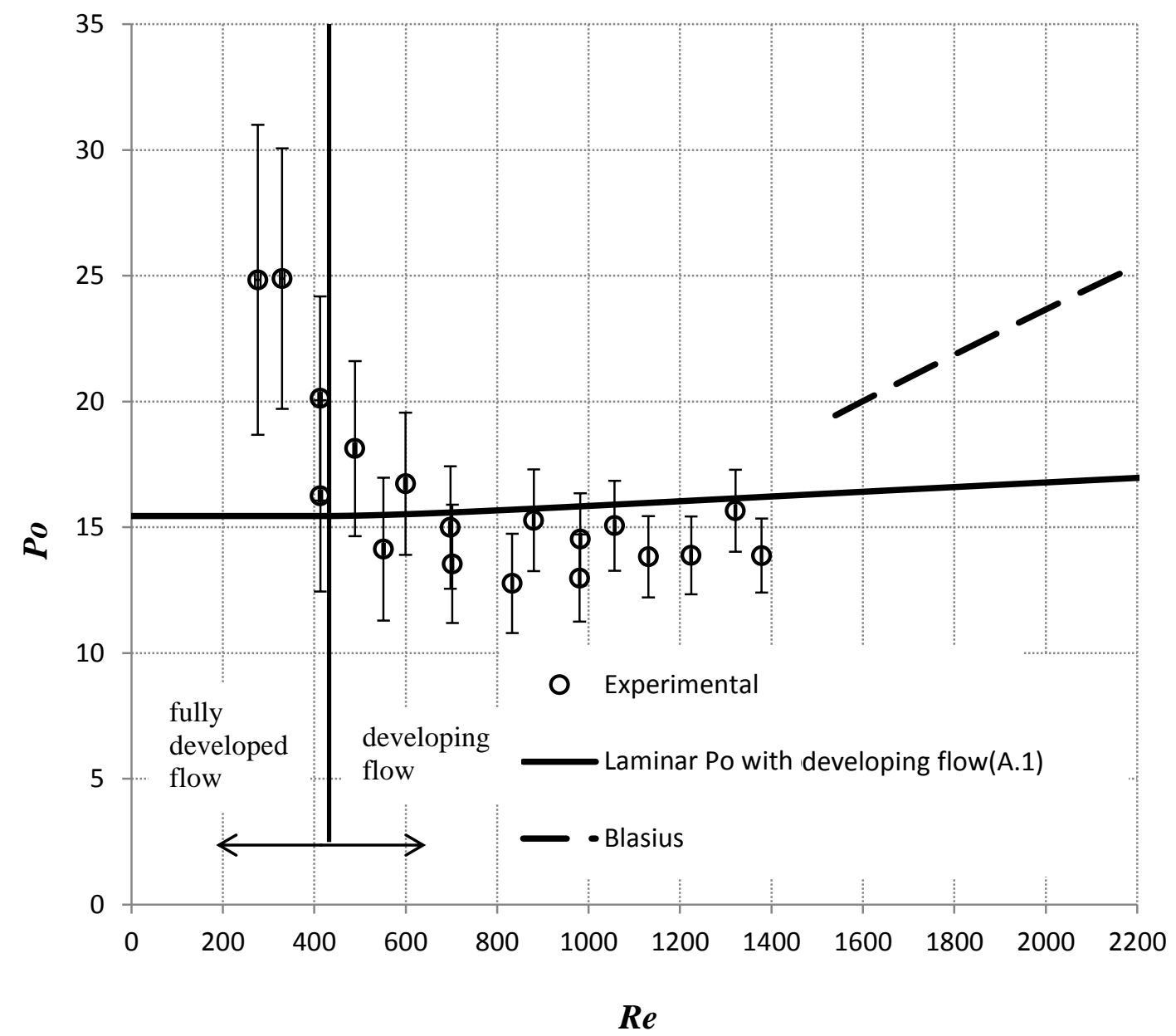

Figure 5.3 Poiseuille number versus Reynolds number for Ch5

\subsubsection{Comparision of Minichannels}

The theoretical values of Poiseuille number are different for each minichannel due to different aspect ratios. Therefore, the experimental $P o$ values are normalized by dividing them by their theoretical Po values. Figure 5.4 shows this normalized term for all minichannels at different Reynolds numbers for all data points. It is important to note that laminar Po values with developing flow effects from Table 2.2 are used as for the theoretical value. 
For the early laminar range, there is a decreasing trend at a Reynolds number range of $250<R e<700$ as noted before. In contrast, $P o$ for all the minichannels shows a somewhat constant trend with slightly increasing slope for Ch6 and Ch7 for Reynolds number higher than 700. Additionally, almost all data is within a $20 \%$ range for the Reynolds number range $700<R e<1800$. For this $R e$ interval, $P o$ for Ch7 shows the highest incline slope due to developing effects. This situation explains that there is a larger developing effect than predicted by theory for minichannels having hydraulic diameter around Ch7. Due to having a larger hydraulic diameter than $\mathrm{Ch} 7$, the incline slope of $\mathrm{Po}$ for flow inside Ch6 is smaller than Ch7. Having the largest hydraulic diameter, Ch5 has almost no incline trend for Reynolds numbers higher than 700. This means the experimental results and theory are in good agreement for Ch5. Considering the largest uncertainties for Po and taking developing effects into account, constant $P o$ theory holds for the tested minichannels and no unexpected deviations are present in the study. Furthermore, no signs of early transition up to a Reynolds number of 1700 are observed.

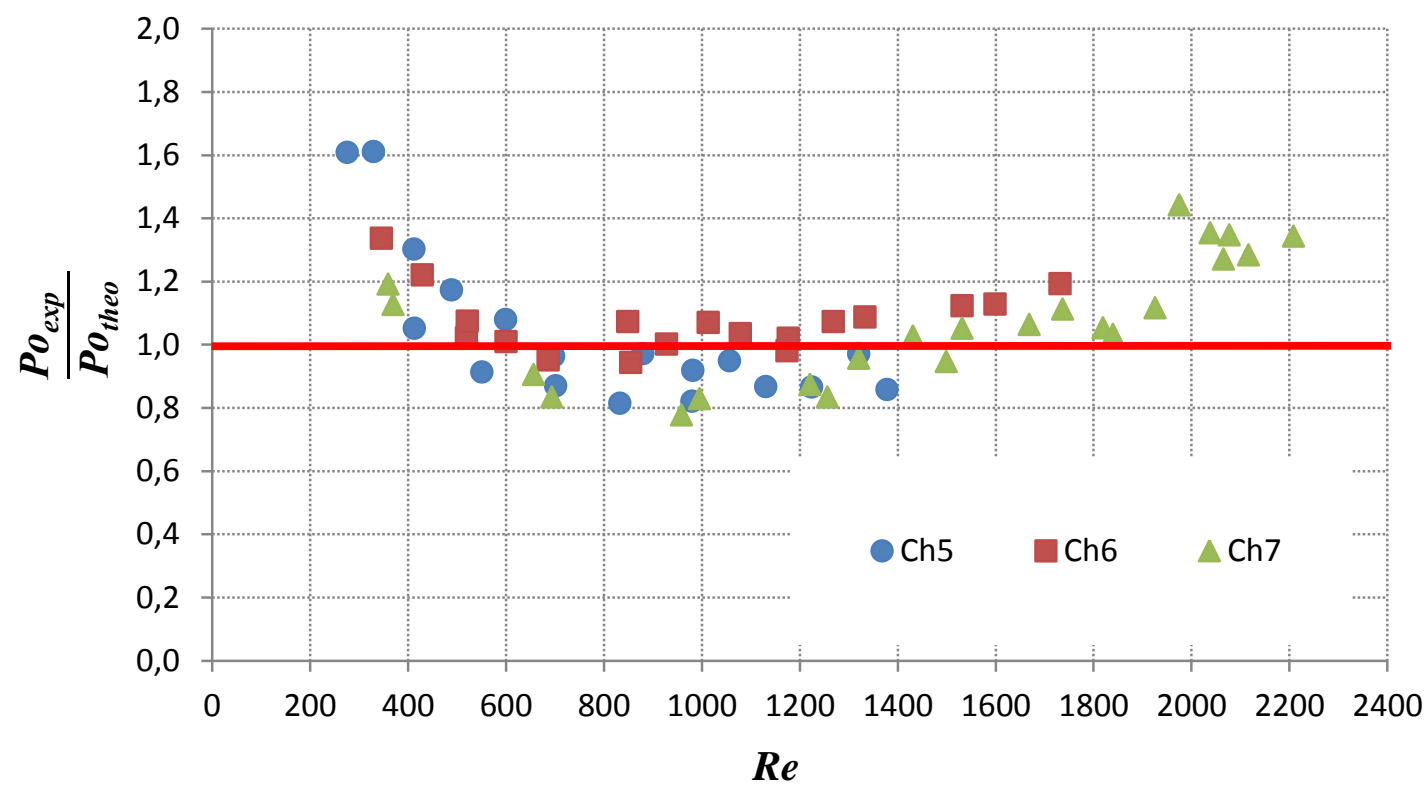

Figure 5.4 Experimental $P o$ to theoretical $P o$ ratio for all minichannels 


\subsection{Heat Transfer}

In this section, heat transfer experimental results of single phase flow inside minichannels obtained after data reduction are presented. The experimental results are compared with two types of correlations: conventional correlations and small scale correlations. These correlations are listed in Table 2.6 and Table 2.7. It is important to note that some characteristics of the correlations do not match with the tested channels. To be more specific, some of the correlations are for different geometries like circular channels while the boundary condition of several correlations is constant wall temperature. Furthermore, some correlations are for thermally developing or simultaneously developing flow whereas other correlations are suggested to evaluate heat transfer for fully developed flow. Nevertheless, there are articles $[22,28]$ reporting that some of these correlations well predicted experimental data for flow in small scale channels even though the conditions of the experiments are not the same as with the correlations. As a consequence, the agreement of several correlations is examined with the experimental data despite this situation. The results are presented in tabular and graphical form. The data in the tables and graphs are close to each other but not identical in terms of correlations results, because the Prandtl numbers are not identical even though they are very close. The exact Prandtl number of the experimental data was used for the correlations results in Tables. However, Prandtl number for data of a minichannel is arithmetically averaged for correlations in graphs so as to clearly observe the trend without any tiny jumps and dips. Similar to the fluid flow section, a turbulent correlation is also applied to graphs to investigate any possible transition to the turbulent regime. The Gnielinski correlation [13] is used as the turbulent correlation due to its wide acceptance in the literature. It should be noted that there are two correlations named as Gnielinski in graphs as one of them is for laminar flow [29]. The turbulent Gnielinski correlation is as given in Eqn. (5.2)

$$
N u_{f d}=\frac{\left(f_{t} / 2\right)(R e-1000) P r}{\left.1+12.7\left(f_{t} / 2\right)^{1 / 2}\left(\operatorname{Pr}^{2 / 3}-1\right)\right)}
$$


where $f_{t}$ is the fanning friction factor for turbulent flow and given in Eqn. (5.3)

$$
4 f_{t}=(1.82 \ln R e-1.64)^{-2}
$$

Additionally, note that all data in the experiments are in thermally developing region because $\mathrm{x}^{*}<1.0$ for all data for all minichannels. This situation will be discussed in details for each minichannels separately.

\subsubsection{Minichannel $1(\mathrm{Ch} 7)$}

The experimental average Nusselt number results and its comparison with conventional correlations are presented in Table 5.5 and shown in Figure 5.5. The single phase liquid flow inside the channels is thermally developing for most of the data. Therefore, thermally developing Nusselt numbers in Table 2.5 are also found meaningful in terms of comparison despite the fact that these Nusselt numbers are local Nusselt numbers. The other correlations in Table 5.5 are average Nusselt numbers for thermally developing or simultaneously developing flow except for the last correlation presented which is for fully developed flow in rectangular channels suggested by Shah and London [5] as demonstrated in Eqn. (2.14). The other correlations can be viewed in Table 2.6. While presenting experimental Nusselt numbers in Table 5.5, the ratio of calculated Nusselt number to experimental Nusselt number is applied for correlations in order to view the difference between experiments and correlations numerically. Nusselt numbers show an incline for early $R e$ range, up to a Reynolds number of 700 , which contradicts the constant $\mathrm{Nu}$ theory. All correlations failed to predict the data for this $R e$ range. For low flow rates, the logarithmic mean temperature differences are smaller and therefore uncertainties in temperature measurements are magnified. Additionally, Figure 4.1 states that more energy lost to surroundings at low Re which is also another reason of deviation of Nusselt numbers. At the middle $R e$ range, the Nusselt number shows good agreement with the fully developed Shah and London correlation and thermally developing Nusselt numbers. On the other hand, the other correlations overestimated the results by approximately $50 \%$. This difference is likely due to different geometry conditions. If a scaling factor is applied to the other correlations, they would predict the 
experimental $\overline{N u}$ since their trends are similar to the experimental $\overline{N u}$. The Shah and London correlation for thermally developing flow and laminar Gnielinski correlation demonstrate a very similar trend with the experimental data. For instance, the Shah and London correlation for thermally developing flow predicts the results quite well if a scaling constant of approximately 0.68 is applied. For such a case, the experimental $\overline{N u}$ would be predicted within $10 \%$ limits for a Reynolds number range $400<\operatorname{Re}<1800$, which is the smallest deviation between predicted and experimental results among the correlations. Similar statements can be made for the laminar Gnelinski correlation. Same can be considered for laminar Gnelinski correlation.

Figure 5.5 illustrates the average Nusselt number trends for a range of Reynolds numbers. As mentioned above, there is an increase in average Nusselt number for low $R e$. Several researchers [20,22,24] found a similar increase of $N u$ at low $R e$ ranges. Stronger thermally developing effects than expected might also be the reason for this incline in the low Re range in addition to experimental errors. Around a Reynolds number of approximately 1800, a drastic incline in $\overline{N u}$ occurred as demonstrated in Figure 5.5. To follow and compare the trend with the turbulent Gnielinski correlation, the correlation is divided by 2.2 for only $\mathrm{Ch} 7$. To put it differently, Gnielinski correlation predictions in Figure 5.5 are shifted by multiplying them with a constant equal to $1 / 2.2$. The Gnielinski correlation shows excellent agreement with data after a Reynolds number of 1800. Thus, flow enters the turbulence region around $R e=1800$, which is consistent with the fluid flow results and therefore lends strength to this conclusion. 
Table 5.5 Experimental and calculated $\overline{N u}$ using conventional correlations(Ch7)

\begin{tabular}{|c|c|c|c|c|c|c|c|}
\hline $\operatorname{Re}$ & Exp. $^{1}$ & $\begin{array}{l}\text { Theo. }^{2} \\
\text { /Exp }\end{array}$ & $\begin{array}{c}\text { S\&P HF } \\
\text { /Exp }\end{array}$ & $\begin{array}{c}\text { S\&P WT } \\
\text { /Exp }\end{array}$ & $\begin{array}{c}\text { S\&L TD } \\
\quad / \operatorname{Exp}\end{array}$ & $\begin{array}{l}\text { Gni. }^{6} \\
\text { /Exp }\end{array}$ & $\begin{array}{c}\text { S\&L FD }^{7} \\
\quad / \operatorname{Exp}\end{array}$ \\
\hline 360 & 2.44 & 1.54 & 1.64 & 1.98 & 1.93 & 1.64 & 1.52 \\
\hline 370 & 2.53 & 1.49 & 1.58 & 1.90 & 1.86 & 1.57 & 1.46 \\
\hline 657 & 3.03 & 1.26 & 1.44 & 1.71 & 1.64 & 1.42 & 1.23 \\
\hline 694 & 3.25 & 1.18 & 1.35 & 1.60 & 1.53 & 1.33 & 1.14 \\
\hline 958 & 3.50 & 1.11 & 1.36 & 1.58 & 1.50 & 1.33 & 1.06 \\
\hline 996 & 3.58 & 1.09 & 1.33 & 1.54 & 1.47 & 1.30 & 1.04 \\
\hline 1221 & 3.86 & 1.03 & 1.33 & 1.50 & 1.42 & 1.28 & 0.96 \\
\hline 1257 & 3.66 & 1.08 & 1.41 & 1.58 & 1.50 & 1.34 & 1.01 \\
\hline 1320 & 3.77 & 1.06 & 1.42 & 1.58 & 1.50 & 1.35 & 0.98 \\
\hline 1431 & 3.85 & 1.05 & 1.43 & 1.57 & 1.49 & 1.35 & 0.96 \\
\hline 1500 & 3.73 & 1.09 & 1.48 & 1.62 & 1.54 & 1.39 & 0.99 \\
\hline 1532 & 3.55 & 1.15 & 1.56 & 1.70 & 1.61 & 1.46 & 1.04 \\
\hline 1669 & 4.05 & 1.02 & 1.40 & 1.51 & 1.43 & 1.30 & 0.92 \\
\hline 1737 & 4.21 & 0.99 & 1.42 & 1.51 & 1.43 & 1.31 & 0.88 \\
\hline 1819 & 4.07 & 1.03 & 1.49 & 1.57 & 1.49 & 1.37 & 0.91 \\
\hline 1840 & 4.36 & 0.96 & 1.40 & 1.47 & 1.39 & 1.28 & 0.85 \\
\hline 1926 & 4.70 & 0.90 & 1.32 & 1.37 & 1.31 & 1.20 & 0.79 \\
\hline 1976 & 5.38 & 0.79 & 1.18 & 1.22 & 1.16 & 1.07 & 0.69 \\
\hline 2039 & 5.15 & 0.83 & 1.21 & 1.25 & 1.19 & 1.09 & 0.72 \\
\hline 2065 & 5.46 & 0.78 & 1.20 & 1.22 & 1.17 & 1.07 & 0.68 \\
\hline 2078 & 5.31 & 0.80 & 1.21 & 1.24 & 1.18 & 1.09 & 0.70 \\
\hline 2116 & 5.53 & 0.77 & 1.15 & 1.18 & 1.12 & 1.03 & 0.67 \\
\hline 2209 & 5.78 & 0.75 & 1.15 & 1.16 & 1.11 & 1.02 & 0.64 \\
\hline \multicolumn{2}{|c|}{ Min. Diff. (\%) } & 1.9 & 15 & 16 & 11 & 2.4 & 0.8 \\
\hline \multicolumn{2}{|c|}{ Max. Diff. (\%) } & 54 & 64 & 98 & 93 & 64 & 52 \\
\hline
\end{tabular}

${ }^{\mathrm{T}}$ Exp. indicates experimental results

${ }^{2}$ Theo.indicates theoretical results with thermally developing flow (2.19)

${ }^{3}$ S\&P HF indicates Stephan \& Preusser with CHF boundary condition (2.20)

${ }^{4}$ S\&P WT indicates Stephan \& Preusser with CWT boundary condition (2.21)

${ }^{5}$ S\&L TD İndicates Shah and London with thermally developing flow (2.22)

${ }^{6} \mathrm{Gni}$. İndicates Gnielinski laminar flow (2.23)

${ }^{7}$ S\&L FD indicates Shah and London fully developed flow (2.14) 


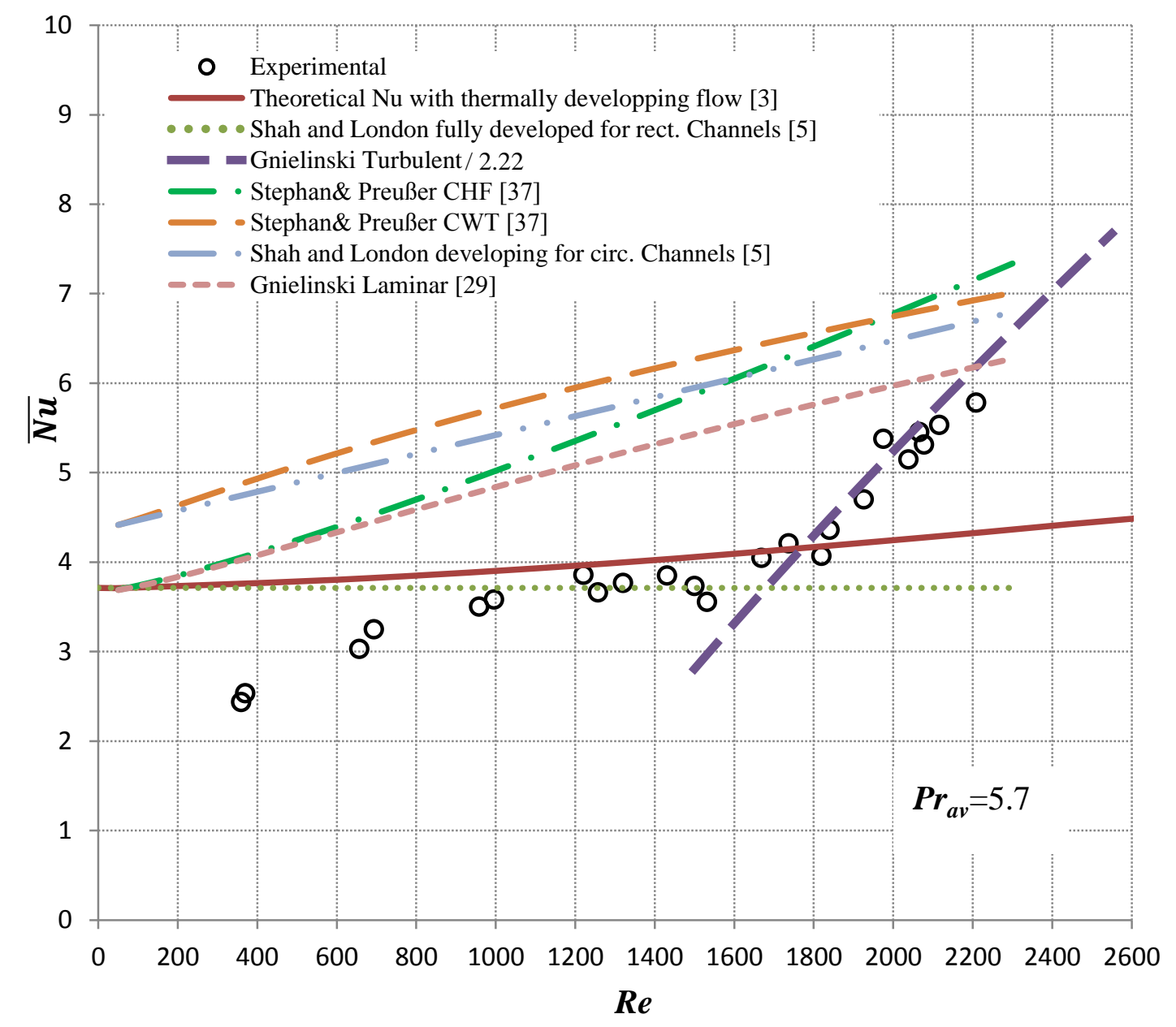

Figure 5.5 Experimental average Nusselt number and calculated Nusselt number through conventional correlations versus Reynolds number (Ch7)

Table 5.6 presents the experimental $\overline{N u}$ results and ratio of predicted $\overline{N u}$ number from small scale correlations to experimental results. The small scale channel correlations extremely overestimate the $\overline{N u}$ results. Choi's correlation and Garimella's correlation predicted heat transfers more than two times while Peng et al.'s correlation goes as high as four times the experimental $\overline{N u}$ results for several data. Figure 5.6 displays the experimental and calculated $\overline{N u}$ from small scale correlations. Only Weng and Peng's correlation somewhat follows the experimental $\overline{N u}$ trend. However, it also overestimates the data roughly by $30 \%$ for the middle $R e$ range. Unlike small scale correlations, experimental $\overline{N u}$ values for $\mathrm{Ch} 7$ are independent of $R e$ excluding developing effects. 
Table 5.6 Experimental and calculated $\overline{N u}$ using small scale correlations (Ch7)

\begin{tabular}{|c|c|c|c|c|c|}
\hline $\boldsymbol{R e}$ & Exp. & $\begin{array}{c}\text { Choi et al. } \\
\text { [38] } \\
\text { /Exp. }\end{array}$ & $\begin{array}{c}\text { Peng et al. } \\
\text { [14] } \\
\text { /Exp. }\end{array}$ & $\begin{array}{c}\text { Wang } \\
\text { \&Peng } \\
{[12]} \\
\text { /Exp. }\end{array}$ & $\begin{array}{l}\text { Garimella[19] } \\
\text { /Exp. }\end{array}$ \\
\hline 360 & 2.44 & 0.71 & 2.56 & 0.66 & 1.58 \\
\hline 370 & 2.53 & 0.69 & 2.48 & 0.64 & 1.52 \\
\hline 657 & 3.03 & 1.14 & 2.98 & 0.86 & 1.43 \\
\hline 694 & 3.25 & 1.11 & 2.81 & 0.82 & 1.34 \\
\hline 958 & 3.50 & 1.53 & 3.24 & 1.00 & 1.50 \\
\hline 996 & 3.58 & 1.54 & 3.20 & 0.99 & 1.49 \\
\hline 1221 & 3.86 & 1.84 & 3.41 & 1.10 & 1.65 \\
\hline 1257 & 3.66 & 1.99 & 3.62 & 1.17 & 1.76 \\
\hline 1320 & 3.77 & 2.10 & 3.72 & 1.22 & 1.84 \\
\hline 1431 & 3.85 & 2.25 & 3.82 & 1.27 & 1.95 \\
\hline 1500 & 3.73 & 2.41 & 3.99 & 1.33 & 2.08 \\
\hline 1532 & 3.55 & 2.58 & 4.21 & 1.41 & 2.20 \\
\hline 1669 & 4.05 & 2.47 & 3.84 & 1.31 & 2.09 \\
\hline 1737 & 4.21 & 2.58 & 3.94 & 1.35 & 2.20 \\
\hline 1819 & 4.07 & 2.80 & 4.17 & 1.44 & 2.38 \\
\hline 1840 & 4.36 & 2.64 & 3.90 & 1.36 & 2.24 \\
\hline 1926 & 4.70 & 2.58 & 3.72 & 1.30 & 2.18 \\
\hline 1976 & 5.38 & 2.35 & 3.34 & 1.17 & 1.98 \\
\hline 2039 & 5.15 & 2.46 & 3.44 & 1.22 & 2.06 \\
\hline 2065 & 5.46 & 2.45 & 3.39 & 1.20 & 2.07 \\
\hline 2078 & 5.31 & 2.49 & 3.44 & 1.22 & 2.10 \\
\hline 2116 & 5.53 & 2.39 & 3.28 & 1.17 & 2.01 \\
\hline 2209 & 5.78 & 2.47 & 3.30 & 1.18 & 2.09 \\
\hline \multicolumn{2}{|c|}{ Min. Diff. (\%) } & 11 & 148 & 0.3 & 34 \\
\hline \multicolumn{2}{|c|}{ Max. Diff. (\%) } & 180 & 321 & 44 & 124 \\
\hline
\end{tabular}

The local Nusselt number versus dimensionless axial thermal distance which is the reciprocal of Graetz $\operatorname{Number}\left(x^{*}=1 / G z=x /\left(D_{h} \operatorname{Re} \operatorname{Pr}\right)\right)$ is illustrated in Figure 5.7. The purpose of this graph is to determine the effect of axial distance on local $\mathrm{Nu}$ and visualize the thermal developing effect along the channel. It is important to note that $R e$ and $x$ is different for each thermocouple for a constant $x^{*}$ value. The scatter at low $x^{*}$ is obvious especially for the first and the last thermocouple for each minichannel. The reason for this is flow becomes turbulent at the end of the channel and thus the 
local Nusselt number increases significantly. The thermal entry length of turbulent flow is very small compared to laminar flow. Thus, thermally developing effects are not as important for turbulent flow as observed for TC5 and TC6. Therefore, the steep incline in $N u$ at low $x^{*}$ is due to the dependency on $R e$ rather than thermally developing effects. The local Nusselt number does not converge to a value for the $x^{*}$ range of $0<x^{*}<0.24$. As a result, the flow is not fully developed for any data along the channel because $x^{*}<1.0$ even when experimental errors are considered as expected. Generally, a good precision is observed for local $N u$ for each local $N u$ at each of the thermocouple locations.

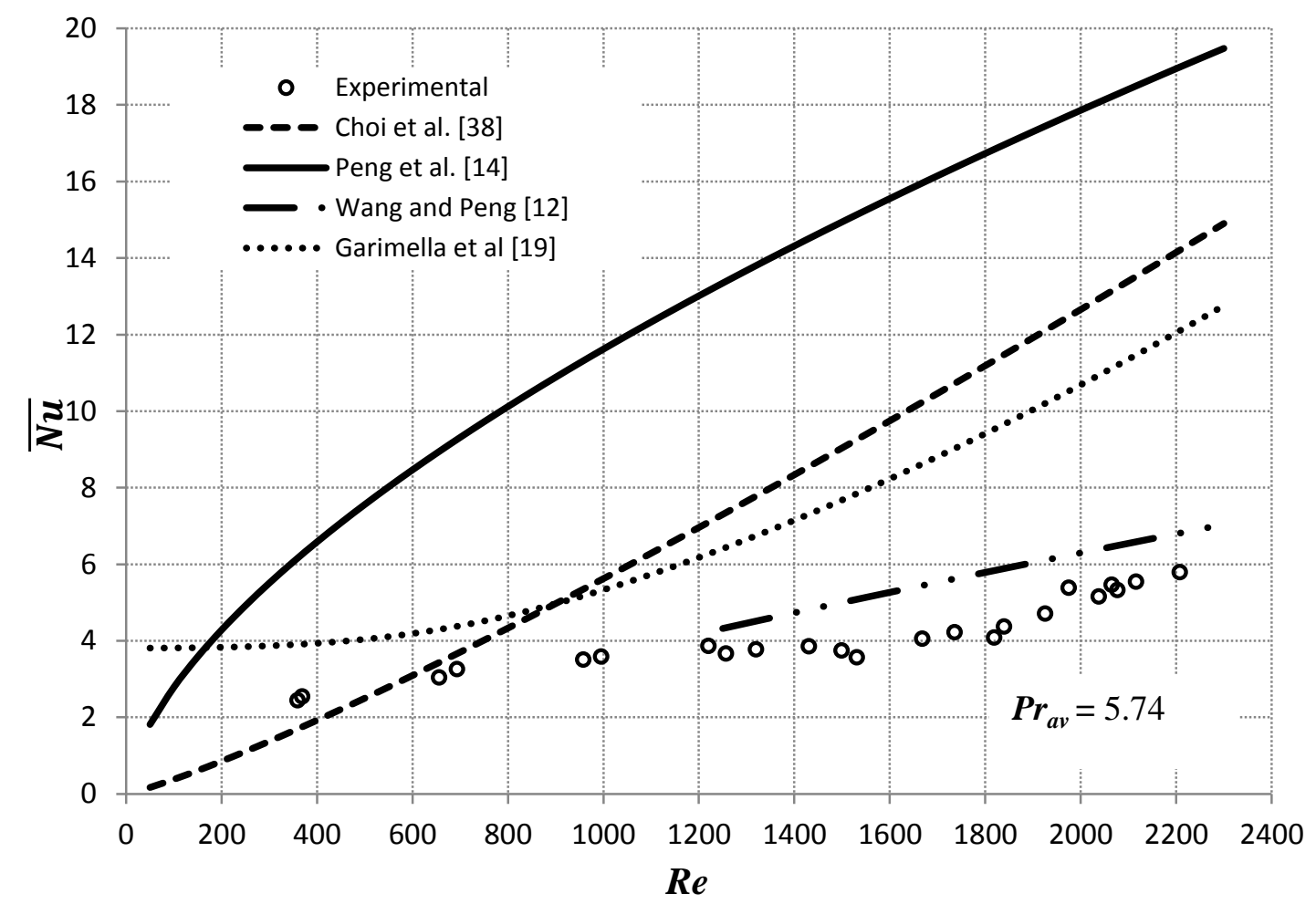

Figure 5.6 Experimental average Nusselt number and calculated Nusselt number using small scale correlations versus Reynolds number (Ch7) 


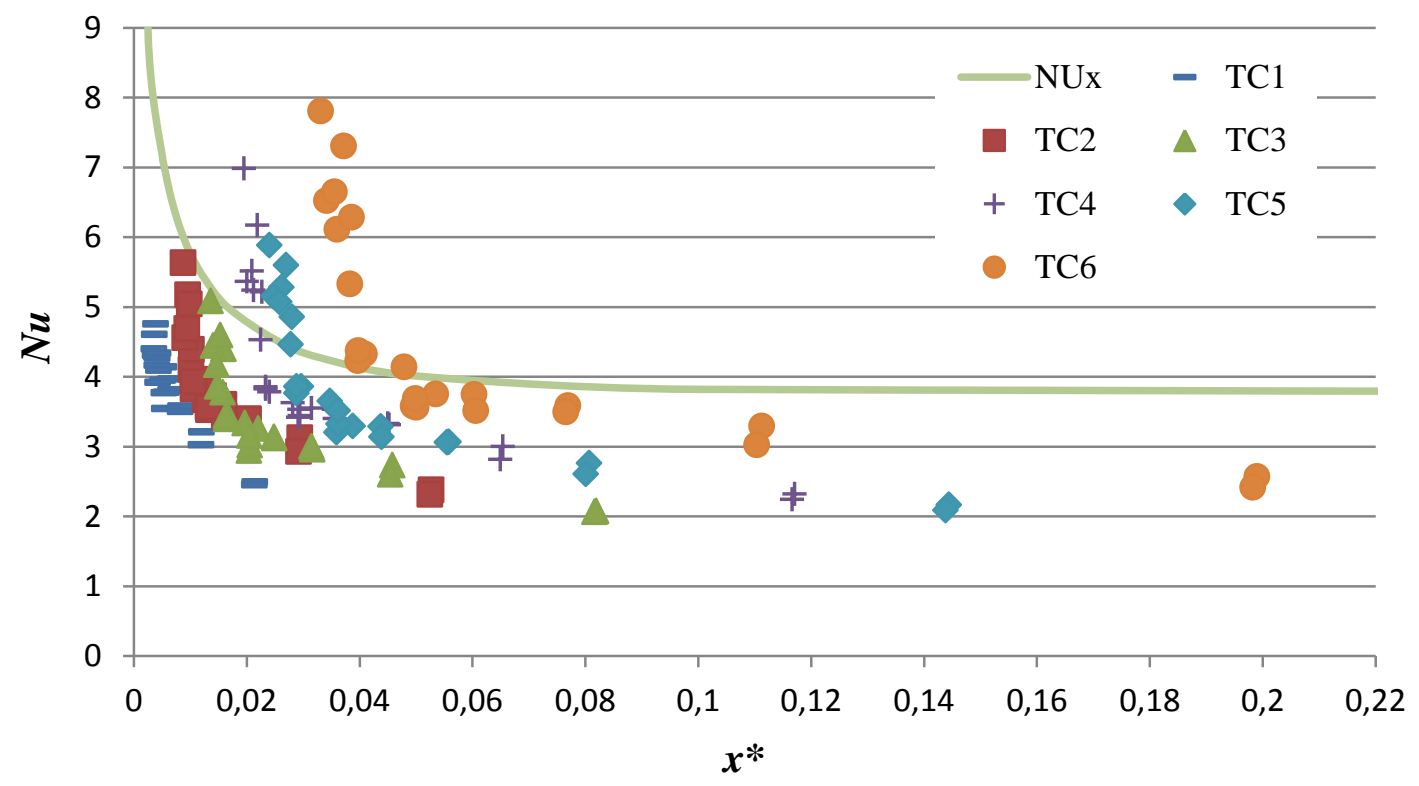

Figure 5.7 Local Nusselt number versus $x^{*}(\mathrm{Ch} 7)$

\subsubsection{Minichannel 2 (Ch6)}

Experimental $\overline{N u}$ results and the ratio of calculated theoretical $\overline{N u}$ from conventional correlations to experimental $\overline{N u}$ are listed in Table 5.7. The theoretical correlations show very good agreement with experimental results. The laminar Gnielinski correlation and the Stephan and Preusser correlation for constant heat flux condition provide predictions within approximately $10 \%$ deviation limits. Furthermore, theoretical values for thermally developing laminar flow also show good agreement with experimental $\overline{N u}$. The worst match is found for the fully developed Shah and London correlation for high Reynolds number range because of developing region effects. 
Table 5.7 Experimental and calculated $\overline{N u}$ using conventional correlations (Ch6)

\begin{tabular}{|c|c|c|c|c|c|c|c|}
\hline$R e$ & Exp. $^{1}$ & $\begin{array}{c}\text { Theo. }^{2} \\
\text { /Exp }\end{array}$ & $\begin{array}{c}\text { S\&P HF } \\
\text { /Exp }\end{array}$ & $\begin{array}{c}\text { S\&P WT }^{4} \\
/ \text { Exp }\end{array}$ & $\begin{array}{c}\text { S\&L TD } \\
\text { /Exp }\end{array}$ & $\begin{array}{l}\text { Gni. }^{6} \\
/ \text { Exp }\end{array}$ & $\begin{array}{c}\text { S\&L FD } \\
\text { /Exp }\end{array}$ \\
\hline 346 & 4.02 & 1.12 & 1.00 & 1.21 & 1.18 & 1.00 & 1.11 \\
\hline 429 & 4.55 & 1.00 & 0.91 & 1.09 & 1.06 & 0.90 & 0.98 \\
\hline 519 & 4.41 & 1.03 & 0.97 & 1.16 & 1.11 & 0.96 & 1.01 \\
\hline 521 & 4.34 & 1.05 & 0.98 & 1.17 & 1.13 & 0.97 & 1.03 \\
\hline 601 & 4.75 & 0.96 & 0.92 & 1.10 & 1.05 & 0.91 & 0.94 \\
\hline 687 & 4.88 & 0.94 & 0.93 & 1.09 & 1.04 & 0.91 & 0.92 \\
\hline 849 & 5.24 & 0.88 & 0.91 & 1.06 & 1.01 & 0.89 & 0.85 \\
\hline 855 & 4.99 & 0.92 & 0.96 & 1.11 & 1.06 & 0.93 & 0.89 \\
\hline 928 & 4.92 & 0.94 & 1.00 & 1.15 & 1.09 & 0.97 & 0.91 \\
\hline 1013 & 5.52 & 0.84 & 0.91 & 1.04 & 0.99 & 0.88 & 0.81 \\
\hline 1079 & 4.98 & 0.94 & 1.04 & 1.17 & 1.11 & 1.00 & 0.90 \\
\hline 1175 & 5.08 & 0.92 & 1.05 & 1.17 & 1.11 & 1.00 & 0.88 \\
\hline 1177 & 4.97 & 0.94 & 1.07 & 1.20 & 1.13 & 1.02 & 0.90 \\
\hline 1269 & 5.20 & 0.91 & 1.05 & 1.16 & 1.10 & 1.00 & 0.86 \\
\hline 1334 & 5.24 & 0.90 & 1.07 & 1.17 & 1.11 & 1.01 & 0.85 \\
\hline 1532 & 5.42 & 0.88 & 1.09 & 1.16 & 1.10 & 1.01 & 0.82 \\
\hline 1599 & 5.49 & 0.88 & 1.11 & 1.16 & 1.11 & 1.02 & 0.81 \\
\hline 1732 & 5.71 & 0.85 & 1.09 & 1.13 & 1.08 & 0.99 & 0.78 \\
\hline \multicolumn{2}{|c|}{ Min. Diff. (\%) } & 0 & 0 & 4 & 1 & 0 & 1 \\
\hline \multicolumn{2}{|c|}{ Max. Diff. (\%) } & 15 & 11 & 21 & 18 & 12 & 22 \\
\hline
\end{tabular}

${ }^{1}$ Exp. indicates experimental results

${ }^{2}$ Theo.indicates theoretical results with thermally developing flow (2.19)

${ }^{3}$ S\&P HF indicates Stephan \& Preusser with CHF boundary condition (2.20)

${ }^{4}$ S\&P WT indicates Stephan \& Preusser with CWT boundary condition (2.21)

${ }^{5}$ S\&L TD İndicates Shah and London with thermally developing flow (2.22)

${ }^{6} \mathrm{Gni}$. İndicates Gnielinski laminar flow (2.23)

${ }^{7}$ S\&L FD indicates Shah and London fully developed flow (2.14)

Figure 5.8 illustrates experimental $\overline{N u}$ and conventional $\overline{N u}$ values predicted using conventional correlations versus Reynolds number. The laminar Gnielinski follows the experimental data closely. Other conventional correlations are also showing good agreement with the experimental $\overline{N u}$. On the other hand, the thermally developing effect is clearly seen in experimental $\overline{N u}$. Note that all data for $\mathrm{Ch} 7$ are in thermally developing region. This effect is found to be higher than the theoretical $\overline{N u}$ with developing flow. On the other hand, it should be noted that the slope of the increase due to thermally developing effects is lower compared to $\mathrm{Ch} 7$. The turbulent 
Gnielinski correlation without a scaling constant is also displayed in Figure 5.8. According to its trend, there is no sign of early transition to turbulent flow in this Reynolds range, $250<R e<1800$. Furthermore, the repeated data show good precision.

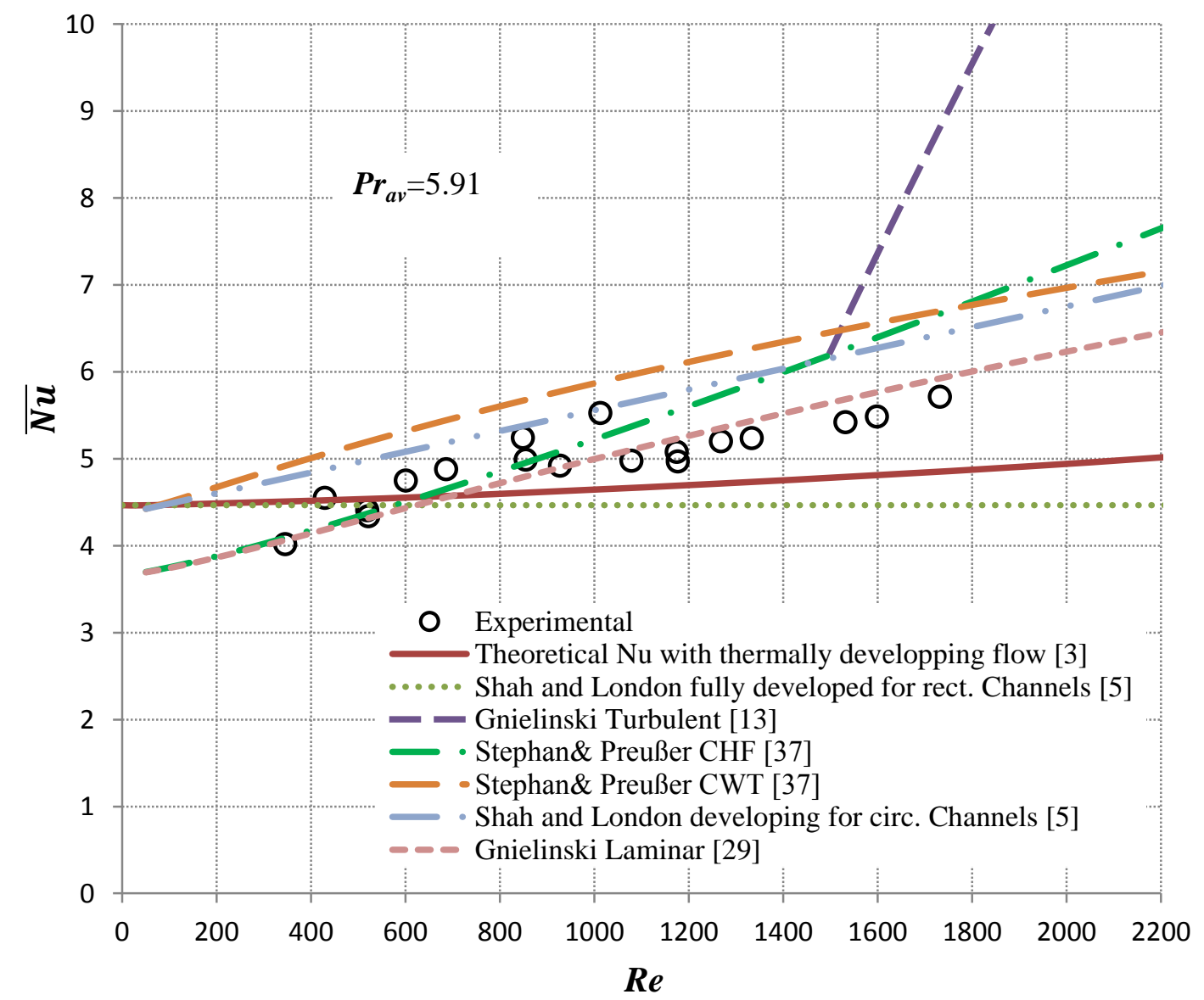

Figure 5.8 Experimental average Nusselt number and calculated Nusselt number through conventional correlations versus Reynolds number (Ch6)

The comparison of experimental $\overline{N u}$ and predicted $\overline{N u}$ using small scale correlations is presented in Table 5.8. Unlike Ch7, small scale correlations show better agreement with experimental $\overline{N u}$. Garimella's correlation showed a good match which is within $15 \%$ up to Reynolds numbers equal to 1000 . For $R e>1000$, this correlation overestimates the data. This is due to the experimental data used for the correlation. The flow entered the transition regime gradually at Reynolds ranging between 800 and 2000 in Garimella's experimental work [19]. Peng et al.'s correlation shows 
good agreement for a high Reynolds number range, $1050<R e$, and predicted the data within $11 \%$ deviation limits in this Re range.

Table 5.8 Experimental and calculated $\overline{N u}$ using small scale correlations (Ch6)

\begin{tabular}{c|c|ccc|c}
\hline Re & Exp. & $\begin{array}{c}\text { Choi et al. } \\
{[38]} \\
\text { /Exp. }\end{array}$ & $\begin{array}{c}\text { Peng et al. } \\
\text { [14] }\end{array}$ & $\begin{array}{c}\text { Wang } \\
\text { \&Peng } \\
{[\mathbf{1 2}]}\end{array}$ & $\begin{array}{c}\text { Garimella[19] } \\
\text { /Exp. }\end{array}$ \\
\hline & & & & $\begin{array}{c}\text { /Exp. } \\
\text { (Exp. }\end{array}$ & \\
\hline 346 & 4.02 & 0.41 & 0.58 & 0.39 & 1.14 \\
\hline 429 & 4.55 & 0.46 & 0.59 & 0.41 & 1.02 \\
\hline 519 & 4.41 & 0.60 & 0.68 & 0.49 & 1.07 \\
\hline 521 & 4.34 & 0.61 & 0.69 & 0.50 & 1.09 \\
\hline 601 & 4.75 & 0.66 & 0.69 & 0.51 & 1.02 \\
\hline 687 & 4.88 & 0.75 & 0.73 & 0.55 & 1.02 \\
\hline 849 & 5.24 & 0.90 & 0.78 & 0.61 & 1.03 \\
\hline 855 & 4.99 & 0.95 & 0.82 & 0.65 & 1.09 \\
\hline 928 & 4.92 & 1.06 & 0.88 & 0.70 & 1.15 \\
\hline 1013 & 5.52 & 1.05 & 0.83 & 0.67 & 1.09 \\
\hline 1079 & 4.98 & 1.25 & 0.96 & 0.78 & 1.26 \\
\hline 1175 & 5.08 & 1.36 & 0.99 & 0.82 & 1.32 \\
\hline 1177 & 4.97 & 1.39 & 1.01 & 0.84 & 1.35 \\
\hline 1269 & 5.20 & 1.45 & 1.01 & 0.85 & 1.37 \\
\hline 1334 & 5.24 & 1.53 & 1.04 & 0.89 & 1.44 \\
\hline 1532 & 5.42 & 1.73 & 1.09 & 0.95 & 1.57 \\
\hline 1599 & 5.49 & 1.80 & 1.11 & 0.97 & 1.63 \\
\hline 1732 & 5.71 & 1.88 & 1.11 & 0.99 & 1.68 \\
\hline Min. Diff. $(\%)$ & 5.2 & 1.3 & 1.2 & 2.1 \\
Max. Diff. (\%) & 88 & 42 & 61 & 68 \\
\hline
\end{tabular}

Figure 5.9 shows the experimental $\overline{N u}$ and calculated $\overline{N u}$ from small scale correlations for visualization purposes. Choi's correlation is very steep and linear over this Reynolds number range. It shows no agreement at all with the experimental $\overline{N u}$. Wang and Peng's correlation is for turbulent flow with Reynolds number larger than 1500 as indicated in Table 2.7. Even though the flow is not turbulent, Wang and Peng's correlation shows good agreement for the high $R e$ range. Additionally, it is observed that Peng et al.'s correlation is quite sensitive to the distance between channels by looking at the difference in its trends between Figure 5.6 and Figure 5.9. 


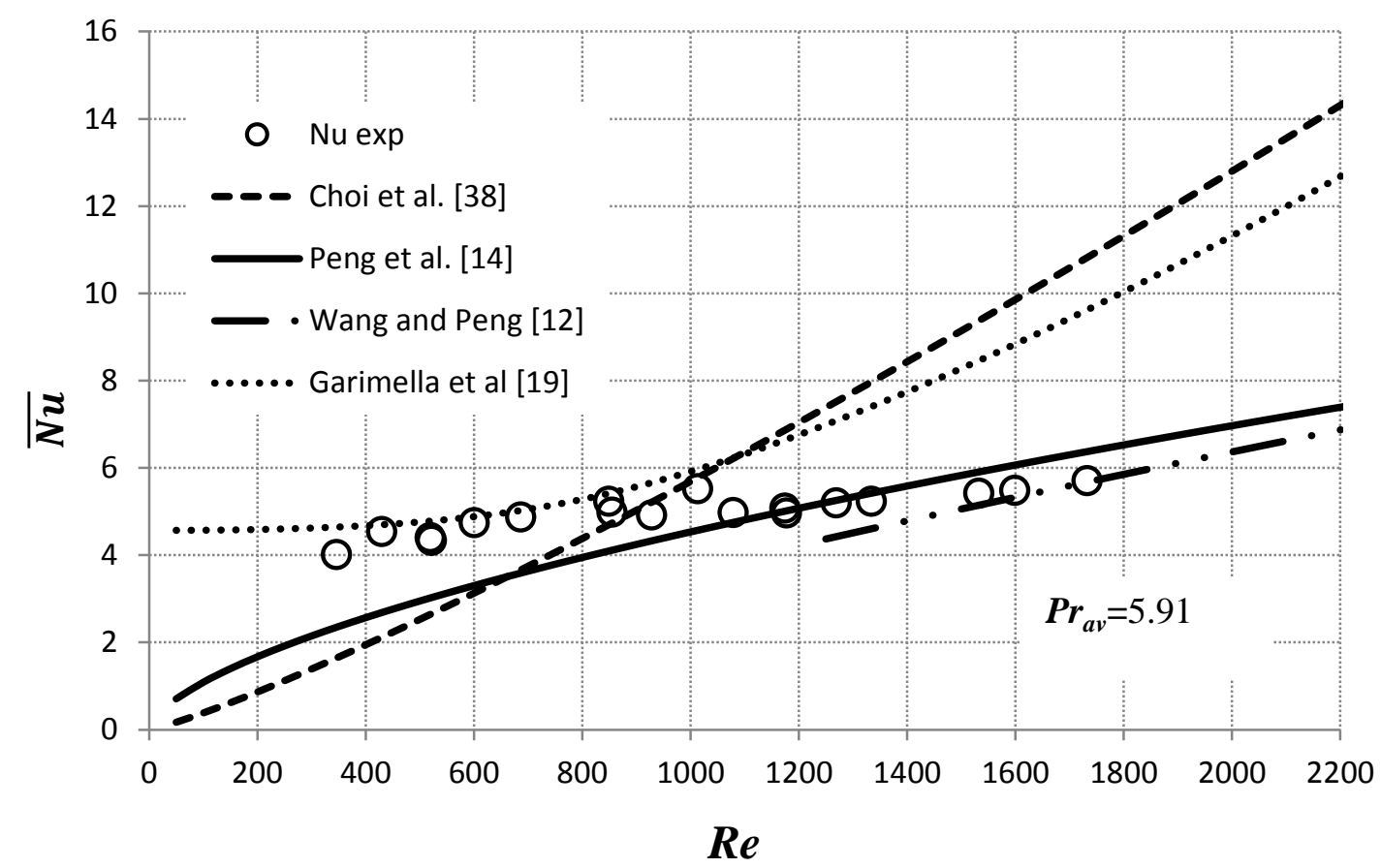

Figure 5.9 Experimental average Nusselt number and calculated Nusselt number through small scale correlations versus Reynolds number (Ch6)

Figure 5.10 shows local $N u$ versus $x^{*}$ for different thermocouple locations. Unlike $\mathrm{Ch} 7$, the scatter for low flow rates is quite small. The possible reasons for the scatter are small temperature variations along the channel due to uncertainties in temperature measurements. $\mathrm{Pr}$ is very sensitive to changes in temperature and a small change in temperature may shift the $x^{*}$ value. Nevertheless, the scatter is small and the thermally developing effect is clearly present in Figure 5.10. The experimental $\mathrm{Nu}$ is lower than theory for $x^{*}$ larger than 1.0 which indicates the flow is not thermally fully developed despite the experimental errors. However, the slope decays significantly after $x *$ equals to 0.4 . 


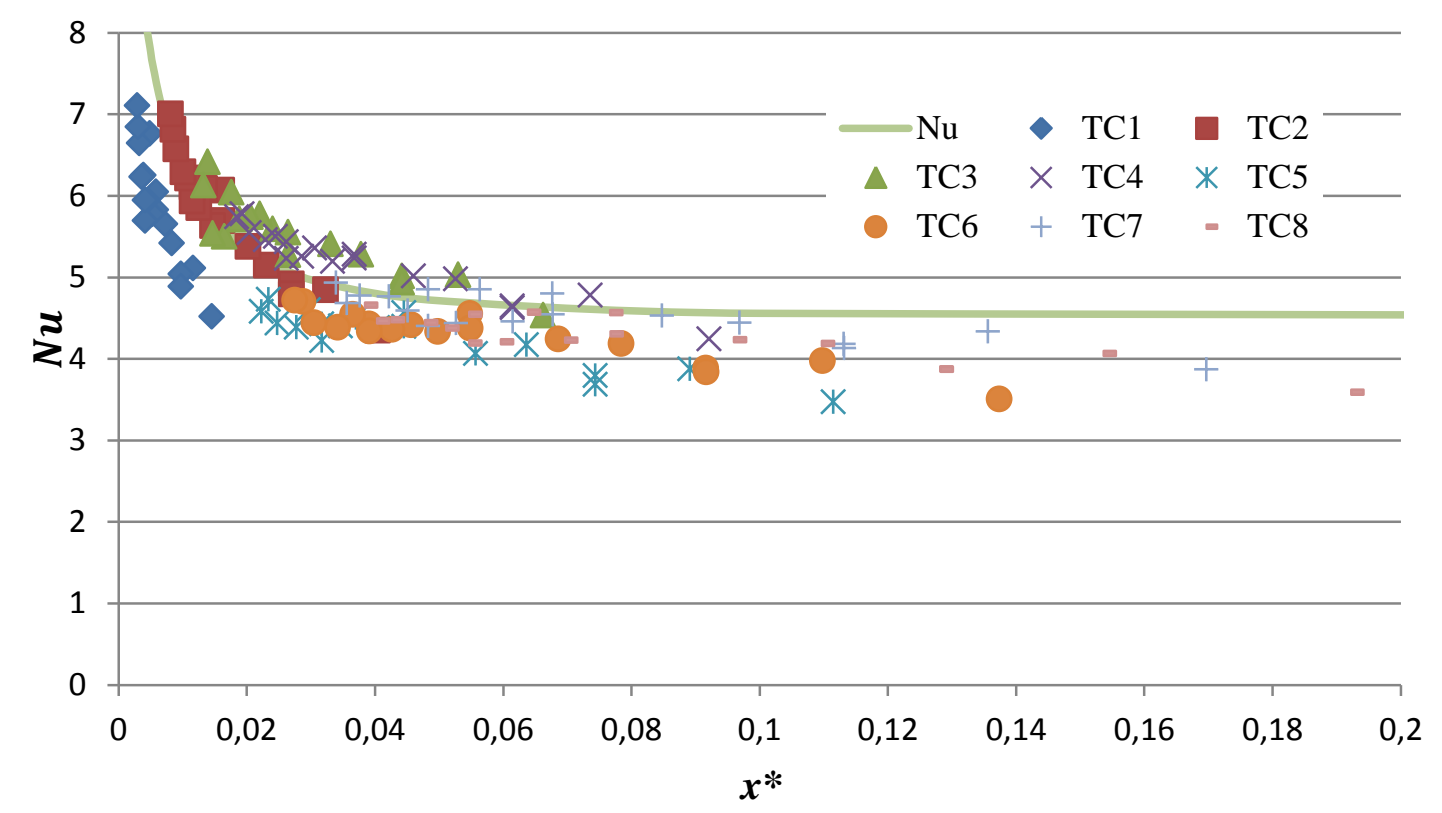

Figure 5.10 Local Nusselt number versus $x^{*}(\mathrm{Ch} 6)$

\subsubsection{Minichannel 3 (Ch5)}

Table 5.9 shows the experimental $\overline{N u}$ values and normalized predicted $\overline{N u}$ values using conventional correlations by dividing by experimental $\overline{N u}$ values. It is observed that conventional correlations failed to predict accurately the experimental $\overline{N u}$ values. The Shah and London correlation for fully developed rectangular channels predicted the closest values with $65 \%$ overestimation. Other correlations generally predicted twice the experimental data. The sudden experimental $\overline{N u}$ drop is curious considering experimental $\overline{N u}$ of flow in other minichannels. A possible reason for this might be deviation of the actual boundary condition from a constant heat flux boundary condition. Constant heat flux boundary condition assumes a uniform heat flux from all surfaces. In the experiments, the heaters were placed on the outer surface. On the other hand, experimental average Nusselt number is evaluated using heat transfer area inside the minichannels. As hydraulic diameter increases, the temperature along the wetted perimeter might not be constant due to temperature variations because of the existence of the inner walls in multiport minichannels in addition to experimental uncertainty. Therefore, H1 boundary condition might not be fully applied for the experimental study. This implies that the 
temperature at heated surface might be higher than the inner wall especially for larger diameter multiport minichannels. Since the temperature on the heated surface is measured, the calculated $\overline{N u}$ values might be relatively lower. It is believed that this effect increases as hydraulic diameter increases. Nevertheless, evaluation of average Nusselt number through this approach is important to determine heat transfer with conventional methods. The experimental $\overline{N u}$ values of flow inside multiport minichannels with diameters $1.42 \mathrm{~mm}$ from [33] and $2.06 \mathrm{~mm}$ from [28]are similar to those in the present minichannels. In other words, the correlations also over predicted these $\overline{N u}$ results in accordance with current experimental $\overline{N u}$ values.

Table 5.9 Experimental and calculated $\overline{N u}$ using conventional correlations (Ch5)

\begin{tabular}{|c|c|c|c|c|c|c|c|}
\hline $\operatorname{Re}$ & Exp. $^{1}$ & $\begin{array}{l}\text { Theo. }^{2} \\
\text { /Exp }\end{array}$ & $\begin{array}{c}\text { S\&P HF } \\
\text { /Exp }\end{array}$ & $\begin{array}{c}\text { S\&P WT } \\
\text { /Exp }\end{array}$ & $\begin{array}{l}\text { S\&L TD }^{5} \\
/ \text { Exp }\end{array}$ & $\begin{array}{l}\text { Gni. }^{6} \\
/ \text { Exp }\end{array}$ & $\begin{array}{c}\text { S\&L FD }{ }^{7} \\
/ \operatorname{Exp}\end{array}$ \\
\hline 277 & 1.89 & 2.18 & 2.07 & 2.49 & 2.45 & 2.06 & 2.16 \\
\hline 330 & 2.11 & 1.96 & 1.89 & 2.27 & 2.22 & 1.88 & 1.94 \\
\hline 413 & 2.25 & 1.85 & 1.82 & 2.19 & 2.12 & 1.81 & 1.82 \\
\hline 413 & 2.29 & 1.82 & 1.78 & 2.14 & 2.08 & 1.77 & 1.79 \\
\hline 489 & 2.44 & 1.70 & 1.71 & 2.05 & 1.98 & 1.69 & 1.67 \\
\hline 551 & 2.35 & 1.77 & 1.81 & 2.16 & 2.08 & 1.79 & 1.74 \\
\hline 600 & 2.40 & 1.74 & 1.80 & 2.15 & 2.06 & 1.78 & 1.71 \\
\hline 702 & 2.63 & 1.60 & 1.69 & 2.00 & 1.91 & 1.66 & 1.55 \\
\hline 698 & 2.46 & 1.71 & 1.81 & 2.14 & 2.05 & 1.78 & 1.66 \\
\hline 833 & 2.63 & 1.61 & 1.76 & 2.07 & 1.97 & 1.73 & 1.56 \\
\hline 880 & 2.40 & 1.76 & 1.96 & 2.29 & 2.18 & 1.92 & 1.70 \\
\hline 980 & 2.50 & 1.71 & 1.95 & 2.25 & 2.13 & 1.89 & 1.64 \\
\hline 982 & 2.49 & 1.71 & 1.96 & 2.26 & 2.14 & 1.90 & 1.64 \\
\hline 1057 & 2.50 & 1.71 & 1.99 & 2.27 & 2.16 & 1.92 & 1.64 \\
\hline 1131 & 2.53 & 1.70 & 2.02 & 2.29 & 2.17 & 1.95 & 1.62 \\
\hline 1224 & 2.48 & 1.74 & 2.12 & 2.38 & 2.25 & 2.03 & 1.65 \\
\hline 1321 & 2.60 & 1.67 & 2.06 & 2.29 & 2.17 & 1.96 & 1.57 \\
\hline 1378 & 2.55 & 1.71 & 2.14 & 2.36 & 2.24 & 2.03 & 1.60 \\
\hline \multicolumn{2}{|c|}{ Min. Diff. (\%) } & 61 & 69 & 100 & 145 & 69 & 55 \\
\hline \multicolumn{2}{|c|}{ Max. Diff. (\%) } & 118 & 114 & 149 & 91 & 106 & 116 \\
\hline
\end{tabular}

${ }^{\mathrm{T}}$ Exp. indicates experimental results

${ }^{2}$ Theo.indicates theoretical results with thermally developing flow (2.19)

${ }^{3}$ S\&P HF indicates Stephan \& Preusser with CHF boundary condition (2.20)

${ }^{4}$ S\&P WT indicates Stephan \& Preusser with CWT boundary condition (2.21)

${ }^{5}$ S\&L TD İndicates Shah and London with thermally developing flow (2.22)

${ }^{6} \mathrm{Gni}$. İndicates Gnielinski laminar flow (2.23)

${ }^{7} \mathrm{~S} \& \mathrm{~L}$ FD indicates Shah and London fully developed flow (2.14) 
In Figure 5.11, the experimental and theoretical values from conventional correlations are illustrated. The experimental $\overline{N u}$ follows a constant term after a slight increase in the small Reynolds number range. The developing effects are quite small compared to $\mathrm{Ch} 6$ and $\mathrm{Ch} 7$ for flow inside $\mathrm{Ch} 5$ due to a higher hydraulic diameter. Therefore, none of the correlations with developing effects were successful at catching the trend of Ch5. Moreover, no indication of early transition was observed. The precision of the repeated data is very high and these data are almost identical.

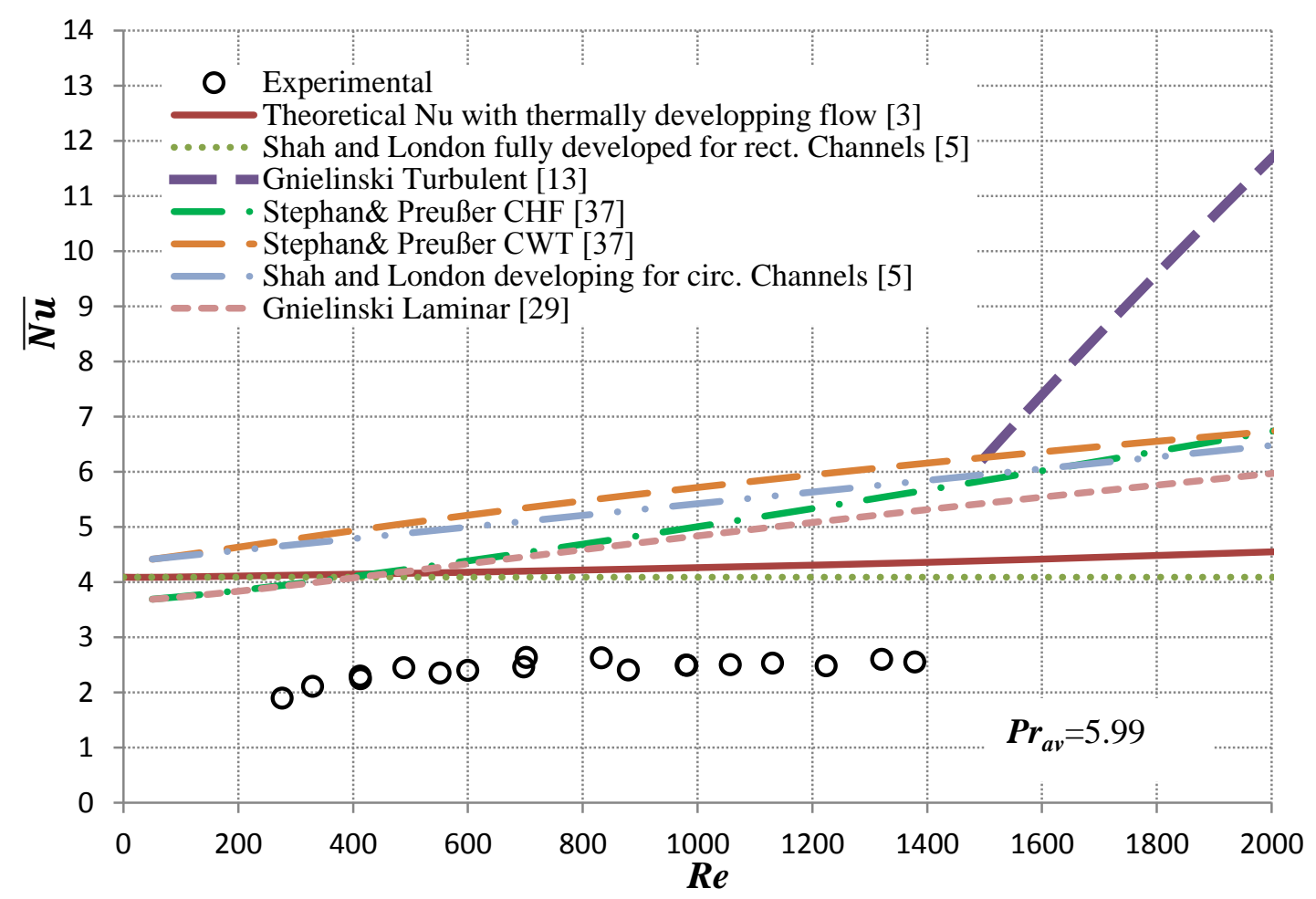

Figure 5.11 Experimental average Nusselt number and calculated Nusselt number through conventional correlations versus Reynolds number (Ch5) 
Comparison of the $\overline{N u}$ value predictions of small scale correlations and experimental $\overline{N u}$ values are given in Table 5.10 and demonstrated in Figure 5.12. Similar to Ch7, none of the small scale correlations showed good agreement with the experimental $\overline{N u}$. The experimental values are approximately constant and show no dependency on Reynolds number like small scale correlations. Since the incline of experimental $\overline{N u}$ is small, constant $\overline{N u}$ for this channel can be evaluated. By averaging experimental $\overline{N u}$ by excluding the first and second data where a slight gradual increase in $\overline{N u}$ occurs, a constant Nusselt number is evaluated to be 2.47 for Ch5.

Table 5.10 Experimental and calculated $\overline{N u}$ using small scale correlations (Ch5)

\begin{tabular}{c|c|c|c|c|c}
\hline Re & Exp. & $\begin{array}{c}\text { Choi et al. } \\
\text { [38] } \\
\text { /Exp. }\end{array}$ & $\begin{array}{c}\text { Peng et al. } \\
\text { [14] } \\
\text { /Exp. }\end{array}$ & $\begin{array}{c}\text { Wang } \\
\text { \&Peng [12] } \\
\text { /Exp. }\end{array}$ & $\begin{array}{c}\text { Garimella[19] } \\
\text { /Exp. }\end{array}$ \\
\hline 277 & 1.89 & 0.67 & 1.50 & 0.69 & 2.25 \\
\hline 330 & 2.11 & 0.74 & 1.51 & 0.72 & 2.03 \\
\hline 413 & 2.25 & 0.91 & 1.63 & 0.81 & 1.94 \\
\hline 413 & 2.29 & 0.89 & 1.59 & 0.79 & 1.90 \\
\hline 489 & 2.44 & 1.01 & 1.65 & 0.84 & 1.82 \\
\hline 551 & 2.35 & 1.21 & 1.86 & 0.97 & 1.92 \\
\hline 600 & 2.40 & 1.31 & 1.91 & 1.02 & 1.93 \\
\hline 702 & 2.63 & 1.42 & 1.91 & 1.04 & 1.84 \\
\hline 698 & 2.46 & 1.52 & 2.05 & 1.12 & 1.98 \\
\hline 833 & 2.63 & 1.75 & 2.14 & 1.20 & 2.01 \\
\hline 880 & 2.40 & 2.05 & 2.43 & 1.38 & 2.25 \\
\hline 980 & 2.50 & 2.24 & 2.50 & 1.45 & 2.32 \\
\hline 982 & 2.49 & 2.25 & 2.52 & 1.46 & 2.33 \\
\hline 1057 & 2.50 & 2.44 & 2.61 & 1.54 & 2.45 \\
\hline 1131 & 2.53 & 2.63 & 2.71 & 1.61 & 2.56 \\
\hline 1224 & 2.48 & 2.94 & 2.90 & 1.75 & 2.79 \\
\hline 1321 & 2.60 & 3.03 & 2.88 & 1.76 & 2.82 \\
\hline 1378 & 2.55 & 3.26 & 3.02 & 1.86 & 3.02 \\
\hline Min. Diff. $(\%)$ & 226 & 50 & 1.8 & 82 \\
\hline Max. Diff. (\%) & 1.1 & 202 & 86 & 202 \\
\hline & & & & & \\
\hline
\end{tabular}




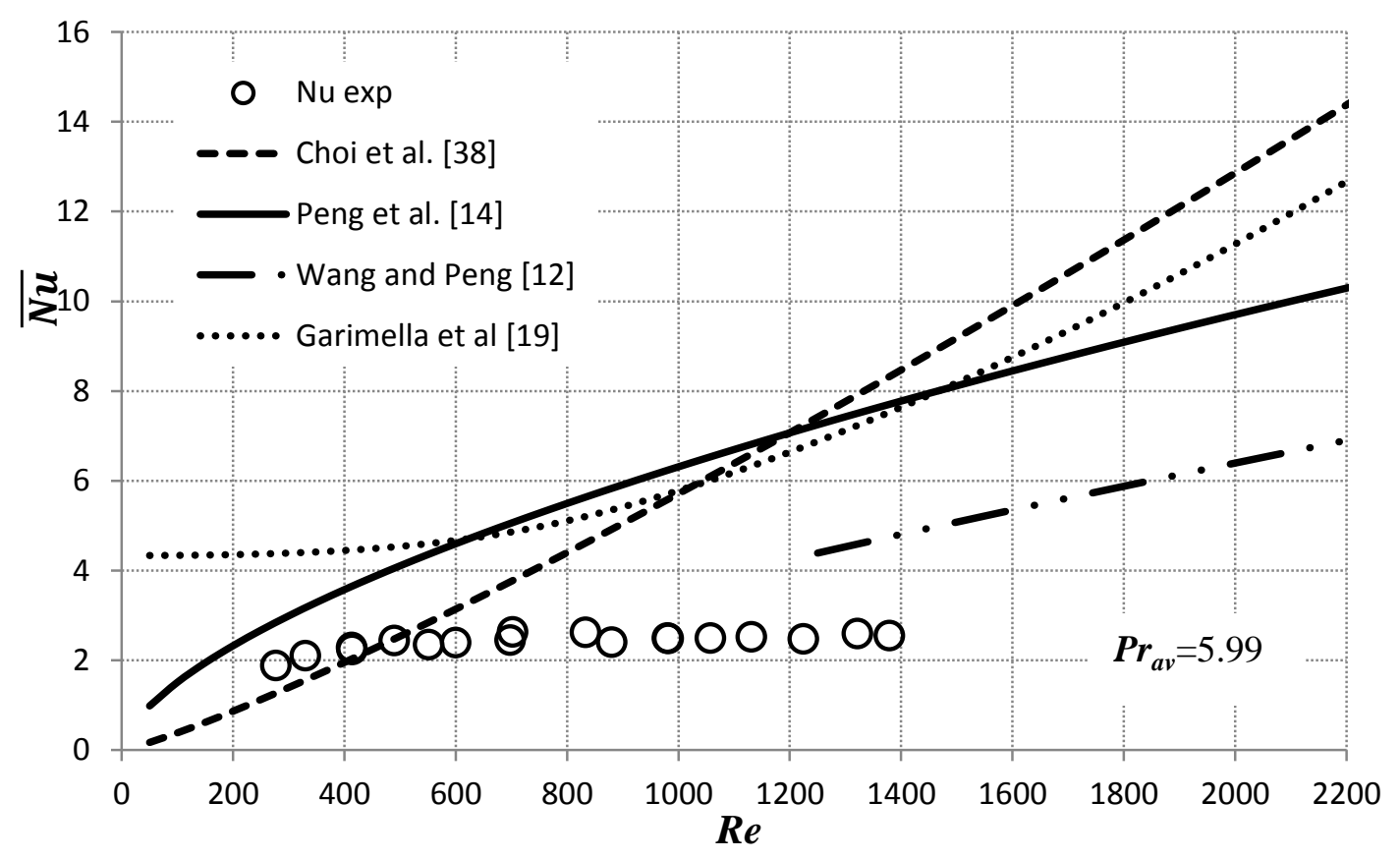

Figure 5.12 Experimental average Nusselt number and calculated Nusselt number through small scale correlations versus Reynolds number (Ch5)

Local $N u$ results over the dimensionless axial length are visualized in Figure 5.13. The decline rate at low $\mathrm{Re}$ range is smaller than for $\mathrm{Ch} 6$ and $\mathrm{Ch} 7$ due to the observed smaller thermally developing effects. The local $N u$ results at the thermocouples locations generally follow a trend except TC3. The large scatter in $N u$ at TC3 indicates a possible temperature measurement error. Additionally, local $N u$ at TC2 is also higher than other $\mathrm{Nu}$ values even though it is constant. This might be due to uncertainties and temperature variation in peripheral direction as has been noted before. Considering these facts, most of the experimental $\mathrm{Nu}$ values are between 2 and 3 which are in accordance with average Nusselt number values in Table 5.9. 


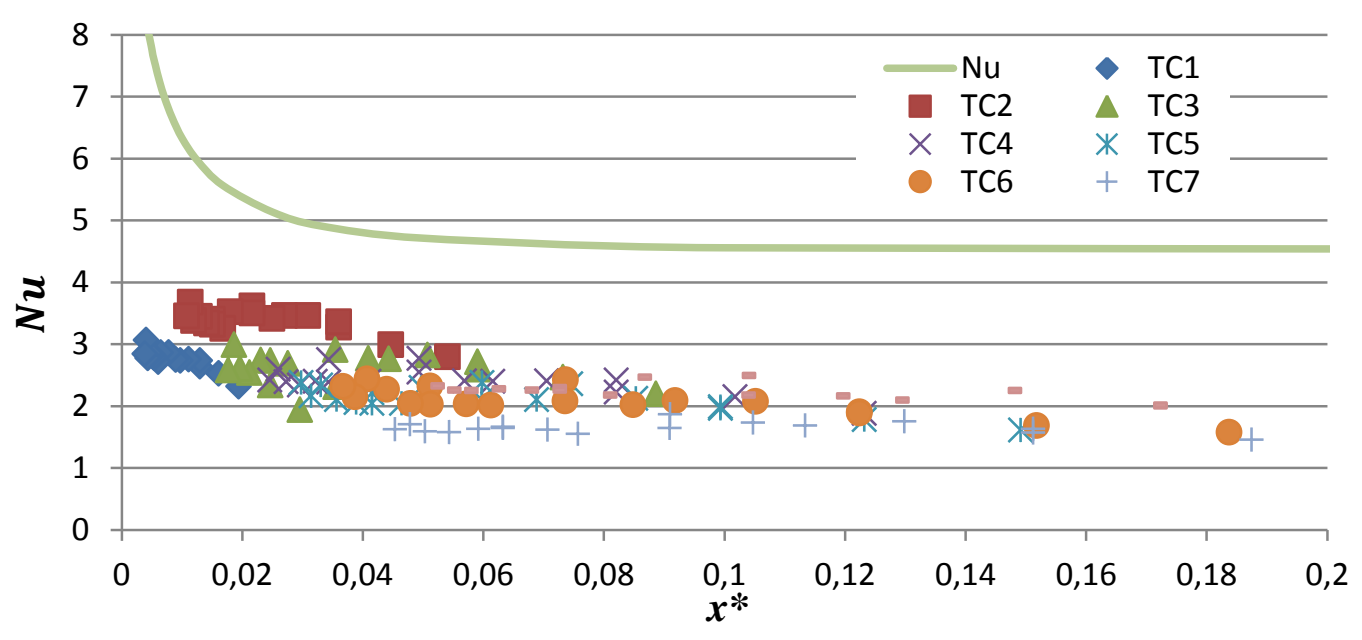

Figure 5.13 Local Nusselt number versus $x *(\mathrm{Ch} 5)$

\subsubsection{Comparision of Minichannels}

Like experimental $P o$ results, the experimental $\overline{N u}$ values are normalized by dividing by conventional values which are estimated using theoretical $N u$ with thermally developing flow (Eqn. (2.14)) and Shah and London correlation for fully developed flow inside rectangular channels (Eqn. (2.19)). For comparison, theoretical $\overline{N u}$ values with thermally developing flow and the Shah and London correlation for fully developed rectangular channels are shown together to visualize the magnitude of thermally developing region effects. The experimental $\overline{N u}$ divided by the theoretical $\overline{N u}$ is illustrated in Figure 5.14. Ch5 has lower normalized values compared with $\mathrm{Ch} 6$ and $\mathrm{Ch} 7$ due to its largest hydraulic diameter. The values for other minichannels are close to unity and approximately within $20 \%$ error limit with theoretical thermally developing flow. The difference between normalized values of fully developed predictions and thermally developing correlation predictions is largest for Ch7 due to smallest hydraulic diameter. On the other hand, the magnitude of this difference for Ch6 is quite close to the difference for $\mathrm{Ch} 7$. On the other hand, thermally developing effects are almost unseen for Ch5 due to lower $x^{*}$ values. At low $R e$ range, theoretical values overestimate experimental $N u$ results for all minichannels even though the values converge to a constant in the higher $R e$ range. 
The convergence rate is found to be according to hydraulic diameter. Specifically, Ch5 having the largest diameter converges fastest while Ch7 having the smallest hydraulic diameter converges the slowest.

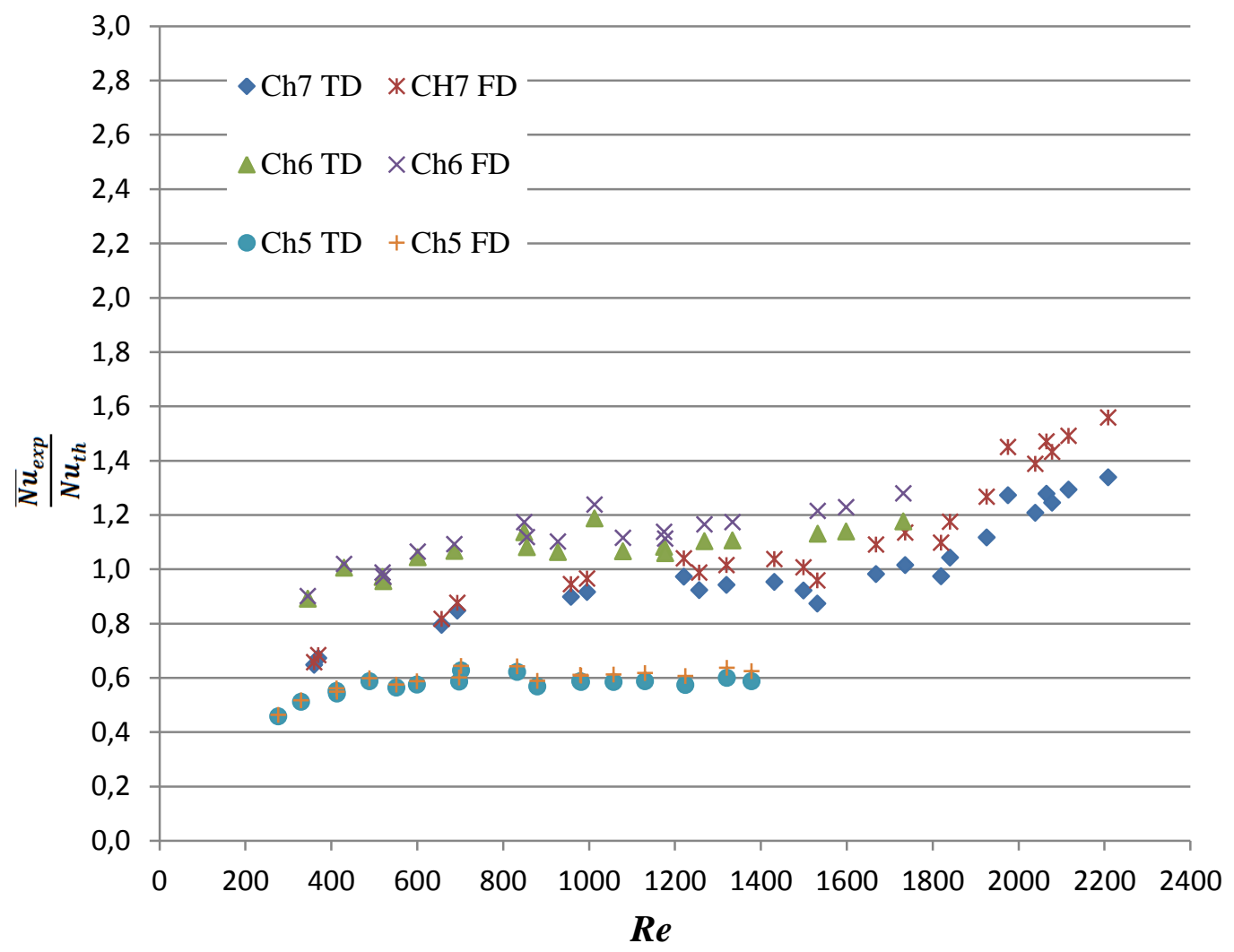

Figure 5.14 The ratio of experimental $\overline{N u}$ to theoretical $\overline{N u}$ for thermally developing flow (TD) and fully developed flow (FD) versus $R e$ for all minichannels

The average heat transfer coefficients in the laminar regime for all channels are shown in Figure 5.15. Similar results can be drawn as with the $\overline{N u}$ vs $R e$ discussion for all minichannels. An interesting point is that the average heat transfer coefficient of Ch6 is larger than that for $\mathrm{Ch} 7$ although its hydraulic diameter is smaller. The reason behind this is the difference in aspect ratio as shown in Table 3.1. Due to its smaller aspect ratio, the heat transfer convection coefficient in $\mathrm{Ch} 7$ is the largest. 


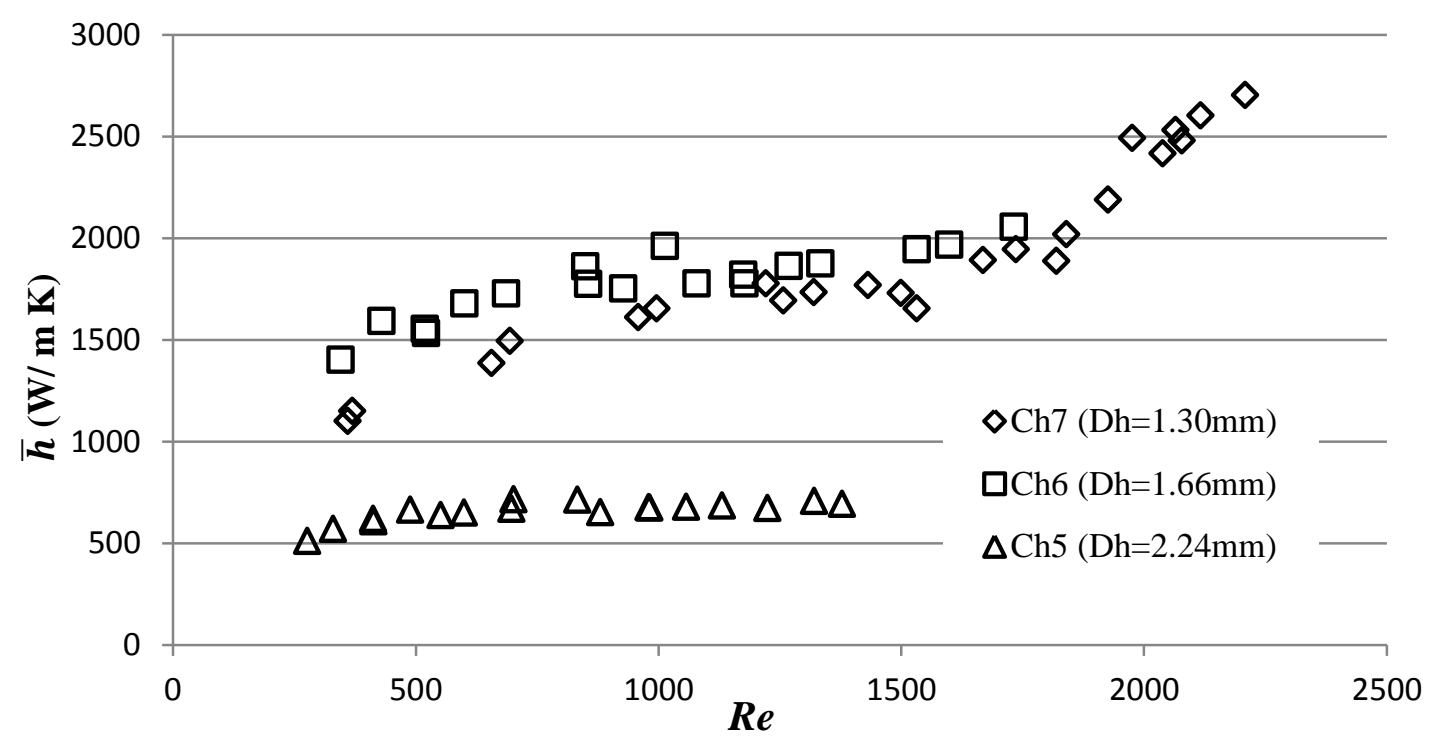

Figure 5.15 Average heat transfer coefficient versus $R e$ for all minichannels

\subsubsection{Conventional Correlations}

Six different theoretical correlations are used to predict the experimental data and applicability of these correlations for the tested minichannels are investigated. The accuracy of the correlations to predict the data and precision to follow the trends with geometric characteristic properties are summarized in Table 5.11. The geometry for most of the correlations is circular. Therefore, trends of the correlations are more meaningful for comparison rather than exact agreement. The laminar Gnielinski correlation and Shah and London correlation for thermally developing flow predicted the trend of experimental $\overline{N u}$ very good for $\mathrm{Ch} 7$ and Ch6. However, these two correlations do not follow the trend of experimental $\overline{N u}$ of Ch5 where developing effects are not as critical as for $\mathrm{Ch} 6$ and $\mathrm{Ch} 7$. One of the possible explanation for this could be that could be differences in dimensionless axial thermal distance for the flow inside the minichannels. However, the distribution of $x_{\text {exit }}^{*}$ values are quite similar for all minichannels as observed in Figure 5.16. Therefore, the difference in thermal development is probably due to different hydraulic diameters of the minichannels. The aspect ratio is different for all channels but cannot be the cause of different thermally developing effects because the aspect ratio of Ch6 and Ch7 are 
close. Another interesting point is that the Stephan \& Preusser correlation with constant wall temperature boundary condition estimated the trend of experimental $\overline{\mathrm{Nu}}$ of Ch6 and $\mathrm{Ch} 7$ better than the Stephan \& Preusser correlation with constant heat flux boundary condition despite the fact that constant heat flux boundary condition was applied during the study. Both Stephan \& Preusser correlations overestimated the thermally developing effect in Ch5 like the laminar Gnielinski correlation and thermally developing Shah and London correlation. Theoretical $\overline{N u}$ values with thermally developing flow from Table 2.5 predicted data within acceptable error limits for Ch6 and Ch7. On the other hand, it could not follow the experimental $\overline{N u}$ over $R e$ as well as laminar Gnielinski correlation and Shah and London for thermally developing correlation for $\mathrm{Ch} 6$ and $\mathrm{Ch} 7$. For $\mathrm{Ch} 5$, all correlations overestimated the experimental $\overline{N u}$. However, the theoretical $\overline{N u}$ with developing flow correlation and fully developed Shah and London correlation for rectangular channels estimated the trend of experimental $\overline{N u}$ quite well.

According to these results, the laminar Gnielinski correlation and the thermally developing Shah and London correlation best predicted the trend of data for channels with hydraulic diameters between $1.3 \mathrm{~mm}$ and $1.7 \mathrm{~mm}$. However, these correlations should be multiplied by a correction factor according to the aspect ratio of rectangular minichannels to improve their accuracy. The author suggests the correction factors in Table 5.12. Using the suggested correction factor, the correlations are able predict experimental values within $11 \%$ error limits for all data except that in the low $R e$ range. 


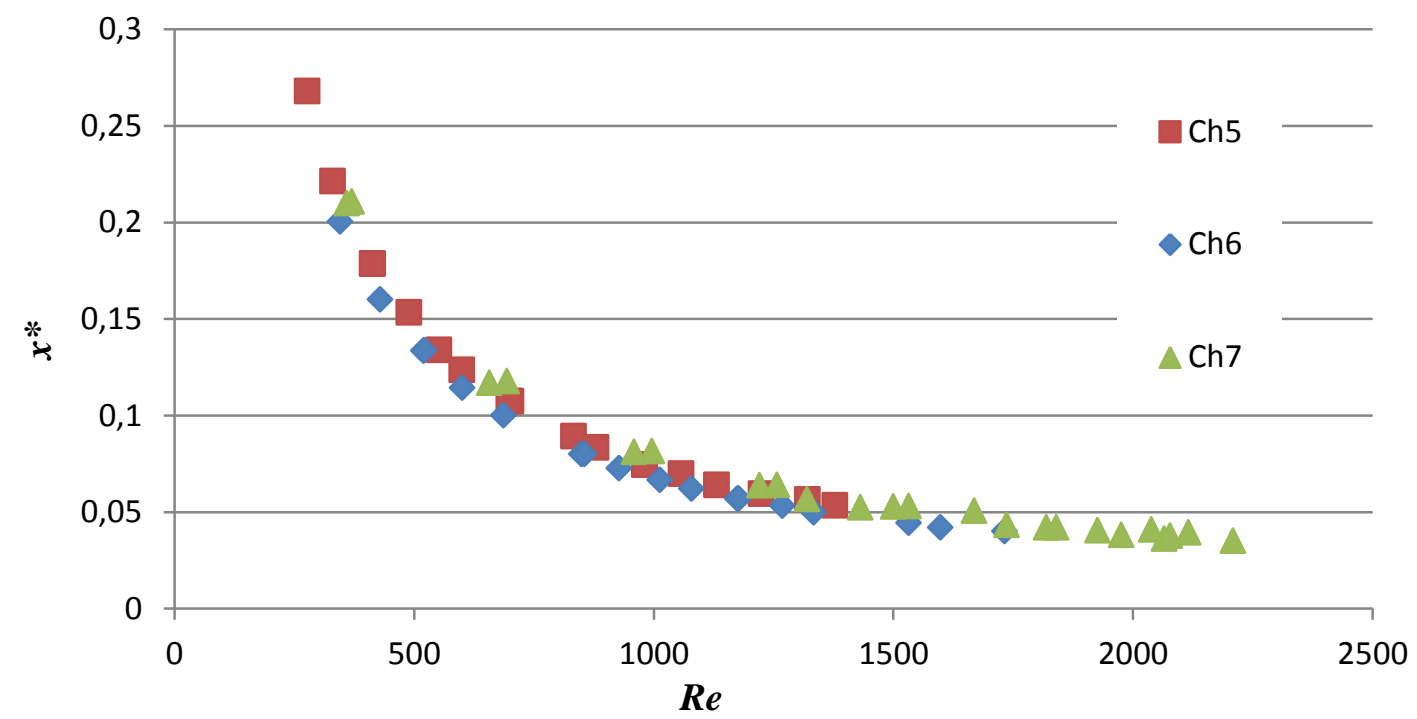

Figure $5.16 x^{*}$ distribution of minichannels versus $R e$

Table 5.11 Agreement and accuracy of predicted $\overline{N u}$ with experimental $\overline{N u}$ considering geometry properties of channels

\begin{tabular}{|c|c|c|c|c|c|c|}
\hline & \multicolumn{2}{|r|}{ Ch7 } & \multicolumn{2}{|r|}{ Ch6 } & \multicolumn{2}{|r|}{ Ch5 } \\
\hline & Trend & Accuracy & Trend & Accuracy & Trend & Accuracy \\
\hline Theo. $^{1}$ & average & agreement & average & $\begin{array}{c}\text { slight } \\
\text { underestimation }\end{array}$ & very good & overestimation \\
\hline S\&P HF ${ }^{2}$ & poor & overestimation & poor & agreement & poor & overestimation \\
\hline S\&P WT ${ }^{3}$ & good & overestimation & good & $\begin{array}{c}\text { slight } \\
\text { overestimation }\end{array}$ & poor & overestimation \\
\hline S\&L TD ${ }^{4}$ & very good & overestimation & very good & $\begin{array}{c}\text { slight } \\
\text { overestimation }\end{array}$ & poor & overestimation \\
\hline Gni. $^{5}$ & very good & overestimation & very good & $\begin{array}{c}\text { high } \\
\text { agreement }\end{array}$ & poor & overestimation \\
\hline S\&L FD ${ }^{6}$ & poor & agreement & poor & underestimation & very good & overestimation \\
\hline$\alpha$ & & 0,89 & & 0,41 & & 0,52 \\
\hline$D_{h}(\mathbf{m m})$ & & 1,3 & & 1,66 & & 2,27 \\
\hline
\end{tabular}

${ }^{\mathrm{I}}$ Theo.indicates theoretical results with thermally developing flow

${ }^{2}$ S\&P CHF indicates Stephan \& Preusser with constant heat flux boundary condition

${ }^{3}$ S\&P CWT indicates Stephan \& Preusser with constant wall temperature boundary condition

${ }^{4}$ S\&L TD İndicates Shah and Londan with thermally developing flow

${ }^{5} \mathrm{Gni}$. İndicates Gnielinski laminar flow

${ }^{6} \mathrm{~S} \& \mathrm{~L}$ FD indicates Shah and London fully developed flow 
Table 5.12 Correction factors for conventional correlations for $\mathrm{Ch} 6$ and $\mathrm{Ch} 7$

\begin{tabular}{ccc} 
& Ch7 & Ch6 \\
\hline S\&L TD $^{\mathbf{1}}$ & 0.68 & 0.91 \\
Gni. $^{2}$ & 0.74 & 1.00 \\
$\boldsymbol{\alpha}$ & 0.89 & 0.41 \\
\hline
\end{tabular}

${ }^{\mathrm{T}}$ S\&L TD İndicates Shah and Londan with thermally developing flow ${ }^{2} \mathrm{Gni}$. İndicates Gnielinski laminar flow

\subsubsection{Small Scale Correlations}

The Choi correlation is very dependent on $R e$ as shown in Table 2.7. There is a very steep incline in the laminar range. For small scale channels used in Choi's work [39], the thermally developing effect is not considered during $\overline{N u}$ evaluation even though $x *$ is less than 0.03 for some data. However, the slope of the incline is very high to be considered as an effect of a developing flow. Therefore, for Choi's results the author suspects an early transition due to experimental error, high relative roughness or undiscovered tripping at the inlet of the channel since no Reynolds dependency except developing effects were observed in the current results.

The Peng et al. correlation is different from the other correlations if the terms in the correlation are considered. It contains a geometric term which is the hydraulic diameter divided by the distance between channel mid points to consider port effects of the channels. This correlation was able to predict the high Re range in the laminar region for Ch6 however it overestimated $\mathrm{Ch} 5$ and $\mathrm{Ch} 7$. This is due to a shift caused by the mentioned geometric term. Moreover, the correlation assumes the heat transfer convection coefficient to be dependent on $R e$ and the flow to be fully developed by not including any axial length term in the correlation as demonstrated in Table 2.7. On the other hand, the $x^{*}$ values of the tested channels are between 0.01 and 0.5 , which can be considered the thermally developing region for conventional channels. The non-constant values of $\overline{N u}$ values in the correlation, which is considered as a Reynolds number dependency, might also be thermally developing effect. 
The Garimella correlation is a lengthy correlation which includes thermally developing effects and is valid for laminar, transition and turbulent regimes. The transition gradually starts in the Reynolds number range $800<R e<2000$ for this correlation. For current experimental $\overline{N u}$ values, the Garimella correlation somewhat predicted the trend of $\overline{N u}$ up to a Reynolds number between 800 and 1000 for all minichannels. After this Reynolds number range, it failed to follow the experimental $\overline{N u}$ values. For Ch6, the predictions of the correlation are quite close to measured values although it overestimates the results for the other two minichannels. A correction factor for different aspect ratios can be considered similar to the discussed conventional correlations for this $R e$ range.

The Wang correlation is suggested by replacing the 0.023 constant of the DittusBoelter turbulent correlation [13] with 0.00805 and is suggested for turbulent flow for Reynolds number larger than 1500. The critical Reynolds number is defined as between 400 and 1000 in their experimental study. However, since this Reynolds number range coincides with that for the laminar region of conventional channels, the correlation is included for comparision. Despite that it is for turbulent flow, the correlation provided more accurate predictions than the other small scale correlations except the Peng et al. correlation for Ch6 and showed a somewhat similar trend with the results of all minichannels for the Reynolds number range, $1000<R e<2000$. 


\section{CHAPTER 6}

\section{CONCLUSION AND FUTURE WORK}

\subsection{Summary}

Heat transfer in small channels is becoming more important owing to their enhanced heat transfer characteristics. However, fluid flow and heat transfer characteristics are not clearly established for single phase fluid flow inside minichannels and there are still wide discrepancies and question marks about this issue within the literature. Some studies suggest conventional channel theory is not adequate and new correlations are required for heat transfer and fluid flow inside minichannels whereas other studies support that conventional theory applies. Therefore, the aim of this study is to determine the fluid flow and heat transfer characteristics of single phase fluid flow inside three minichannels to further investigate these discrepancies after a detailed literature review. Rectangular minichannels are tested due to the large number of investigations in the literature focused on circular minichannels. In this study the port numbers of the tested minichannels are different from each other to observe its effects on fluid flow and heat transfer. The laminar regime is studied within the scope of this study owing to the larger discrepancies in this regime compared to the turbulent regime.

The fundamentals of the fluid flow and heat transfer particularly for tested channels are briefly explained in separate sections. Pressure losses increase rapidly as hydraulic diameter decreases; thus, the flow inside minichannels is usually limited to the developing region to minimize pressure losses. Therefore, conventional heat transfer correlations both for developed flow and developing flow are reviewed. Furthermore, the small scale correlations from literature review are also provided in tabular form for comparison of results. Fluid flow characteristics for developing and 
developed flow are also provided. Additionally, small scale correlations from the literature review section are gathered and presented in tabular form.

A new experimental test set-up is constructed with available equipment in the lab and a limited project budget. The properties of equipment are explained. After designing the test cycle, assembly of the components, manufacturing of new parts, and calibration of the equipments are explained in detail.

The scope of the study is single phase fluid flow and heat transfer in the laminar region and experimental conditions are provided to view the limits of the study. The approach taken and procedures followed during the experimentation are explained in detail. Repeatability analysis is also performed for several data for each channel and relatively good repeatability is observed. Uncertainties are evaluated to distinguish differences between the experimental results and theory due to experimental errors and physical deviations. In additional to the mentioned chapter on theory, the calculations used for data reduction are also explained explicitly.

After experimental investigation of the three minichannels, the data are reduced to meaningful parameters. The reduced data are considered and discussed separately in two sections: fluid flow section for pressure drop and heat transfer section for cooling. First, the results from each minichannel are discussed separately. Subsequently, a comparison is made between fluid flow and heat transfer results for all minichannels. The applicability of conventional theory to these experimental results is discussed. The applicability of small scale correlations is also examined. 


\subsection{Conclusions}

Based on the experimental data for all three minichannels, the following conclusions are drawn on fluid flow and heat transfer:

Poiseuille theory for developing flow holds for almost all data for all minichannels considering the uncertainties and deviation at low Re. Hence, the pressure drop in minichannels can be roughly evaluated using Po theory with developing flow.

Effects due to developing flow are found to be most important for smaller hydraulic diameter channels. As the hydraulic diameter increases, incline in Po versus $R e$ due to developing effect decreases. The effects of developing flow might be higher for smaller minichannels.

Only flow in $\mathrm{Ch} 7$ entered the turbulence region at a critical Reynolds number between 1800 and 2000. The transition from laminar to turbulence was clearly observed for both fluid flow and heat transfer results. The flow in other minichannels was in the laminar region. Therefore, it is concluded that flow is laminar for these minichannels and similar to tested minichannels for Reynolds number range, $R e<$ 1800 reported in the literature..

Several different conventional correlations predicted the trends for all minichannels. For Ch6 and C7, the laminar Gnielinski correlation and the thermally developing Shah and London correlation best predicted the trends of the results whereas the theoretical $\mathrm{Nu}$ with developing flow best predicted the results of $\mathrm{Ch} 5$. The difference is believed to be due to thermally developing effect. Like fluid flow, developing effect is more critical for smaller hydraulic diameter channels according to the results.

The geometry of channels for Gnielinski correlation and thermally developing Shah and London correlation are circular whereas the minichannels in this study are rectangular. The effect of geometry should be corrected to improve their accuracy for the rectangular channels. Therefore, correction factors should be applied to the laminar Gnielinski correlation and thermally developing Shah and London 
correlation. A correction factor set for these two correlations is suggested to be used with rectangular channels with similar aspect ratio based on the experimental results. Among the small scale correlations, the Garimella correlation which accounts for developing flow followed the experimental trends up to $R e$ of 800 . After this range, the correlation predicts the flow to enter the transition region but this is not the case for any minichannels tested. The Peng et. al. correlation only provided good agreement with experimental results for Ch6 for large $R e$ but showed very poor agreement for the other channels for all $R e$. Furthermore, the Choi correlation over estimated all experimental data whereas the Wang and Peng correlation showed somewhat similar agreement with the experimental $\overline{N u}$ trends. The small scale correlations except for Garimella do not account for thermally developing effects which is believed to be the source of the $\overline{N u}$ dependency on $R e$ in the laminar regime. In conclusion, only the Garimella correlation with a correction factor applied is found appropriate for the tested minichannels. Lastly, no signs of $\overline{N u}$ dependency on $R e$ is observed excluding the thermally developing region.

The port number effect on heat transfer and fluid flow effect was found to be not obvious for the tested channels because of different hydraulic diameter. In other words, it was difficult to draw a clear conclusion how different port numbers affect the results. For better investigation of port effect, it was found that channels with fixed hydraulic diameter but different port number are needed. Otherwise, hydraulic diameter becomes dominant factor and hydraulic diameter is found to be the most important geometric factor in the scope of this study. 


\subsection{Future Work}

Several modifications are suggested to improve the accuracy of the results or extend the scope the work and are summarized below:

- The equipment used in the test set-up are mostly available equipment in the laboratory. Therefore, the implementation of new equipment with higher sensitivity will increase the accuracy of the results and decrease the uncertainty, especially at low Reynolds number range.

- The Reynolds number range in this experimental work only includes the laminar regime. Purchase of a gear pump with higher discharge flow rates would extend the Reynolds range to cover the transition and turbulent regimes. As a result, fluid flow and heat transfer characteristics of flow in the transition regime and turbulent regime can be investigated.

- By using different channel configuration, geometrical effects can be investigated more extensively. Some possible investigation may be performed by varying one and fixing two of the following properties for rectangular multiport minichannels: port number, hydraulic diameter and aspect ratio. Afterwards, a heat transfer correlation might be suggested for flow with similar geometric properties.

- Vacuum conditions around the test section can be applied to overcome any possible natural convection heat loss and thermal energy storage in the insulation.

- Different types of fluids such as liquid R-134 or propanol can be used to verify that results are also applicable to other fluids.

- A low voltage high current DC power supply can be purchased for directly heating minichannels by using its wall as a resistance. 


\section{REFERENCES}

[1] "Energy Efficiency Trends in Residential and Commercial Buildings: U.S. Department of Energy, October 2008."

[2] J. J. Conti, P. D. Holtberg, and J. A. Beamon, “Annual Energy Outlook 2013 with projections to 2040," 2013.

[3] S. Kandlikar, S. Garimella, D. Li, S. Colin, and M. King, Heat transfer and fluid flow in minichannels and microchannels, Fifth Ed. Oxford: Elsevier Ltd, 2005.

[4] S. Kakaç, R. K. Shah, and W. Aung, Handbook of Single-Phase Convective Heat Transfer, First Ed. New York: John Wiley \& Sons Inc., 1987.

[5] R. K. Shah and A. L. London, Laminar Flow Forced Convection in Ducts. New York: Academic Press, 1978.

[6] S. G. Kandlikar and W. J. Grande, "Evolution of Microchannel Flow Passages-- Thermohydraulic Performance and Fabrication Technology," Heat Transf. Eng., vol. 24, no. 1, pp. 3-17, 2003.

[7] S. Mehendale, "Fluid flow and heat transfer at micro-and meso-scales with application to heat exchanger design," Appl. Mech. Rev., vol. 53, no. 7, 2000.

[8] R. W. Keyes, "Physical Limits in Digital Electronic," Proc. IEEE, vol. 69, pp. 267-278, 1975.

[9] D. B. Tuckerman and R. F. W. Pease, "High-performance heat sinking for VLSI,” IEEE Electron Device Lett., vol. 2, no. 5, pp. 126-129, May 1981.

[10] J. Pfahler, J. Harley, H. Bau, and J. Zemel, "Liquid transport in micron and submicron channels," Sensors Actuators A Phys., 1989.

[11] X. F. Peng, G. P. Peterson, and B. X. Wang, "Frictional flow characteristics of water flowing through rectangular microchannels," Exp. Heat Transf., vol. 7, no. 4, pp. 249-264, Oct. 1994.

[12] B. X. Wang and X. F. Peng, "Experimental investigation on liquid forcedconvection heat transfer through microchannels," Int. J. Heat Mass Transf., vol. 37, no. 93, pp. 73-82, 1994. 
[13] F. Incropera, A. Lavine, and D. DeWitt, Fundamentals of heat and mass transfer, Sixth Ed. New Jersey, 2007.

[14] X. F. Peng and G. P. Peterson, "Convective heat transfer and flow friction for water flow in microchannel structures," Int. J. Heat Mass Transf., vol. 39, no. 12, pp. 2599-2608, Aug. 1996.

[15] M. Spiga and G. Morini, "Nusselt numbers in laminar flow for H2 boundary conditions," Int. J. Heat Mass Transf., vol. 39, no. 6, pp. 1165-1174, 1996.

[16] G. L. Morini, "Analytical determination of the temperature distribution and Nusselt numbers in rectangular ducts with constant axial heat flux," Int. J. Heat Mass Transf., vol. 43, 2000.

[17] F. W. Schmidt and M. E. Newell, "Heat transfer in fully developed laminar flow through rectangular and isosceles triangular ducts," Int. J. Heat Mass Transf., vol. 10, no. 8, pp. 1121-1123, Aug. 1967.

[18] T. Adams and S. Abdel-Khalik, "An experimental investigation of singlephase forced convection in microchannels," Int. J. Heat Mass Transf., vol. 41, no. 6-7, pp. 851-857, 1998.

[19] S. Garimella, William J. Dowling, Mark, "The Effect of Simultaneously Developing Flow on Heat Transfer in Rectangular Tubes," Heat Transf. Eng., vol. 22, no. 6, pp. 12-25, Nov. 2001.

[20] W. Owhaib and B. Palm, "Experimental investigation of single-phase convective heat transfer in circular microchannels," Exp. Therm. Fluid Sci., vol. 28, no. 2-3, pp. 105-110, Jan. 2004.

[21] D. Lelea, S. Nishio, and K. Takano, "The experimental research on microtube heat transfer and fluid flow of distilled water," Int. J. Heat Mass Transf., vol. 47, no. 12-13, pp. 2817-2830, Jun. 2004.

[22] B. Agostini, B. Watel, A. Bontemps, and B. Thonon, "Liquid flow friction factor and heat transfer coefficient in small channels: an experimental investigation," Exp. Therm. Fluid Sci., vol. 28, no. 2-3, pp. 97-103, Jan. 2004.

[23] J. Judy, D. Maynes, and B. W. Webb, "Characterization of frictional pressure drop for liquid flows through microchannels," Int. J. Heat Mass Transf., vol. 45, no. 17, pp. 3477-3489, Aug. 2002.

[24] P. Gao, S. Le Person, and M. Favre-Marinet, "Scale effects on hydrodynamics and heat transfer in two-dimensional mini and microchannels," Int. J. Therm. Sci., vol. 41, no. 11, pp. 1017-1027, Nov. 2002. 
[25] N. Caney, P. Marty, and J. Bigot, "Friction losses and heat transfer of singlephase flow in a mini-channel," Appl. Therm. Eng., vol. 27, no. 10, pp. 17151721, Jul. 2007.

[26] G. Maranzana, I. Perry, and D. Maillet, "Mini- and micro-channels: influence of axial conduction in the walls," Int. J. Heat Mass Transf., vol. 47, no. 17-18, pp. 3993-4004, Aug. 2004.

[27] P. S. Lee, S. V. Garimella, and D. Liu, "Investigation of heat transfer in rectangular microchannels," Int. J. Heat Mass Transf., vol. 48, no. 9, pp. 1688-1704, Apr. 2005.

[28] C. H. Stignor, B. Sundén, and P. Fahlén, “An Experimental Study of LiquidPhase Heat Transfer in Multiport Minichannel Tubes," Heat Transf. Eng., vol. 30, no. 12, pp. 941-951, Oct. 2009.

[29] V. Gnielinski, "Zur Warmebertragung bei laminarer Rohrstromung und konstanter Wandtemperatur (in German)," Chemie Ing. Tech., vol. 61, no. 2, pp. 160-161, Feb. 1989.

[30] Y. S. Muzychka and M. M. Yovanovich, "Laminar Forced Convection Heat Transfer in the Combined Entry Region of Non-Circular Ducts," J. Heat Transfer, vol. 126, no. 1, p. 54, 2004.

[31] H. S. Park and J. Punch, "Friction factor and heat transfer in multiple microchannels with uniform flow distribution," Int. J. Heat Mass Transf., vol. 51, no. 17-18, pp. 4535-4543, Aug. 2008.

[32] W. M. Kays and M. E. Crawford, Convective Heat and Mass Transfer, Third Ed. McGraw-Hill, 1993.

[33] P. Fernando, B. Palm, T. Ameel, P. Lundqvist, and E. Granryd, “A minichannel aluminium tube heat exchanger - Part I: Evaluation of singlephase heat transfer coefficients by the Wilson plot method," Int. J. Refrig., vol. 31, no. 4, pp. 669-680, Jun. 2008.

[34] V. Gnielinski, "New equations for heat and mass transfer in turbulent pipe and channel flow," Int. Chem. Eng., vol. 16, no. 2, pp. 359-368, 1976.

[35] M. J. Kohl, S. I. Abdel-Khalik, S. M. Jeter, and D. L. Sadowski, “An experimental investigation of microchannel flow with internal pressure measurements," Int. J. Heat Mass Transf., vol. 48, no. 8, pp. 1518-1533, Apr. 2005 .

[36] F. M. White, Fluid Mechanics. New York: McGraw-Hill, 1998. 
[37] R. J. Phillips, "Forced convection, liquid cooled, microchannel heat sinks," Massachusetts Institute of Technology, 1987.

[38] K. Stephan and P. PreuBer, "Warmeübergang und maximale warmestromdichte behaltersieden binaer und ternarer flüsssigkeitgemische," Chem. Ing. Tech., vol. 51, no. 37, 1979.

[39] S. B. Choi, R. F. Barron, and R. O. Warrington, "Fluid flow and heat transfer in microtubes," ASME DSC, pp. 123-134, 1991.

[40] N. T. Nguyen, D. Bochnia, R. Kiehnscherf, and W. Dötzel, "Investigation of forced convection in microfluid systems," Sensors Actuators A Phys., vol. 55, no. 1, pp. 49-55, Jul. 1996.

[41] Y. A. Ağartan, "Experimental comparison of different minichannel geometries for use in evaporators," Middle East Technical University, 2012.

[42] B. Tekin, "Experimental investigation of R134a flow in a $1.65 \mathrm{~mm}$ copper minitube," Middle East Technical University, 2011.

[43] "Cole Parmer, Thermo Scientific NESLAB RTE-series Refrigerated Circulating Baths." [Online]. Available:

http://www.coleparmer.com/catalog/product_view.asp?sku=1350030\&pfx=K H. [Accessed: 07-Nov-2013].

[44] “Cole Parmer, Benchtop Digital Drive.” [Online]. Available: http://www.coleparmer.com/catalog/Product_view.asp?sku=7401455\&pfx=K H\&referred_id=2269. [Accessed: 07-Nov-2013].

[45] M. E. Steinke, S. G. Kandlikar, J. H. Magerlein, E. G. Colgan, and A. D. Raisanen, "Development of an Experimental Facility for Investigating SinglePhase Liquid Flow in Microchannels," Heat Transf. Eng., vol. 27, no. 4, pp. 41-52, May 2006.

[46] "Flowtech, Rotameter Type Flowmeter." [Online]. Available: http://www.flowtech.com.tr/ueruenler/debi-aki/11-dk-800-serisidebimetreler.html. [Accessed: 07-Nov-2013].

[47] "Superior Electric, Variable Transformer." [Online]. Available: http://www.esonic.com/aboutus/cat/V/variable transformers.pdf. [Accessed: 07-Nov-2013].

[48] “Cole Parmer, Oakton Integral handle RTD probes." [Online]. Available: http://www.coleparmer.com/Product/Integral_Handle_RTD_Needle_Probe_2 _L/KH-08117-80?sku=0811780\&pfx=KH\&referred_id=2269. [Accessed: 07Nov-2013]. 
[49] "Cole Parmer, 30-gauge wire." [Online]. Available:

http://www.coleparmer.co.uk/catalog/product_view.asp?sku=0854204\&pfx=K H. [Accessed: 07-Nov-2013].

[50] “Cole Parmer, Compact Pressure Transducer." [Online]. Available: http://www.coleparmer.com/catalog/product_view.asp?sku=6834740. [Accessed: 07-Nov-2013].

[51] "Validyne, Products ${ }^{\circledR}$ P55 Compact Differential Pressure Transducer." [Online]. Available: http://www.validyne.com/ProductDisplay.aspx?Pid=2. [Accessed: 09-Nov-2013].

[52] "Egerate, MCH TECHNIC 305D-2 DC Power Supply." [Online]. Available: http://www.egerate-

store.com/Default.aspx?_Args=ProductInfo,43\&LNG=EN. [Accessed: 07Nov-2013].

[53] “Mica Insulation Plate." [Online]. Available: http://www.micagroup.net/inner_pages/mica_insulation_late.html.

[54] “Izocam, Glass Wool Insulation." [Online]. Available: http://www.izocam.com.tr/en-us/products/insulation-materials/glasswool.aspx.

[55] “404, Adhesive Bonder." [Online]. Available: http://www.404.com.tr/urunlerimiz/siviconta_kirmizi.html.

[56] J. Koo and C. Kleinstreuer, "Viscous dissipation effects in microtubes and microchannels," Int. J. Heat Mass Transf., vol. 47, pp. 3159-3169, 2004.

[57] G. Morini, "Viscous heating in liquid flows in micro-channels," Int. J. Heat Mass Transf., vol. 48, pp. 3637-3647, 2005.

[58] J. P. Holman, Experimental Methods For Engineers, 6th Ed. McGraw-Hill, 1994.

[59] R. Paton, "Calibration and Standards in Flow Measurement." [Online]. Available: http://www.wiley.com/legacy/wileychi/hbmsd/pdfs/mm269.pdf.

[60] “Oakton Acorn RTD thermometer." [Online]. Available: http://www.coleparmer.com/Product/Oakton_Acorn_Temp_6_RTD_thermom eter/EW-35626-20.

[61] "The Calibration of Thermocouples and Thermocouple Materials." [Online]. Available: http://www.nist.gov/calibrations/upload/sp250-35.pdf. 
[62] "Calibration Pressure Measurements." [Online]. Available: http://www.usbr.gov/pmts/geotech/rock/EMpart_2/USBR1040.pdf.

[63] "Parken Accurate Pressure Gauges." [Online]. Available: http://www.pakkens.com.tr/basincolcerler.html?page=shop.product_details\&flypage=flypage.tpl\&product_id=2 0\&category_id=12.

[64] S. G. Kandlikar, "A Roadmap for Implementing Minichannels in Refrigeration and Air-Conditioning Systems - Current Status and Future Directions," Heat Transf. Eng., vol. 28, no. 12, pp. 973-985, Dec. 2007.

[65] "APWS-IF97, Thermodynamic and Transport properties of Water and Steam." [Online]. Available: http://www.cheresources.com/content/articles/physicalproperties/thermodynamic-and-transport-properties-of-water-and-steam. [Accessed: 10-Nov-2013].

[66] R. J. Moffat, "Contributions to the theory of single-sample uncertainty analysis," J. Fluids Eng., vol. 104, pp. 250-261, 1982.

[67] W. M. Kays and A. L. London., Compact heat exchangers. Malabar: Krieger Pub. Co., 1998.

[68] “Agilent, 34970A Data Acquisition / Data Logger Switch Unit.” [Online]. Available:

http://www.home.agilent.com/agilent/product.jspx?cc=TR\&lc=eng\&ckey=10 00001313:epsg:pro\&nid=-33640.536881544.00\&id=1000001313:epsg:pro. [Accessed: 07-Nov-2013]. 


\section{APPENDIX A}

\section{INTERPOLATION EQUATIONS FOR POISEUILLE NUMBER AND NUSSELT NUMBER}

The coefficients of approximate interpolation equation [3], Eqn. (A.1), for Poiseuille number $(\mathrm{Po})$ for developing flow is presented in the Table A.1. For intermediate values of aspect ratios, use linear interpolation.

$$
P o=\frac{a+c\left(x^{+}\right)^{0.5}+e\left(x^{+}\right)}{1+b\left(x^{+}\right)^{0.5}+d\left(x^{+}\right)+f\left(x^{+}\right)^{1.5}}
$$

Table A.1 Interpolation equations for Table 2.2[3]

\begin{tabular}{lllllll}
\hline & \multicolumn{6}{l}{ Constants } \\
\cline { 2 - 7 } Equations & $a$ & $b$ & $c$ & $d$ & $e$ & $f$ \\
\hline$\alpha=1.0$ & 141.97 & -7.0603 & 2603 & 1431.7 & 14364 & -220.77 \\
$\alpha=0.5$ & 142.05 & -5.4166 & 1481 & 1067.8 & 13177 & -108.52 \\
$\alpha=0.2$ & 142.1 & -7.3374 & 376.69 & 800.92 & 14010 & -33.894 \\
$\alpha=0.1$ & 286.65 & 25.701 & 337.81 & 1091.5 & 26415 & 8.4098 \\
\hline
\end{tabular}

The coefficients of approximate interpolation equation [3], Eqn. (A.2), for fully developed Nusselt number for three side heated $\left(N u_{f d, 3}\right)$ and four side heated channels $\left(N u_{f d, 4}\right)$ is presented in the Table A.2.

$$
N u_{f d}=\frac{a+c \alpha+e \alpha^{2}}{1+b \alpha+d \alpha^{2}+f \alpha^{3}}
$$


Table A.2 Interpolation equations for Table 2.4 [3]

\begin{tabular}{|c|c|c|c|c|c|c|}
\hline \multirow[b]{2}{*}{ Equations } & \multicolumn{6}{|c|}{ Constants } \\
\hline & $a$ & $b$ & $c$ & $d$ & $e$ & $f$ \\
\hline$N u_{f d, 3}$ & 8.2321 & 2.0263 & 1.2771 & 0.29805 & 2.2389 & 0.0065322 \\
\hline$N u_{f d 4}$ & 8.2313 & 1.9349 & -2.295 & 0.92381 & 7.928 & 0.0033937 \\
\hline
\end{tabular}

The coefficients of approximate interpolation equations [3], Eqn. (A.3) and Eqn. (A.4), for developing Nusselt number $(\mathrm{Nu})$ for four side heated channels is presented in the Table A.3. Use Eqn. (A.4) for $\alpha=1$ and Eqn. (A.3) for other $\alpha$ values in Table A.3. For intermediate values of aspect ratios, use linear interpolation.

$$
\begin{gathered}
N u=\frac{a+c\left(x^{*}\right)+e\left(x^{*}\right)^{2}}{1+b\left(x^{*}\right)+d\left(x^{*}\right)^{2}+f\left(x^{*}\right)^{3}} \\
N u=a+b\left(x^{*}\right)+c\left(\ln \left(x^{*}\right)\right)^{2}+d\left(\ln \left(x^{*}\right)\right)+e\left(x^{*}\right)^{-1.5}
\end{gathered}
$$

Table A.3 Interpolation equations for Table 2.5 [3]

\begin{tabular}{lllllll}
\hline \multirow{7}{*}{ Equations } & \multicolumn{6}{l}{ Constants } \\
\cline { 2 - 7 } & $a$ & $b$ & $c$ & $d$ & $e$ & $f$ \\
\hline$\alpha=0.10$ & 36.736 & 2254 & 17559 & 66172 & 555480 & 1212.6 \\
$\alpha=0.25$ & 30.354 & 1875.4 & 13842 & 154970 & 783440 & -8015.1 \\
$\alpha=0.33$ & 31.297 & 2131.3 & 14867 & 144550 & 622440 & -13297 \\
$\alpha=0.50$ & 28.315 & 3049 & 27038 & 472520 & 1783300 & -35714 \\
$\alpha=1.00$ & 6.7702 & -3.1702 & 0.4187 & 2.1555 & $2.76 \times 10^{-6}$ & NA \\
\hline
\end{tabular}




\section{APPENDIX B}

\section{DETAILS OF THE COMPONENTS IN THE EXPERIMENTAL SET-UP}

It should be noted that information about most of the components in this experimental set-up are identical with data in two former MSc. Students' theses [41], [42] because several same components are used for the experiments.

\section{B.1. REFRIGERATED CIRCULATING BATH}

The technical details of the bath used for conditioning coolant in the cycle are given below [43].
Brand Name:
Cole Parmer
Catalog Number:
KH-13500-30

Bath Capacity:

7 Liters

Temperature Range:

-40 to $200^{\circ} \mathrm{C}$

Temperature stability:

$\pm 0.01^{\circ} \mathrm{C}$

Temperature control:

PID

Temperature setting :

Digital

Temperature display:

LED

Temperature sensor:

$100 \Omega$ Pt RTD

Cooling capacity:

$800 \mathrm{~W} @ 20^{\circ} \mathrm{C}, 650 \mathrm{~W} @ 0{ }^{\circ} \mathrm{C}, 500 \mathrm{~W} @-10^{\circ} \mathrm{C}$

Wattage:

$2550 \mathrm{~W}$ total, $2000 \mathrm{~W}$ heater 
Pressure pump: $\quad$ Max flow $15 \mathrm{~L} / \mathrm{min}$, Max head 5 psi

Compressor: $\quad 1 / 2 \mathrm{hp}$

Refrigerant: $\quad$ R-404A

Bath opening: $\quad 65 / 8 " \times 71 / 4 "$

Working depth: $\quad 6 "$

Overall dimensions : $\quad 265 / 8 " \mathrm{~W}$ x $\quad 213 / 8 " \mathrm{H}$ x $187 / 8$ "D

Power Input: $\quad 230 \mathrm{VAC}, 50 \mathrm{~Hz}$

Amperes: $\quad 12 \mathrm{~A}$

\section{B.2. DIGITAL GEAR PUMP SYSTEM}

The technical details of the gear pump used to pressurize the cycle are presented below [44].

Brand Name: Cole Parmer

Catalog Number: KH-74014-55

Wetted parts Body: 316 SS

Gears: PPS

Seals: $\quad$ PTFE

Flow rate: $\quad 0.316 \mathrm{~mL} / \mathrm{rev}$

$18.96 \mathrm{~mL} / \mathrm{min}$ at $60 \mathrm{rpm}$

$1137.6 \mathrm{~mL} / \mathrm{min}$ at $3600 \mathrm{rpm}$

Differential pressure $\quad 75 \mathrm{psi}(\max )$

Max system pressure $\quad 300$ psi

Max temperature $\quad 40^{\circ} \mathrm{C}$ (system)

Temperature range $\quad-46$ to $54^{\circ} \mathrm{C}$ 
Port size

Viscosity

Dimensions

Power
$1 / 8 " \mathrm{NPT}(\mathrm{F})$

0.2 to $1500 \mathrm{cp}$

7 3/4"L x 11 1/2"W x 7 1/4"H

$220 \mathrm{VAC}$

\section{B.3. COMPACT PRESSURE TRANSDUCER}

The technical details of the compact pressure transducers used to measure pressure values at the inlet and exit of test section are presented below [50].

Brand Name:

Cole Parmer

Catalog Number:

KH-68347-40

Output

4-20 mA

Process connection

1/4" NPT (M)

Range

200 psia

Accuracy

$0.5 \%$ full scale

Power

8 to $30 \mathrm{VDC}$

\section{B.4. RTD PROBE}

RTDs are used in both cycles to determine the temperature at the inlet and exit of channel to determine fluid temperature [48]

Brand Name:

Cole Parmer

Catalog Number:

KH-08117-80

Temp range:

-50 to $500^{\circ} \mathrm{C}$

Probe length:

$2 "$

Diameter:

0.093" 
Time constant: $\quad 10$ seconds

Sheath material: $\quad 316$ SS

\section{B.5. THERMOCOUPLE WIRE}

Thermocouples are used to measure the wall temperature of channel in which fluids flow [49].

Brand Name:

Cole Parmer

Catalog Number:

KH-08542-04

Length:

$1000 \mathrm{ft}$

Temp range:

-200 to $204^{\circ} \mathrm{C}$

Error limit:

$\pm 0.75 \%$ reading from -200 to $-65^{\circ} \mathrm{C}$;

$\pm 0.5^{\circ} \mathrm{C}$ from -65 to $130^{\circ} \mathrm{C}$

$\pm 0.75 \%$ reading from 130 to $350^{\circ} \mathrm{C}$

Type:

$\mathrm{T}$

Advantages: $\quad$ Chemical, moisture and abrasion resistance

Gauge: $\quad 30$

ID: $\quad 0.0100 "(0.25 \mathrm{~mm}) \mathrm{dia}$

OD: $\quad 0.030^{\prime \prime} \times 0.048^{\prime \prime}$

Model:

T30-2-506 


\section{B.6. FLOWMETER}

The details of the flowmeter used to measure flow rate in the cycle is presented below [46].

Brand name: $\quad$ Flowtech

Model: $\quad$ DK800S-6

Temp range: $\quad 0$ to $60^{\circ} \mathrm{C}$

Pressure range: $\quad$ up to $1 \mathrm{MPa}$

Accuracy: $\quad 2.5 \%$

Flow range: $\quad 6$ to $60 \mathrm{lt} / \mathrm{h}$

Weight: $\quad 0.45 \mathrm{~kg}$

\section{B.7. DIFFERENTIAL PRESSURE TRANSDUCER}

The details of differential pressure transducer for measuring pressure drop along the channel is provided below [51].

$\begin{array}{ll}\text { Brand Name: } & \text { Validyne } \\ \text { Catalog Number: } & 1-\mathrm{N}-1-28-\mathrm{S}-4-\mathrm{A} \\ \text { Dimensions } & 1.5^{\prime \prime} \mathrm{L} \text { x } 1.5^{\prime \prime} \mathrm{W} \text { x } 4.5^{\prime \prime} \mathrm{H} \\ \text { Output } & \pm 5 \mathrm{Vdc} @ 0.5 \mathrm{~mA} \\ \text { Operating temperature } & -65 \text { to } 250^{\circ} \mathrm{F}\left(-54 \text { to } 121^{\circ} \mathrm{C}\right) \\ \text { Process connection } & 1 / 8^{\prime \prime} \mathrm{NPT}(\mathrm{F}) \\ \text { Range } & \pm 0.08 \text { to } \pm 3200 \text { psid } \\ \text { Accuracy } & \pm 0.25 \% \text { full scale } \\ \text { Power } & 9 \text { to } 55 \mathrm{Vdc}\end{array}$




\section{B.8. DC POWER SUPPLY}

The details of DC power supply for powering data acquisition system is provided below [52].

Brand Name:

$\mathrm{MCH}$ Technic

Catalog Number:

MCH 305D-2 DC Power Supply

Voltage:

0-30V Adjustable

Current:

0-5A Adjustable

Dual-Output DC Power Source

Two Independent: $\quad 30 \mathrm{~V}-5 \mathrm{~A}$

With Serial Button: 60V-5A

With Parallel Button: 30V-10A

Voltage

0 to Descripted Continuously Variable

Stability

Voltage: $\leq 0.01 \%+2 \mathrm{mV}$

Load: $\leq 0.0 \%+2 \mathrm{mV}$

Recover Time

$\leq 100 \mu \mathrm{S}$

Ripple \& Noise

$\leq 1$ MVRMS (efficent)

Temperature Factor

$\leq 300 \mathrm{PPM} /{ }^{\circ} \mathrm{C}$

Current

0 to Descripted Continuously Variable

Current, Load Stability $\quad \leq 0.2 \%+3 \mathrm{~mA}$

Ripple \& Noise

$\leq 3 \mathrm{mArms}$

Working Condition

Line Power Supply

$220 \mathrm{~V} \pm 10 \% 50 / 60 \mathrm{~Hz}$

Operating Temperature:

$-10^{\circ} \mathrm{C}$ to $40^{\circ} \mathrm{C}$ Moisture $\leq 90 \%$

Storage Temperature:

$-20^{\circ} \mathrm{C}$ to $80^{\circ} \mathrm{C}$ Moisture $\leq 80 \%$ 


\section{B.9. DATA ACQUISITION SYSTEM}

The details of data acquisition system for measurement storage is listed below [68].

Brand Name: Agilent

Catalog Number: 34970A Data Acquisition / Switch Unit

Slot

Interface

Multimeter

Scanning

Modules

Memory

Alarm

Measurement

Software

without programming

Brand Name:

Catalog Number:

Module

Model description:

Type

Speed $(\mathrm{ch} / \mathrm{sec})$

Max volts

Max amps
3

GPIB and RS232

Digital and internal with 6 1/2-digit (22-bit)

up to 250 channels per second

8 switch and control plug-in

50k readings

Hi/Lo on each channel

Thermocouples, RTDs and thermistors, ac/dc volts and current; resistance; frequency and period

Free Bench Link data logger software enables tests

Agilent

34901A 20-Channel Multiplexer +2 Current Channels

(Built-in thermocouple reference junction)

34901A 20 ch Multiplexer+ 2 current channels

2-wire armature (4-wire selectable)

60

$300 \mathrm{~V}$

$1 \mathrm{~A}$ 


\section{B.10. VARIABLE TRANSFORMER (VARIAC)}

The details of variable transformer for controlling the power of the heater is given below [47].

Brand Name: $\quad$ Superior Electric

Catalog Number: $\quad 226 \mathrm{U}$

Input Volts 240

Input hertz $\quad 50 / 60$

Output Volts $\quad 0-280$

Output max amps $\quad 7.5$

Output max power $\quad 2.1 \mathrm{KVA}$

Weight $18 \mathrm{lbs}$

Phase Single phase

\section{B.11. POWER ANALYZER}

The details of power analyzer used to measure the power supplied to the heater is given below.

Brand Name

AEMC Instruments

Type:

True RMS Power Analyzer 3930

Current ranges: $\quad 0.1$ to $1.3 \mathrm{amps}, 0.5$ to $6.5 \mathrm{amps}$ and 1.0 to $13 \mathrm{amps}$

Voltage ranges: $\quad 10$ to 130 and 50 to $650\left(\mathrm{~V}_{\mathrm{rms}}\right)$

Supply: $\quad 58 \mathrm{~V}, 100 \mathrm{~V}, 127 \mathrm{~V}, 220 \mathrm{~V}$ and $380 \mathrm{~V}$

Dimensions: $\quad 13 \times 7.1 \times 12.1 ”(330 \times 180 \times 310 \mathrm{~mm})$

Weight: $\quad 2.7 \mathrm{~kg}$

Accuracy: $\quad 1.5 \%$ 


\section{APPENDIX C}

\section{THE TECHNICAL DRAWINGS OF THE MANIFOLD}

The manifolds were manufactured from aluminum. After cutting the aluminum blocks into rectangle blocks as shown in Figure C.1 and Figure C.2, the inner water passage inside manifolds were manufactured using CNC machines. The four dots on the outside corners of the upper cover were used for placing screws to attach upper and lower covers. The inner two dots are just for showing the location of RTD and pressure transducers which are attached on lower cover. The back side of the lower cover were drilled and threaded for pipe connection. Similarly, two holes were drilled and threaded on top surface of lower cover for RTD and pressure transducer connection. The dimensions of these connections are presented in Figure C.3. Additionally, the assembly of the manifold is shown in Figure C.3. The minichannel was connected with the manifold at the shallow long passage inside the manifold while piping was connected with the manifold at the back of the assembly. 

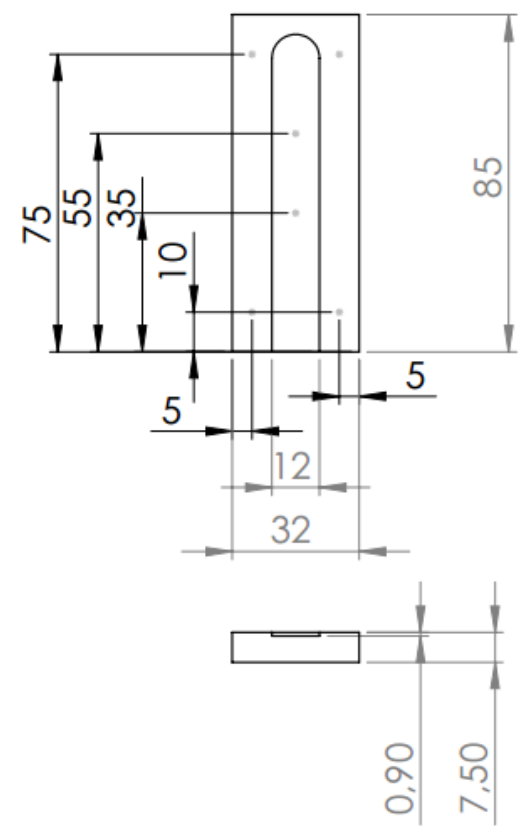

Figure C.1 Upper cover of the manufactured manifold 

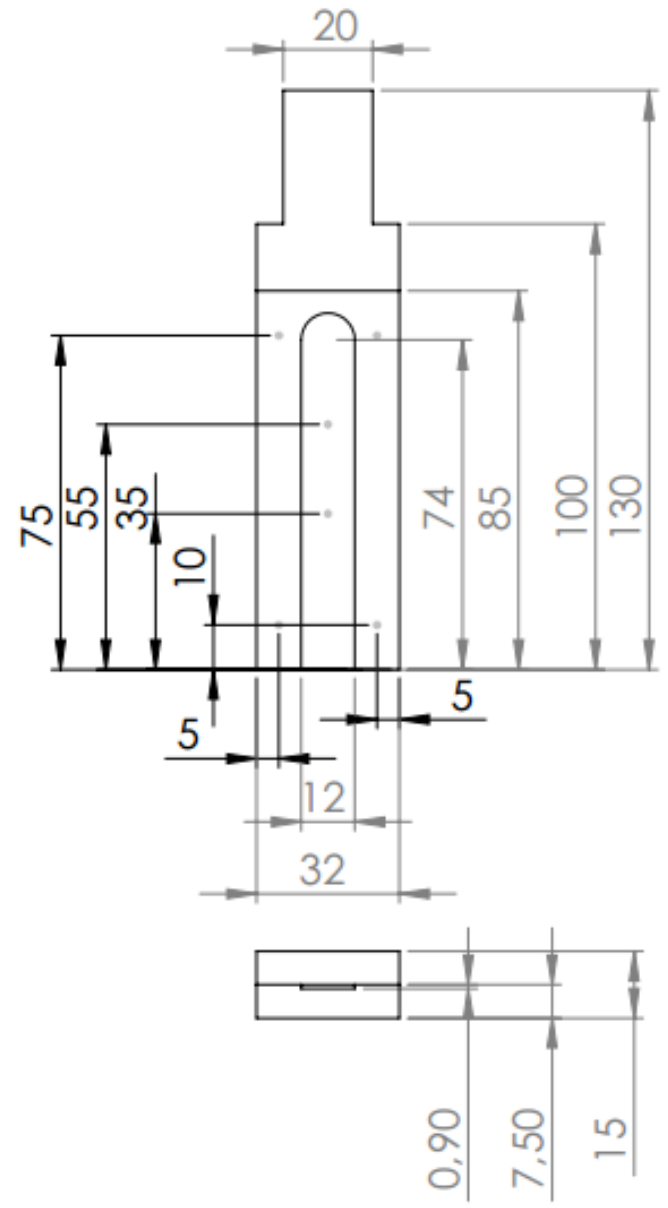

Figure C.2 Lower cover of the manufactured manifold 

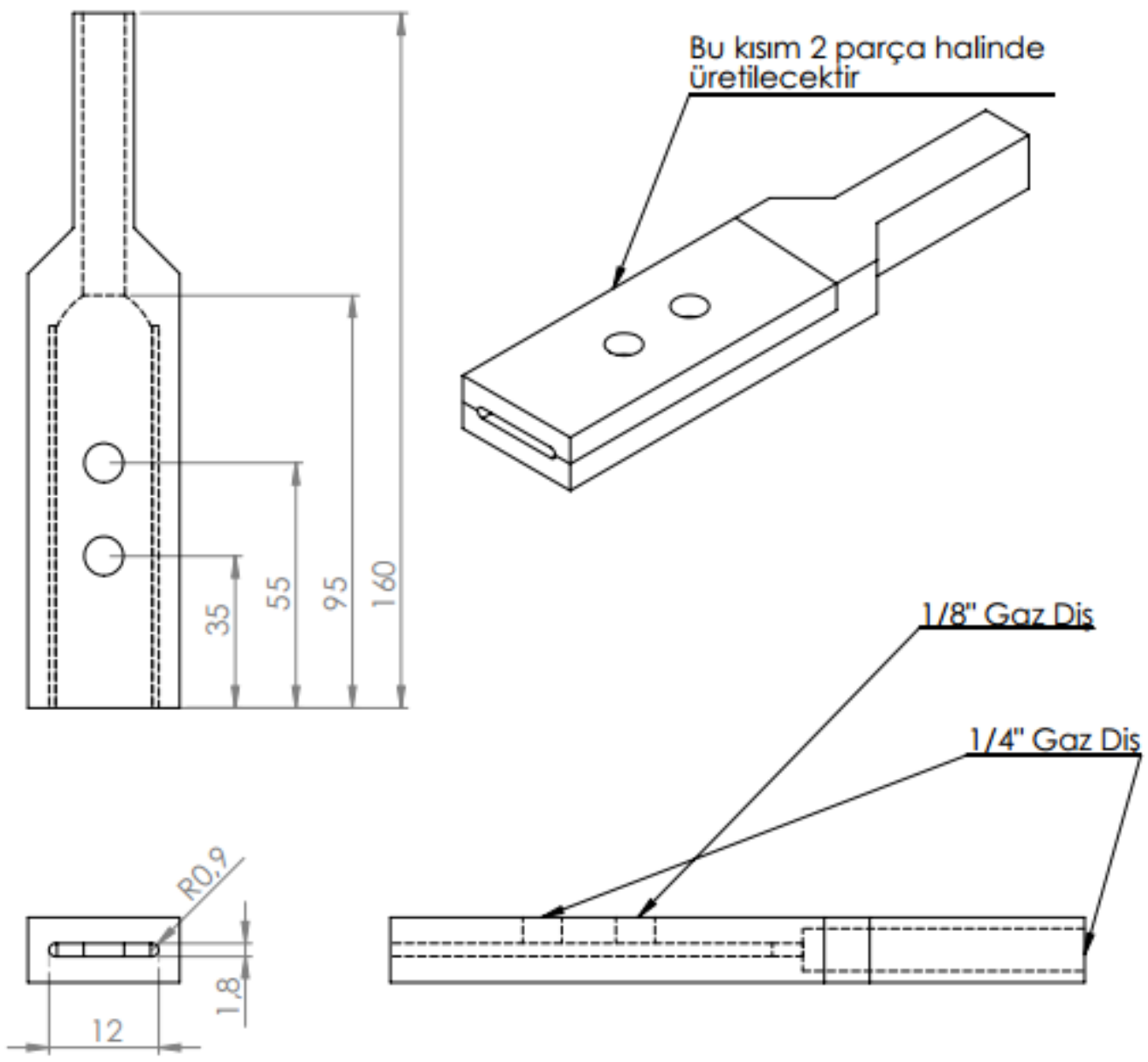

Figure C.3 A sample assembled manifold after manufacture 


\section{APPENDIX D}

\section{THE CALIBRATION TABLES AND GRAPHS FOR MEASUREMENT DEVICES}

The Table D.1 shows the data of gravimetric calibration. $Q_{\text {read }}$ and $Q_{a c t}$ are actual flowmeter measurement from calibration experiment and read flow meter value, respectively.

Table D.1: Gravimetric calibration data for flowmeter

\begin{tabular}{cccccc}
$\boldsymbol{Q}_{\text {read }}(\mathbf{L} / \mathbf{h})$ & Weight $(\mathbf{g})$ & Time$(\mathbf{s})$ & Volume $(\mathbf{L})$ & $\boldsymbol{Q}_{a c t}(\mathbf{L} / \mathbf{h})$ & $\boldsymbol{Q}_{\text {read }} / \boldsymbol{Q}_{\text {act }}$ \\
\hline 10 & 3670 & 1400 & 3.68 & 9.47 & 1.06 \\
15 & 3895 & 970 & 3.91 & 14.5 & 1.03 \\
20 & 3983 & 730 & 3.99 & 19.7 & 1.02 \\
25 & 3962 & 570 & 3.97 & 25.1 & 1.00 \\
30 & 3935 & 480 & 3.95 & 29.6 & 1.01 \\
35 & 4054 & 410 & 4.07 & 35.7 & 0.98 \\
40 & 4048 & 360 & 4.06 & 40.6 & 0.99 \\
45 & 4068 & 320 & 4.08 & 45.9 & 0.98 \\
50 & 3930 & 290 & 3.94 & 48.9 & 1.02 \\
55 & 3996 & 260 & 4.01 & 55.5 & 0.99 \\
60 & 4028 & 240 & 4.04 & 60.6 & 0.99 \\
\hline
\end{tabular}




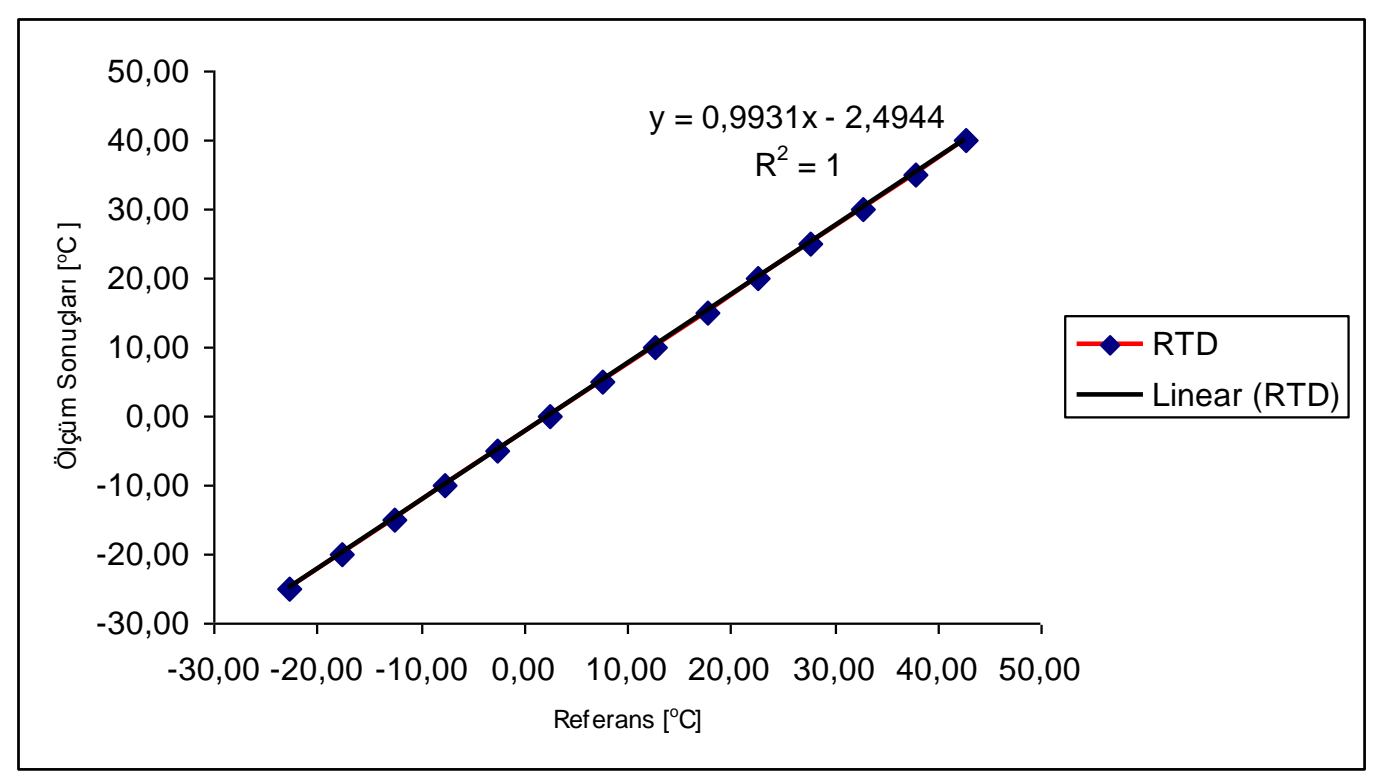

Figure D.1: A sample calibration curve for a calibrated RTD

Table D.2: Calibration data for RTDs and Thermocouples

\begin{tabular}{|c|c|c|c|c|c|c|c|}
\hline $\mathbf{T}_{\text {ref }}\left({ }^{\circ} \mathbf{C}\right)$ & $\mathbf{T}_{\text {TC }}\left({ }^{\circ} \mathbf{C}\right)$ & $\mathbf{T}_{\text {RTD_exit }}\left({ }^{\circ} \mathbf{C}\right)$ & $\mathbf{T}_{\text {RTD inlet }}\left({ }^{\circ} \mathbf{C}\right)$ & $\mathbf{T}_{\text {ref }}\left({ }^{\circ} \mathbf{C}\right)$ & $\mathbf{T}_{\mathbf{T C}}\left({ }^{\circ} \mathbf{C}\right)$ & $\mathbf{T}_{\text {RTD_exit }}\left({ }^{\circ} \mathbf{C}\right)$ & $\left.\mathbf{T}_{\text {RTD inlet }}{ }{ }^{\mathbf{C}}\right)$ \\
\hline 10.0 & 10.0 & 10.1 & 10.1 & 27.6 & 27.6 & 27.7 & 27.7 \\
\hline 10.4 & 10.4 & 10.5 & 10.5 & 28.0 & 28.0 & 28.1 & 28.2 \\
\hline 10.8 & 10.8 & 10.8 & 10.9 & 28.4 & 28.4 & 28.5 & 28.6 \\
\hline 11.2 & 11.2 & 11.2 & 11.3 & 28.8 & 28.8 & 28.9 & 28.9 \\
\hline 11.6 & 11.6 & 11.7 & 11.7 & 29.2 & 29.2 & 29.1 & 29.4 \\
\hline 12.0 & 12.0 & 12.1 & 12.2 & 29.6 & 29.6 & 29.7 & 29.7 \\
\hline 12.4 & 12.4 & 12.5 & 12.6 & 30.0 & 30.0 & 30.1 & 30.1 \\
\hline 12.8 & 12.8 & 12.9 & 12.9 & 30.4 & 30.4 & 30.5 & 30.5 \\
\hline 13.2 & 13.2 & 13.3 & 13.3 & 30.8 & 30.8 & 30.9 & 31.0 \\
\hline 13.6 & 13.6 & 13.7 & 13.8 & 31.2 & 31.2 & 31.3 & 31.3 \\
\hline 14.0 & 14.0 & 14.0 & 14.1 & 31.6 & 31.6 & 31.7 & 31.7 \\
\hline 14.4 & 14.4 & 14.4 & 14.5 & 32.0 & 32.0 & 32.1 & 32.1 \\
\hline 14.8 & 14.8 & 14.9 & 15.0 & 32.4 & 32.4 & 32.5 & 32.6 \\
\hline 15.2 & 15.2 & 15.3 & 15.3 & 32.8 & 32.8 & 32.9 & 32.9 \\
\hline 15.6 & 15.6 & 15.7 & 15.7 & 33.2 & 33.2 & 33.2 & 33.3 \\
\hline 16.0 & 16.0 & 16.1 & 16.1 & 33.6 & 33.6 & 33.7 & 33.8 \\
\hline 16.4 & 16.4 & 16.5 & 16.6 & 34.0 & 34.0 & 34.1 & 34.1 \\
\hline 16.8 & 16.8 & 16.9 & 17.0 & 34.4 & 34.4 & 34.5 & 34.5 \\
\hline 17.2 & 17.2 & 17.3 & 17.3 & 34.8 & 34.8 & 34.9 & 35.0 \\
\hline 17.6 & 17.6 & 17.7 & 17.7 & 35.2 & 35.2 & 35.3 & 35.3 \\
\hline 18.0 & 18.0 & 18.1 & 18.1 & 35.6 & 35.6 & 35.7 & 35.7 \\
\hline 18.4 & 18.4 & 18.5 & 18.5 & 36.0 & 36.0 & 36.1 & 36.1 \\
\hline & & & & & & & \\
\hline
\end{tabular}




\begin{tabular}{|l|l|l|l|l|l|l|l|}
\hline 18.8 & 18.8 & 18.9 & 18.9 & 36.4 & 36.4 & 36.5 & 36.5 \\
\hline 19.2 & 19.2 & 19.3 & 19.3 & 36.8 & 36.8 & 36.9 & 36.9 \\
\hline 19.6 & 19.6 & 19.7 & 19.8 & 37.2 & 37.2 & 37.3 & 37.4 \\
\hline 20.0 & 20.0 & 20.1 & 20.2 & 37.6 & 37.6 & 37.7 & 37.8 \\
\hline 20.4 & 20.4 & 20.5 & 20.6 & 38.0 & 38.0 & 38.1 & 38.1 \\
\hline 20.8 & 20.8 & 20.9 & 20.8 & 38.4 & 38.4 & 38.5 & 38.5 \\
\hline 21.2 & 21.2 & 21.1 & 21.4 & 38.8 & 38.8 & 38.9 & 38.9 \\
\hline 21.6 & 21.6 & 21.7 & 21.7 & 39.2 & 39.2 & 39.3 & 39.3 \\
\hline 22.0 & 22.0 & 22.1 & 22.1 & 39.6 & 39.6 & 39.7 & 39.8 \\
\hline 22.4 & 22.4 & 22.5 & 22.5 & 40.0 & 40.0 & 40.1 & 40.1 \\
\hline 22.8 & 22.8 & 22.9 & 22.9 & 40.4 & 40.4 & 40.4 & 40.5 \\
\hline 23.2 & 23.2 & 23.3 & 23.3 & 40.8 & 40.8 & 40.8 & 40.9 \\
\hline 23.6 & 23.6 & 23.7 & 23.7 & 41.2 & 41.2 & 41.3 & 41.4 \\
\hline 24.0 & 24.0 & 24.1 & 24.1 & 41.6 & 41.6 & 41.6 & 41.7 \\
\hline 24.4 & 24.4 & 24.4 & 24.5 & 42.0 & 42.0 & 42.1 & 42.1 \\
\hline 24.8 & 24.8 & 24.9 & 25.0 & 42.4 & 42.4 & 42.5 & 42.5 \\
\hline 25.2 & 25.2 & 25.3 & 25.3 & 42.8 & 42.8 & 42.8 & 43.0 \\
\hline 25.6 & 25.6 & 25.7 & 25.8 & 43.2 & 43.2 & 43.3 & 43.3 \\
\hline 26.0 & 26.0 & 26.1 & 26.1 & 43.6 & 43.6 & 43.6 & 43.7 \\
\hline 26.4 & 26.4 & 26.5 & 26.5 & 44.0 & 44.0 & 44.1 & 44.1 \\
\hline 26.8 & 26.8 & 26.8 & 26.9 & 44.4 & 44.4 & 44.5 & 44.6 \\
\hline 27.2 & 27.2 & 27.3 & 27.3 & 44.8 & 44.8 & 44.9 & 44.9 \\
\hline
\end{tabular}

Table D.3: The calibration results for the CPTs 


\begin{tabular}{|c|c|c|c|c|c|c|c|c|}
\hline PSI & 221 & 222 & PSI & 221 & 222 & PSI & $221(\mathrm{~A})$ & $222(\mathrm{~A})$ \\
\hline \multicolumn{3}{|c|}{$0-200$ psi çıkış } & \multicolumn{3}{|c|}{$0-200$ psi iniş } & \multicolumn{3}{|c|}{$0-200$ psi ortalama } \\
\hline 0 & 0,003983 & 0,003985 & 0 & 0,003982 & 0,003989 & 0 & 0,003983 & 0,003987 \\
\hline$\overline{1}$ & 0,004064 & 0,004063 & 1 & 0,004061 & 0,004065 & 1 & 0,004063 & 0,004064 \\
\hline 2 & 0,004137 & 0,004136 & 2 & 0,00414 & 0,004143 & 2 & 0,004138 & 0,00414 \\
\hline 3 & 0,004212 & 0,004214 & 3 & 0,004216 & 0,004217 & 3 & 0,004214 & 0,004215 \\
\hline 4 & 0,004291 & 0,004295 & 4 & 0,004298 & 0,004299 & 4 & 0,004295 & 0,004297 \\
\hline 5 & 0,004366 & 0,00437 & 5 & 0,004376 & 0,004377 & 5 & 0,004371 & 0,004373 \\
\hline 6 & 0,004445 & 0,004448 & 6 & 0,004453 & 0,004454 & 6 & 0,004449 & 0,004451 \\
\hline 7 & 0,004524 & 0,004526 & 7 & 0,00453 & 0,00453 & 7 & 0,004527 & 0,004528 \\
\hline 8 & 0,004601 & 0,004602 & 8 & 0,004606 & 0,004607 & 8 & 0,004603 & 0,004604 \\
\hline 9 & 0,00468 & 0,00468 & 9 & 0,004683 & 0,004684 & 9 & 0,004681 & 0,004682 \\
\hline 10 & 0,004759 & 0,004758 & 10 & 0,004764 & 0,004761 & 10 & 0,004761 & 0,00476 \\
\hline 11 & 0,004838 & 0,004837 & 11 & 0,004841 & 0,004842 & 11 & 0,004839 & 0,00484 \\
\hline 12 & 0,004917 & 0,004915 & 12 & 0,004918 & 0,004917 & 12 & 0,004917 & 0,004916 \\
\hline 13 & 0,004997 & 0,004994 & 13 & 0,004996 & 0,004995 & 13 & 0,004997 & 0,004994 \\
\hline 14 & 0,005078 & 0,005073 & 14 & 0,005078 & 0,005076 & 14 & 0,005078 & 0,005074 \\
\hline 15 & 0,005152 & 0,005147 & 15 & 0,005156 & 0,005152 & 15 & 0,005154 & 0,00515 \\
\hline 20 & 0,005543 & 0,005536 & 20 & 0,005551 & 0,005545 & 20 & 0,005547 & 0,00554 \\
\hline 40 & 0,007121 & 0,007114 & 40 & 0,007133 & 0,007124 & 40 & 0,007127 & 0,007119 \\
\hline 60 & 0,008742 & 0,008733 & 60 & 0,008706 & 0,008695 & 60 & 0,008724 & 0,008714 \\
\hline 80 & 0,010273 & 0,01026 & 80 & 0,010282 & 0,010268 & 80 & 0,010277 & 0,010264 \\
\hline 100 & 0,011859 & 0,011846 & 100 & 0,011862 & 0,011847 & 100 & 0,011861 & 0,011846 \\
\hline 120 & 0,013432 & 0,013416 & 120 & 0,013435 & 0,013417 & 120 & 0,013433 & 0,013417 \\
\hline 140 & 0,01502 & 0,015001 & 140 & 0,015017 & 0,014993 & 140 & 0,015018 & 0,014997 \\
\hline 160 & 0,016588 & 0,016564 & 160 & 0,016597 & 0,016574 & 160 & 0,016592 & 0,016569 \\
\hline 180 & 0,018162 & 0,018146 & 180 & 0,018169 & 0,018148 & 180 & 0,018165 & 0,018147 \\
\hline 200 & 0,019752 & 0,019717 & 200 & 0,019747 & 0,019723 & 200 & 0,019749 & 0,01972 \\
\hline
\end{tabular}

221

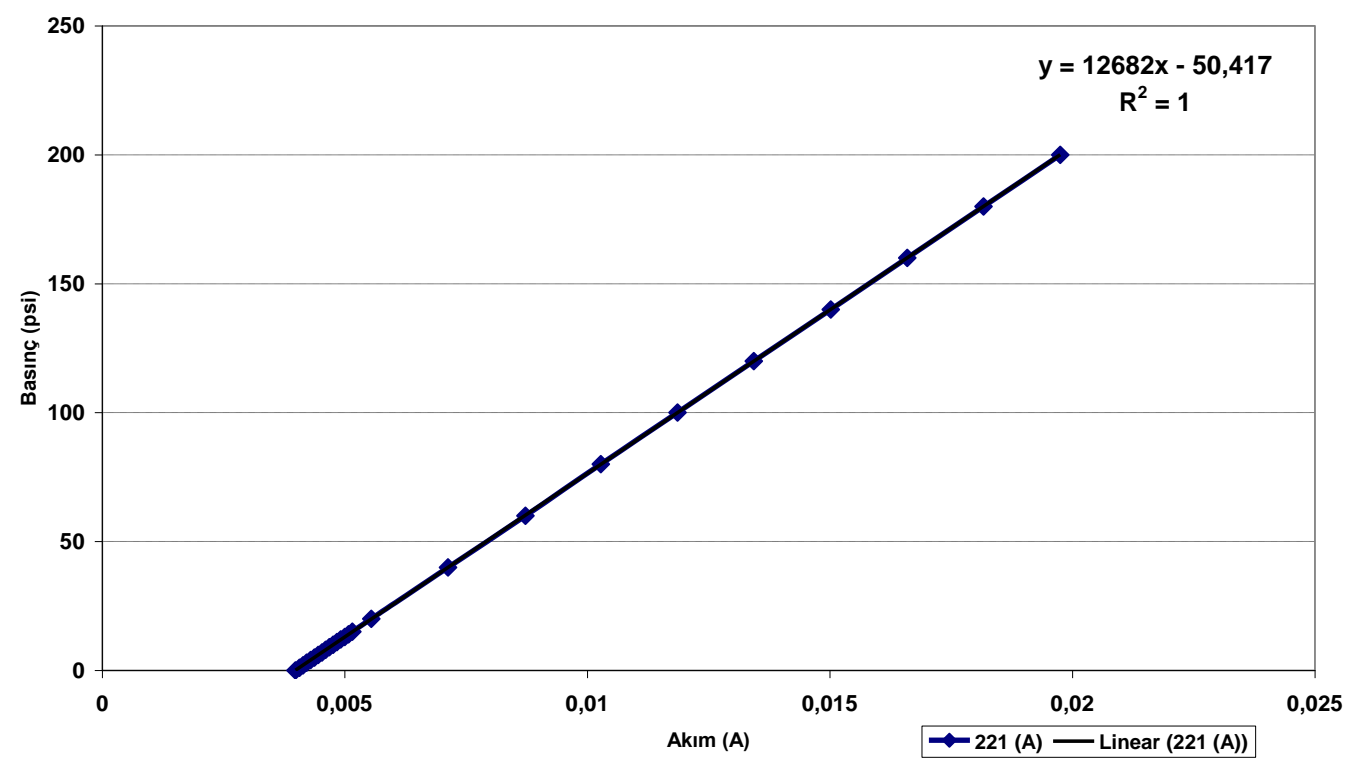

Figure D.2: The calibration curve for the CPT [equation (14)] 
Table D.4 The calibration results for the differential pressure transducer

\begin{tabular}{|c|c|}
\hline bar & $\mathbf{~ V}$ \\
\hline 0,0 & 0,342348 \\
\hline 0,5 & 0,88057 \\
\hline 1,0 & 1,362816 \\
\hline 1,5 & 1,85528 \\
\hline 2,0 & 2,377242 \\
\hline 2,5 & 2,746445 \\
\hline 3,0 & 3,294953 \\
\hline 3,5 & 3,660102 \\
\hline 4,0 & 4,213051 \\
\hline 4,5 & 4,685636 \\
\hline 5,0 & 5,166647 \\
\hline
\end{tabular}

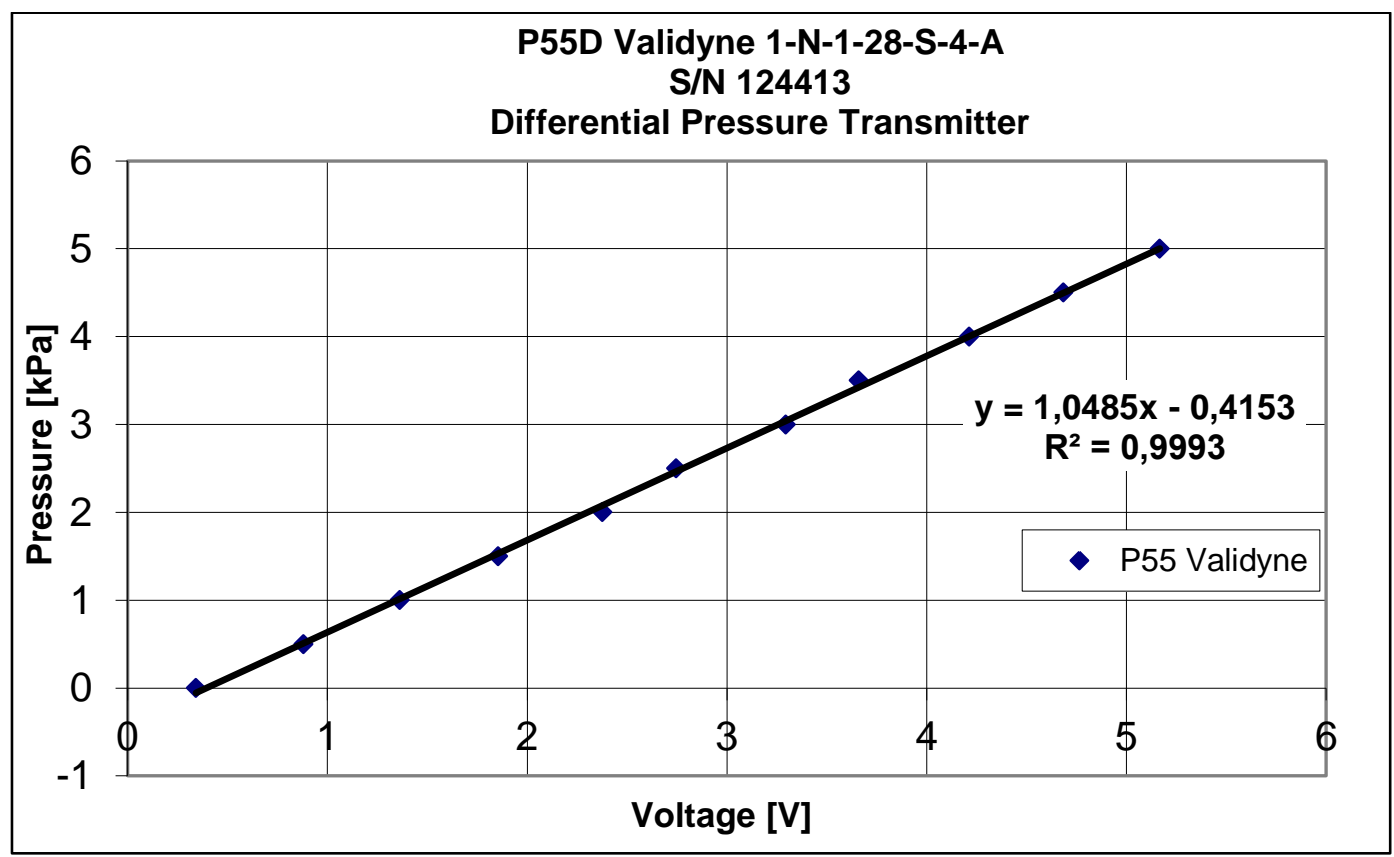

Figure D.3 The calibration curve for the DPT 


\section{APPENDIX E}

\section{THE RAW EXPERIMENTAL RESULTS}

In this section, the raw data of the experiments are presented. Using these data, the results of experiments can be used for repetition of experiments or benchmarking. The raw experimental data are presented in 3 separate tables. These tables are provided in the following pages as Table E.1, Table E.2 and Table E.3 


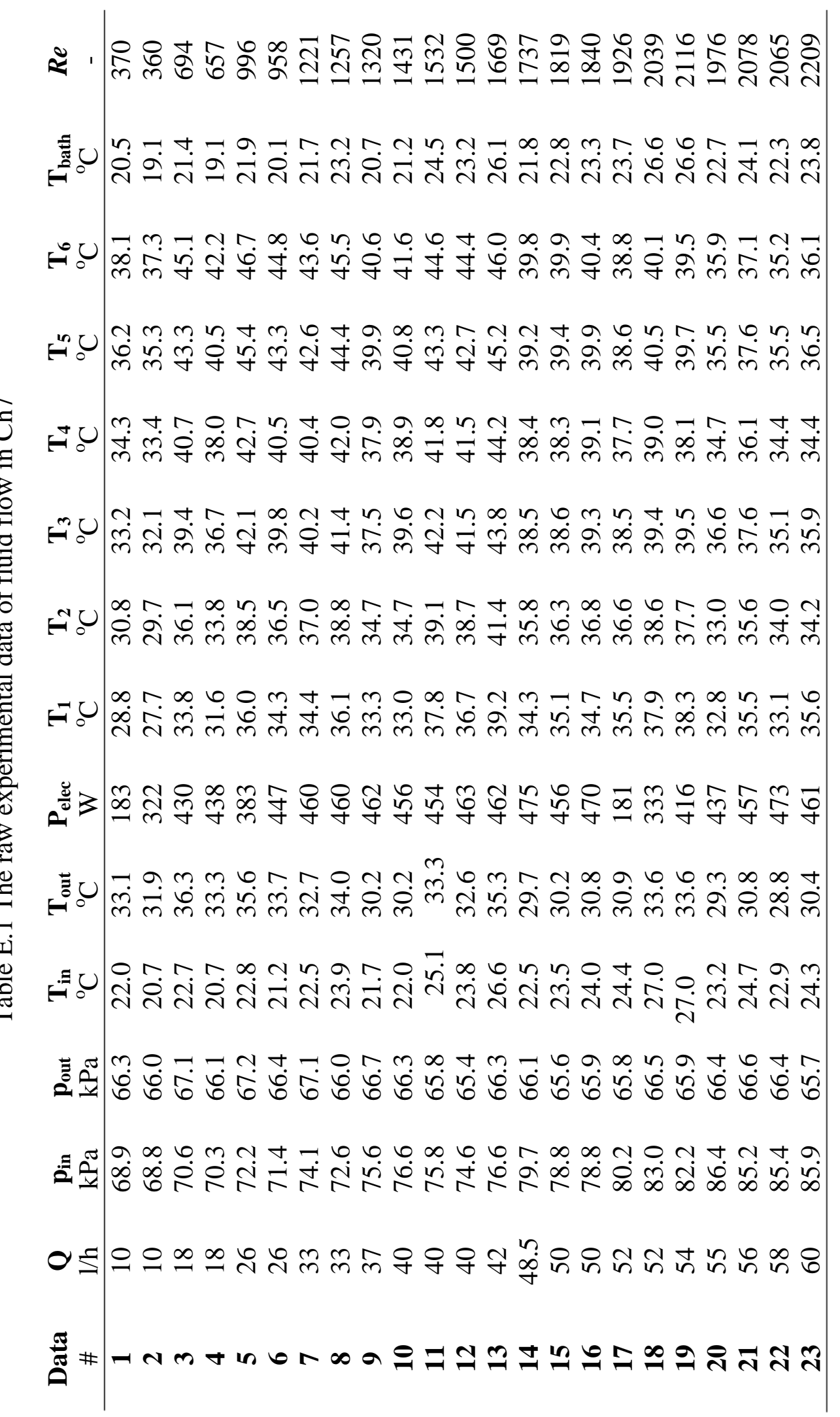




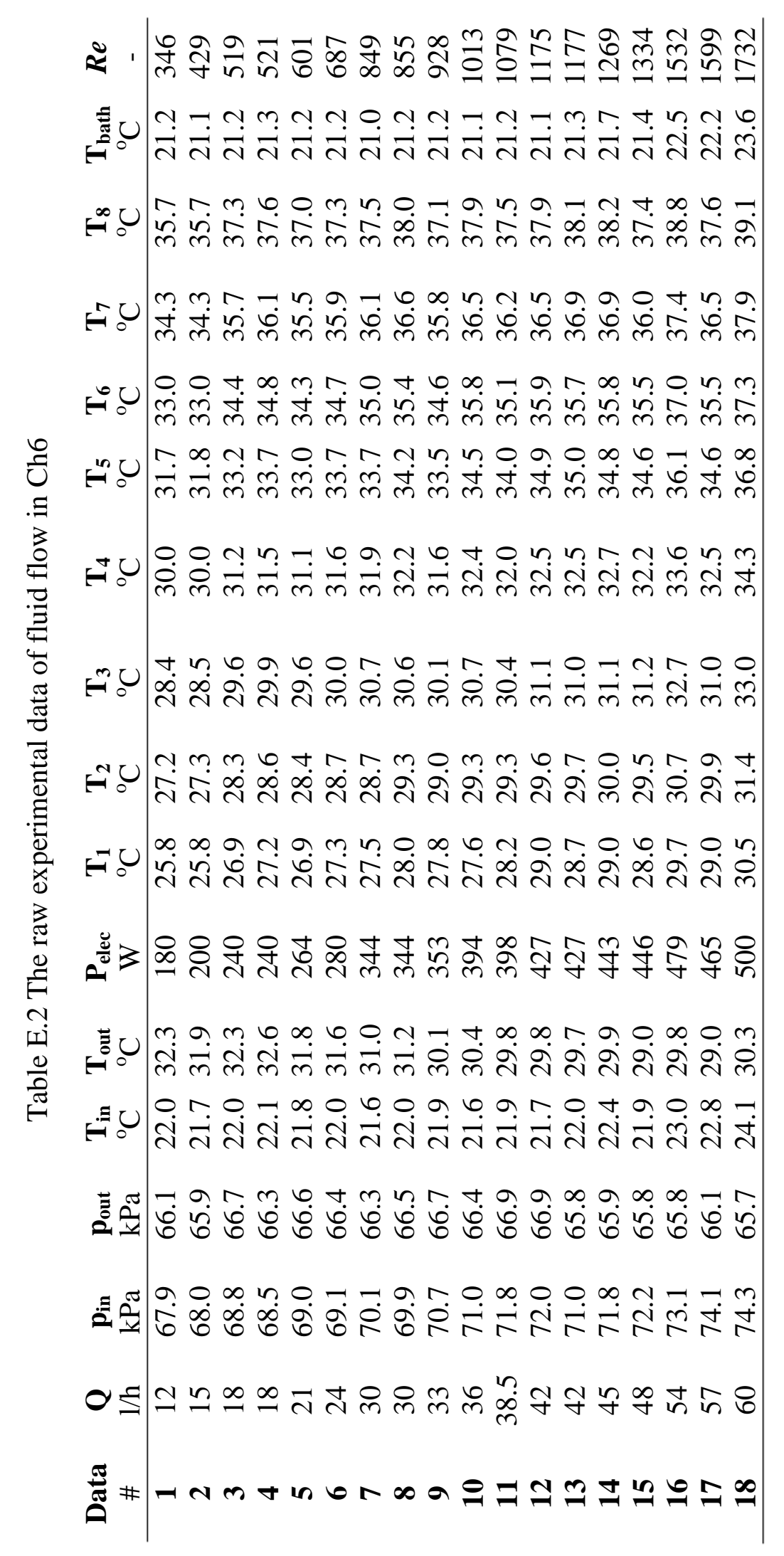




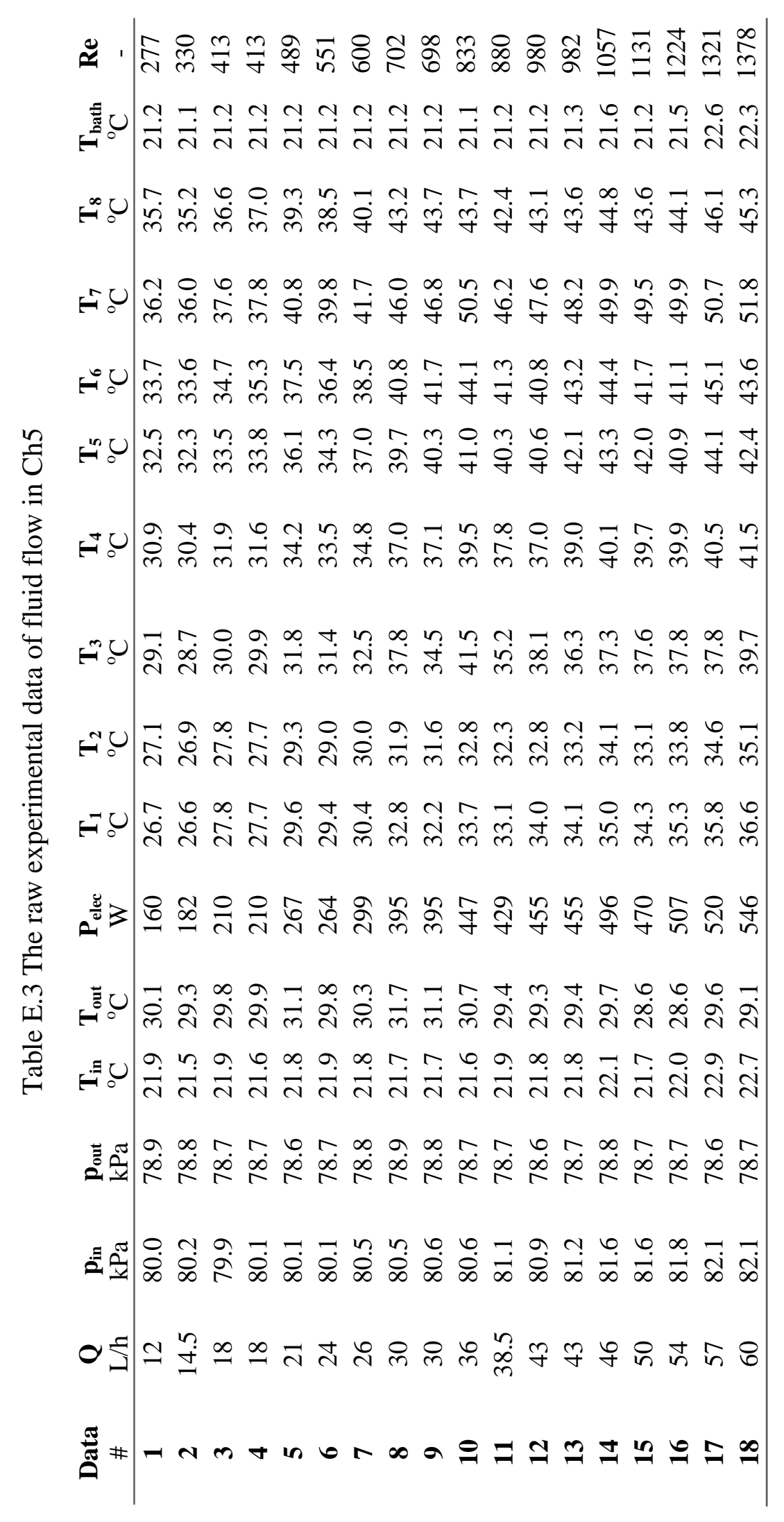




\section{APPENDIX F}

\section{THE WATER PROPERTIES}

The water properties during the experiments were found by using excel add-in for water generated by using standard industrial standard IAPWS-IF97. Here, properties of water were presented with comparison heat transfer book of Incropera et al. [13] .

Table F.1 Density of water for different temperature at a pressure of 0.9 bar

\begin{tabular}{cccc}
\multicolumn{3}{c}{ Density $\left(\mathrm{kg} / \mathrm{m}^{3}\right)$} \\
\hline $\mathrm{T}\left({ }^{\circ} \mathrm{C}\right)$ & APWS-IF97[65] & $\begin{array}{c}\text { Incropera } \\
{[13]}\end{array}$ & $\begin{array}{c}\text { Relative } \\
\text { Difference }\end{array}$ \\
\hline 275 & 999.9 & 1000.0 & $0.01 \%$ \\
280 & 999.9 & 1000.0 & $0.01 \%$ \\
285 & 999.5 & 1000.0 & $0.05 \%$ \\
290 & 998.8 & 999.0 & $0.02 \%$ \\
295 & 997.8 & 998.0 & $0.02 \%$ \\
300 & 996.6 & 997.0 & $0.05 \%$ \\
305 & 995.1 & 997.0 & $0.19 \%$ \\
310 & 993.4 & 993.0 & $-0.03 \%$ \\
315 & 991.5 & 991.1 & $-0.04 \%$ \\
320 & 989.4 & 989.1 & $-0.03 \%$ \\
325 & 987.2 & 987.2 & $0.00 \%$ \\
330 & 984.8 & 984.3 & $-0.06 \%$ \\
335 & 982.2 & 982.3 & $0.01 \%$ \\
340 & 979.5 & 979.4 & $-0.01 \%$ \\
\hline
\end{tabular}


Table F.2 Specific heat of water for different temperature at a pressure of 0.9 bar Specific Heat( $\mathrm{kJ} / \mathrm{kg} \mathrm{K})$

\begin{tabular}{cccc}
\hline $\mathrm{T}\left({ }^{\circ} \mathrm{C}\right)$ & APWS-IF97[65] & $\begin{array}{c}\text { Incropera } \\
{[13]}\end{array}$ & $\begin{array}{c}\text { Relative } \\
\text { Difference }\end{array}$ \\
\hline 275 & 4.213 & 4.211 & $-0.06 \%$ \\
280 & 4.201 & 4.198 & $-0.07 \%$ \\
285 & 4.193 & 4.189 & $-0.09 \%$ \\
290 & 4.187 & 4.184 & $-0.08 \%$ \\
295 & 4.184 & 4.181 & $-0.06 \%$ \\
300 & 4.181 & 4.179 & $-0.05 \%$ \\
305 & 4.180 & 4.178 & $-0.04 \%$ \\
310 & 4.179 & 4.179 & $0.01 \%$ \\
315 & 4.179 & 4.179 & $0.01 \%$ \\
320 & 4.179 & 4.180 & $0.02 \%$ \\
325 & 4.180 & 4.182 & $0.05 \%$ \\
330 & 4.182 & 4.184 & $0.06 \%$ \\
335 & 4.184 & 4.186 & $0.06 \%$ \\
340 & 4.186 & 4.188 & $0.04 \%$ \\
\hline
\end{tabular}

Table F.3 Thermal conductivity of water for different temperature at a pressure of 0.9 bar

Thermal Conductivity (W/m K)

\begin{tabular}{cccc}
\hline T $\left({ }^{\circ} \mathrm{C}\right)$ & APWS-IF97[65] & $\begin{array}{c}\text { Incropera } \\
{[13]}\end{array}$ & $\begin{array}{c}\text { Relative } \\
\text { Difference }\end{array}$ \\
\hline 275 & 0.564581 & 0.574 & $1.64 \%$ \\
280 & 0.574082 & 0.582 & $1.36 \%$ \\
285 & 0.583516 & 0.59 & $1.10 \%$ \\
290 & 0.592769 & 0.598 & $0.87 \%$ \\
295 & 0.601733 & 0.606 & $0.70 \%$ \\
300 & 0.610318 & 0.613 & $0.44 \%$ \\
305 & 0.618454 & 0.62 & $0.25 \%$ \\
310 & 0.626091 & 0.628 & $0.30 \%$ \\
315 & 0.633196 & 0.634 & $0.13 \%$ \\
320 & 0.639754 & 0.64 & $0.04 \%$ \\
325 & 0.645761 & 0.645 & $-0.12 \%$ \\
330 & 0.651226 & 0.65 & $-0.19 \%$ \\
335 & 0.656163 & 0.656 & $-0.02 \%$ \\
340 & 0.660594 & 0.66 & $-0.09 \%$ \\
\hline
\end{tabular}


Table F.4 Dynamic viscosity of water for different temperature at a pressure of 0.9 bar Dynamic viscosity $\left(\mathrm{N} \mathrm{s} / \mathrm{m}^{2}\right)$

\begin{tabular}{cccc}
\hline $\mathrm{T}\left({ }^{\circ} \mathrm{C}\right)$ & APWS-IF97[65] & $\begin{array}{c}\text { Incropera } \\
{[13]}\end{array}$ & $\begin{array}{c}\text { Relative } \\
\text { Difference }\end{array}$ \\
\hline 275 & 0.565 & 0.574 & $1.64 \%$ \\
280 & 0.574 & 0.582 & $1.36 \%$ \\
285 & 0.584 & 0.590 & $1.10 \%$ \\
290 & 0.593 & 0.598 & $0.87 \%$ \\
295 & 0.602 & 0.606 & $0.70 \%$ \\
300 & 0.610 & 0.613 & $0.44 \%$ \\
305 & 0.618 & 0.620 & $0.25 \%$ \\
310 & 0.626 & 0.628 & $0.30 \%$ \\
315 & 0.633 & 0.634 & $0.13 \%$ \\
320 & 0.640 & 0.640 & $0.04 \%$ \\
325 & 0.646 & 0.645 & $-0.12 \%$ \\
330 & 0.651 & 0.650 & $-0.19 \%$ \\
335 & 0.656 & 0.656 & $-0.02 \%$ \\
340 & 0.661 & 0.660 & $-0.09 \%$ \\
\hline
\end{tabular}

Prandtl number is generated by using its general equation:

$$
\operatorname{Pr}=\frac{C_{p} \mu}{k}
$$

